\title{
REPERCUSIONES FISIOLÓGICAS DEL USO DE EQUIPOS DE PROTECCIÓN INDIVIDUAL FRENTE A RIESGOS BIOLÓGICOS SOBRE LOS TRABAJADORES DE LA SALUD
}

Presentada por:

D. Francisco Martín Rodríguez para optar al grado de Doctor/a por la Universidad de Valladolid

Dirigida por:

Dra. Verónica Casado Vicente Dr. Miguel Ángel Castro Villamor 



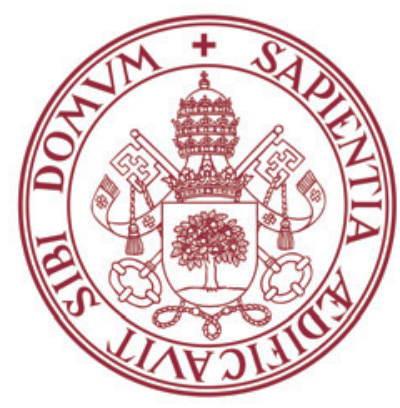

\section{Universidad deValladolid}

DÑA. VERÓNICA CASADO VICENTE, DOCTORA EN MEDICINA Y CIRUGÍA, Y D. MIGUEL ÁNGEL CASTRO VILLAMOR, DOCTOR EN MEDICINA Y CIRUGÍA, UNIDAD DOCENTE DE MEDICINA FAMILIAR Y COMUNITARIA. DEPARTAMENTO DE MEDICINA, DERMATOLOGÍA Y TOXICOLOGÍA. FACULTAD DE MEDICINA. VALLADOLID.

\section{CERTIFICAN}

Que D. FRANCISCO MARTÍN RODRÍGUEZ, ha realizado bajo su dirección el trabajo que presenta para optar al grado de Doctor con el título: "Repercusiones fisiológicas del uso de equipos de protección individual frente a riesgos biológicos sobre los trabajadores de la Salud"

Examinado dicho trabajo, estimamos que reúne los requisitos precisos para ser presentada y defendida para optar al título de Doctor. Y para que así conste y obre a los efectos oportunos, firmamos la presente certificación en Valladolid, 12 de Septiembre de 2017.

Fdo.: Dra. Dña. Verónica Vicente Casado

Fdo. Dr. D. Miguel Ángel Castro Villamor 



\section{Agradecimientos}

Me gustaría comenzar, para no olvidar a nadie y aunque no cite expresamente a ninguna persona, agradecer a todos aquellos que de manera directa o indirecta han hecho posible la realización de esta tesis doctoral.

A mis directores, Dra. Dña. Verónica Casado Vicente y Dr. D. Miguel Ángel Castro Villamor, por sus enseñanzas técnicas y su seguimiento intensivo de los trabajos, por facilitarme una orientación continua; pero, sobre todo, por su apoyo en este proceso, su disponibilidad y la ilusión que transmiten por la investigación, así como por la confianza depositada en mí y en el proyecto de esta tesis.

A todos los participantes del estudio, estudiantes y profesionales, que voluntariamente han decidido regalarme unas horas de su tiempo, y permitirme hacerles "jugarretas" varias. Sin ellos este estudio no habría sido posible.

A los alumnos de $4^{\circ}$ curso del Grado de Enfermería de la Universidad de Valladolid, que colaboraron en la realización de la fase de campo del estudio. Sin su apoyo no hubiese sido posible realizar el caso clínico.

A Pedro Arnillas, germen de esta tesis, que ha sido parte fundamental para su desarrollo, y que ha aportado en cada momento ideas y ha colaborado de forma directa en la realización de la fase de campo.

Finalmente, no quisiera terminar sin agradecer a mi familia la paciencia demostrada. Las tesis enriquecen en muchos aspectos, pero su realización resta tiempo a la vida familiar y a los amigos. Ellos, por fortuna, lo han sabido comprender.

A todos: muchas gracias. 



\section{Listado de abreviaturas}

\begin{tabular}{|c|c|}
\hline AMBU & Airway Mask Bag Unit \\
\hline ATC & Anatomical, Therapeutic, Chemical Classification System \\
\hline BOE & Boletín Oficial del Estado \\
\hline CE & Conformité Européenne \\
\hline CEIC & Comité Ético de Investigación Clínica \\
\hline CIE & Clasificación Internacional de Enfermedades \\
\hline ECDC & European Centre for Disease Prevention \& Control \\
\hline ECG & Electrocardiograma \\
\hline ECOE & Evaluación Clínica Objetiva Estructurada \\
\hline EE. UU. & Estados Unidos \\
\hline EPI & Equipo de Protección Individual \\
\hline EVE & Enfermedad por Virus Ébola \\
\hline $\mathrm{FC}$ & Frecuencia Cardiaca \\
\hline FCM & Frecuencia Cardiaca Máxima \\
\hline FCUA & Frecuencia Cardiaca Umbral Anaeróbico \\
\hline FFP & Filtering Face Piece \\
\hline FR & Frecuencia Respiratoria \\
\hline GCS & Glasgow Coma Scale \\
\hline HazMat & Hazardous Materials \\
\hline HTA & Hipertensión Arterial \\
\hline IMC & Índice de Masa Corporal \\
\hline IP & Índice de Perfusión \\
\hline IPAQ & International Physical Activity Questionnaires \\
\hline LPM & Latidos por Minuto \\
\hline NBQ & Nuclear-Biológico-Químico \\
\hline NRBQ & Nuclear-Radiológico-Biológico-Químico \\
\hline NRBQex & Nuclear-Radiológico-Biológico-Químico-Explosivos \\
\hline
\end{tabular}


OMS Organización Mundial de la Salud

PCR Parada Cardiorrespiratoria

RCP Reanimación Cardiopulmonar

SEM Servicios de Emergencias Médicos

Sp02 Saturación de Oxígeno

SRAS Síndrome Respiratorio Agudo Severo

SVA Soporte Vital Avanzado

TAD Tensión Arterial Diastólica

TAS Tensión Arterial Sistólica

UA Umbral Anaeróbico

UAT Umbral Anaeróbico Teórico

UBE Unidad de Bebida Estándar

UL Umbral de Lactato

US United States 


\section{Índice de contenidos}

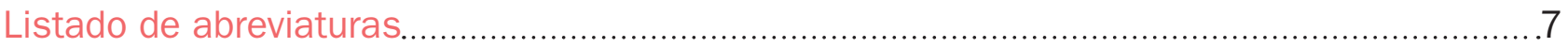

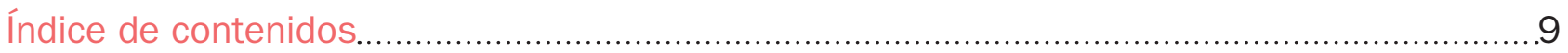

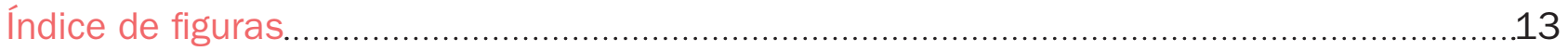

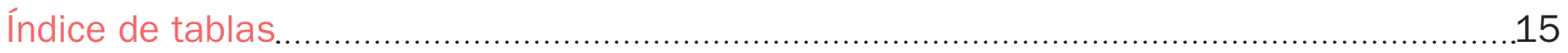

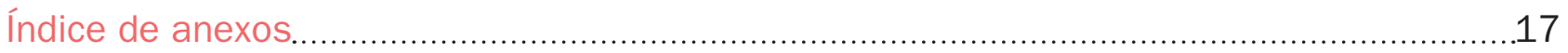

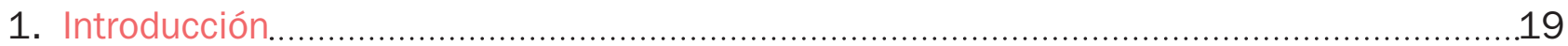

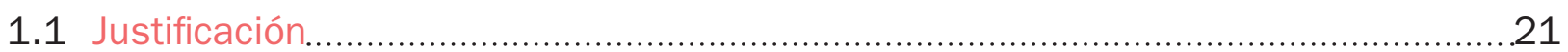

1.2 Descripción del problema..........................................................................................23

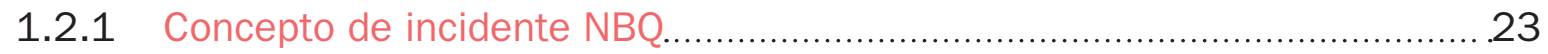

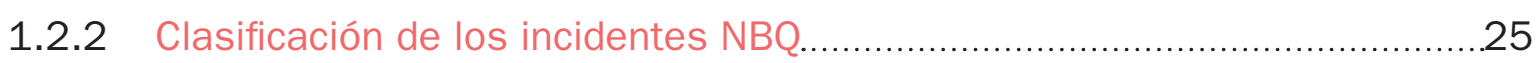

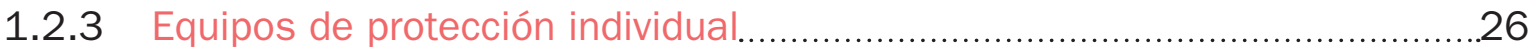

1.3 Definición del problema............................................................................................29

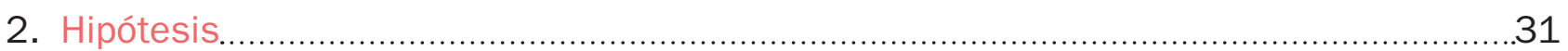

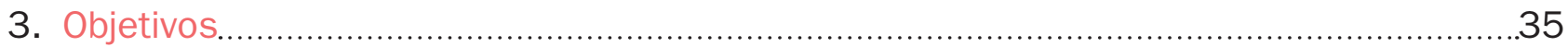

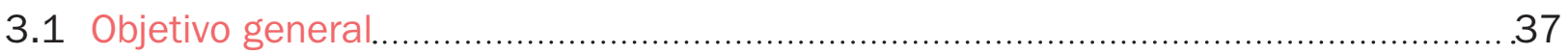

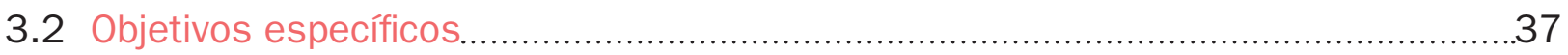

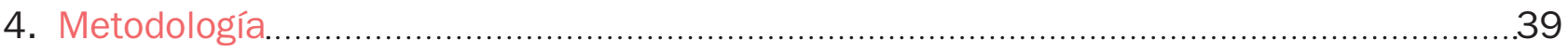

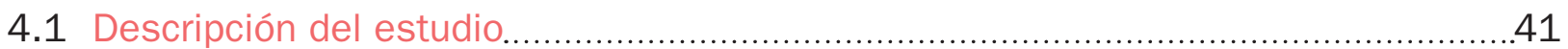

4.1.1 Tipo de estudio y de muestreo......................................................................41

4.1.2 Análisis y descripción de la población diana................................................41

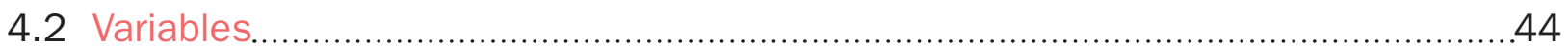

4.2.1 Datos biográficos e historia médica.......................................................44

4.2.2 Variables de antropometría y bioimpedancia...............................................49

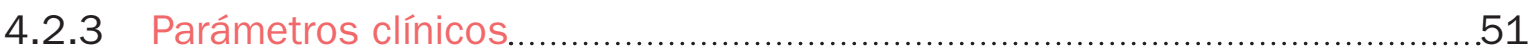

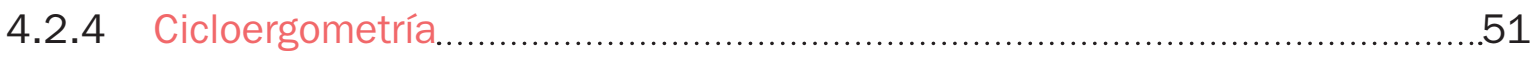

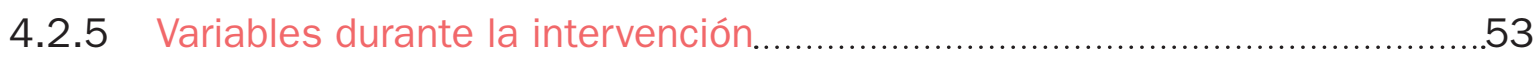

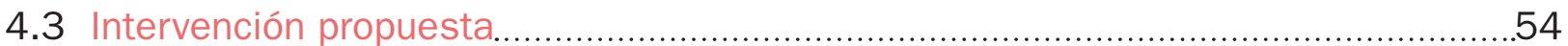

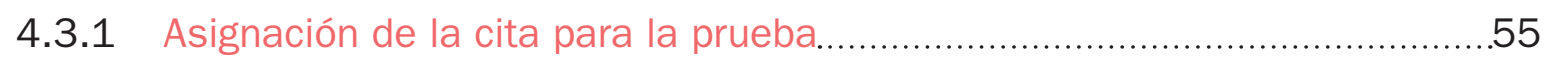

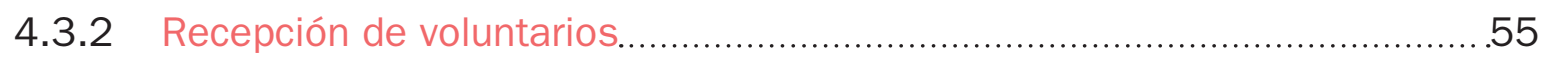

4.3.3 Filiación y entrega de documentación........................................................56

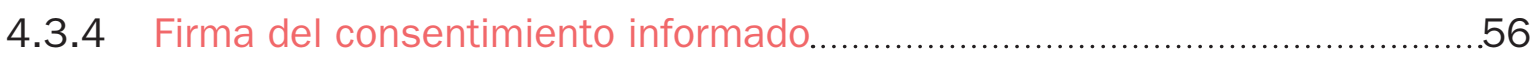

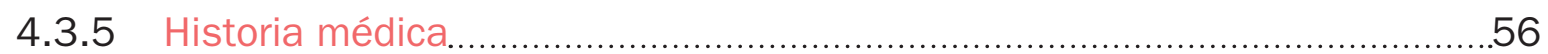

4.3.6 Estudio antropométrico y bioimpedancia...................................................57

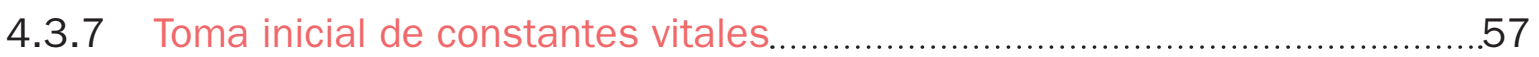

4.3.8 Cicloergometría y determinación del umbral de lactato..................................58

4.3.9 Colocación de la telemetría........................................................................61

4.3.10 Explicación del procedimiento y del caso........................................................61

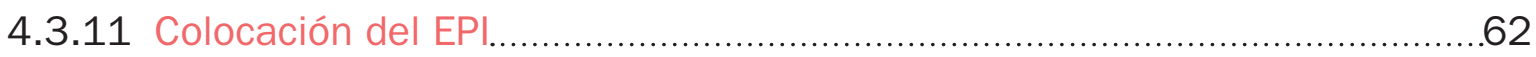

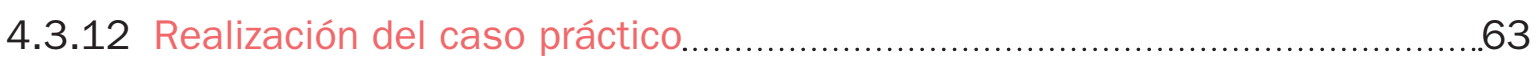

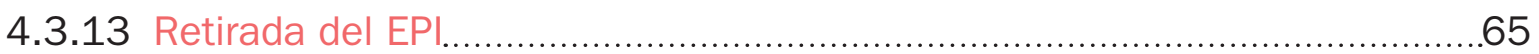


4.3.14 Toma de constantes vitales y antropometría posterior................................65

4.4 Método de recogida de datos...........................................................................66

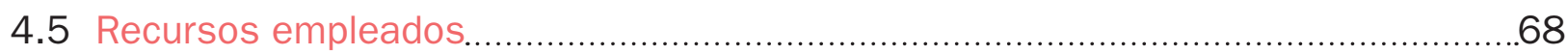

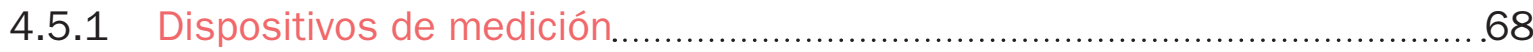

4.5.2 Equipo de protección individual................................................................ 74

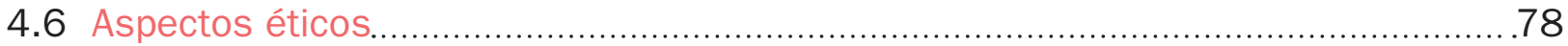

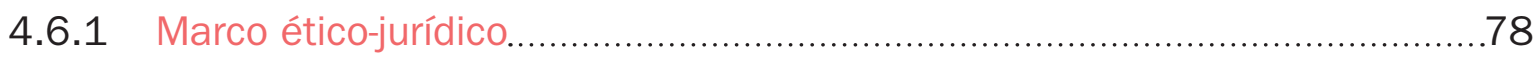

4.6.2 Privacidad sobre la identidad de los voluntarios.........................................78

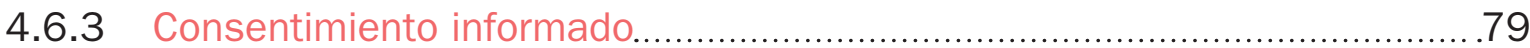

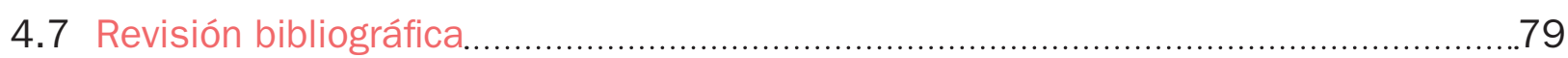

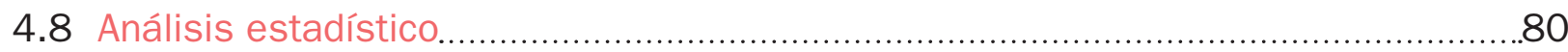

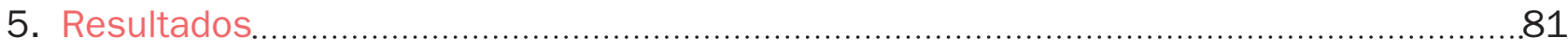

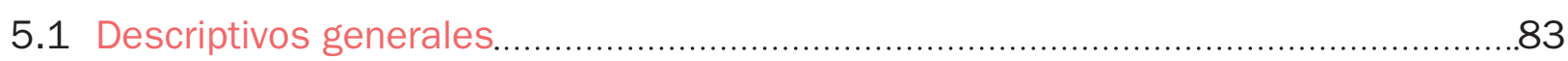

5.2 Parámetros basales y antropométricos.....................................................................85

5.3 Descripción de los parámetros horarios y ambientales de la prueba.......................89

5.4 Variaciones de parámetros fisiológicos...................................................................90

5.5 variaciones antropométricas.................................................................................95

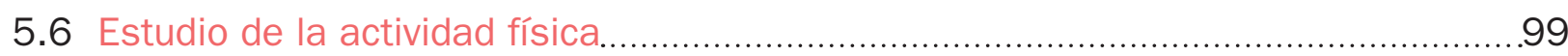

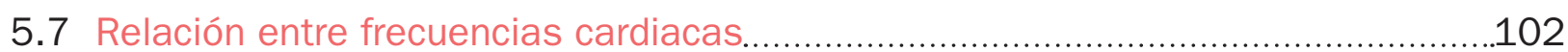

5.8 Estudio de la frecuencia cardiaca durante el caso clínico.....................................108

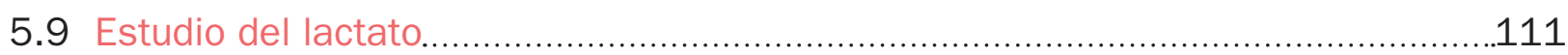

5.10 Variación del índice de perfusión...........................................................................116

5.11 Selección de talla de trajes de protección..........................................................122

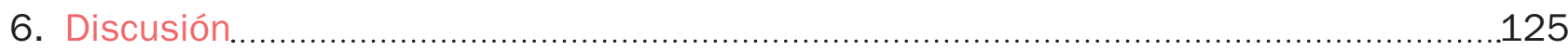

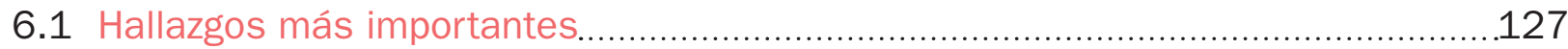

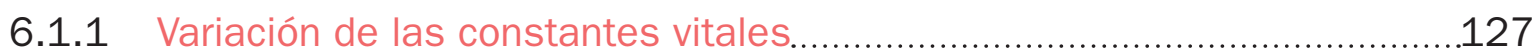

6.1.2 Relación entre la frecuencia cardiaca máxima durante la reanimación y el nivel de actividad física (IPAQ).......

6.1.3 Relación entre la frecuencia cardiaca máxima durante la reanimación y el umbral anaeróbico (protocolo Conconi).......

6.1.4 Relación entre la fórmula de Tanaka y la FC máxima, y entre el UAT y el umbral anaeróbico (cicloergometría)...................................................130

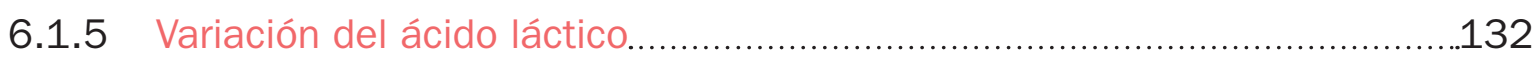

6.1.6 Comportamiento del índice de perfusión..................................................133

6.1.7 Patrón fisiológico de mala tolerancia al uso de equipos de protección

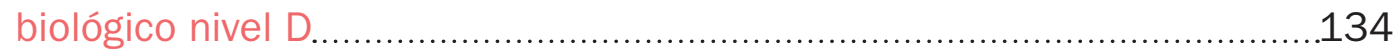

6.1.8 Selección de las tallas de los trajes de protección....................................138 


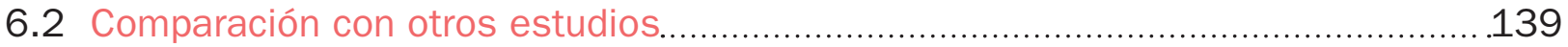

6.3 Aplicación práctica............................................................................................. 141

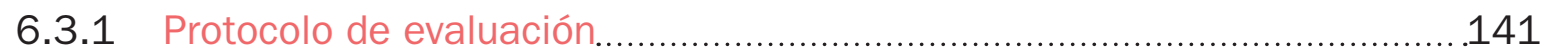

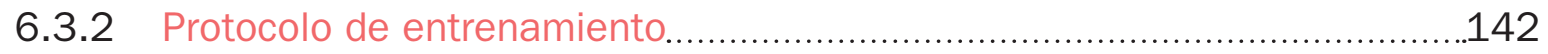

6.3.3 Selección adecuada de la talla de traje....................................................142

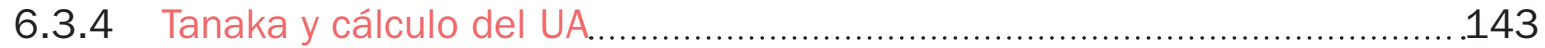

6.3.5 Uso de los valores de ácido láctico.........................................................143

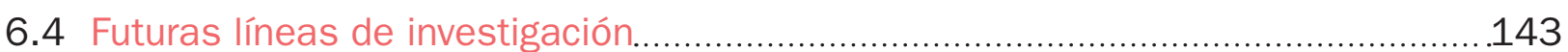

6.5 Limitaciones de la investigación........................................................................ 144

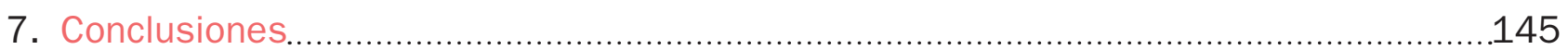

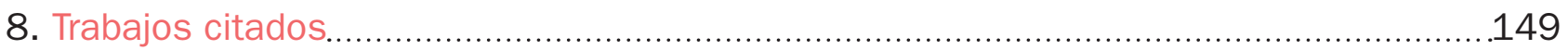

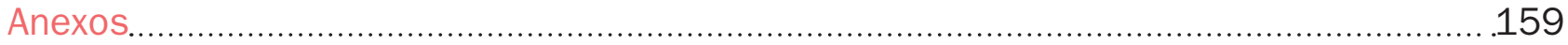




\section{Índice de figuras}

Figura 1. Actuación de los SEM con equipos de protección biológica..................................21

Figura 2. Momentos posteriores al atentado en Londres del 3 de junio de $2017^{(8)} \ldots \ldots \ldots \ldots . . .22$

Figura 3. Víctima contaminada con productos químicos..................................................24

Figura 4. El empleo de EPI precisa de un esfuerzo y concentración mayores por parte del interviniente, a la vez que limita enormemente sus movimientos y su tiempo de trabajo.

Figura 5. Uso de EPI nivel A, encapsulados y con equipo de respiración autónomo.............26

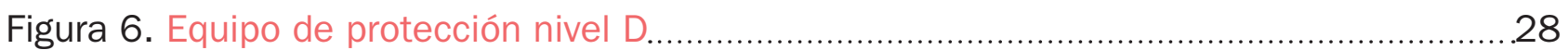

Figura 7. Labores de descontaminación.................................................................................29

Figura 8. Distribución ideal de la muestra por conglomerados............................................43

Figura 9. Gráfico de cicloergometría. Varón, 35 años, nivel de actividad física alta..............60

Figura 10. Distribución de las aulas del ECOE ................................................................67

Figura 11. Báscula de precisión segmental TANITA BC-601 .............................................69

Figura 12. Monitor de presión arterial no invasivo SCHILLER BP-200 plus.........................69

Figura 13. Desviación entre los valores de hemoglobina total en laboratorio y con el

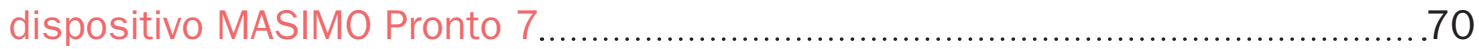

Figura 14. Medidor de ácido láctico Accutrend ${ }^{\circledR}$ Plus.............................................................71

Figura 15. ECG basado en PC modelo Cardio Perfect de la marca Welch Allyn ${ }^{\circledR}$..................72

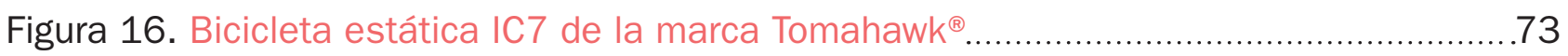

Figura 17. Maniquí de soporte vital avanzado Megacode Kelly ${ }^{\circledR}$...........................................76

Figura 18 . Relación entre el aumento de la temperatura corporal y el nivel de actividad

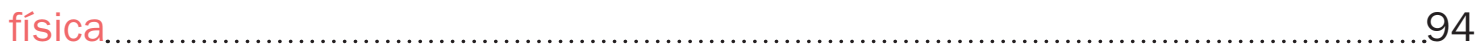

Figura 19. Distribución de frecuencias de actividad física por sexo...................................101

Figura 20. Distribución de frecuencias de actividad física por subgrupo de estudio:

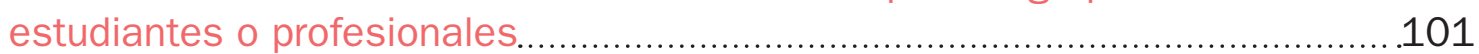

Figura 21. Distribución del umbral anaeróbico por sexo......................................................104

Figura 22. Distribución del umbral anaeróbico por subgrupo de estudio: estudiantes o

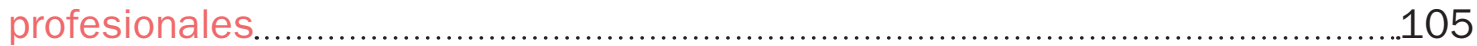

Figura 23. Distribución del umbral anaeróbico en función del nivel de actividad física......105

Figura 24. Relación entre el UAT y la FCUA con el nivel de actividad física........................106

Figura 25. Frecuencia cardiaca en el caso clínico con el EPI colocado en el total de la

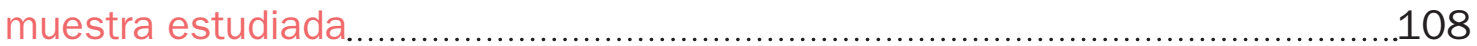

Figura 26. Frecuencia cardiaca en el caso clínico en los subgrupos estudiados...............108

Figura 27. Frecuencia cardiaca en el caso clínico según sexo del sujeto.........................109

Figura 28. Gráfico de Bland-Altmann para evaluar las diferencias entre la frecuencia cardiaca en el umbral anaeróbico y la frecuencia cardiaca en el caso clínico (media de momentos 22 y 23). El eje de ordenadas es la diferencia entre ambas medidas (FCUA- media de 22 y 23) y el eje de abscisas es la media de ambas medidas. El valor 0 supondría que no hay error entre ambas. Los valores negativos representan sujetos que alcanzan más valor en la RCP que la prevista por la ergometría.. 
Figura 29. Gráfico de distribución de las alteraciones de ácido láctico en relación con el nivel de entrenamiento......

Figura 30. Relación del umbral de potencia con el umbral de lactato por subgrupos estudiados ( $p$ de interacción <0,05).....

Figura 31 . Curva de rendimiento diagnóstico (ROC) del modelo multivariable final para predecir la mala tolerancia (lactato final $>4 \mathrm{mmol} / \mathrm{L}$ ).

Figura 32. Valores medios del índice de perfusión por grupos de estudio, antes y después de la prueba.

Figura 33. Distribución de la variación del índice de perfusión en función del nivel de actividad física.

Figura 34. Evolución de las frecuencias cardiacas durante la realización del caso clínico para el global de la muestra.

Figura 35. Ejemplo de cicloergometría, varón de 43 años, nivel de actividad física tipo 3 (alto). FCM fórmula Tanaka 175,9 Ipm, UAT 155 Ipm. FCM test 181 Ipm, UA test $154 \mathrm{lpm}$.

Figura 36. Comportamiento del ácido láctico en 4 determinaciones durante el estudio. La línea azul marca el umbral de $4 \mathrm{mmol} / \mathrm{L}$ a partir del cual comienza la lactacidemia.

Figura 37. Comportamiento de la FC durante toda la prueba.

Figura 38. Patrón de comportamiento de IP, $\mathrm{SpO}_{2}$ y $\mathrm{Hb}$ total, determinaciones basal y final 


\section{Índice de tablas}

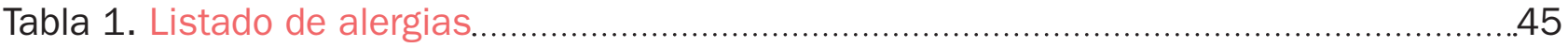

Tabla 2. Fórmula para calcular los gramos de alcohol por bebida......................................46

Tabla 3. Clasificación Internacional de Enfermedades (CIE) 10. ${ }^{a}$ revisión ${ }^{\left({ }^{3}\right)}$..........................4 47

Tabla 4. Listados de principios activos por grupos ATC …….........................................48

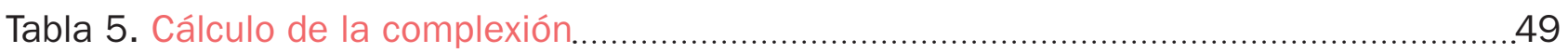

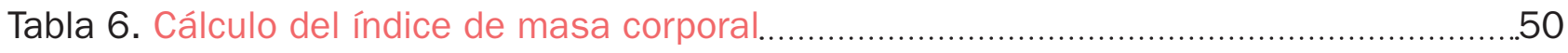

Tabla 7. Estimación del peso ideal (ecuación de Hamwi).................................................50

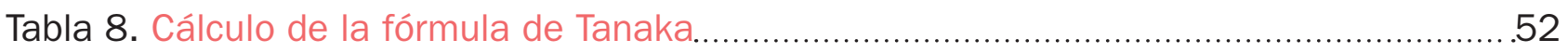

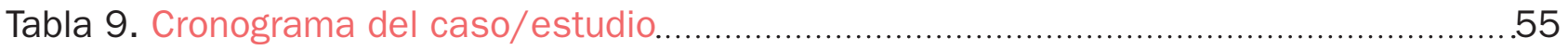

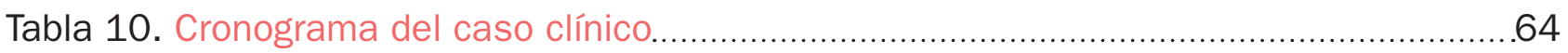

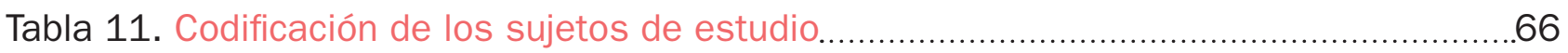

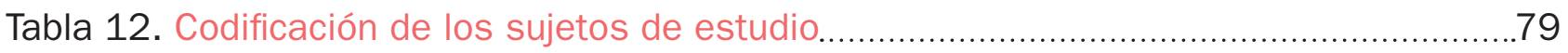

Tabla 13. Características de los grupos de estudio …………….......................................... 83

Tabla 14. Características de los subgrupos de estudio......................................................... 84

Tabla 15. Descripción de los parámetros basales por grupo de estudio.................................86

Tabla 16. Descripción de los parámetros por subgrupo...................................................... 88

Tabla 17. Distribución de la hora de realización de la prueba en los grupos de estudio......89

Tabla 18. Descripción de los datos de temperatura y humedad en el momento de la

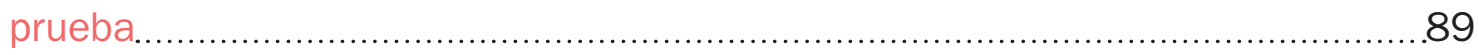

Tabla 19. Variaciones de parámetros fisiológicos en el global de la muestra........................90

Tabla 20. Variaciones en los parámetros fisiológicos por subgrupos de estudio..................91

Tabla 21. Variaciones en los parámetros fisiológicos por subgrupos y sexo..........................92

Tabla 22. Variaciones antropométricas del global de la muestra.......................................95

Tabla 23. Variaciones antropométricas comparando los grupos de estudio..........................96

Tabla 24. Variaciones antropométricas por grupos de estudio ............................................96

Tabla 25. Variaciones antropométricas por subgrupos de estudio......................................97

Tabla 26. Variaciones antropométricas por subgrupo y sexo............................................98

Tabla 27. Distribución de frecuencias de la actividad física por grupos de estudio...............99

Tabla 28. Distribución de frecuencias de la actividad física por grupos de estudio............100

Tabla 29. Diferencias de parámetros entre los grupos de estudio.....................................102

Tabla 30. Diferencias de parámetros entre los subgrupos de estudio. ..............................103

Tabla 31. Comparaciones emparejadas entre las distintas medidas de las frecuencias

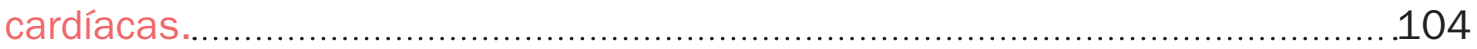

Tabla 32. Modelo multivariable de regresión lineal para explicar el cambio en la fre-

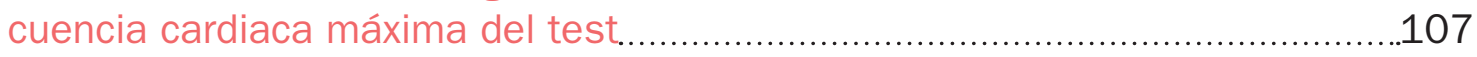

Tabla 33. Modelo multivariable de regresión logística para evaluar la probabilidad de tolerar mal la prueba..

Tabla 34. Descripción de las medias de lactato por grupo de estudio..

Tabla 35. Modelo multivariable de regresión lineal para estudiar el lactato final en grupos y subgrupos. 
Tabla 36. Modelo multivariable de regresión logística para evaluar la probabilidad de tolerar RCP.

Tabla 37. Modelo logístico multivariable para predecir mala tolerancia (lactato final $>4$ $\mathrm{mmol} / \mathrm{L})$.

Tabla 38. Variación media del índice de perfusión por grupos de estudio, antes y después de la prueba.

Tabla 39. Correlaciones de los parámetros cuantitativos con los índices de perfusión, antes y después de la prueba, así como su variación absoluta.

Tabla 40. Correlaciones de los parámetros antropométricos cuantitativos con los índices de perfusión, antes y después de la prueba, así como su variación absoluta

Tabla 41. Correlaciones de los parámetros fisiológicos cuantitativos con los índices de perfusión, antes y después de la prueba, así como su variación absoluta......119

Tabla 42 . Modelo multivariable de regresión lineal para explicar el índice de perfusión final en la población estudiada.

Tabla 43. Fiabilidad de la talla de traje real con la solicitada por el voluntario.....

Tabla 44. Modelo de regresión logística para explicar los factores asociados a una talla de traje errónea.

Tabla 45. Parámetros estudiados para la obtención del patrón fisiológico de mala tolerancia

Tabla 46. Relación entre la talla de traje pedida y la real.

Tabla 47. Parámetros propuestos para el protocolo de evaluación.

Tabla 48. Parámetros propuestos para el protocolo de entrenamiento 


\section{Índice de anexos}

Anexo 1. Algunas características de los distintos niveles de protección. US Environmental Protection Agency.....

Anexo 2. Hoja de inscripción de voluntarios.........................................................................162

Anexo 3. Cuestionario internacional de actividad física IPAQ .............................................164

Anexo 4. Formulario de consentimiento informado..........................................................167

Anexo 5. Hoja de reconocimiento 1. Filiación y examen médico.........................................171

Anexo 6. Hoja de reconocimiento 2. Antropometría y bioimpedancia................................172

Anexo 7. Hoja de reconocimiento 3. Toma de constantes vitales.....................................173

Anexo 8. Hoja de reconocimiento 4-a. Cicloergometría.......................................................174

Anexo 9. Hoja de reconocimiento 4-b. Cicloergometría.......................................................175

Anexo 10. Hoja de reconocimiento 5. Checking y criterios de exclusión..............................176

Anexo 11. Hoja de reconocimiento 6. Caso clínico...........................................................177

Anexo 12. Especificaciones técnicas de la cinta métrica mecánica marca SECA mode-

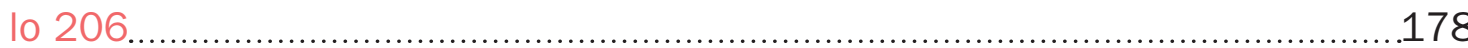

Anexo 13. Especificaciones técnicas de la cinta ergonómica para medir perímetros

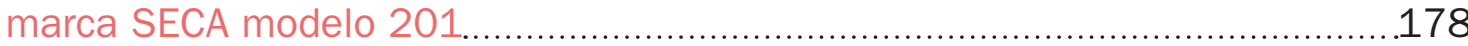

Anexo 14. Especificaciones técnicas de la báscula diagnóstica TANITA modelo BC-601..178

Anexo 15. Especificaciones técnicas del monitor de presión arterial no invasiva marca SCHILLER modelo BP-200 plus.

Anexo 16. Especificaciones técnicas del cronómetro marca CASIO modelo HS-3V-1........179

Anexo 17. Especificaciones técnicas de termómetro timpánico marca BRAUN modelo ThermoScan PRO 6000

Anexo 18. Especificaciones técnicas del medidor no invasivo de hemoglobina marca MASIMO modelo Pronto 7 .....

Anexo 19. Especificaciones técnicas del medidor no invasivo saturación de oxígeno marca MASIMO modelo Rad-5VTM.

Anexo 20. Especificaciones técnicas del medidor de ácido láctico marca Roche modelo Accutrend $^{\circledR}$ Plus.

Anexo 21. Especificaciones técnicas del glucómetro Accu-Chek Mobilede la marca Roche ${ }^{\circledR}$

Anexo 22. Especificaciones técnicas del espirómetro modelo MiniSpir de la marca MIR. 181

Anexo 23. Especificaciones técnicas del ECG modelo Cardio Perfect de la marca Welch Allyn ${ }^{\circledR}$

Anexo 24. Especificaciones técnicas la bicicleta estática IC7 de la marca Tomahawk ${ }^{\circledR}$....181

Anexo 25. Especificaciones técnicas del ordenador portátil ThinkPad Yoga 260 marca Lenovo.

Anexo 26. Especificaciones técnicas del pulsómetro marca Polar modelo A300......

Anexo 27. Especificaciones técnicas del medidor dual DTP 1 marca PCE ${ }^{\circledR}$

Anexo 28. Especificaciones técnicas del luxómetro 172 marca PCE ${ }^{\circledR}$

Anexo 29. Especificaciones técnicas del cubrebotas modelo CoverChem Plus ${ }^{\circledR}$ marca ASATEX ${ }^{\circledR}$ 
Anexo 30. Especificaciones técnicas del buzo modelo CoverStar Plus ${ }^{\circledR}$ marca ASTAEX ${ }^{\circledR} . .184$

Anexo 31. Especificaciones técnicas de los guantes TouchNTuff ${ }^{\oplus}$ marca Ansell ${ }^{\oplus}$................185

Anexo 32. Especificaciones técnicas del capuz modelo CoverStar ${ }^{\circledR}$ marca ASTAEX ${ }^{\circledR}$...........185

Anexo 33. Especificaciones técnicas del buzo modelo CoverStar Plus ${ }^{\circledR}$ marca ASATEX ${ }^{\circledR}$...186

Anexo 34. Especificaciones técnicas de las gafas panorámicas modelo Budget ${ }^{\circledR} 4800$ de la marca 3M.

Anexo 35. Especificaciones técnicas de los guantes industry de la marca Medical Care ${ }^{\circledR}$

Anexo 36. Informe del Comité Ético de Investigación Clínica. 


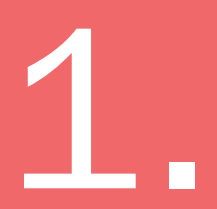

- Introducción

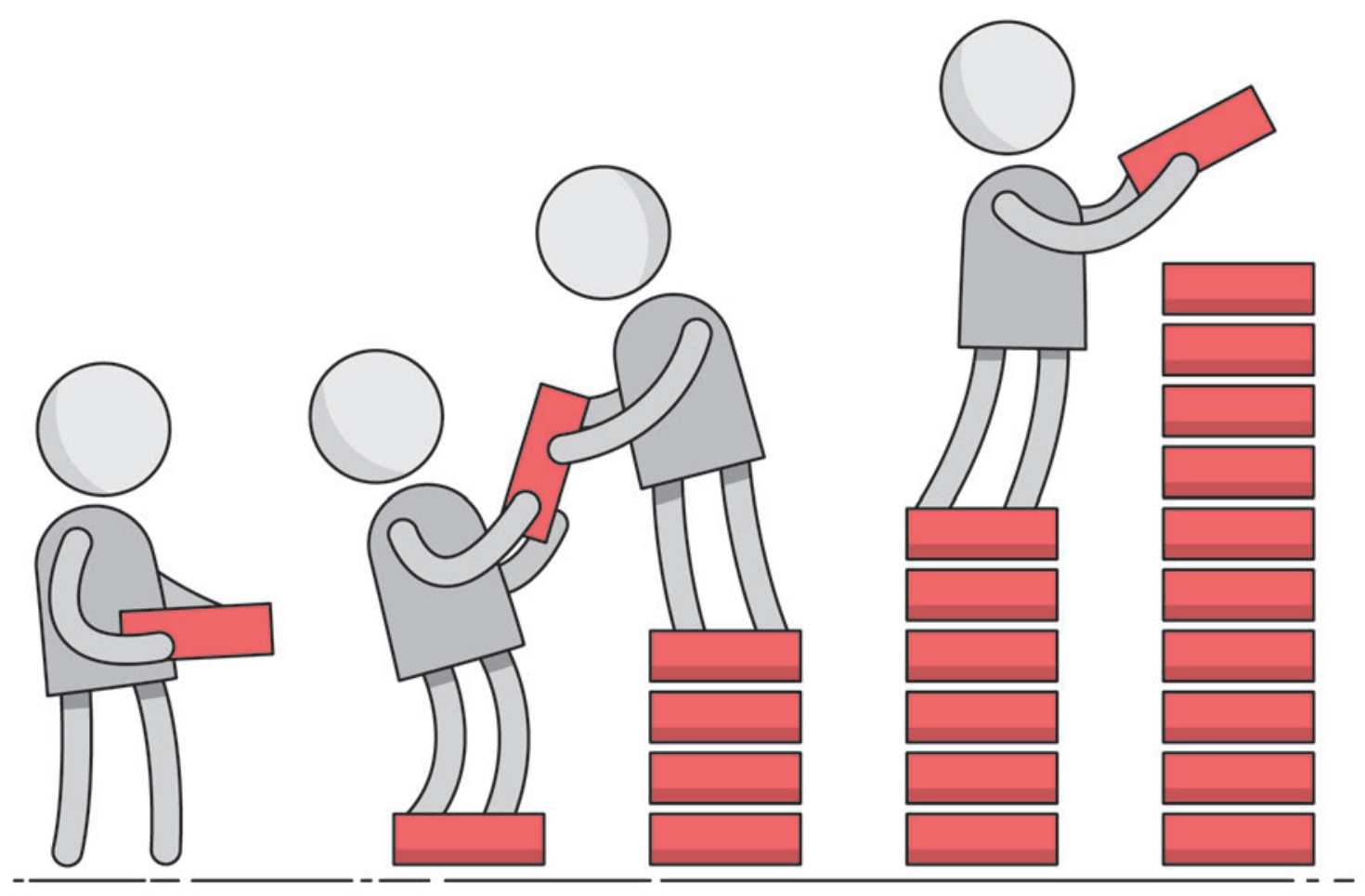




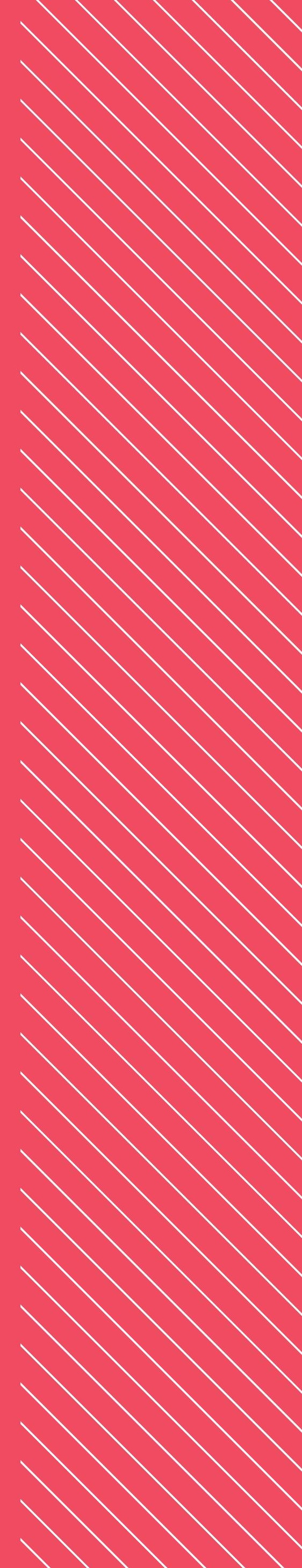




\subsection{Justificación}

Resulta cada vez más habitual, en los últimos tiempos, asistir a numerosos incidentes —bien provocados, o bien fortuitos-, que generan situaciones de emergencia colectiva en las que se encuentran inmersas ciertas sustancias con riesgo nuclear, biológico o químico. Situaciones que precisan una respuesta altamente especializada; en definitiva: situaciones que deben ser manejadas por los Servicios de Urgencias y Emergencias de una forma integral ${ }^{(1)}$, y que se han convertido en parte ordinaria de la cartera de servicios de los equipos de emergencias ${ }^{(2)}$.

Una crisis, de forma general, implica una pérdida de control del sistema, real o sentida, con ausencia de respuesta especializada, al menos en los momentos iniciales. Este tipo de situaciones desestructuran el sistema de emergencias, que debe ser capaz de responder de una forma oportuna y racional al suceso generado, mediante una intervención integral e integrada ${ }^{(3)}$.

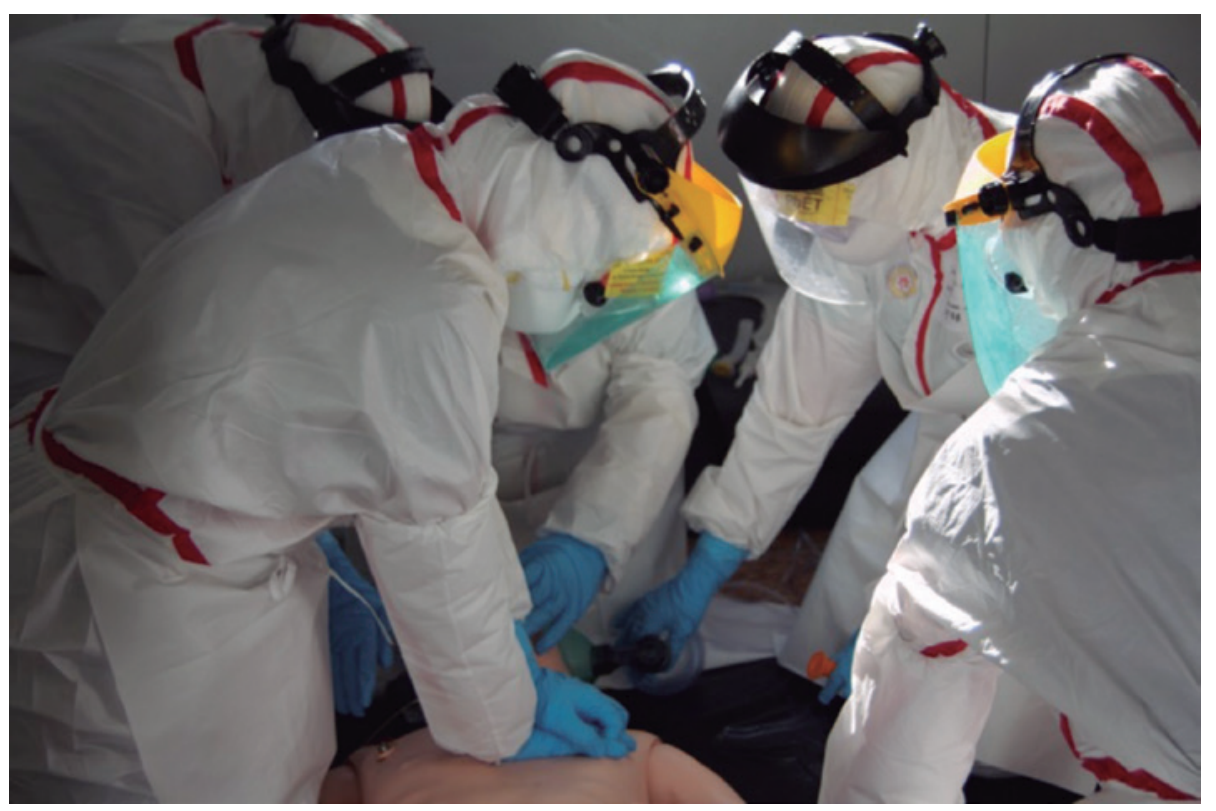

Figura 1. Actuación de los SEM con equipos de protección biológica

No resulta sorprendente que, a la par que cambian el mundo y, con él, la sociedad —cada vez más desarrollada e industrializada-, los servicios de emergencias deban hacer frente a situaciones que en otros tiempos no formaban parte de sus objetivos de intervención, situaciones tales como el manejo sanitario de accidentes con mercancías peligrosas o intervenciones en situaciones con riesgo NBQ ${ }^{(4)}$.

Para hacer frente a estas situaciones, Ios SEM deben cambiar su forma de pensar y de actuar: de una medicina sustitutiva y meramente asistencial, se debe pasar, además, a gestionar la situación de una forma coherente y racional, es decir, ser capaces de llevar a cabo la llamada medicina de gestión de crisis, que integra las estrategias para resolver una situación y los procedimientos asistenciales oportunos.

El trabajo habitual de los equipos de emergencias es, en sí mismo, difícil, cambiante y, en muchas ocasiones, se desarrolla en contextos complejos ${ }^{(5)}$. Dichas situaciones justifican que estos profesionales deban disponer de unas actitudes y aptitudes especiales, tanto en formación y entrenamiento como en dotación de materiales y recursos, debido a que su actividad se desarrollará en múltiples escenarios y contará con necesidades muy diversas ${ }^{(6)}$. 
Debido al gran dinamismo de las situaciones a las que se enfrentan, los equipos de emergencias requieren una forma específica de trabajar, para la que se deben tomar decisiones en breves lapsos de tiempo, decisiones críticas que afectan de forma directa sobre la salud de los pacientes, y que es necesario tomar con pocos datos e incluso, en ocasiones, con datos poco fiables; en definitiva: resoluciones vitales que generan una carga de estrés significativa en el profesional, y que precisan de un plus de formación y capacitación.

Algunos de los sucesos acaecidos con víctimas en masa, tales como los recientes atentados de Barcelona, Londres, París o Bruselas, nos enfrentan a nuevas situaciones con nuevos escenarios inestables, donde los SEM deben empezar a trabajar bajo nuevos estándares, en los que deben primar tanto la seguridad propia como la seguridad del entorno ${ }^{(7)}$.

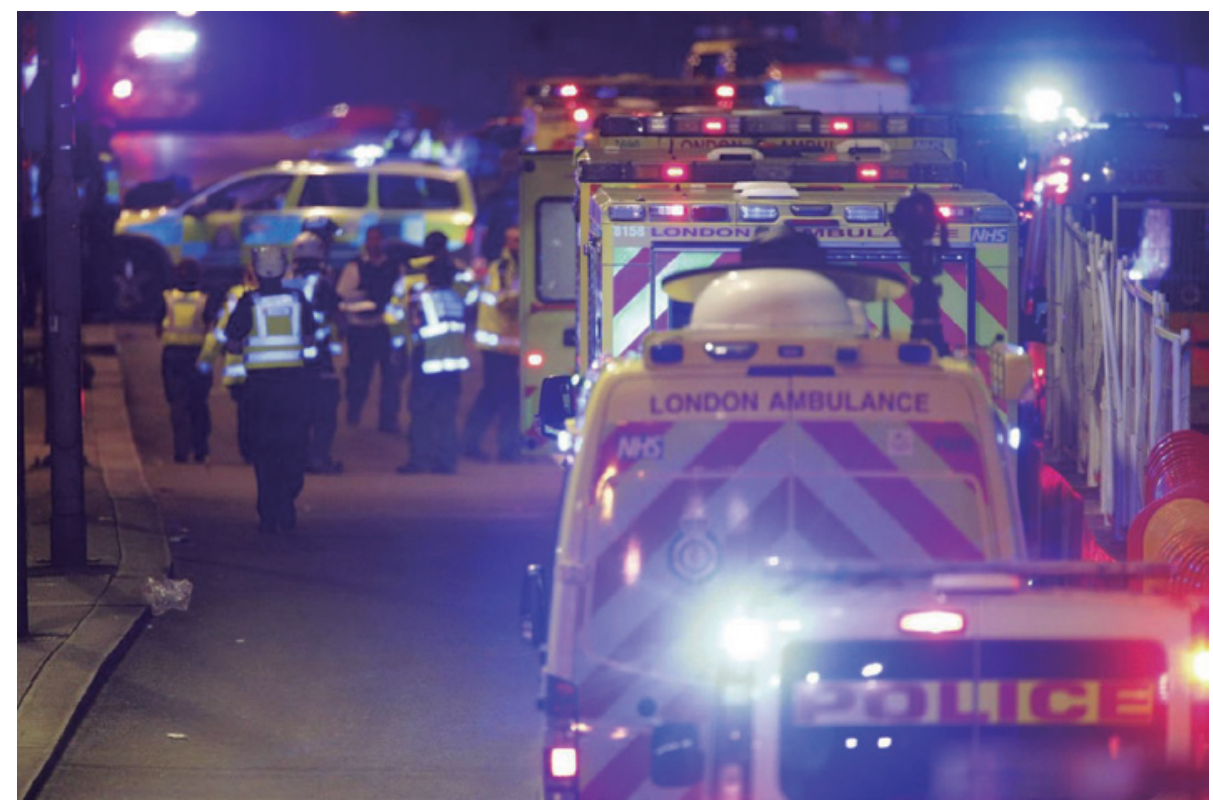

Figura 2. Momentos posteriores al atentado en Londres del 3 de junio de $2017^{(8)}$

Los incidentes en los que se ven involucrados agentes NBQ representan un verdadero problema de gestión, de asistencia y, con un carácter más relevante y novedoso para los SEM, de protección y autoprotección ${ }^{(9)}$, elementos fundamentales para el control de un escenario inestable, que marcan de una forma nítida la línea general de la estrategia, que tiene como fin evitar nuevas contaminaciones, ya sea de los propios profesionales o del entorno ${ }^{(10)}$.

Trabajar con EPI adaptados al riesgo supone el manejo de materiales nuevos o poco conocidos, en el mejor de los casos, aunque en muchas ocasiones resulta probable que los profesionales deban emplear equipos desconocidos o para los que no han obtenido la formación pertinente. No solo se debe manejar la patología médica o quirúrgica de los afectados, sino que es necesario tener en mente otros factores como la contención del incidente, la descontaminación o el manejo masivo de heridos y/o contaminados; todo ello bajo un estricto nivel de protección (11).

Estos operativos resultan, por lo tanto, especialmente sensibles, pues requieren una gran formación previa, conocimientos extrasanitarios, capacitación en el uso de EPI específicos para riesgos concretos, y, además, un manejo diferencial de los pacientes afectados por este tipo de situaciones: triaje inverso, descontaminación, uso de antídotos, etc., hechos que conllevan que las actuaciones en este tipo de incidente sean esencialmente complejas y requieran un mayor grado de adiestramiento, como nos han demostrado acontecimientos como la crisis por la enfermedad del virus Ébola ${ }^{(12)}$. 


\subsection{Descripción del problema}

\subsubsection{Concepto de incidente NBQ}

Los incidentes NBQ engloban aquellas amenazas de origen nuclear, biológico o químico con capacidad de producir un número de víctimas y/o afectados a causa de la exposición a este tipo de agentes ${ }^{(13)}$.

Resulta una tarea compleja la de aunar conceptos, incluso en la propia definición de las siglas, ya que en la bibliografía especializada se pueden encontrar, asimismo, denominaciones como NRBQ (en la que se diferencia el incidente nuclear originado por una explosión nuclear accidental o deliberada, del radiológico, en el que la contaminación aparece por fuentes de radiación) o NRBQex (en este caso, ex señala el empleo de explosivos de alta potencia) ${ }^{(14)}$.

Las crisis producidas por los agentes NBQ son enormemente variables en su presentación y su repercusión. Cuando se desencadena uno de estos incidentes o se produce un ataque de este tipo, existe un gran potencial de desestructuración del sistema, independientemente del número de víctimas ${ }^{(15)}$.

Además de las características propias de las crisis sanitarias, se puede establecer una serie de características propias de los incidentes NBQ:

- El potencial de afectación y desestructuración es muy grande. En función de las condiciones medioambientales, meteorológicas u orográficas, se pueden ver afectadas vastas regiones de terreno y amplios núcleos de población, incluso con pequeñas cantidades de un tóxico, químico o fuente radiactiva ${ }^{(16)}$.

- Una vez que el agente entra en contacto con un número mayor o menor de personas, aparece un nuevo tipo de afectado que no está presente en otro tipo de crisis: la víctima contaminada ${ }^{(17)}$. A diferencia de otro tipo de incidentes con víctimas en masa, además de identificar y clasificar a los heridos en función de su gravedad, se debe considerar a los sujetos contaminados como otra víctima que precisa una atención especial (descontaminación, aislamiento, cuarentena, etc.), aunque no presente ningún tipo de lesión o de manifestación clínica por la exposición al agente NBQ. El trato de este tipo de afectados es crucial para mantener la salud colectiva y minimizar las repercusiones del incidente NBQ.

- Este tipo de incidentes representa uno de los mayores retos institucionales para el control de la exposición. Debido a la facilidad de dispersión ya mencionada, el control del agente resulta ser una tarea que exige la implicación y el trabajo de diferentes agentes sociales (servicios sanitarios, policiales, rescate, protección civil, etc.), e incluso requiere la toma de medidas por parte de diferentes estados, con el fin de minimizar las consecuencias del impacto. Particularmente con los agentes biológicos, la facilidad de movimiento de los seres humanos debida a los modernos medios de transporte conlleva de forma potencial que las enfermedades puedan tener presencia casi instantánea en diferentes lugares del mundo.

- Los incidentes NBQ, asimismo, tienen una importante repercusión en el funcionamiento habitual de la población. Este tipo de incidentes producen una gran alarma dentro de la sociedad. La probable presencia de un agente - que no se puede ver, del que no se sabe cuándo va a atacar y que puede estar presente en el entorno habitual- puede generar terror y respuestas desproporcionadas dentro de la sociedad. Del mismo modo, puede acontecer la reacción contraria, es decir, que determinados sujetos no tomen las adecuadas medidas de protección debido a una percepción de seguridad infundada. 


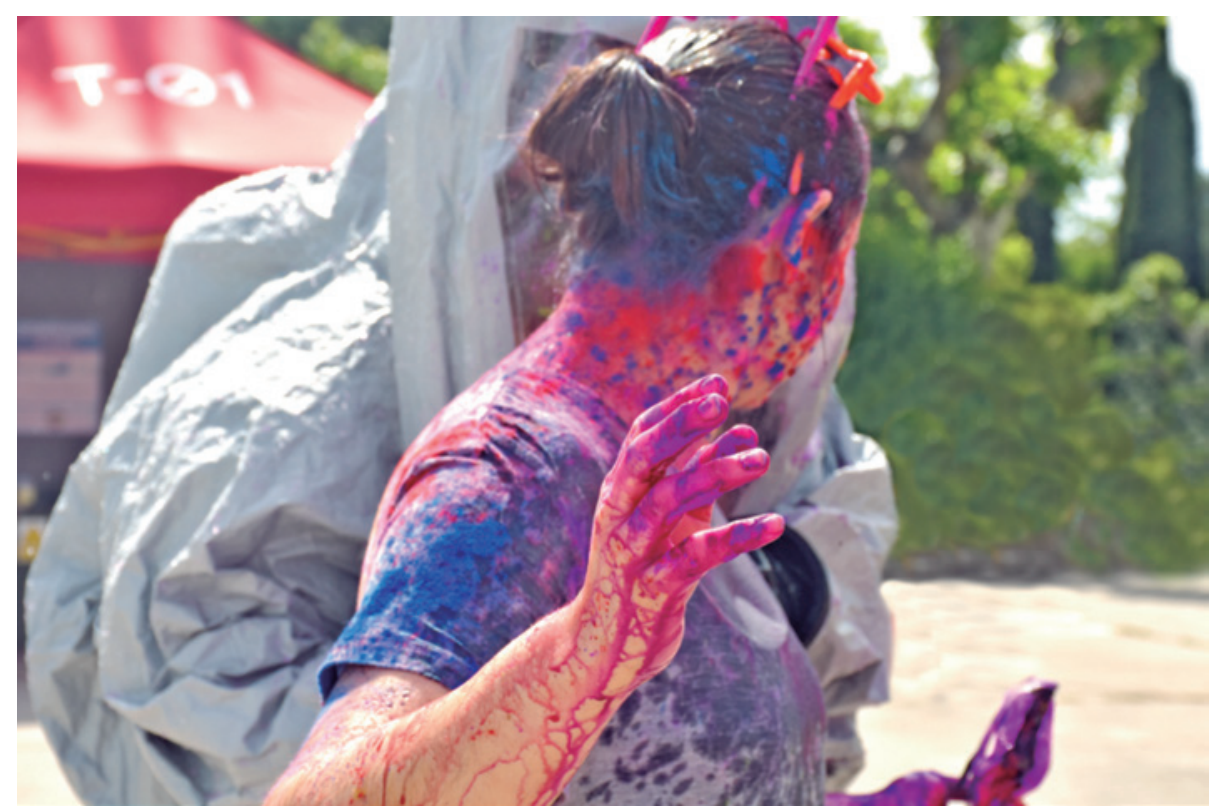

Figura 3. Víctima contaminada con productos químicos

- Muchos de los incidentes por exposición a agentes NBQ pueden resultar difíciles de detectar en el modo y tiempo adecuados para que la reacción del sistema minimice las consecuencias a corto y largo plazo. Esta característica no depende ni siquiera de su carácter incidental o intencional. Como ejemplo, se puede mencionar la dificultad manifiesta ante los ataques con esporas de Ántrax en EE. UU. en $2001^{(18)(19)}$ para el diagnóstico inicial de los afectados, pues las primeras manifestaciones eran completamente inespecíficas. En otros casos, como el desastre de Bhopal en 1984, los propios responsables negaron su implicación en los primeros momentos, impidiendo la adecuada puesta en marcha de las medidas oportunas.

- Por otro lado, se generan unas condiciones de trabajo excepcionales para los intervinientes que dificultan la realización de sus tareas. Independientemente de que se trate de un incidente con grave destrucción de las estructuras existentes (como, por ejemplo, la destrucción de un reactor nuclear), o de un incidente en el que las estructuras físicas permanecen intactas (diseminación intencionada de un agente químico), los intervinientes deben trabajar con equipos especiales que producen limitaciones (de movimiento o de tiempo de trabajo, entre otras). Algunos de ellos trabajarán con equipos de alta protección que impiden la intervención durante periodos prolongados de tiempo y precisan de un mayor esfuerzo físico ${ }^{(20)(21)}$. Otros, por su parte, trabajarán con niveles de protección menores, con los que posiblemente no se encuentren familiarizados o adecuadamente entrenados. A estas limitaciones cabe añadirles las restricciones de movimientos, debidas a la zonificación de espacios virtuales en función de la afectación, que determinan tanto las operaciones a realizar como los niveles de protección necesarios. 


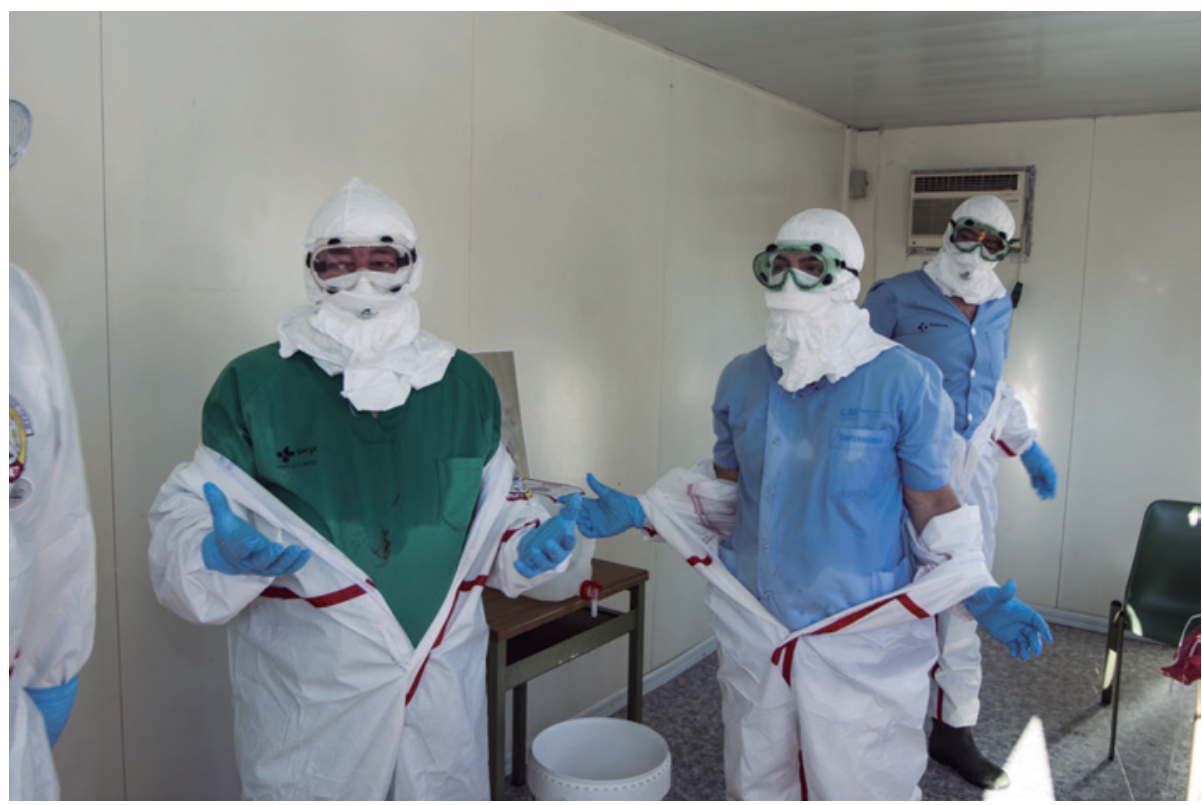

Figura 4. El empleo de EPI precisa de un esfuerzo y concentración mayores por parte del interviniente, a la vez que limita enormemente sus movimientos y su tiempo de trabajo

\subsubsection{Clasificación de los incidentes NBQ}

Las crisis por exposición a este tipo de agentes pueden tener una presentación variable; asimismo, se debe tener en cuenta que dicha exposición puede producirse a consecuencia de un incidente o realizarse de forma intencionada. También pueden clasificarse en función del contexto en el que aparezcan, teniendo en cuenta especialmente si es un ambiente bélico o civil. En este estudio se ha determinado presentarlas en función del agente causal.

\subsubsection{Incidentes nucleares}

La emisión de radiaciones puede estar producida por la diseminación de un agente radiactivo o por una explosión nuclear. Dicha radiación puede estar constituida por neutrones, partículas alfa, beta, rayos gamma e incluso rayos $\mathrm{X}$. En el caso de las explosiones, además de la gran destrucción de estructuras físicas y la elevada cuantía de víctimas, la radiación variará desde el momento inicial de la explosión, y puede llevar a producir afectación global si las partículas radiactivas son diseminadas a la estratosfera. Los eventos radiactivos sin explosión nuclear se producen por la dispersión de fuentes de emisión de ondas o partículas que pueden afectar a los organismos vivos de grandes extensiones de terreno, sin producir alteración o destrucción de las estructuras físicas ${ }^{(22)}$.

\subsubsection{Incidentes químicos}

Los agentes químicos están constituidos por sustancias que a través de la exposición directa, o la contaminación del agua, alimentos o terreno, genera un síndrome tóxico cuya afección puede variar desde la incapacitación temporal hasta la muerte. Los efectos clínicos y la contaminación ambiental dependerán de las características físico-químicas de las sustancias, así como de su mecanismo de acción sobre los organismos ${ }^{(23)}$. 
Afortunadamente, la práctica totalidad de incidentes que se producen con sustancias químicas en España son debidos a accidentes fortuitos de circulación con mercancías peligrosas. Según fuentes del Ministerio de Fomento, en el año 2014 se produjeron en España 104 accidentes reportados con mercancías peligrosas, 23 con mercancía derramada y 81 sin mercancía derramada ${ }^{24)}$.

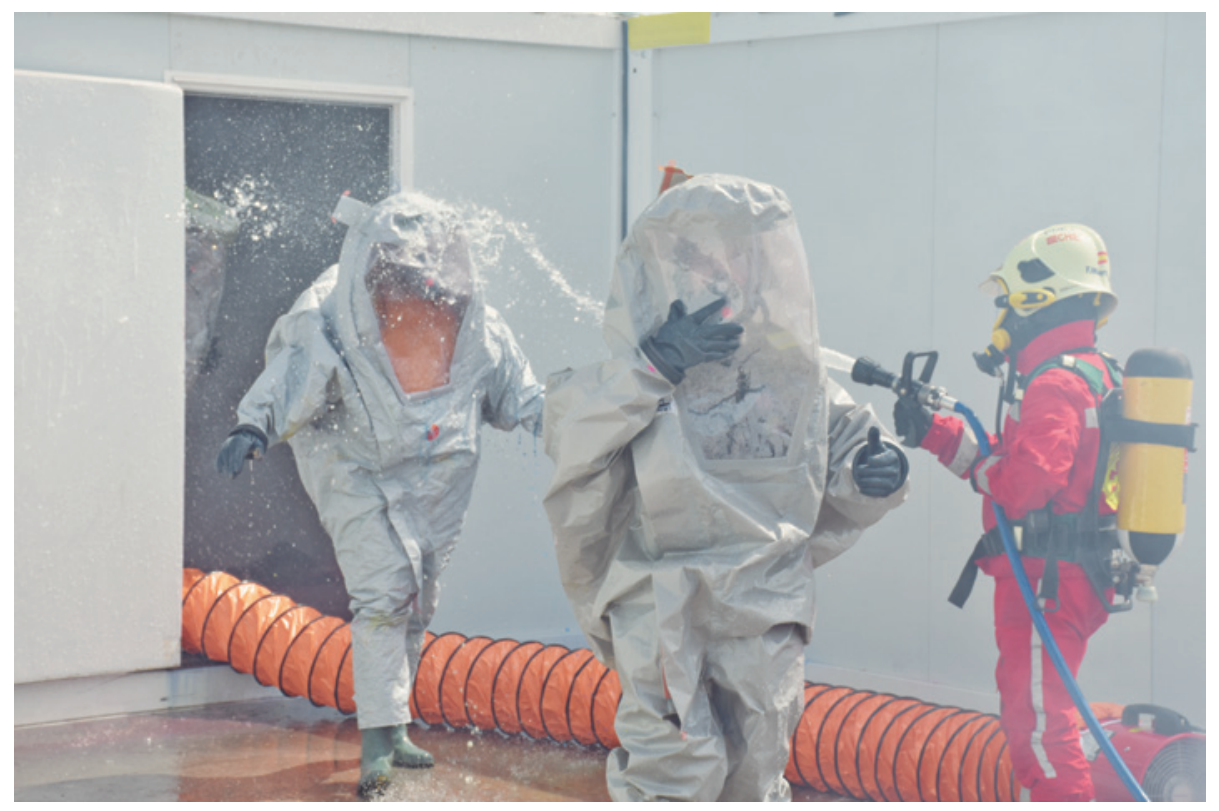

Figura 5. Uso de EPI nivel A, encapsulados y con equipo de respiración autónomo

\subsubsection{Incidentes biológicos}

Se entiende por agentes biológicos aquellos microorganismos, toxinas o sustancias de origen biológico que son capaces de originar enfermedad en el hombre, fauna, flora y, raramente, en materiales. Implica toda exposición a dichos agentes que pueda producir infección, alergia o toxicidad. Se incluyen microorganismos (también los genéticamente modificados), endoparásitos humanos, cultivos celulares, toxinas de microorganismos $u$ organismos pluricelulares (incluso aquellos sintetizados por el hombre). A lo largo de las últimas décadas, diferentes hechos han renovado la situación de riesgo biológico en el mundo, como la epidemia de Síndrome Respiratorio Agudo Severo (SRAS), la gripe Aviar o la gripe $\mathrm{A}^{(25)}$. Los efectos sanitarios del cambio climático, la facilidad de las comunicaciones y el transporte de viajeros por el mundo, así como la amenaza del bioterrorismo, reavivan la necesidad de una mayor conciencia y preparación ante estas situaciones ${ }^{(26)}$.

\subsubsection{Equipos de protección individual}

Cuando se habla de incidentes NBQ (HazMat, en terminología anglosajona), se hace referencia a incidentes con sustancias nucleares, biológicas o químicas. Este tipo de incidentes, aunque por el momento se trata de casos aislados, ocurren con cierta frecuencia, por lo que debemos estar preparados para intervenir ante esta clase de escenarios. La mayoría son provocados bien por situaciones accidentales, bien porque no se han tomado las medidas de seguridad oportunas para la manipulación o transporte de determinadas sustancias. A estos accidentes hay que añadir la posibilidad de 
que se realicen actos terroristas, situación que, desafortunadamente, cada vez se produce con más frecuencia, tal y como se ha demostrado en varios intentos de ataques frustrados por la policía a nivel mundial en los últimos años ${ }^{(27)}$.

El riesgo de que ocurra una situación NBQ es porcentualmente menor que ante otro tipo de desastres, pero, debido a sus múltiples y variadas repercusiones, el sistema debe estar especialmente preparado y entrenado; y los equipos de protección individual en sus diversos tipos deben representar la columna vertebral en los sistemas de protección, de prevención de contagios y, por definición, de control de la situación.

\subsubsection{Marco jurídico}

El Real Decreto 773/1997, 30 de mayo, sobre disposiciones mínimas de seguridad y salud relativas a la utilización por los trabajadores de equipos de protección individual (BOE núm. 140, de 12 de junio) establece en su artículo 2 la definición de Equipo de protección individual: como "cualquier equipo destinado a ser llevado o sujetado por el trabajador para que le proteja de uno o varios riesgos que puedan amenazar su seguridad o su salud, así como cualquier complemento o accesorio destinado a tal fin" (28).

Por otro lado, el Real Decreto 1407/1992, de 20 de noviembre, regula las condiciones para la comercialización y libre circulación intracomunitaria de los equipos de protección individual (BOE núm. 311, de 28 de diciembre) ${ }^{(29)}$.

\subsubsection{Clasificación de los EPI en situaciones NBQ}

Desde el punto de vista NBQ, los EPI adecuados deben presentar el mayor grado de protección disponible, además de resultar adecuado para el riesgo al que se enfrentan los intervinientes. De esta forma, el grado de protección se puede clasificar en 4 niveles (US Environmental Protection Agency) ${ }^{(30)}$ :

- Nivel A. Su principal característica es la estanqueidad, lo que permite trabajar en ambientes tóxicos. Índice máximo de protección respiratoria, piel y mucosas. Presentan equipos de respiración autónoma, guantes internos y externos, botas resistentes a productos químicos, casco interno, equipo de transmisión craneal, y un traje hermético de tejido sintético grueso que protege contra las acciones de las sustancias químicas. Son equipos pesados y calientes que requieren de una buena condición física por parte de quien los vaya a usar. Limitan en gran medida la realización adecuada de las labores de reanimación.

- Nivel B. Traje de protección contra salpicaduras químicas, con protección respiratoria contra atmósferas pobres en oxígeno o concentraciones muy altas de tóxicos mediante respiración con presión positiva. Consta, además, de guantes internos, externos, botas resistentes a productos químicos, casco y radio. Este nivel ofrece una protección adecuada a nivel respiratorio y cutáneo, es menos caro y menos pesado que el equipo de nivel A, pero continúa limitando las labores de reanimación.

- Nivel C. Ropa de protección contra salpicaduras químicas, con protección respiratoria para atmósferas con una concentración de oxígeno suficiente (> 18\%) pero con concentraciones posiblemente peligrosas de sustancias químicas, mediante el uso de mascarilla facial con filtro químico (es fundamental elegir el filtro adecuado en función del tóxico presente, ya que hay filtros que combinan la protección de varias sustancias químicas y protección contra partículas, pero no existe un equipo útil para todo tipo de contaminantes). Cuenta también con protección ocular, guantes internos, externos y botas resistentes a químicos. La protección respiratoria es inferior al equipo de nivel B, pero con la misma condición de protección para la piel. 
- Nivel D. Representa la mínima protección. El equipo está compuesto por traje de protección química tipo 5-6, gorro, mascarilla FFP3, guantes y protección ocular (Figura 6).

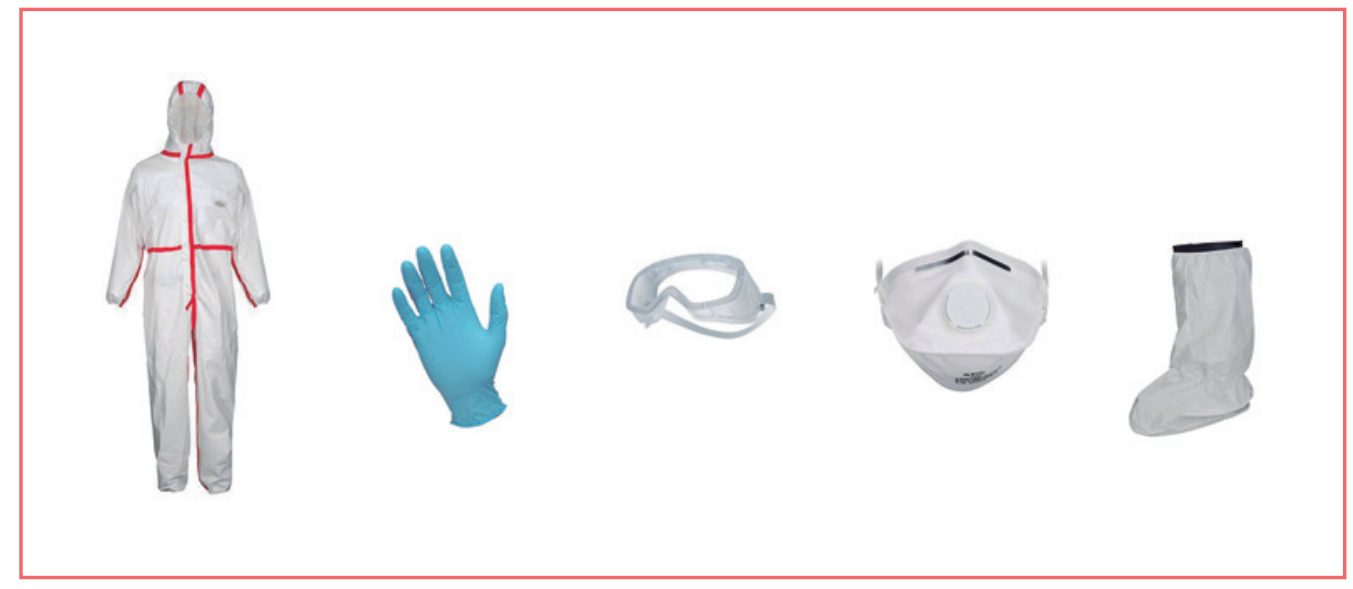

Figura 6. Equipo de protección nivel D

\subsubsection{Los riesgos en la escena}

La elección de un tipo de protección u otra dependerá de diversos factores. En primer lugar, se deberían identificar previamente los agentes presentes y conocer sus efectos, recordando que los agentes químicos se dividen en dos grupos: partículas, por un lado, y gases y vapores, por otro. Las partículas, por su parte, se pueden encontrar en forma de polvos, nieblas o humos.

Un dato que necesariamente se debe tener en cuenta a la hora de elegir el equipo de protección adecuado es si el ambiente donde se va a desarrollar la labor presenta una concentración adecuada de oxígeno y si se tiene que trabajar en presencia de temperaturas extremas.

Si se desconocen la naturaleza y propiedades del agente, siempre se procederá por criterios de máxima seguridad, de forma que se procederá a intervenir con el equipo de máxima protección disponible (nivel A, tipo 1).

Es fundamental conocer cuáles son las propiedades de la sustancia (corrosiva, explosiva, biológica, radiactiva, etc.), así como qué ocurre cuando el agente se calienta, si desprende vapores tóxicos (necesidad de trabajar con equipos autónomos de respiración) o cuáles son los efectos de la exposición a corto y a largo plazo.

Los EPI deben cumplir una serie de requisitos que permitan elegir unos u otros en función de las circunstancias. A nivel de protección cutánea, dependerán del grado de protección necesario (aislamiento, confinamiento, etc.), de la resistencia química del material, de su maleabilidad y confortabilidad, así como de la facilidad de limpieza y descontaminación. Se dispone de trajes de protección total u overalls, capuchas, guantes, botas de caña alta, prendas desechables o petos, entre otros. En el Anexo 1 se pueden consultar algunas características de los distintos niveles de protección (US Environmental Protection Agency).

Si en la intervención se sospecha que pueden existir vapores o humos, o no se conoce la naturaleza del agente, además de actuar con un grado de protección máxima a nivel cutáneo, es preciso realizar una adecuada protección respiratoria, que puede oscilar desde equipos de respiración autónoma a 
mascarillas de protección (como mínimo, mascarillas FFP3). La elección de uno u otro dispositivo dependerá de factores como el tipo de riesgo (tóxicos, disminución del oxígeno ambiental, etc.), tipos de ambiente (locales confinados, distancias, accesibilidad, pozos, barrancos, limitaciones de movilidad, etc.), de la actividad a realizar (movilidad, actividad física o frecuencia) y tiempo de uso y grado de protección (continuo, intermitente o en emergencias) ${ }^{(31)}$.

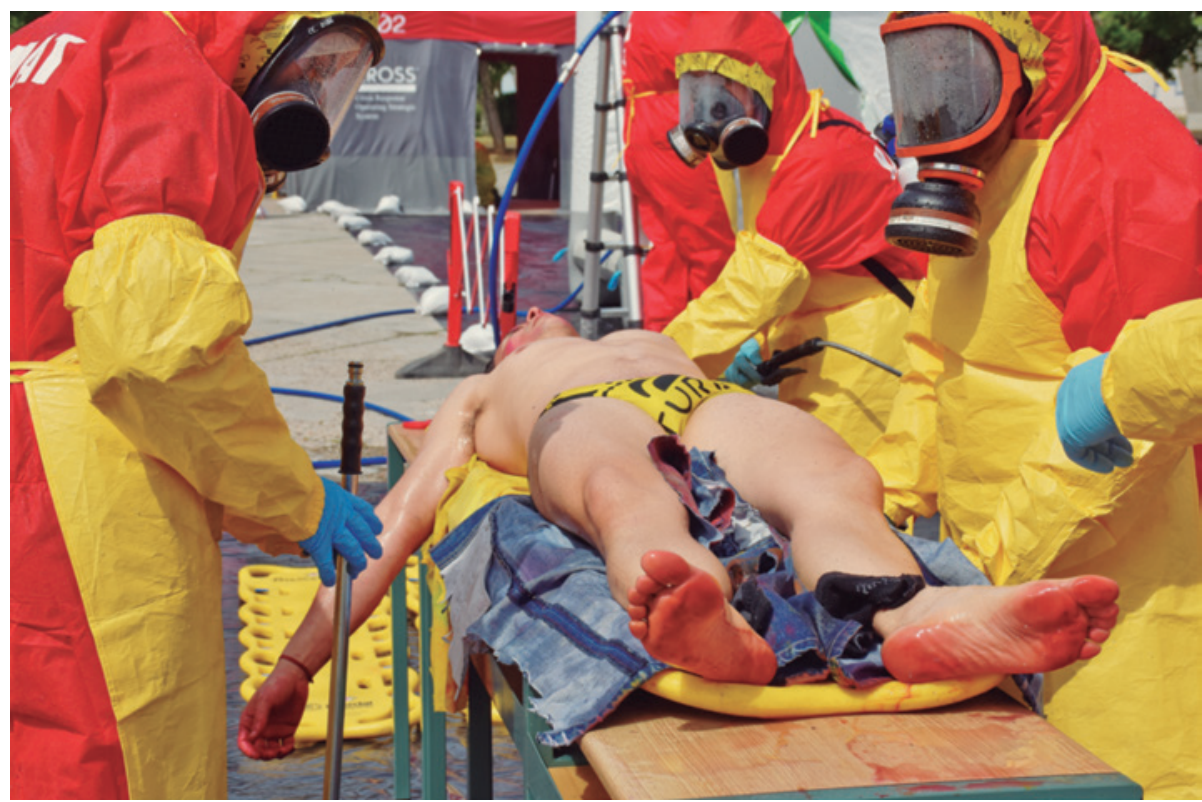

Figura 7. Labores de descontaminación

\subsection{Definición del problema}

Una vez expuestos los antecedentes, y tras una búsqueda bibliográfica exhaustiva, no ha sido posible encontrar ningún estudio que relacione el uso de EPI en los trabajadores de la salud y los efectos que estos equipos provocan en dichos profesionales, respondiendo preguntas tales como: ¿cuál es el tiempo razonable con el que se debe estar con la equipación?, ¿todo el mundo es apto para usar estos sistemas de protección?, ¿cómo se comporta el organismo ante el estrés físico que supone trabajar bajo estas especiales condiciones?, ¿podemos detectar previamente qué trabajadores no son idóneos para trabajar con estas equipaciones?

Estudios como el de Joseph T. Costello ${ }^{(32)}$ tratan de explicar los efectos del uso de equipos específicos contra agentes químicos y antifragmentación, y cómo se comporta el organismo a nivel de estrés psicológico, poniendo a 12 voluntarios a prueba, y observando su comportamiento a nivel de estrés, temperatura y peso. Otros estudios ${ }^{(33)(34)(35)(36)}$ valoran aspectos parciales, como el uso de mascarillas de protección, uso de trajes, o la relación continuada de determinados riesgos y sus efectos sobre la salud de los trabajadores.

Sin embargo, por todo lo anteriormente mencionado, se plantea que podría resultar muy útil estudiar y describir qué efectos provoca el uso de equipos de protección individual frente a agentes biológicos sobre los trabajadores de la salud, e intentar relacionar determinadas constantes vitales y/o mediciones y sus alteraciones con la mayor o menor predisposición fisiológica al uso de dichos equipos. 


\section{2. \\ Hipótesis}

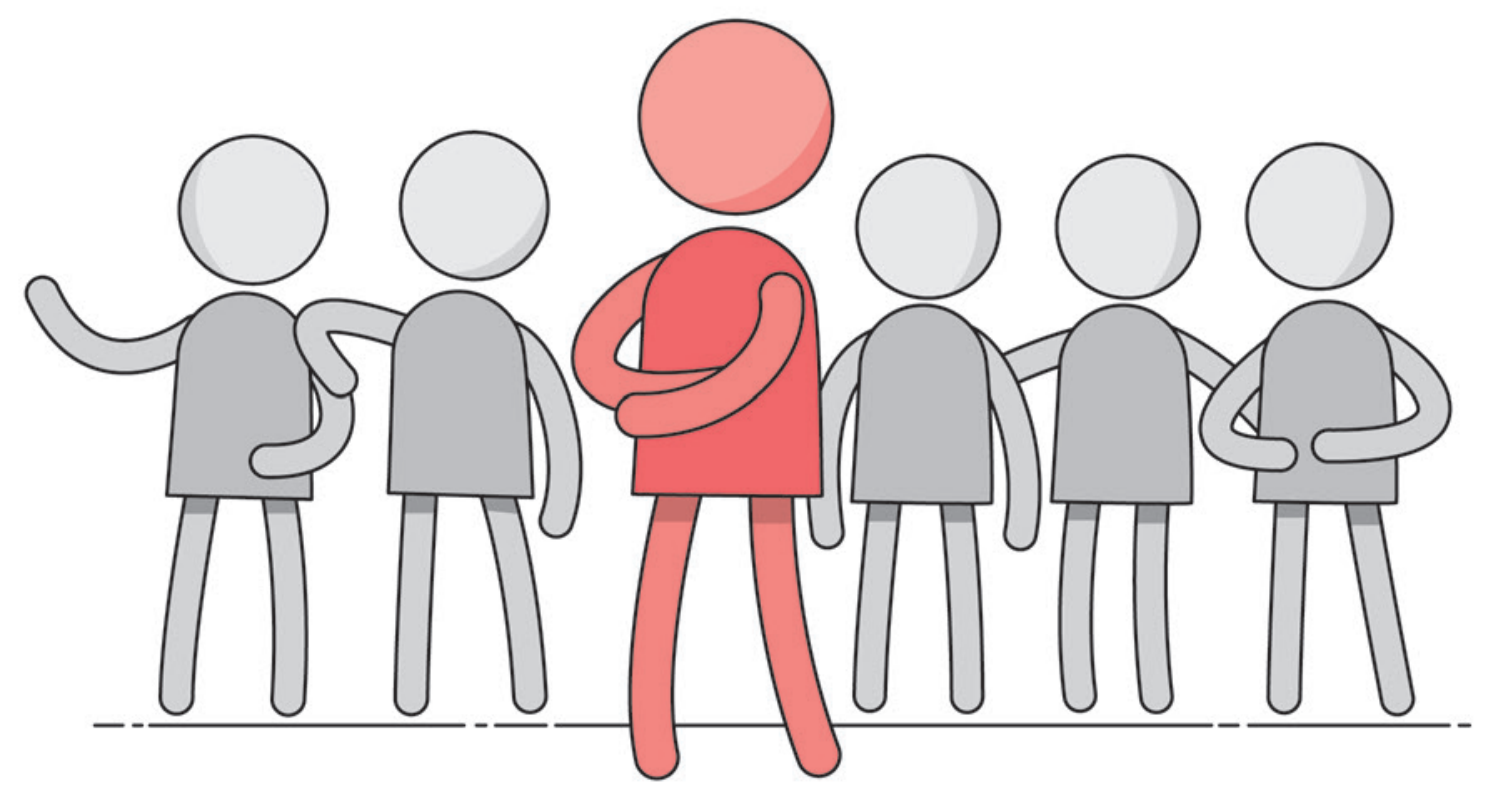

Universidad deValladolid 


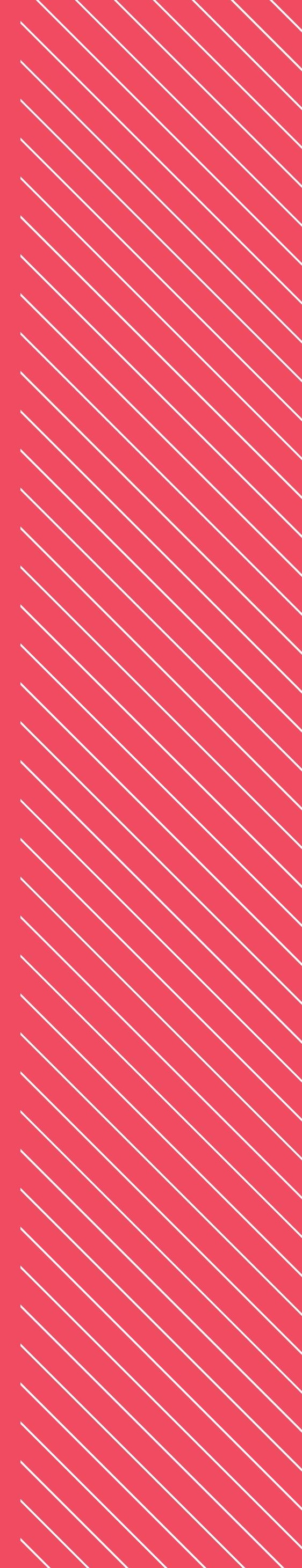


Por medio del uso de EPI se han mejorado tanto la asistencia a las víctimas, como la supervivencia de los intervinientes en incidentes de carácter químico o biológico, pero el uso de este tipo de protección, por otro lado, podría traducirse en la reducción de la capacidad operativa de una persona. En la selección de equipos de protección para la preparación biológica y química se debe llegar a un equilibrio entre el grado de protección necesario para el peligro potencial en cuestión y la dificultad resultante para llevar a cabo las funciones por parte de los usuarios.

Desempeñar su labor en situaciones de riesgo NBQ con el nivel necesario de protección afecta de forma directa a la fisiología de los trabajadores de la salud, ya que genera un estrés físico muy significativo, llegando a un punto en el que es aconsejable dejar el operativo en curso y proceder a la retirada del equipo de protección, por los riesgos no tolerables o el elevado estrés fisiológico que está sufriendo el trabajador.

La hipótesis de partida de esta tesis doctoral, por tanto, se basa en intentar determinar el nivel de tolerancia fisiológica aceptable del uso de equipos de protección individual contra agentes biológicos, portando una equipación nivel D. 


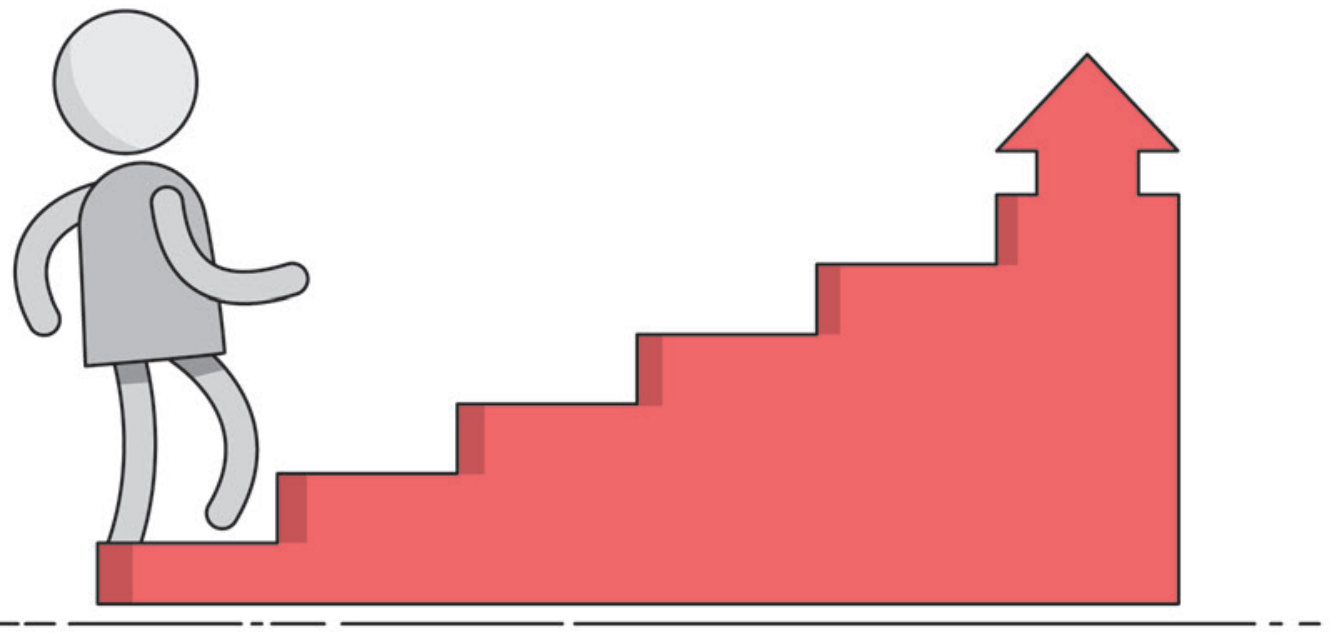




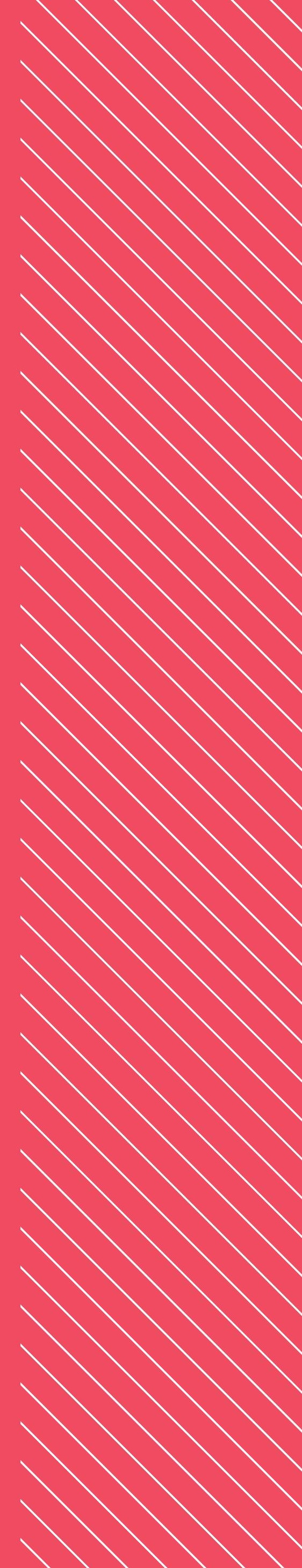




\subsection{Objetivo general}

El objetivo general de esta investigación es describir los cambios fisiológicos que experimentan los profesionales que se equipan con trajes de protección individual nivel D durante su labor en situaciones de riesgo biológico.

\subsection{Objetivos específicos}

- Detallar los parámetros fisiológicos y antropométricos relacionados con el estudio.

- Evaluar la relación que presenta el nivel de actividad física medida mediante el cuestionario IPAQ, con la respuesta fisiológica que experimentan los voluntarios al realizar una reanimación con un EPI categoría D frente a riesgos biológicos.

- Analizar el impacto fisiológico que tiene sobre la frecuencia cardiaca máxima realizar una RCP con un EPI categoría D frente a riesgos nucleares, biológicos o químicos.

- Comparar la FCM obtenida mediante fórmulas matemáticas con la FCM obtenida mediante una cicloergometría.

- Estudiar la vinculación entre el aumento de la frecuencia cardiaca y la modificación de los niveles de ácido láctico, tanto en la cicloergometría como en la realización del caso práctico.

- Describir el comportamiento del índice de perfusión, así como su afectación sobre el estrés físico a este parámetro.

- Constatar la existencia de un patrón fisiológico de mala tolerancia al sobreesfuerzo físico originado por el uso de equipos de protección.

- Comprobar el grado de acierto en la elección en la talla del traje nivel D, categoría 4-5-6B para la actuación en incidentes con riesgo biológico. 


\section{4.}

-Metodología

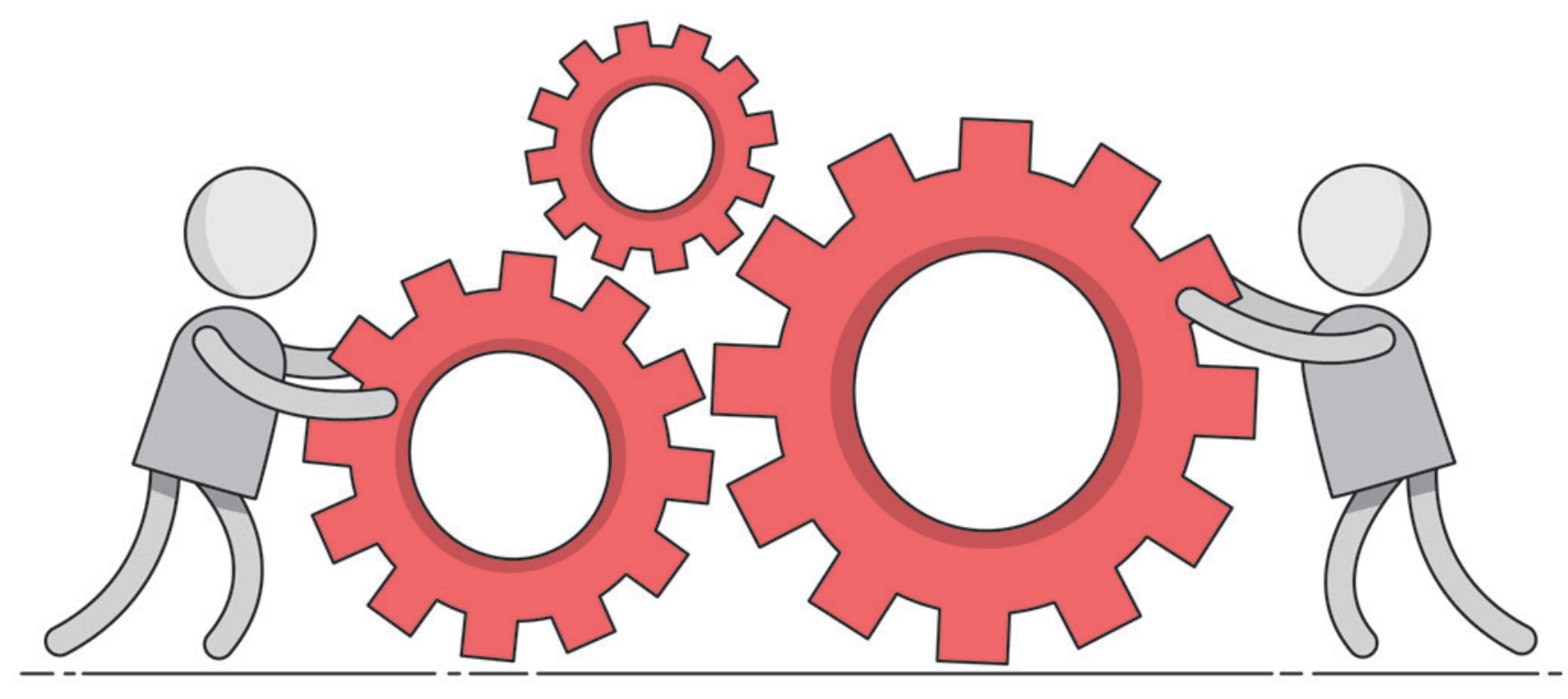




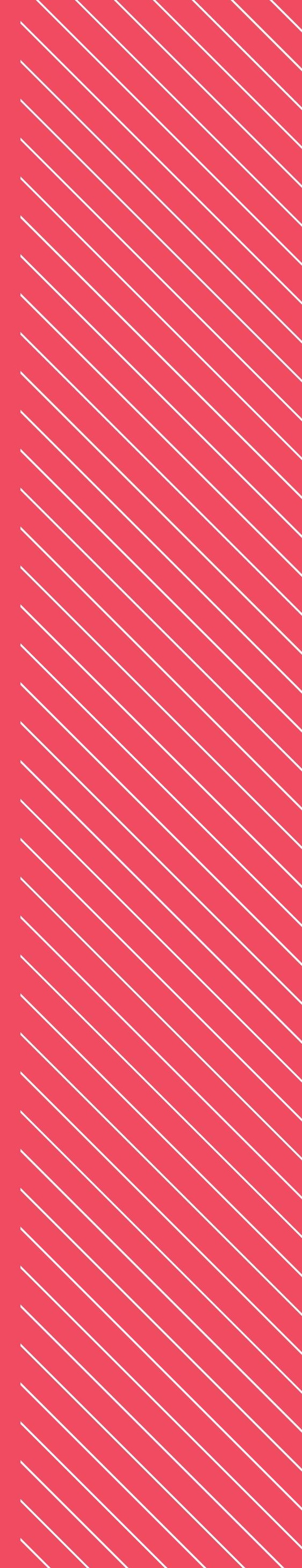




\subsection{Descripción del estudio}

\subsubsection{Tipo de estudio y de muestreo}

El tipo de investigación que se ha llevado a cabo se trata de un estudio quasi-experimental no controlado sobre 96 voluntarios elegidos mediante un muestreo aleatorio estratificado por sexo, nivel de formación y categoría profesional, de una muestra de oportunidad de 164 voluntarios.

\subsubsection{Análisis y descripción de la población diana}

\subsubsection{Selección de la muestra}

Los participantes en el estudio son individuos seleccionados de entre todos aquellos voluntarios que han mostrado su interés en participar en el estudio.

Para contar con un pool suficiente de voluntarios, se realizó una campaña de información en los dos hospitales de Valladolid (Hospital Clínico Universitario y Hospital Universitario Río Hortega), en la Gerencia de Emergencias Sanitarias de Castilla y León y en la Facultad de Ciencias de la Salud de la Universidad de Valladolid. Dicha campaña de reclutamiento se llevó a cabo a través de charlas informativas, la elaboración y distribución de un tríptico y un correo electrónico que se envió desde la Gerencia de Emergencias a todos sus trabajadores. La información previa que se suministraba a los futuros participantes fue la siguiente —el documento original puede consultarse en el Anexo 2: Hoja de inscripción de voluntarios-:

- Concepto de incidente NBQ, implicaciones para el sector de la salud.

- Estado de la epidemia actual del virus Ébola.

- Confidencialidad sobre la identidad de los voluntarios. Al entrar a formar parte del estudio, se les asigna un número de identificación, no constando su nombre y apellidos en ningún documento generado en el estudio, excepto en el consentimiento informado, que se guarda en archivo diferente al resto de datos.

- Comunicación sobre el interrogatorio sobre su historial médico que se realizaría a lo largo del estudio.

- Técnicas no invasivas e invasivas que se desarrollan en el estudio.

- Necesidad de realización de una cicloergometría de esfuerzo, informando sobre sus posibles complicaciones.

- Tiempo estimado.

- Advertencia expresa sobre la posible renuncia en cualquier momento del estudio.

- Advertencia de que, en el estudio, la puesta y retirada del EPI (en todo momento es guiada por un supervisor) no sería evaluada, así como tampoco la destreza en la realización de las técnicas médicas sobre el maniquí de simulación. El objetivo del estudio no es determinar la calidad de las técnicas realizadas o la corrección en la puesta y restirada del equipo, sino las repercusiones fisiológicas que origina esta intervención sobre los voluntarios. 


\subsubsection{Características específicas de los participantes}

Debido a las particularidades de uso de este tipo de EPI frente a riesgos biológicos, y teniendo en cuenta qué profesionales sanitarios tienen más posibilidades de enfrentarse a este tipo de riesgos en los momentos iniciales, la población diana que con más probabilidad tendrá que asumir una situación de este tipo son el personal de emergencias sanitarias y de urgencias hospitalarias.

Dentro de este sector de trabajo existen multitud de categorías profesionales, pero únicamente dos han sido seleccionadas: Licenciados en Medicina y Grados en Enfermería, ya que, en el caso de situación de emergencia por riesgo biológico, resultan personal imprescindible, y son los que más tiempo ocuparán con el paciente, y más ciclos de puesta y retirada de EPI van a realizar.

Mediante el estudio y la observación de la realidad de los centros sanitarios se puede advertir que una parte fundamental de estos servicios son los estudiantes tanto de Medicina como de Enfermería, que están de forma continua presentes en los servicios. Por todo ello, también se incluyeron como sujetos del estudio a estos estudiantes de grado, para, además, poder analizar si existen diferencias relacionadas con la experiencia laboral o con la edad de los voluntarios.

\subsubsection{Cálculo de tamaño muestral y distribución por grupos de los participantes}

Para la elaboración del presente estudio se ha tomado una muestra n de 100 voluntarios; por lo tanto, el tamaño muestra válido para el estudio es de 96 sujetos: 40 hombres y 56 mujeres.

El cálculo del tamaño muestral se realizó aceptando un riesgo alfa de 0.05 y un riesgo beta de 0.2 en un contraste bilateral, precisándose 96 sujetos, y asumiendo que la proporción inicial de acontecimientos es del $0.01 \mathrm{y}$ al final del 0.1 . Se ha estimado una tasa de pérdidas de seguimiento del $4 \%$, por lo que la muestra final estimada fue de 100 sujetos.

De entre todos los voluntarios que mostraron su disposición a participar en el estudio (167 en total) se realizó un sorteo aleatorio por conglomerados, distribuyendo la muestra de la siguiente manera:

- Se intentó distribuir la nuestra al 50\% entre hombres y mujeres.

- A su vez, de cada uno de estos subgrupos, $50 \%$ de grado y $50 \%$ profesionales activos.

- De todos los alumnos de grado, 50\% estudiantes del Grado de Enfermería y 50\% de la Licenciatura de Medicina.

- Del subgrupo de profesionales, 50\% de personal de Urgencias Hospitalarias y 50\% de Emergencias Sanitarias.

- Por último, del subgrupo de Urgencias o Emergencias, se ha intentado distribuir por categorías profesionales, es decir, 50\% Grados en Enfermería y 50\% Licenciados en Medicina. 


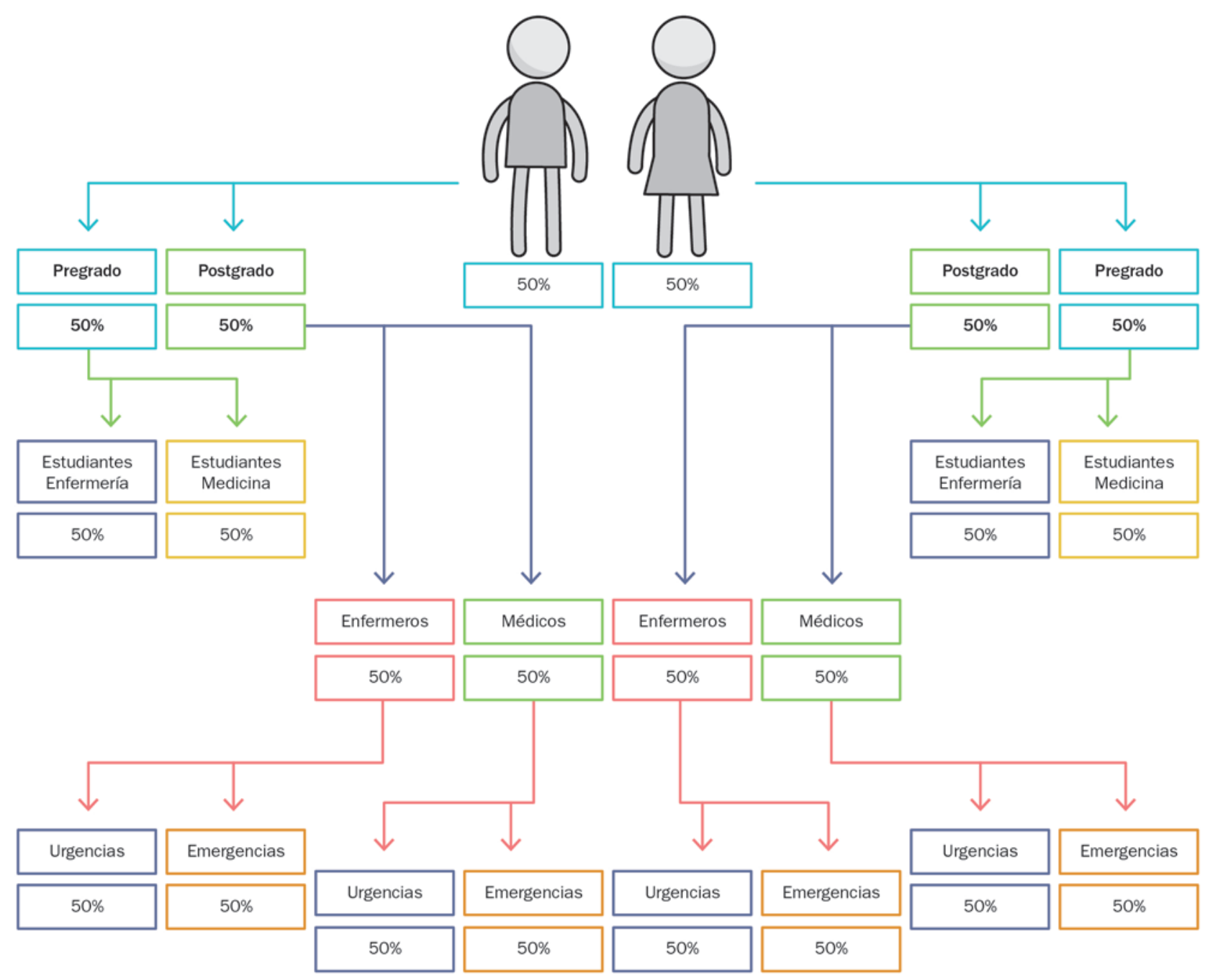

Figura 8. Distribución ideal de la muestra por conglomerados

\subsubsection{Criterios de inclusión y exclusión}

De los voluntarios seleccionados, se considera apta para realizar el estudio cualquier persona entre 18 y 65 años, que pertenezca a alguno de los subgrupos anteriormente descritos y que no coincidiera con ningún criterio de exclusión. Se consideró criterio de exclusión la presencia de alguna de estas alteraciones:

- Arritmias.

- Síndrome coronario agudo.

- Crisis asmática en curso.

- Espirometría anormal (del mejor de tres intentos).

- Frecuencia cardiaca basal mayor de 150 latidos por minuto.

- Frecuencia cardiaca basal menor de 35 latidos por minuto.

- Tensión arterial sistólica mayor de 160 mmHg.

- Tensión arterial diastólica mayor de 95 mmHg.

- Tensión arterial sistólica menor de 80 mmHg.

- Índice de masa corporal mayor de 40. 
- Impotencia funcional.

- Escala de Coma de Glasgow menor de 15 puntos.

- Saturación de oxígeno menor del $92 \%$.

- Glucemia capilar por debajo de $65 \mathrm{mg} / \mathrm{dl}$.

- Hemoglobina capilar menor de 8 gr.

- Temperatura mayor de $38^{\circ} \mathrm{C}$.

- Cirugía mayor 30 días anteriores.

- Portador de DAl/Holter.

- Epilepsia.

- Anticoagulación.

- Deficiencia auditiva severa.

- Deficiencia visual severa.

- Enfermedades cutáneas en fase aguda.

- Infecciones en curso.

- Enfermedades inmunológicas sistémicas.

\subsection{Variables}

\subsubsection{Datos biográficos e historia médica}

Grupo. Variable cualitativa nominal. Los valores que puede presentar son:

1.1. Estudiantes del Grado de Enfermería.

1.2. Estudiantes de la Licenciatura de Medicina.

1.3. Graduado en Enfermería.

1.4. Licenciado en Medicina.

2. Subgrupo. Variable cualitativa nominal. A su vez, los sujetos de los grupos de Graduado en Enfermería y Licenciados en Medicina pueden presentar los siguientes valores:

2.1. Servicios de Urgencias Hospitalarias.

2.2. Servicios de Emergencias Prehospitalarias.

3. Sexo. Variable cualitativa nominal.

3.1. Hombre.

3.2. Mujer.

4. Raza. Variable cualitativa nominal.

4.1. Blanco.

4.2. Africano.

4.3. Asiático.

4.4. Aborigen.

4.5. Indígena.

5. Edad. Variable cuantitativa continua. Unidad de medición en años.

6. Estado civil. Variable cualitativa nominal.
6.1. Soltero.
6.2. Casado.
6.3. Divorciado.
6.4. Viudo. 
7. Número de hijos. Variable cuantitativa discreta.

8. Años de experiencia. Variable cuantitativa continua. Se refiere a la experiencia laboral o años de estudios: los subgrupos de profesionales reflejan los años de experiencia trabajando, y los subgrupos de grado o licenciatura los años que llevan cursando estudios superiores. Unidad de medición en años.

9. Credo. Variable cualitativa nominal.

9.1. Ateo.

9.2. Agnóstico.

9.3. Creyente no practicante.

9.4. Creyente practicante.

10. Experiencia NBQ. Variable cualitativa ordinal.

10.1. Ninguna. No tiene ningún tipo de formación teórica o práctica en el manejo sanitario de incidentes con riesgo NBQ.

10.2. Curso básico. Formación teórica y práctica de los conocimientos básicos y esenciales sobre la gestión de incidentes con riesgo NBQ. Curso inicial, de no más de 20 horas de duración, incluyendo al menos 5 secuencias completas de puesta y retirada de equipo de protección.

10.3. Curso avanzado. Formación teórica y entrenamiento práctico en situaciones con riesgo NBQ. Curso avanzado, de más de 20 horas, incluyendo al menos 10 secuencias completas de puesta y retirada de equipo de protección.

10.4. Experiencia real. Profesional que ha participado en situaciones reales de riesgo NBQ, no en simulaciones, sino en casos o amenazas de riesgo real.

11. Horas desde la última ingesta. Variable cuantitativa continua. En este valor se refleja el tiempo transcurrido en horas desde la última ingesta.

12. Horas de sueño. Variable cuantitativa continua. Este valor indica las horas de sueño de la noche anterior a realizar el estudio.

13. Alergias. Variable cualitativa nominal.

Tabla 1. Listado de alergias

\begin{tabular}{|c|c|c|}
\hline 13.1. Ninguna. & 13.2. Humedad. & 13.3. Ácaros. \\
\hline 13.4. Alimentos. & 13.5. Sol. & 13.6. Níquel. \\
\hline 13.7. Picaduras. & 13.8. Látex. & 13.6. Níquel. \\
\hline 13.10. Polen. & 13.11. Animales. & 13.12. Insectos. \\
\hline 13.13. Hongos. & 13.14. Polvo. & 13.15. Anticonvulsivos. \\
\hline 13.16. Yodo y derivados. & 13.17. Insulina. & 13.18. Antibióticos betalactámicos. \\
\hline 13.19. Sulfamidas. & 13.20. AINES & 13.21. Aspirina. \\
\hline 13.22. Hormonas. & 13.23. Corticoides. & 13.24. Antihipertensivos. \\
\hline 13.25. Colirios. & 13.26. Quinolonas. & 13.27. Macrólidos. \\
\hline 13.28. Otros. & 13.29. - & 13.30. - \\
\hline
\end{tabular}


14.Embarazo. Variable cualitativa nominal. En este valor se refleja si las voluntarias mujeres están embarazas o no.

15. Fecha de la última regla. Variable cuantitativa continua. En este valor se refleja el tiempo transcurrido desde la fecha de la última regla en días.

16. Alcohol. Variable cualitativa nominal En este valor se refleja si el voluntario ingiere alcohol o no.

17. Cantidad de alcohol. Variable cuantitativa continua. Con el objetivo de unificar criterios en cuanto a la ingesta semanal de alcohol, la O.M.S. estipuló su medida a través de la Unidad de Bebida Estándar (U.B.E.). En este valor se refleja la cantidad de alcohol ingerida por semana por los voluntarios que han manifestado que bebían alcohol. Cada U.B.E. representa en España 10 gramos de alcohol puro ${ }^{(37)}$.

Tabla 2. Fórmula para calcular los gramos de alcohol por bebida

ml. de bebida alcohólica x Graduación x 0,8 / 100

18. Tabaco. Variable cualitativa nominal En este valor se refleja si el voluntario fuma o no.

19. Cantidad de tabaco. Variable cuantitativa discreta. Refleja el número de cigarros/día.

20. Número de años fumando. Variable cuantitativa continua. Unidad de medición: años completos.

21.Diabetes mellitus. Variable cualitativa nominal. En este valor se refleja si el voluntario tiene una DM diagnosticada.

22. Hipertensión arterial. Variable cualitativa nominal. En este valor se refleja si el voluntario tiene una HTA diagnosticada.

23. Dislipemia. Variable cualitativa nominal. En este valor se refleja si el voluntario tiene una dislipemia diagnosticada, ya sea por hipercolesterolemia aislada, hipertrigliceridemia aislada o dislipemia mixta.

24. Enfermedades tiroideas. Variable cualitativa nominal. En este valor se refleja si el voluntario tiene una enfermedad tiroidea diagnosticada.

25. Déficit de ácido fólico. Variable cualitativa nominal. En este valor se refleja si el voluntario tiene déficit de esta sustancia.

26. Déficit de Vitamina B12. Variable cualitativa nominal. En este valor se refleja si el voluntario tiene déficit de esta vitamina.

27. Anemia. Variable cualitativa nominal. En este valor se refleja si el voluntario tiene otros tipos de anemia que no sean por déficit de ácido fólico o vitamina B12.

28. Ansiedad. Variable cualitativa nominal. En este valor se refleja si el voluntario sufre problemas de ansiedad.

29. Patología 1. Variable cualitativa nominal. En este valor se refleja si el voluntario sufre un problema de salud clasificado en el CIE 10, en los siguientes grupos de patologías. 
Tabla 3. Clasificación Internacional de Enfermedades (CIE) 10. a revisión (38)

\begin{tabular}{|c|c|c|}
\hline I & A00-B99 & Ciertas enfermedades infecciosas y parasitarias \\
\hline II & C00-D48 & Neoplasias \\
\hline III & D50-D89 & $\begin{array}{l}\text { Enfermedades de la sangre y de los órganos hematopoyéticos y otros } \\
\text { trastornos que afectan el mecanismo de la inmunidad }\end{array}$ \\
\hline IV & E00-E90 & Enfermedades endocrinas, nutricionales y metabólicas \\
\hline V & F00-F99 & Trastornos mentales y del comportamiento \\
\hline VI & G00-G99 & Enfermedades del sistema nervioso \\
\hline VII & HOO-H59 & Enfermedades del ojo y sus anexos \\
\hline VIII & H6O-H95 & Enfermedades del oído y de la apófisis mastoides \\
\hline IX & $100-199$ & Enfermedades del sistema circulatorio \\
\hline$x$ & J00-J99 & Enfermedades del sistema respiratorio \\
\hline XI & K00-K93 & Enfermedades del aparato digestivo \\
\hline XII & LOO-L99 & Enfermedades de la piel y el tejido subcutáneo \\
\hline XIII & M00-M99 & Enfermedades del sistema osteomuscular y del tejido conectivo \\
\hline XIV & NoO-N99 & Enfermedades del aparato genitourinario \\
\hline XV & 000-099 & Embarazo, parto y puerperio \\
\hline XVI & P00-P96 & Ciertas afecciones originadas en el periodo perinatal \\
\hline XVII & Q00-Q99 & Malformaciones congénitas, deformidades y anomalías cromosómicas \\
\hline XVIII & R00-R99 & $\begin{array}{l}\text { Síntomas, signos y hallazgos anormales clínicos y de laboratorio, no clasi- } \\
\text { ficados en otra parte }\end{array}$ \\
\hline IXX & S00-T98 & $\begin{array}{l}\text { Traumatismos, envenenamientos y algunas otras consecuencias de causa } \\
\text { externa }\end{array}$ \\
\hline$X X$ & V01-Y98 & Causas externas de morbilidad y de mortalidad \\
\hline XXI & ZOO-Z99 & $\begin{array}{l}\text { Factores que influyen en el estado de salud y contacto con los servicios } \\
\text { de salud }\end{array}$ \\
\hline XXII & U00-U99 & Códigos para situaciones especiales \\
\hline
\end{tabular}

30. Patología 2. Variable cualitativa nominal. En este valor se refleja si el voluntario sufre problemas de salud clasificados en el CIE 10. Esta variable se complementa en el caso de que el voluntario tenga más de una patología.

31.Patología 3. Variable cualitativa nominal. En este valor se refleja si el voluntario sufre problemas de salud clasificados en el CIE 10. Esta variable se complementa en el caso de que el voluntario 
tenga más de dos patologías.

32.Patología 4. Variable cualitativa nominal. En este valor se refleja si el voluntario sufre problemas de salud clasificados en el CIE 10. Esta variable se complementa en el caso de que el voluntario tenga más de tres patologías.

33. Toma de bebidas estimulantes. Variable cualitativa nominal. En esta variable se refleja la toma de bebidas estimulantes como café, té, Coca-Cola o bebidas energéticas.

34. Medicación 1. Variable cualitativa nominal. En este valor se refleja si el voluntario está tomando una medicación comprendida en el listado de principios activos por grupos ATC.

\section{Tabla 4. Listados de principios activos por grupos ATC}

\begin{tabular}{|l|l|l|l|}
\hline 1 & Grupo A & Tracto alimentario y metabolismo \\
\hline 2 & Grupo B & Sangre y órganos hematopoyéticos \\
\hline 3 & Grupo C & Sistema cardiovascular \\
\hline 4 & Grupo D & Dermatológicos \\
\hline 5 & Grupo G & Sistema genitourinario y hormonas sexuales \\
\hline 6 & Grupo H & $\begin{array}{l}\text { Preparados hormonales sistémicos, excluyendo hormonas sexuales e } \\
\text { insulinas }\end{array}$ \\
\hline 7 & Grupo J & Antiinfecciosos para uso sistémico \\
\hline 8 & Grupo L & Agentes antineoplásicos e inmunomoduladores \\
\hline 9 & Grupo M & Sistema músculo-esquelético \\
\hline 10 & Grupo N & Sistema nervioso \\
\hline 11 & Grupo P & Productos antiparasitarios, insecticidas y repelentes \\
\hline 12 & Grupo R & Sistema respiratorio \\
\hline 13 & Grupo S & Órganos de los sentidos \\
\hline 14 & Grupo V & Varios \\
\hline
\end{tabular}

35. Medicación 2. Variable cualitativa nominal. En este valor se refleja si el voluntario está tomando más de una medicación comprendida en el listado de principios activos por grupos ATC. Refiriéndose esta variable a la segunda medicación.

36. Medicación 3. Variable cualitativa nominal. En este valor se refleja si el voluntario está tomando más de dos medicaciones comprendidas en el listado de principios activos por grupos ATC. Refiriéndose esta variable a la tercera medicación. 


\subsubsection{Variables de antropometría y bioimpedancia}

37. Talla. Variable cuantitativa continua. Refleja la estatura del voluntario en centímetros.

38. Contorno de pecho. Variable cuantitativa continua. Indica el perímetro del voluntario en centímetros. Se mide durante la respiración normal con el sujeto de pie y la cinta métrica pasada horizontalmente, bajo las axilas, y alrededor de la prominencia del busto.

39. Contorno de cintura. Variable cuantitativa continua. Indica el perímetro de la cintura del voluntario en centímetros. El perímetro abdominal se midió en el punto medio de la distancia entre la última costilla flotante y la cresta ilíaca con el individuo en pie, relajado y al final de una espiración suave.

40. Perímetro de cadera. Variable cuantitativa continua. Representa el perímetro de la cadera del voluntario en centímetros. La medida se tomó de la cadera a nivel de los glúteos.

41. Contorno de cuello. Variable cuantitativa continua. Indica el perímetro del cuello del voluntario en centímetros. La medición se realizó en la zona más estrecha del cuello.

42. Contorno de la muñeca. Variable cuantitativa continua. Muestra el perímetro de la muñeca del sujeto en centímetros. La medición se realizó a nivel del proceso distal del radio y la apófisis estiloides cubital. Se tomó el perímetro de la muñeca izquierda.

43. Contorno del brazo. Variable cuantitativa continua. Muestra el perímetro del brazo del sujeto en centímetros. Medición del punto medio entre acromion y olecranon. Se tomó el contorno del brazo izquierdo.

44.Complexión. Variable cualitativa nominal. Los valores que puede presentar son:

44.1. Complexión delgada.

44.2. Complexión normal.

44.3. Complexión fuerte.

Para el cálculo de la complexión del sujeto se comparó la altura en centímetros con el perímetro de la muñeca. Los valores se trasladaron a una tabla, de modo que los valores por debajo de estas cifras indican individuos con complexión delgada y los sujetos con valores por encima indican individuos con complexión fuerte.

Tabla 5. Cálculo de la complexión

\begin{tabular}{|l|l|l|l|}
\hline \multicolumn{2}{|c|}{ Hombres } & \multicolumn{2}{c|}{ Mujeres } \\
\hline Estatura en cm & Perímetro muñeca & Estatura en cm & Perímetro muñeca \\
\hline $155-157$ & $15-16.5$ & $145-147.5$ & $14-14.5$ \\
\hline $160-167.5$ & $16-17$ & $150-157.5$ & $14-15$ \\
\hline $170-177.5$ & $16.5-17.5$ & $160-167.5$ & $14.5-15.9$ \\
\hline $180-187.2$ & $17.5-18.5$ & $170-177.5$ & $16-17$ \\
\hline$>190$ & $17.5-19$ & $>180$ & $17-17.5$ \\
\hline $\begin{array}{l}\text { Los valores por debajo de estas cifras indican individuos con complexión delgada y los sujetos } \\
\text { con valores por encima indican individuos con complexión fuerte. }\end{array}$ & \\
\hline
\end{tabular}


45.Peso. Variable cuantitativa continua. Indica el peso del voluntario en kilogramos y un decimal.

46. Porcentaje de grasa corporal. Variable cuantitativa continua. Es la cantidad de grasa corporal expresada como una porción del peso total, indicada en porcentaje.

47. Masa muscular. Variable cuantitativa continua. Esta variable refleja el peso de los músculos corporales, tanto esqueléticos como lisos, y el agua contenida en los mismos. La unidad de medida se expresa en porcentaje.

48. Porcentaje de masa ósea. Variable cuantitativa continua. Evidencia la cantidad de masa ósea en relación con el peso total, indicada en porcentaje.

49. Índice de masa corporal. Variable cuantitativa continua. Cociente que se utiliza para calcular la grasa corporal a través del peso y de la altura, siendo la unidad de medida del IMC en el sistema MKS expresada en $\mathrm{kg} / \mathrm{m}^{2}$.

EI IMC permite clasificar a las personas sedentarias en función de su composición corporal. Según recomendaciones de la OMS, los individuos según su IMC se clasifican en:

- IMC < 15: personas en situación de inanición o delgadez extrema.

- IMC entre 15 y 18.5: personas con excesiva delgadez.

- IMC entre 18.5 y 25: personas con el peso ideal.

- IMC entre 25 y 30: personas con sobrepeso.

- IMC entre 30 y 40: personas obesas.

- IMC > 40: personas con obesidad mórbida.

Tabla 6. Cálculo del índice de masa corporal

$$
\mathrm{IMC}=\text { peso }[\mathrm{kg}] / \text { estatura }[\mathrm{m} 2]
$$

50. Porcentaje de agua corporal total. Variable cuantitativa continua. Cantidad total de líquido que hay en el cuerpo de una persona, expresada como porcentaje de su peso total.

51. Estimación del peso ideal. Variable cuantitativa continua. Se calcula mediante una fórmula matemática y estudios poblacionales. Para esta tesis doctoral se ha seleccionado la ecuación de Hamwi.

Tabla 7. Estimación del peso ideal (ecuación de Hamwi)

\begin{tabular}{l|l} 
Hombres & Peso ideal $(\mathrm{kg})=48.08+[(\mathrm{H}-152.4) / 2.54] \times 2.720$ \\
\hline Mujeres & Peso ideal $(\mathrm{kg})=45.35+[(\mathrm{H}-152.4) / 2.54] \times 2.267$
\end{tabular}

*Siendo $\mathrm{H}$ la altura en $\mathrm{cm}$

52. Peso ideal corregido. Variable cuantitativa continua. La estimación del peso ideal mediante la ecuación de Hamwi precisa ser corregida en función de la complexión del individuo. En sujetos de complexión fuerte se debe añadir un 10\% a su estimación de peso ideal, y en sujetos de complexión delgada se debe restar un $10 \%$ a su estimación de peso ideal ${ }^{(39)}$. 


\subsubsection{Parámetros clínicos}

53. Frecuencia cardiaca de reposo. Variable cuantitativa continua. Se refiere al número de pulsaciones por minuto que tiene el voluntario. Se evalúa tomando las pulsaciones tras despertarse en su domicilio y sin haberse levantado de la cama.

54. Frecuencia cardiaca real. Variable cuantitativa continua. Indica el número de pulsaciones por minuto del voluntario en reposo el día de la prueba. La toma se realiza con el sujeto sentado y después de cinco minutos de reposo.

55. Tensión arterial sistólica. Variable cuantitativa continua. Refleja la presión arterial sistólica o máxima. La lectura se realiza con el sujeto sentado y después de cinco minutos de reposo.

56. Tensión arterial diastólica. Variable cuantitativa continua. Refleja la presión arterial diastólica o mínima. La lectura se realiza con el sujeto sentado y después de cinco minutos de reposo.

57. Frecuencia respiratoria. Variable cuantitativa continua. Señala el número de respiraciones por minuto de la persona. La toma se realiza con el sujeto sentado y después de cinco minutos de reposo. Se contabilizan los movimientos torácicos durante 30 segundos y el resultado se multiplica por dos.

58. Temperatura. Variable cuantitativa continua. Indica la temperatura tomada en la membrana timpánica del voluntario. La cavidad auditiva debe estar limpia y seca.

59. Hemoglobina total. Variable cuantitativa continua. Mide la cantidad total de hemoglobina, en un rango de 0-25 mg/dl. El sujeto debe tener las uñas limpias — sin laca o similar-y con buena temperatura para que la medición sea óptima.

60. Índice de perfusión (IP). Variable cuantitativa continua. Es la proporción entre el flujo de sangre no pulsátil y el pulsátil a través del lecho capilar periférico. El IP es una variable que evalúa de forma continua y no invasiva el estado de los fluidos del voluntario. El margen de medición de este parámetro es 0,02-20\%. Cuanto mayor sea el IP, mejor es la respuesta del sujeto ${ }^{(40)}$.

61.Saturación de oxígeno. Variable cuantitativa continua. Determina la cantidad de hemoglobina saturada por oxígeno. Rango de medición de 1-100\%.

\subsubsection{Cicloergometría}

62. Electrocardiograma. Variable cualitativa nominal. A cada sujeto de estudio se le realiza un ECG de reposo. Después del análisis, el ECG puede ser normal o patológico, y, en el caso de resultar patológico, es preciso observar si cumple criterios de exclusión o simplemente es anormal. Para la realización de la prueba el voluntario está colocado en el cicloergómetro, en posición de pedalear y con el adecuado confort, pero sin realizar ningún esfuerzo.

63. Espirometría. Variable cualitativa nominal. Cada voluntario realiza tres espirometrías y se selecciona la mejor de ellas. El resultado puede ser normal o patológico. Si no es normal, representa un criterio de exclusión.

64. Actividad física. Variable cualitativa nominal. Para cuantificar esta variable se empleó el cuestionario internacional de actividad física IPAQ ${ }^{(41)}$ (ver Anexo 3). La unidad de medida se denomina MET, y se corresponde con la suma de las siguientes actividades: caminar, actividad física moderada y actividad física vigorosa. 
Una vez realizado el cuestionario de actividad física, los voluntarios se clasifican en tres niveles:

- Nivel alto.

- Actividad física vigorosa por lo menos 3 días por semana logrando un total de al menos 1500 MET.

- 7 días de cualquier combinación de caminata, con actividad física moderada y/o actividad física vigorosa, logrando un total de al menos 3000 MET.

- Nivel moderado.

- 3 o más días de actividad física vigorosa por lo menos 20 minutos por día.

- 5 o más días de actividad física moderada y/o caminata al menos 30 minutos por día.

- 5 o más días de cualquiera de las combinaciones de caminata, actividad física moderada o vigorosa logrando como mínimo un total de 600 MET.

- Nivel bajo o inactivo. No cumple ningún criterio de los anteriores.

65. Motivación para realizar la cicloergometría. Variable cualitativa nominal. Se preguntó al voluntario su motivación para realizar la prueba de esfuerzo, clasificando la respuesta en alta, media o baja.

66. Frecuencia cardiaca máxima. Variable cuantitativa continua. Indica el número de pulsaciones teóricas máximas por minuto del voluntario. La cifra teórica se obtiene mediante el uso de la fórmula de Tanaka ${ }^{(42)}$.

Tabla 8. Cálculo de la fórmula de Tanaka

$$
\mathrm{FCM}=208,75-[0,73 * \text { edad }]
$$

67. Umbral anaeróbico teórico. Variable cuantitativa continua. Se refiere a la frecuencia cardiaca máxima a partir de la cual el sujeto pasa a generar energía mediante metabolismo anaeróbico. Se calcula aplicando un porcentaje del $88 \%$ de la FCM.

68. Glucemia basal. Variable cuantitativa continua. Mide la cantidad de glucosa en sangre, con un rango de medición de 10 a $600 \mathrm{mg} / \mathrm{dl}$. La toma se realiza con el voluntario colocado en la bicicleta y en reposo, representando este dato la cifra de glucemia basal.

69.Ácido láctico basal. Variable cuantitativa continua. Determina la cantidad de ácido láctico en sangre, con un intervalo de medición de $0,8-21,7 \mathrm{mmol} / \mathrm{L}$. La toma se realiza con el voluntario colocado en la bicicleta y en reposo, representando este dato la cifra de lactato basal.

70. Tiempo de cicloergometría. Variable cuantitativa continua. Se refiere al tiempo transcurrido desde que el voluntario comienza a pedalear en la prueba de esfuerzo hasta que llega a la fase anaeróbica y la fase de relajación. La unidad de medida son los minutos.

71. Frecuencia cardiaca umbral anaeróbico. Variable cuantitativa continua. Indica el número de pulsaciones del voluntario en máximo esfuerzo, justo en el paso de metabolismo aeróbico a anaeróbico. La cifra se obtiene en el momento en el que se observa la fase de meseta en la monitorización del voluntario cuando está realizando la prueba de esfuerzo.

72. Umbral de lactato. Variable cuantitativa continua. Determina la cantidad de ácido láctico en sangre, con un intervalo de medición de 0,8-21,7 mmol/L. La toma se realiza con el voluntario colocado en la bicicleta y en el punto de máximo esfuerzo, es decir, cuando ha comenzado a generar energía mediante el metabolismo anaeróbico, representando este dato la cifra del umbral de lactato. 
73. Umbral de glucosa. Variable cuantitativa continua. Mide la cantidad de glucosa en sangre, con un rango de medición de 10 a $600 \mathrm{mg} / \mathrm{dl}$. La toma se realiza con el voluntario colocado en la bicicleta y en el punto de máximo esfuerzo, es decir, cuando ha comenzado a generar energía mediante el metabolismo anaeróbico, representando este dato la cifra del umbral de glucosa.

74. Potencia en vatios. Variable cuantitativa continua. Señala la potencia generada en la bicicleta durante la prueba de esfuerzo por parte del voluntario. La unidad de medida es el vatio.

75. Frecuencia cardiaca máxima del test. Variable cuantitativa continua. Indica el número de pulsaciones máximas del voluntario durante el transcurso de la ergometría.

76. Tensión arterial sistólica de esfuerzo. Variable cuantitativa continua. Refleja la presión arterial sistólica o máxima. La lectura se realiza con el sujeto sentado en la bicicleta, justo en el momento en el que concluye la ergometría.

77. Tensión arterial diastólica de esfuerzo. Variable cuantitativa continua. Refleja la presión arterial diastólica o mínima. La lectura se realiza con el sujeto sentado en la bicicleta, justo en el momento en el que concluye la ergometría.

\subsubsection{Variables durante la intervención}

78. Hora de la prueba. Variable cualitativa nominal. Esta variable determina la hora en la que se ha realizado el caso/intervención. Los valores que puede adoptar son:

-10:00

$\cdot 12: 00$

-16:00

-18:00

79. Temperatura de la sala. Variable cuantitativa continua. Este dato nos indica la temperatura a la que se encuentra la sala donde se realiza el caso/intervención. La unidad de medida son los grados centígrados.

80. Humedad de la sala. Variable cuantitativa continua. En esta variable se señala en porcentaje la humedad relativa de la sala durante la realización del caso/intervención.

81. Luminosidad de la sala. Variable cuantitativa continua. Se refiere al grado de luminosidad de la sala donde se realiza el caso/intervención medido con un luxómetro. La unidad de medida es el lux.

82. Talla de traje pedida. Variable cualitativa nominal. Indica la talla de traje de protección NBQ 4B solicitada por el voluntario para realizar el caso/intervención. Los valores que puede presentar son:

$\cdot \mathrm{S}$

$\cdot M$

$\cdot \mathrm{L}$

$\cdot \mathrm{XL}$

$\cdot 2 X L$

- $3 X \mathrm{~L}$

83. Talla de traje real. Variable cualitativa nominal. Indica la talla de traje de protección NBQ 4B asignado por la organización del estudio para el voluntario y que se corresponde con el más adecuado para su cuerpo, en función de sus datos antropométricos y en relación con la recomendación del fabricante del equipo. Los valores que puede presentar son los mismos que en la talla de traje pedida, enumerados anteriormente. 
84. Frecuencia cardiaca, minutos 1-9. Variable cuantitativa continua. Indica el número de pulsaciones por minuto del voluntario durante la colocación del EPI NBQ, tomada cada dos minutos mediante el uso de un pulsómetro. Las mediciones se realizan en los minutos 1, 3, 5, 7 y 9.

85. Frecuencia cardiaca, minutos 10-21. Variable cuantitativa continua. Indica el número de pulsaciones por minuto del voluntario durante la realización del caso/intervención equipado con el EPI NBQ, tomada cada minuto mediante el uso de un pulsómetro. Las mediciones se realizan en los minutos $10,11,12,13,14,15,16,17,18,19,20$ y 21.

86. Frecuencia cardiaca, minutos 22 y 23 . Variable cuantitativa continua. Indica el número de pulsaciones por minuto del voluntario durante la realización del caso/intervención equipado con el EPI NBQ, en los minutos exactos en los que está realizando masaje cardiaco externo sobre el maniquí de simulación y que corresponden con su nivel de máximo esfuerzo. Las mediciones se realizan en los minutos 22 y 23.

87. Umbral de lactato durante la RCP. Variable cuantitativa continua. Determina la cantidad de ácido láctico en sangre, con un intervalo de medición de 0,8-21,7 mmol/L. La toma se realiza cuando el voluntario acaba de concluir sus dos minutos de masaje cardiaco externo sobre el maniquí. Para ello, se corta la parte superior de ambos guantes en un dedo, y se extrae una muestra de sangre para su análisis, representando este dato la cifra del umbral de lactato en esfuerzo máximo con el EPI colocado.

88. Frecuencia cardiaca minutos 24-30. Variable cuantitativa continua. Indica el número de pulsaciones por minuto del voluntario después de la realización del caso/intervención equipado con el EPI NBQ, en los minutos exactos en los que está realizando la retirada del EPI. Las mediciones se realizan en los minutos $24,25,28$ y 30.

\subsection{Intervención propuesta}

El presente estudio se ha llevado a cabo en una situación tipo o controlada. La situación tipo sobre la que se pretende testar la repercusión fisiológica de este tipo de equipamiento consta de las siguientes secciones:

En primer lugar, se realiza un examen de salud previo al equipamiento (más adelante se detallan los parámetros a estudiar), y se monitoriza de forma continua el ECG, la frecuencia cardiaca, la frecuencia respiratoria y la saturación de oxígeno mediante telemetría, así como los niveles de ácido láctico y glucosa mediante tomas capilares.

A continuación, y bajo supervisión, se equipa con un EPI tipo para esta clase de riesgos (recomendaciones de la ECDC) ${ }^{(43)}$, y el sujeto entra a una habitación con atmósfera controlada (superficie de $\cong 20 \mathrm{~m}^{2}$, temperatura de $30^{\circ} \mathrm{C}$, humedad cercana al 50\%, y buena iluminación). Una vez dentro de la habitación deberá realizar un caso guiado sobre un maniquí de simulación avanzada. Todos los voluntarios realizarán las mismas técnicas y darán masaje cardiaco (punto de máximo esfuerzo) durante dos minutos seguidos.

Cuando el voluntario haya realizado el caso, se esperará tres minutos para permitir la recuperación y se procederá a la descontaminación y retirada controlada del equipo bajo supervisión, para realizar inmediatamente otra evaluación de constantes vitales.

La duración estimada del caso con cada sujeto es de dos horas, distribuidas de la manera indicada en la subsiguiente tabla: 
Tabla 9. Cronograma del caso/estudio

\begin{tabular}{|l|l|}
\hline Tiempo (minutos) & Acciones a realizar \\
\hline 5 & Recepción de voluntarios \\
\hline 5 & Filiación y entrega de documentación \\
\hline 5 & Firma del consentimiento informado \\
\hline 10 & Historia médica y BAl \\
\hline 5 & Estudio antropométrico y de bioimpedancia \\
\hline 5 & Toma inicial de constantes vitales \\
\hline 15 & Cicloergometría y determinación del UL \\
\hline 5 & Explicación del procedimiento \\
\hline 5 & Colocación de telemetría \\
\hline 10 & Colocación del EPI \\
\hline 30 & Realización del caso práctico \\
\hline 10 & Retirada del EPI \\
\hline 10 & Toma de constantes finales y antropometría \\
\hline
\end{tabular}

A continuación, en los siguientes apartados se describen de forma detallada los pasos seguidos a lo largo de todo el procedimiento.

\subsubsection{Asignación de la cita para la prueba}

Una vez que los voluntarios hubieron manifestado su intención de participar en el estudio, a todos los voluntarios posibles se les dividió en grupos por conglomerados: grado/licenciatura y profesionales; médicos y enfermeros; Urgencias Hospitalarias y Emergencias; hombre o mujer —así, teniendo en cuenta todas las variables-, y entre todos los voluntarios posibles de cada conglomerado se realizó un sorteo aleatorio.

Tras la selección realizada, se les comunicó individualmente —-mediante correo electrónico y llamada de teléfono- su inclusión en el estudio y la fecha y hora de realización de la prueba.

\subsubsection{Recepción de voluntarios}

A los participantes en el estudio, una vez seleccionados, se les asignó un día y una hora para la realización de la prueba. Los voluntarios, en grupos de cuatro, se presentaron en la Facultad de Medicina de la Universidad de Valladolid, Edificio de Ciencias de Salud, situado en la Calle Ramón y Cajal, 7 , 47005, Valladolid. El estudio se desarrolló en las aulas ECOE, ubicadas en el sótano.

Una vez que el voluntario se encontraba en las aulas ECOE, se le condujo a un aula para dejar sus pertenencias y teléfono móvil; y, posteriormente, se le acompañó al aula n. 1. 


\subsubsection{Filiación y entrega de documentación}

Una vez que los voluntarios se encontraban en el aula $n .^{\circ} 1$, se les asignó un número para el estudio y una carpeta con toda la documentación que se iba necesitar (hoja de recogida de datos y documento de consentimiento informado).

En dicho momento se conocieron los cuatro voluntarios que iban a realizar el caso.

\subsubsection{Firma del consentimiento informado}

Llegados a este punto, los voluntarios debieron leer de forma obligatoria el documento de consentimiento informado (el modelo puede encontrarse en el Anexo 4), poner su nombre, apellidos y fecha, y decidir si querían continuar con el estudio firmando el documento. De esta forma, el sujeto conoció las técnicas y procedimientos a los que iba a ser sometido, y las infrecuentes pero posibles complicaciones que se podrían generar por algunas técnicas; asimismo, quedaron informados de la confidencialidad de todo el proceso.

Una vez firmado el consentimiento informado, pasaron a las siguientes fases del estudio, pudiendo abandonar el mismo en cualquier momento.

\subsubsection{Historia médica}

El voluntario permaneció en el aula $n .^{\circ} 1$ y se procedió a la entrevista clínica y toma de datos generales (pueden consultarse en el Anexo 5). Los datos recogidos en esta entrevista fueron:

- Grupo al que pertenecen (estudiantes o profesionales).

- Categoría profesional (médico o enfermero).

- Centro de trabajo (urgencias o emergencias).

- Sexo.

- Raza.

- Edad.

- Estado civil.

- Número de hijos.

- Años de experiencia o año de carrera.

- Credo.

- Experiencia en situaciones NBQ.

- Hora desde la última comida.

- Horas de sueño.

- Alergias.

- Embarazo.

- Fecha de la última regla.

- Toma de alcohol y cantidad.

- Fumador, año de inicio y cantidad diaria.

- Antecedentes médico-quirúrgicos.

- Toma de medicación.

- Auscultación. 


\subsubsection{Estudio antropométrico y bioimpedancia}

Una vez terminada la entrevista, el voluntario pasó al aula n. ${ }^{\circ} 2$, en la que se llevó a cabo un estudio antropométrico con el fin de valorar los siguientes parámetros (ver Anexo 6):

- Talla en centímetros.

- Contorno de pecho. Se midió durante la respiración normal con el sujeto de pie y la cinta métrica pasada horizontalmente, bajo las axilas y alrededor de la prominencia del busto.

- Contorno de cintura. Se midió en el punto medio de la distancia entre la última costilla flotante y la cresta ilíaca con el individuo en pie, relajado y al final de una espiración suave.

- Perímetro de cadera, al nivel de los glúteos.

- Contorno de cuello (medición en la zona más estrecha).

- Contorno de muñeca. La medición se realizó a nivel del proceso distal del radio y la apófisis estiloides cubital. Se tomó el perímetro de la muñeca izquierda.

- Contorno de brazo. Medición del punto medio entre acromion y olecranon. Se tomó el contorno del brazo izquierdo.

A continuación, delante del voluntario, se limpió la báscula con una toallita desinfectante y se le pidió que se descalzara y se retirara los calcetines; debía colocar sus pies sobre los medidores de la báscula y coger con sus manos el medidor de impedancia. Se introdujo en la báscula inteligente la edad, el sexo, la altura y el nivel de actividad, obteniendo los siguientes parámetros:

- Peso.

- Grasa corporal.

- Masa muscular.

- Masa ósea.

- IMC.

- Agua total.

A continuación, con todos los datos obtenidos anteriormente tanto del estudio antropométrico como de la báscula inteligente, se realizaron los cálculos necesarios para obtener los siguientes valores:

- Complexión.

- Peso ideal.

- Peso ideal corregido.

\subsubsection{Toma inicial de constantes vitales}

Tras la finalización del procedimiento descrito anteriormente, el voluntario pasó al aula n. ${ }^{\circ} 3$. Una vez allí, se le pidió que se sentara en una silla, se subiera las mangas y esperara 5 minutos en calma, con el fin de que la prueba se realizara en reposo. A continuación, se realizó una toma de constantes vitales que incluía las siguientes comprobaciones (ver Anexo 7):

- Frecuencia cardiaca de reposo. Dato que es aportado por el propio voluntario.

- Frecuencia cardiaca real.

- Tensión arterial sistólica.

- Tensión arterial diastólica.

- Frecuencia respiratoria.

- Temperatura. 
- Hemoglobina total.

- Índice de perfusión.

- Saturación de oxígeno.

Una vez recogidos todos los datos en el aula $n . .^{\circ} 3$, se colocó al voluntario detrás de un biombo y se le pidió que se desvistiera de cintura para arriba (en el caso de mujeres, no fue necesario retirar el sujetador), y se le colocaron los electrodos adhesivos, los cables para realizar la cicloergometría y el medidor de frecuencia cardiaca del pulsómetro, de modo que el voluntario salía del aula $n .^{\circ} 3$ vestido de nuevo, pero con los elementos de monitorización ya colocados.

\subsubsection{Cicloergometría y determinación del umbral de lactato}

Como siguiente paso, el voluntario pasó al aula $n .^{\circ} 4$, donde se le pidió que se sentara en la bicicleta para realizar la prueba, adaptando primero las medidas de la bicicleta a su dinámica corporal (siempre guiados por un especialista).

En este momento, resulta necesario definir algunos conceptos clave para poder comprender los parámetros obtenidos en la cicloergometría y su interpretación. Estos conceptos son los siguientes:

1. Frecuencia cardiaca máxima. Se define como el número de pulsaciones por minuto que presenta el sujeto en el punto de máximo esfuerzo durante la realización de la prueba.

2. Punto de deflexión de la frecuencia cardiaca. Momento del ciclo cardiaco en el que el sujeto experimenta un leve estancamiento o deflexión de su frecuencia cardiaca durante la realización de la prueba (fase de meseta). Este punto se acerca mucho al momento en el que se pasa del metabolismo aeróbico al anaeróbico.

3. Umbral anaeróbico y umbral de lactato. Representa el punto en el que el voluntario pasa de trabajar con un metabolismo aeróbico a uno anaeróbico. Se identifica en la ergometría porque se puede observar la fase de meseta y, a continuación, el índice de fatiga es mayor que el índice de rendimiento (con excepciones en deportistas de élite, cuyo cuerpo está acostumbrado a trabajar en metabolismo anaeróbico).

4. Índice de rendimiento. Indica el momento de máxima eficiencia en el trabajo sobre la bicicleta. Representa el momento de máxima intensidad de producción de energía (en vatios). Valor más alto de potencia alcanzado durante cualquier periodo.

5. Índice de fatiga. Se refiere al momento en el que el sujeto comienza a producir menos energía (medida en vatios), a pesar de que aumenta su frecuencia cardiaca.

6. Trabajo realizado (medido en julios). Se define como la cantidad total de trabajo realizado durante el test.

El voluntario se coloca en una posición ergonómica en la bicicleta y se conectan los cables anteriormente colocados al ordenador portátil. En este momento se realizan las siguientes pruebas:

1. Electrocardiograma de reposo.

2. Espirometría.

3. Toma de tensión arterial.

4. Determinación mediante toma de sangre capilar de ácido láctico basal y de glucemia.

5. Cálculo de la FCM, mediante la fórmula de Tanaka, que nos indica el número de pulsaciones teóricas máximas por minuto del voluntario. 
6. Cálculo del umbral anaeróbico teórico. A la cifra obtenida mediante la fórmula de Tanaka se le aplica un porcentaje del 88\%; este dato nos indica el umbral teórico, que nos sirve para establecer una comparación con el umbral real.

7. Cuestionario internacional de actividad física IPAQ.

Una vez recogidos y calculados estos datos, puede comenzarse la cicloergometría.

\subsubsection{Cicloergometría. Protocolo Conconi}

La prueba de esfuerzo fue realizada en la bicicleta TOMAHAWK ${ }^{\circledR} I C 7$, dotada de potenciómetro Wattrate $^{\mathrm{TM}}$. La potencia se define por la ecuación fuerza * velocidad, y es un parámetro ampliamente usado en fisiología deportiva para cuantificar la calidad e intensidad del entrenamiento ${ }^{\left({ }^{44)}\right.}$.

Todos los voluntarios fueron instruidos en el manejo de esta bicicleta y en la mecánica corporal más adecuada para pedalear de una forma eficiente. La bicicleta permite ser regulada en altura y longitud en manillar y asiento, y es posible realizar ajustes para que la rodilla alcance una posición de flexión parcial entre los $170^{\circ}$ y los $175^{\circ}$ (siendo los $180^{\circ}$ la posición de extensión de la rodilla) durante la fase de descenso del pedaleo. Si el voluntario traía al estudio zapatillas con calas, se adaptaban al pedal, y si traía zapatillas de deporte normales, se introducían los pies en los rastreles y se ajustaban con firmeza.

Todos los voluntarios recibieron las mismas recomendaciones generales:

- Se les informó con antelación (el día que se les comunicó la fecha de realización de la prueba) de que debían venir a realizar el estudio con ropa cómoda de deporte.

- Se les estimuló verbalmente para que durante la prueba se emplearan a fondo, con el fin de alcanzar realmente el metabolismo anaeróbico.

- Durante la realización del test no estaba permitido levantarse del asiento para pedalear, es decir, en todo momento debían permanecer sentados.

- Se estandarizó un tiempo de cinco minutos de calentamiento, en el que los voluntarios comenzaban a pedalear sin ningún tipo de resistencia; así, se perseguía que se familiarizaran con la máquina y se calentaran los músculos.

- La cadencia de pedaleo que debían mantener en todo momento es de 70-80 revoluciones por minuto.

La cicloergometría fue realizada según el protocolo Conconi ${ }^{(45)(46)}$. Se utilizaron fuerzas de resistencia incrementales cada 30 segundos, con una duración mínima del test de 15 minutos (5 de ellos de calentamiento). Los sujetos comenzaron a pedalear durante 5 minutos en el calentamiento sin resistencia, y, a partir de este momento, se incrementaban cada 30 segundos cuatro puntos la resistencia de fuerza de la bicicleta, momento en el que los voluntarios debían permanecer sentados y pedaleando a $70-80$ revoluciones por minuto ${ }^{(47)}$. 


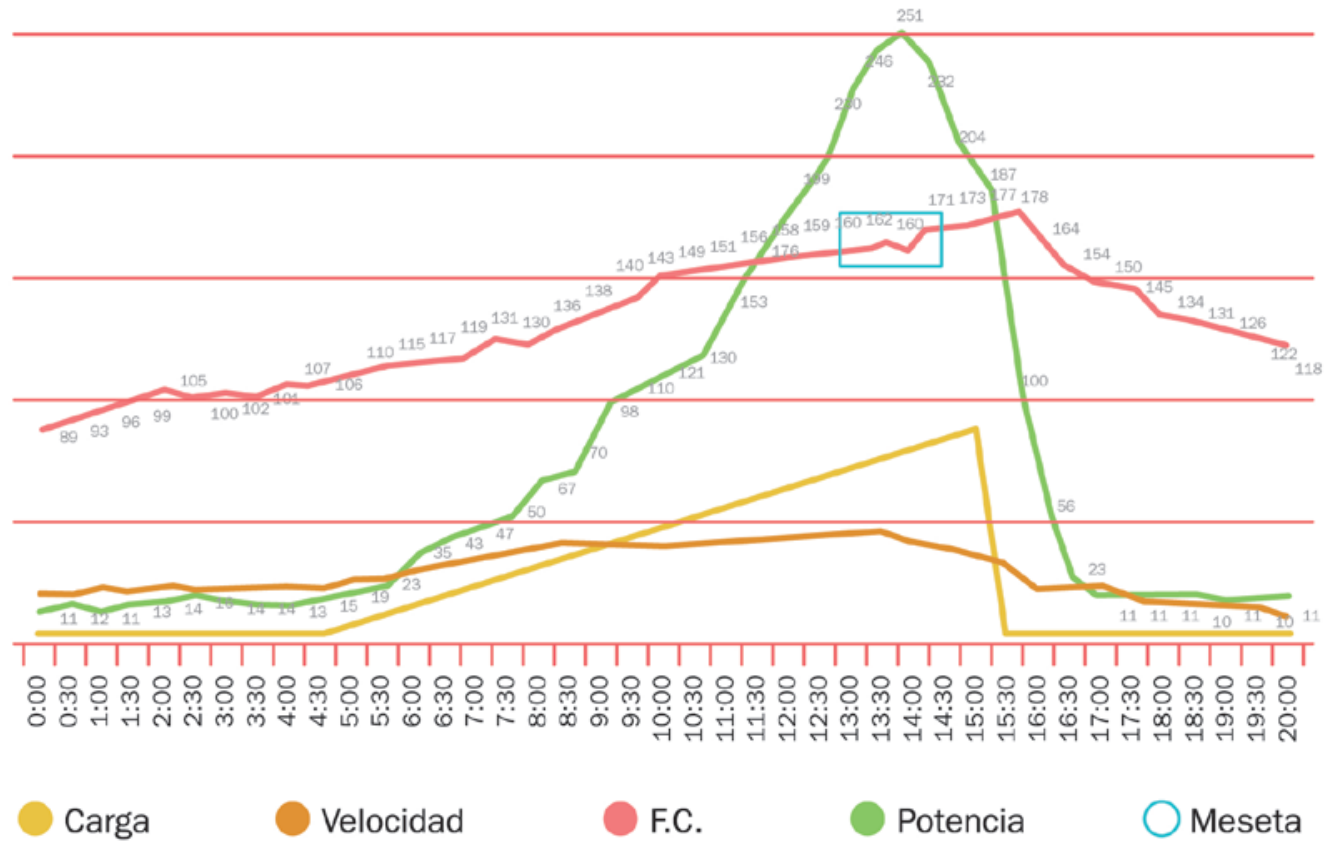

Figura 9. Gráfico de cicloergometría. Varón, 35 años, nivel de actividad física alta

Tomando como referencia el UAT, se vigila de forma intensiva el ECG del voluntario cuando comienza a acercarse a esa FCM teórica, hasta el momento en el que se observe un punto de deflexión en la FC (fase de meseta) y, a continuación, tal y como se puede apreciar en el gráfico, se incrementa la FC pero no aumentan los vatios generados, es decir, el sujeto presenta un índice de fatiga mayor que su índice de rendimiento ${ }^{(48)}$, comenzando en ese momento el metabolismo anaeróbico. Este es el momento en el que se extrae una nueva muestra de sangre capilar para la determinación de ácido láctico y glucosa. El voluntario continúa pedaleando con esa resistencia hasta que se comprueba la validez de las mediciones sanguíneas (90 segundos), momento en el que se retira la resistencia de fuerza de la bicicleta y el voluntario permanece pedaleando libremente durante 5 minutos para regresar a la situación de reposo. En este momento se realiza una toma de tensión arterial ( ver Anexo 8 y Anexo 9).

\subsubsection{Determinación del umbral de lactato}

El ácido láctico es un indicador muy fiable de metabolismo anaeróbico, bien sea por enfermedades sistémicas como shock o sepsis, entre otras; o como un indicador de fatiga muscular en personas sanas.

Cuando la intensidad del ejercicio físico supera la capacidad del cuerpo de poder aportar el oxígeno suficiente para generar energía mediante el ciclo de Krebs, el organismo llega a su umbral láctico o anaeróbico. Las demandas de energía se mantienen, pero la forma ordinaria de producirla ya no es eficiente, por lo que el cuerpo comienza a metabolizar energía mediante el metabolismo anaeróbico, hecho que produce fatiga y aumento del ácido láctico ${ }^{(49)}$. 
El concepto de umbral anaeróbico representa una balanza entre la ventilación pulmonar y las demandas de oxígeno de ese momento. Cuando el oxígeno aportado por la ventilación no es suficiente para los requerimientos, el cuerpo empieza a acumular ácido láctico, y comienza la acidosis metabólica.

En situaciones de gasto energético elevado, el organismo utiliza todo el oxígeno disponible y pone en marcha el sistema anaeróbico glicolítico, generando de forma instantánea aumento de la ventilación pulmonar y lactacidemia.

El umbral de lactato presenta una relación directa con la forma física de cada sujeto, y da muestra de diferencias sustanciales entre personas entrenadas y personas sedentarias. A su vez, el umbral de lactato es marcadamente distinto entre personas entrenadas mediante deportes de resistencia (running, ciclismo, natación de largas distancias, etc.) o mediante deportes más explosivos (sprint, boxeo, cross-training, etc.), aunque en todos los casos aparece fatiga progresiva y lactacidemia.

Para determinar el umbral de lactato se realiza una extracción de sangre capilar justo en el momento en el que acaba el punto de deflexión de la frecuencia cardiaca (fin de la fase de meseta).

\subsubsection{Colocación de la telemetría}

Una vez terminada la cicloergometría, al voluntario se le retiran los cables de monitorización, aunque se mantienen puestos los electrodos en el tórax, y se comprueba el pulsómetro y su correcto funcionamiento.

Llegados a este punto, se comprueba que el voluntario no cumple ningún criterio de exclusión y que ha realizado todas las evaluaciones previas necesarias. Si la comprobación es afirmativa, se le considera apto para la realización del estudio; si no lo es, quedará excluido del mismo (ver Anexo 10).

\subsubsection{Explicación del procedimiento y del caso}

Para llevar a cabo la siguiente parte del estudio, los voluntarios pasan en grupos de cuatro al aula . $^{\circ}$ 5 , lugar en el que se les explica el caso práctico que van a realizar y qué funciones va a desempeñar cada uno.

El diseño del caso práctico fue el siguiente:

El Centro Coordinador de Emergencias 1-1-2 ha recibido una solicitud de ayuda y suministra la siguiente información al equipo interviniente:

“Un varón de origen subsahariano, procedente de Sierra Leona, acaba de pasar el control de aduanas en el aeropuerto de Villanubla, ha comenzado a sentirse mal, se ha desplomado y está inconsciente. Nadie se ha acercado a socorrerle".

Informan desde Seguridad Aérea de que el sujeto presenta sangre en conjuntivas, boca y nariz. Debido a la situación, se activa la Unidad de Soporte Vital Avanzado más cercana, y, ante la posible sospecha de fiebre hemorrágica, se les comunica que deberán preparase con traje de protección según protocolo y atender la incidencia. El jefe de equipo recibe la alerta y procede a movilizar al equipo. 
Cada grupo de cuatro voluntarios hace un equipo de intervención, distribuyendo entre ellos las funciones de la siguiente manera:

- Voluntario n. ${ }^{\circ}$ 1: Jefe de equipo y responsable de comunicaciones con la central. Es el encargado del manejo de la vía aérea y de la ventilación.

- Voluntario n..$^{\circ}$ 2: Encargado del acceso vascular y de la administración de fármacos y fluidos.

- Voluntario n. ${ }^{\circ}$ 3: Responsable de uso del monitor-desfibrilador y de la toma de constantes vitales.

- Voluntario n. ${ }^{\circ}$ 4: Persona de apoyo encargada de colaborar con cualquiera de los otros voluntarios.

En este momento, el equipo de voluntarios recibió los botiquines de intervención: vía aérea, vía venosa, trauma y control de hemorragias y monitorización. Los voluntarios revisaron el material y comenzaron la fase de colocación del EPI.

\subsubsection{Colocación del EPI}

A lo largo del desarrollo de esta fase, los voluntarios permanecieron en el mismo aula $n .^{\circ} 5$, donde se habían colocado cuatro sillas, una por voluntario, para que la puesta del EPI se llevara a cabo con comodidad. Cada voluntario se colocó en su silla y, a su vez, detrás de cada silla había un controlador que encargaría de tomar todos los datos de frecuencia cardiaca durante el desarrollo del caso.

El primer paso fue retirar el pulsómetro de la muñeca del voluntario, ya que, una vez colocados los dos pares de guantes y el traje, no se podría ver. Se comprobó la correcta conexión entre la cinta torácica de medición del pulso y el pulsómetro, y se comenzaron a anotar las cifras de FC cada minuto.

Se informó a los voluntarios de que iban a ser guiados en todo momento en la puesta y retirada del EPI, y de que en ningún momento se evaluaría la corrección de estas técnicas, ya que únicamente se pretendía valorar la respuesta fisiológica al uso de los equipos, no la destreza en su puesta o retirada, al tratarse de técnicas que no tenían por qué conocer.

Los voluntarios, guiados por un miembro del equipo, disponían de diez minutos para equiparse por completo, procediéndose después a la revisión de este equipamiento. El protocolo de puesta y retirada estuvo basado en las recomendaciones de la ECDC ${ }^{(43)}$.

Antes de comenzar la colocación del EPI, se confirmó que los sujetos habían realizado los siguientes pasos previos y se podía responder afirmativamente a estas cuestiones:

- ¿Ha obtenido el visto bueno en los pasos anteriores del estudio?

- ¿Se ha quitado reloj, anillos y pendientes?

- ¿Ha vaciado los bolsillos?

- ¿Lleva pijama de trabajo cerrado por delante?

- ¿Lleva calzado cerrado y sujeto al pie?

- ¿Se ha fijado las gafas con cinta a la frente?

- ¿Se ha recogido el pelo (no coleta alta)?

- ¿Se ha colocado el gorro quirúrgico si lleva el pelo largo?

- ¿Se ha hidratado correctamente?

- ¿Ha ido al WC?

- ¿Se ha lavado las manos?

- ¿Conoce el procedimiento? 
Una vez comprobados los pasos anteriores, y estando todos los aspectos correctos, se puso en marcha el cronógrafo y comenzó el proceso de puesta supervisada del EPI, que constaba de los siguientes pasos:

1. Colocar primer par de calzas.

2. Hacer lazada por delante.

3. Meter piernas en pantalón del buzo.

4. Subir buzo a la cintura.

5. Colocar segundo par de calzas.

6. Hacer lazada por detrás.

7. Ponerse primer par de guantes (finos/cortos) de color verde.

8. Ponerse verdugo: extender bien los faldones.

9. Meter brazos en las mangas del buzo. Puños a la muñeca cubriendo guantes.

10. Meter dedo pulgar en goma antirretracción de la manga del buzo.

11. Subir cremallera hasta el pecho.

12. Colocar la mascarilla, cubrir mentón y nariz. Acomodar pletina nasal. Realizar prueba de ajuste.

13. Ponerse gafas de protección, cubrir mascarilla en puente nasal.

14.Poner capucha de buzo mirándose a espejo: revisar cobertura facial.

15. Subir cremallera hasta el final: cubrir parte inferior de la mascarilla.

16. Retirar protector adhesivo cubrecremallera exterior y cubrirla.

17.Ponerse segundo par de guantes (largos) de color azul por encima del puño del buzo.

Llegados a este punto, se colocó el pulsómetro adherido con esparadrapo en la espalda de cada voluntario, y se comprobó mediante toma de pulso manual el correcto funcionamiento de cada equipo.

Cada voluntario debía observarse en un espejo y comprobar que estaba correctamente equipado; después, los voluntarios hicieron dos sentadillas para comprobar la ergometría y ajustes del equipo y, a continuación, estuvieron en disposición de comenzar el caso.

\subsubsection{Realización del caso práctico}

Para realizar el caso práctico, el equipo de cuatro voluntarios pasó al aula $n .^{\circ} 6$, espacio donde se llevó a cabo.

Antes de comenzar, se les explicó que debían realizar las técnicas y procedimientos simulados sobre el maniquí de simulación de la forma más correcta posible, recordándoles que no se evaluaría la calidad de las técnicas empleadas, sino cómo estas afectan al uso del EPI a nivel fisiológico.

El caso práctico se realizó en una sala diáfana de $20 \mathrm{~m}^{2}$, con humedad, temperatura e iluminación controladas.

Cada grupo de cuatro voluntarios realizó el mismo caso, con la misma secuencia temporal de eventos. Cada miembro del equipo debía estar realizando compresiones torácicas durante 2 minutos y, transcurridos estos 2 minutos, era relevado por otro miembro del equipo que no hubiera dado compresiones. Así sucesivamente hasta que los 4 miembros del equipo hubieran dado los 2 minutos de compresiones torácicas. 
La secuencia de hechos completa, así como las frecuencias cardiacas por minutos, valores de ácido láctico, condiciones ambientales, y demás valores a tener en cuenta fueron recogidos en la pertinente hoja de recogida de datos (ver Anexo 11).

Tabla 10. Cronograma del caso clínico

\begin{tabular}{|c|c|c|c|}
\hline Tiempo & \multicolumn{2}{|l|}{ Situación clínica } & Técnicas \\
\hline 1 & \multicolumn{2}{|c|}{ Paciente vomitando y quejándose } & $\begin{array}{l}\text { - Aspirar secreciones } \\
\text { - Colocar en DLI }\end{array}$ \\
\hline 3 & $\begin{array}{l}\text { Aparecen } \\
\text { convulsiones }\end{array}$ & $\begin{array}{l}\cdot \mathrm{FC} 120 \mathrm{lxm} \\
\cdot \mathrm{SpO}_{2} 80 \% \\
\cdot \mathrm{TA}: 75 / 30 \mathrm{mmHg}\end{array}$ & $\begin{array}{l}\text { • Cánula de guedel } \\
\text { •Canalización vía venosa } \\
\text { •Dormicum }{ }^{\circledR} 7,5 \text { mg/IV }\end{array}$ \\
\hline 5 & $\begin{array}{l}\text { Ceden las } \\
\text { convulsiones }\end{array}$ & $\begin{array}{l}\text { - Sangrado arterial en brazo } \\
\text { - GCS } 7(1-2-4)\end{array}$ & $\begin{array}{l}\text { - Control de sangrado arterial } \\
\text { - Oxigenoterapia } \\
\text { - Monitorización }\end{array}$ \\
\hline 7 & $\begin{array}{l}\text { Cede sangrado } \\
\text { arterial }\end{array}$ & $\begin{array}{l}\cdot \mathrm{FC} 67 \mathrm{Ixm} \\
\cdot \mathrm{SpO}_{2} 81 \% \\
\cdot \operatorname{GCS} 3(1-1-1)\end{array}$ & $\begin{array}{l}\text { •Preparación SRI } \\
\text { •ECG } 12 \text { derivaciones } \\
\text { • Glucemia capilar }\end{array}$ \\
\hline 8 & $\begin{array}{l}\text { Parada } \\
\text { respiratoria }\end{array}$ & $\begin{array}{l}\text { - } \mathrm{FC} 49 \mathrm{lxm} \\
\cdot \text { Pulso palpable } \\
\cdot \mathrm{SpO}_{2} 73 \%\end{array}$ & $\begin{array}{l}\text {-Ventilación con } \mathrm{AMBU}^{\circledR} \\
\text { ·Volumen } \\
\text { ·Segunda vía venosa }\end{array}$ \\
\hline 9 & $\begin{array}{l}\text { Parada } \\
\text { respiratoria }\end{array}$ & $\begin{array}{l}\text { - } \mathrm{FC} 36 \text { Ixm } \\
\text { - Pulso filiforme } \\
\text { - } \mathrm{SpO}_{2} 69 \%\end{array}$ & $\begin{array}{l}\text { - Intubación orotranqueal } \\
\text { • Comprobar intubación } \\
\text { •Atropina } 1 \mathrm{mg} / \mathrm{IV}\end{array}$ \\
\hline $10-17$ & PCR & - Asistolia & -Protocolo SVA \\
\hline $17-20$ & $\begin{array}{l}\text { Tose, comienza } \\
\text { a moverse }\end{array}$ & $\begin{array}{l}\cdot \mathrm{FC} 87 \mathrm{lxm} \\
\cdot \text { Pulso palpable } \\
\text { - } \mathrm{SpO}_{2} 90 \%\end{array}$ & $\begin{array}{l}\text { - Cuidados post-resucitación } \\
\text { - Cursar preaviso hospitalario } \\
\text { - Preparar la evacuación }\end{array}$ \\
\hline
\end{tabular}




\subsubsection{Retirada del EPI}

Una vez realizado el caso práctico, los cuatro voluntarios regresaron al aula $n .^{\circ} 5$, en la que se procedió a la retirada supervisada del EPI, siguiendo las recomendaciones de la ECDC ${ }^{(43)}$.

Los controladores recogieron el pulsómetro de la espalda de cada voluntario, y siguieron el siguiente orden de actuación para la retirada controlada del EPI:

1. Lavado de manos con hipoclorito sódico al 0,5\%.

2. Retirada del primer par de calzas.

3. Lavado de manos después de retirar el primer par de calzas.

4. Descontaminación en sentido cráneo-caudal, parte anterior y posterior.

5. Descontaminación de suelas de calzas.

6. Entrada en cubeta o bolsa amplia de plástico.

7. Lavado de manos.

8. Bajada de cremallera hasta el pecho.

9. Descubrimiento de cabeza replegando capucha con las dos manos.

10. Abertura de chaqueta, tirando de las solapas de los cubrecremalleras.

11. Lavado de manos.

12. Brazos abajo y atrás: bajar chaqueta tirando y exponer hombros.

13. Brazos abajo y atrás: tirar del guante exterior A para aflojar el guante.

14.Pellizco firme del buzo y del guante exterior A para sacar la manga y el guante, queda guante interior.

15. Cruzando brazo y mano enguantada A por delante, se lleva al interior de la manga B.

16. Se sacan manga y guante exterior $\mathrm{B}$. Se libera la mano $\mathrm{B}$, que queda cubierta por el guante interno.

17. Lavado de manos.

18. Bajar buzo plegándolo hacia afuera desde dentro.

19.Sacar una pierna sin tocar la suela de la calza interior, pisar fuera de la cubeta.

20. Sacar otra pierna sin tocar la suela de la calza interior, pisar fuera de la cubeta.

21. Depositar con cuidado el buzo en el contenedor de residuos, con precaución para no apretar el contenido.

22. Lavado de manos.

23. Extraer calza interior $A$, paso al lado.

24. Extraer calza interior B, paso al lado.

25. Lavado de manos.

26. Sacar al tiempo verdugo, gafas y mascarilla: al contenedor y lavado de manos.

27. Retirada con técnica quirúrgica de guantes interiores.

28. Lavado de manos con solución antiséptica.

\subsubsection{Toma de constantes vitales y antropometría posterior}

Una vez retirado el EPI, cada voluntario regresó al aula n. ${ }^{\circ} 2$. Delante del voluntario se limpió la báscula con una toallita desinfectante y se le pidió que se descalzara y se retirara los calcetines. Debía colocar sus pies sobre los medidores de la báscula y coger con sus manos el medidor de impedancia. Se introdujeron en la báscula inteligente los datos de edad, sexo, altura y nivel de actividad, obteniendo los siguientes parámetros: 
- Peso.

- Grasa corporal.

- Masa muscular.

- Masa ósea.

- IMC.

- Agua total.

A continuación, el voluntario pasó al aula $n .^{\circ} 3$, donde se realizó una nueva toma de constantes vitales, incluyendo los siguientes parámetros:

- Glucemia final.

- Lactato final.

- Frecuencia cardiaca.

- Tensión arterial sistólica.

- Tensión arterial diastólica.

- Frecuencia respiratoria.

- Temperatura.

- Hemoglobina total.

- Índice de perfusión.

- Saturación de oxígeno.

Todas las mediciones posteriores fueron recogidas en la hoja de datos n. ${ }^{\circ}$ (ver Anexo 6 ), y en la hoja de datos n. ${ }^{\circ} 3$ (ver Anexo 7).

\subsection{Método de recogida de datos}

Para la recogida de información se empleó un formulario de siete hojas, que fue cumplimentado a medida que los voluntarios fueron pasando de aula en aula, llevando a cabo en cada aula fases diferentes del estudio (ver Anexos 5, 6, 7, 8, 9, 10 y 11).

Se contó con la colaboración de estudiantes de Grado de Enfermería de la Universidad de Valladolid, que voluntariamente aceptaron participar en la investigación, desarrollando tareas como controlar frecuencias cardiacas de los pulsómetros o realizar determinadas mediciones y toma de constantes vitales.

Cuando el voluntario llegaba al vestíbulo de la Facultad de Ciencias de Salud, se le conducía a las aulas del ECOE, y se le asignaba una carpeta codificada con una letra y un número, código que figuraba en cada documento del mismo sujeto, para de esta forma garantizar la confidencialidad. Su nombre y apellidos figuró únicamente en el consentimiento informado, documento archivado en una carpeta diferente al resto de la documentación.

Tabla 11. Codificación de los sujetos de estudio

\begin{tabular}{|l|l|l|}
\hline Género & Código & Número \\
\hline Hombre & M & $101-199$ \\
\hline Mujer & F & $201-299$ \\
\hline
\end{tabular}


Para la realización de la fase de campo del estudio fue posible contar con las aulas del ECOE de la Facultad de Ciencias de la Salud de la Universidad de Valladolid.

Los voluntarios fueron pasando de aula en aula, por un total de seis estaciones, realizando en cada estación diferentes acciones. Cada voluntario portó consigo una carpeta con toda su documentación —codificada con su letra y número- durante la realización de dos circuitos:

- Circuito primario. El voluntario pasó en orden del aula n. ${ }^{\circ}$ al aula n. ${ }^{\circ} 6$, realizando toda la toma previa de datos y contantes, la puesta del EPI y la realización del caso práctico.

- Circuito secundario. El voluntario retornó al aula n. ${ }^{\circ} 5$ para la retirada supervisada del EPI, y luego pasó por las aulas $n .^{\circ} 2$ y 3 para la toma de constantes vitales y estudio de bioimpedancia posterior.

El formulario para la recogida de datos se distribuyó en siete hojas, todas codificadas con la letra y número de cada voluntario.

\section{Aula $\mathrm{n}^{\circ} 1$}

- Filiación y entrega de documentación

- Firma consentimiento informado

- Historia médica

- BAI

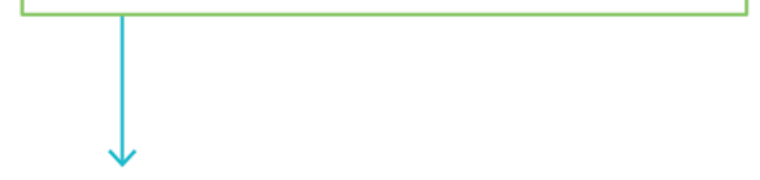

\section{Aula $n^{\circ} 2$}

\section{- Antropometría \\ - Estudio de bio-impredancia}

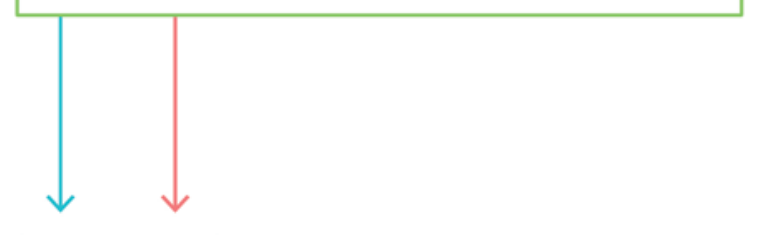

Aula $\mathrm{n}^{\circ} 3$

- Toma de constantes vitales

\section{Aula $n^{\circ} 6$}

- Realización de caso práctico

- Explicación del caso clínico

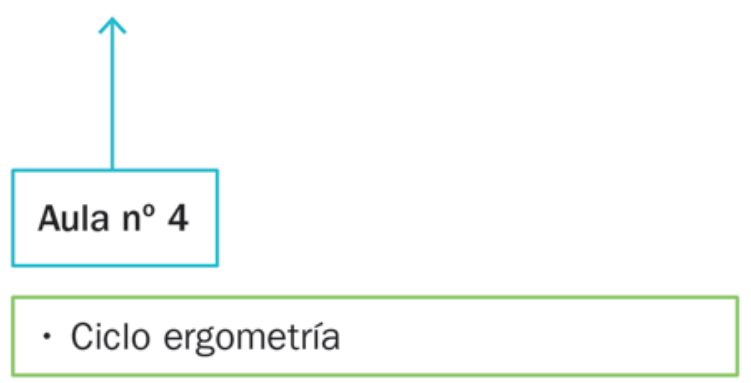

Aula $n^{\circ} 5$

- Colocación del EPI

- Retirada del EPI

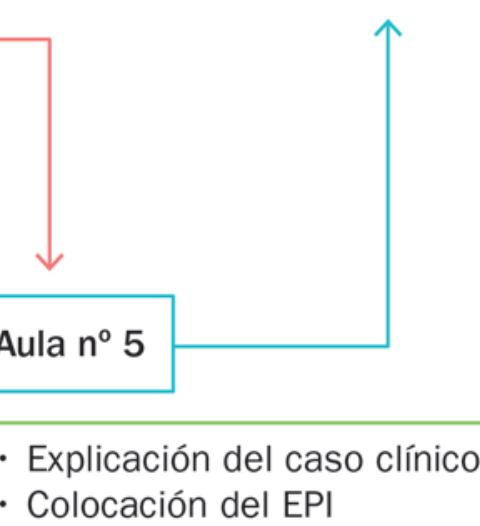

Figura 10. Distribución de las aulas del ECOE 


\subsection{Recursos empleados}

\subsubsection{Dispositivos de medición}

En el presente apartado se realiza una descripción exhaustiva de las características y rangos de medición de todo el aparataje y elementos de medición y análisis empleados en el estudio. Todos los dispositivos poseen declaración de conformidad CE y manual de instrucciones.

\subsubsection{Cinta métrica mecánica}

Para realizar el tallaje de los voluntarios se ha empleado la cinta métrica mecánica marca SECA modelo 206 (ver especificaciones técnicas en Anexo 12).

\subsubsection{Cinta ergonómica para medir perímetros}

Para realizar la medición de todos los perímetros y circunferencias descritos en el estudio antropométrico de los voluntarios se ha empleado la cinta ergonómica para medir perímetros marca SECA modelo 201 (ver especificaciones técnicas en Anexo 13).

\subsubsection{Báscula diagnóstica}

El estudio de peso y bioimpedancia se ha realizado con la báscula de precisión marca TANITA modelo BC-601 (ver especificaciones técnicas en Anexo 14), con las siguientes funcionalidades:

- Pantalla con electrodos retractable para lecturas segmentales de brazos, piernas y tronco.

- Porcentaje de grasa y agua corporal.

- Porcentaje recomendable de grasa en adultos.

- Porcentaje recomendable de grasa en niños.

- Índice de grasa visceral.

- Cálculo de grasa visceral.

- IMC.

- Peso óseo.

- Recomendación de consumo de calorías diarias.

- Edad metabólica.

- Masa muscular. 


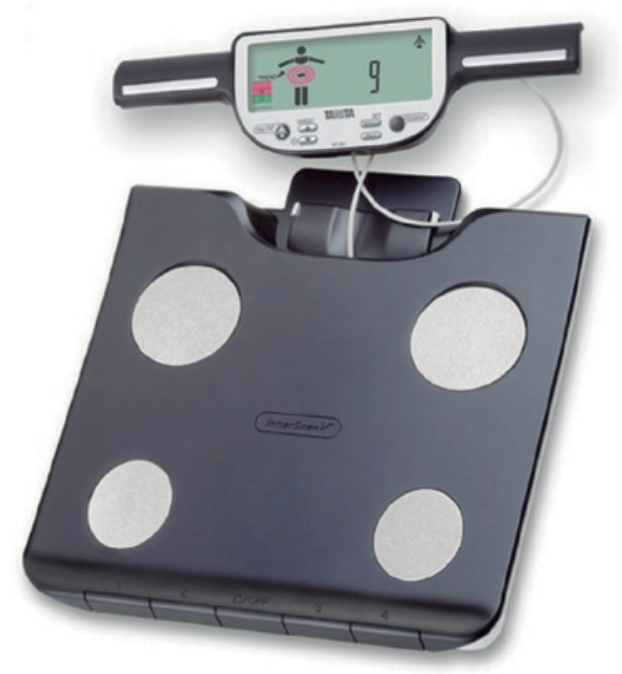

Figura 11. Báscula de precisión segmental TANITA BC-601

\subsubsection{Monitor de presión arterial no invasivo}

Durante los estudios de las constantes vitales - tanto previo como posterior-, para la determinación de la tensión arterial sistólica, diastólica y frecuencia cardiaca, se ha empleado el medidor marca SCHILLER modelo BP-200 plus (ver especificaciones técnicas en Anexo 15). El BP-200 plus es un monitor de la presión arterial no invasivo para las pruebas de esfuerzo, diseñado para medir y mostrar automáticamente las presiones sistólica y diastólica de un paciente a intervalos predeterminados, o cuando lo solicite el usuario. BP-200 plus utiliza dos métodos de medición: el análisis de K-sound SCHILLER con o sin activador de QRS para realizar mediciones durante las pruebas de esfuerzo, y mediciones oscilométricas para las situaciones de reposo.

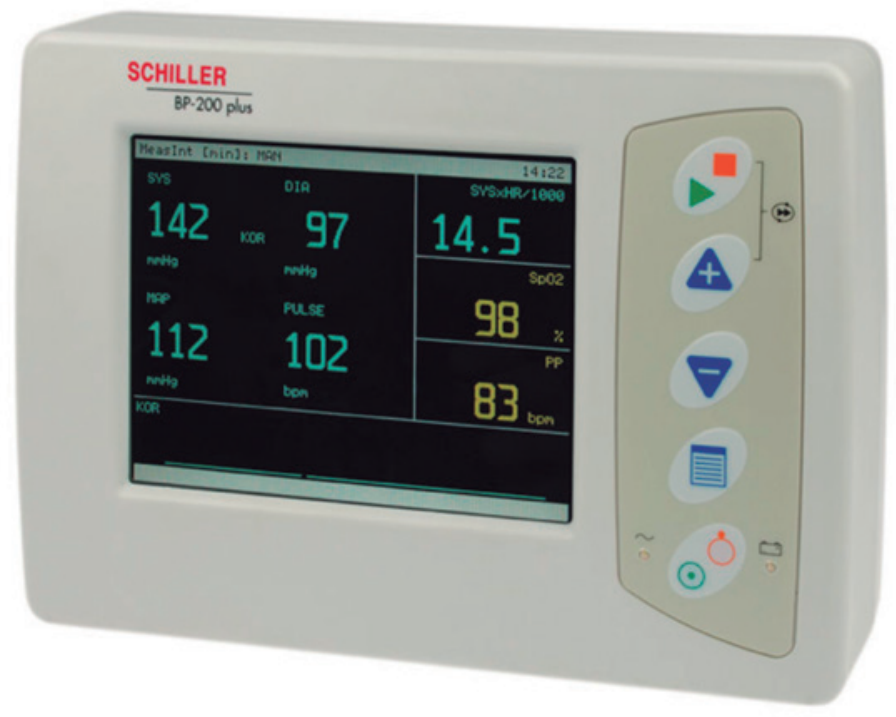

Figura 12. Monitor de presión arterial no invasivo SCHILLER BP-200 plus 


\subsubsection{Cronómetro}

Para la determinación de la frecuencia respiratoria se contabilizaron las respiraciones durante 30 segundos, y la cifra obtenida se multiplicó por dos. Se empleó el cronómetro marca CASIO modelo HS-3V-1 (ver especificaciones técnicas en Anexo 16).

\subsubsection{Termómetro timpánico}

La medición de la temperatura se llevó a cabo con un termómetro timpánico marca BRAUN modelo ThermoScan PRO 6000 con tecnología ExacTemp. Cuando se coloca el Braun PRO 6000 en el oído, el termómetro controla de forma continua la energía de infrarrojos que emiten la membrana timpánica y los tejidos circundantes, hasta que se alcanza un equilibrio de temperatura y se pueda obtener una medición precisa (ver especificaciones técnicas en Anexo 17).

\subsubsection{Medidor no invasivo de hemoglobina}

Para determinar los valores de hemoglobina total, saturación de oxígeno, frecuencia cardiaca e índice de perfusión se ha utilizado el monitor multiparamétrico marca MASIMO modelo Pronto 7, con versión de software b99e80000004ef796 (2.2.15), y versión de revisión del sensor a83f90f0000c53f2 (ver especificaciones técnicas en Anexo 18).

En 11.335 comparaciones de mediciones de $\mathrm{SpHb}$ y mediciones invasivas de hemoglobina (tHb) de un dispositivo de referencia de laboratorio, la precisión de $\mathrm{SpHb}$ fue la siguiente:

- Sesgo de $-0,02 \mathrm{~g} / \mathrm{dl}$.

- Precisión ARMS de 0,99 g/dl.

- Entre 6 y 12 g/dl, con un porcentaje mayor del 95 \% de las lecturas de SpHb, estuvo dentro de 2 $\mathrm{g} / \mathrm{dl}$ del valor de tHb de laboratorio.

- Entre 12 y $18 \mathrm{~g} / \mathrm{dl}$, con un porcentaje mayor del 95 \% de las lecturas de $\mathrm{SpHb}$, estuvo dentro de 2 $\mathrm{g} / \mathrm{dl}$ del valor de $\mathrm{tHb}$ de laboratorio.

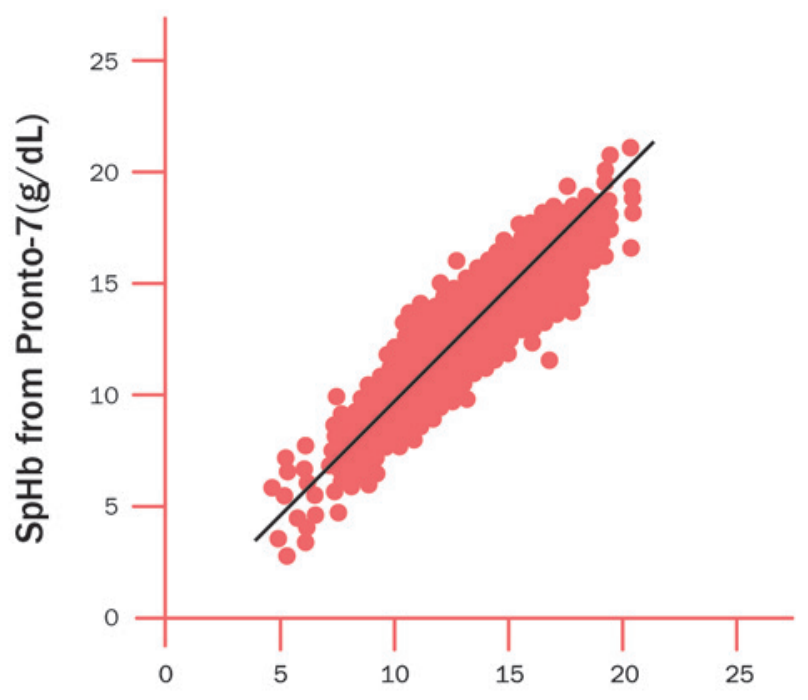

Laboratory Reference tHb $(\mathrm{g} / \mathrm{dL})$

Figura 13. Desviación entre los valores de hemoglobina total en laboratorio y con el dispositivo MASIMO Pronto 7 


\subsubsection{Pulsioxímetro}

Para tomar los valores de saturación de oxígeno y frecuencia cardiaca se empleó el monitor marca MASIMO modelo Rad-5V ${ }^{\mathrm{TM}}$ (ver especificaciones técnicas en Anexo 19).

\subsubsection{Medidor de ácido láctico}

Para medir los niveles de ácido láctico se ha empleado el medidor Accutrend ${ }^{\circledR}$ Plus, de la marca Roche $^{\circledR}$ (ver especificaciones técnicas en Anexo 20).

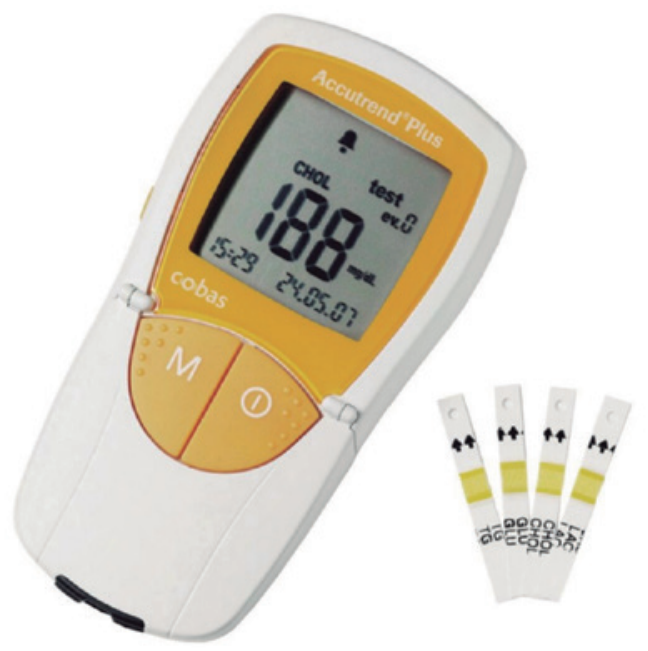

Figura 14. Medidor de ácido láctico Accutrend ${ }^{\circledR}$ Plus

\subsubsection{Glucómetro}

Para medir los niveles de glucosa se ha empleado el medidor Accu-Chek Mobile de la marca Roche ${ }^{\circledR}$ (ver especificaciones técnicas en Anexo 21).

\subsubsection{Espirómetro}

Con el fin de comprobar que la función pulmonar fuera correcta y que los voluntarios fuesen aptos para realizar la cicloergometría se les realizaron a todos los voluntarios tres espirometrías con el dispositivo basado en PC modelo MiniSpir de la marca MIR, con capacidad para medir los siguientes parámetros: FVC, FEV1, FEV1/FVC\%, FEV3, FEV3/FVC\%, FEV6, FEV1/FEV6\%, PEF, FEF25\%, FEF50\%, FEF75\%, FEF25-75\%, FET, VEXT, edad pulmonar, FIVC, FIV1, FIV1/FIVC\%, PIF, VC, IVC, IC, ERV, FEV1/ VC\%, VT, VE, Rf, ti, te, ti/t-tot, VT/ti y MVV (ver especificaciones técnicas en Anexo 22).

\subsubsection{Electrocardiógrafo}

ECG basado en PC modelo Cardio Perfect de la marca Welch Allyn ${ }^{\circledR}$. Este dispositivo permite realizar ECG de reposo y, a continuación, sin retirar los cables y los electrodos, realizar un análisis continuo durante la cicloergometría (ver especificaciones técnicas en Anexo 23).

Entre sus características destacan:

- Sobrepone el ECG previo para señalar diferencias.

- Posibilidad de interpretación y edición de informes en pantalla. 
- Activación/desactivación de visualización de marcapasos.

- Indicación de la calidad de la señal.

- Filtro de ruido muscular, de corriente alterna, antidentado y filtro de línea de base.

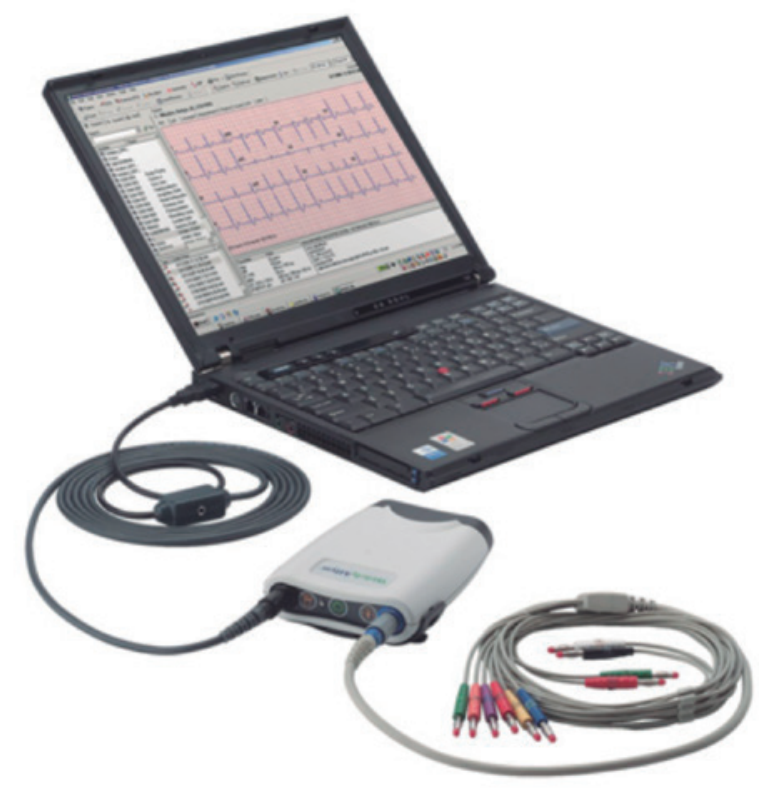

Figura 15. ECG basado en PC modelo Cardio Perfect de la marca Welch Allyn ${ }^{\circledR}$.

- Permite realizar las siguientes visualizaciones y grabaciones:

- Vista 4x3 derivaciones.

- Vista 2x6 derivaciones.

- Vista de promedios. Muestra los promedios de los complejos dominantes de las 12 derivaciones, o de una sola derivación.

- Vista medidas. Incluyen los valores de distintos parámetros comunes, como, por ejemplo, amplitud Q, R y S y los valores ST. Las amplitudes se expresan en microvoltios. Las duraciones se expresan en milisegundos.

- Vista ritmo. Si han registrado tiras de ECG, puede visualizar todo el ECG en la vista ritmo. El PDFC se ha monitorizado en todos los voluntarios.

- Vista vector. Muestra los resultados de un ECG en un vectocardiograma.

- Vista R-R. Es el intervalo entre dos complejos subsiguientes. La vista R-R proporciona una visión global de la variabilidad de la frecuencia cardiaca. Esta vista muestra el número de intervalos, el número mínimo, máximo y medio y la desviación estándar.

- Medición del QT, con corrección mediante el método Bazett.

- Inserción de marcadores en los puntos más importantes del ECG: onda P inicial, onda P final, complejo QRS inicial, complejo QRS final y onda T final.

\subsubsection{Bicicleta estática}

Para la realización de la cicloergometría se empleó la bicicleta estática IC7 de la marca Tomahawk ${ }^{\circledR}$. Se seleccionó este equipo por estar dotado del medidor de potencia WattRate ${ }^{\circledR}$, que permitía conocer de una manera continua e instantánea la potencia que se estaba dando (ver especificaciones técnicas en Anexo 24). 
El sistema de transmisión de dos etapas usa un sistema de poleas tanto en el lado derecho como en el izquierdo para optimizar el pedaleo y el rendimiento del medidor (relación de transmisión de 1:11).

El medido de energía directa WattRate ${ }^{\circledR}$ presenta una tolerancia de medición de + - $1 \%$. Está localizado en la transmisión intermedia y usa fotocélulas para medir directamente la torsión (fuerza de torsión) del eje. El diseño nunca requiere recalibración y es completamente resistente a factores externos tales como la temperatura, humedad y transporte.

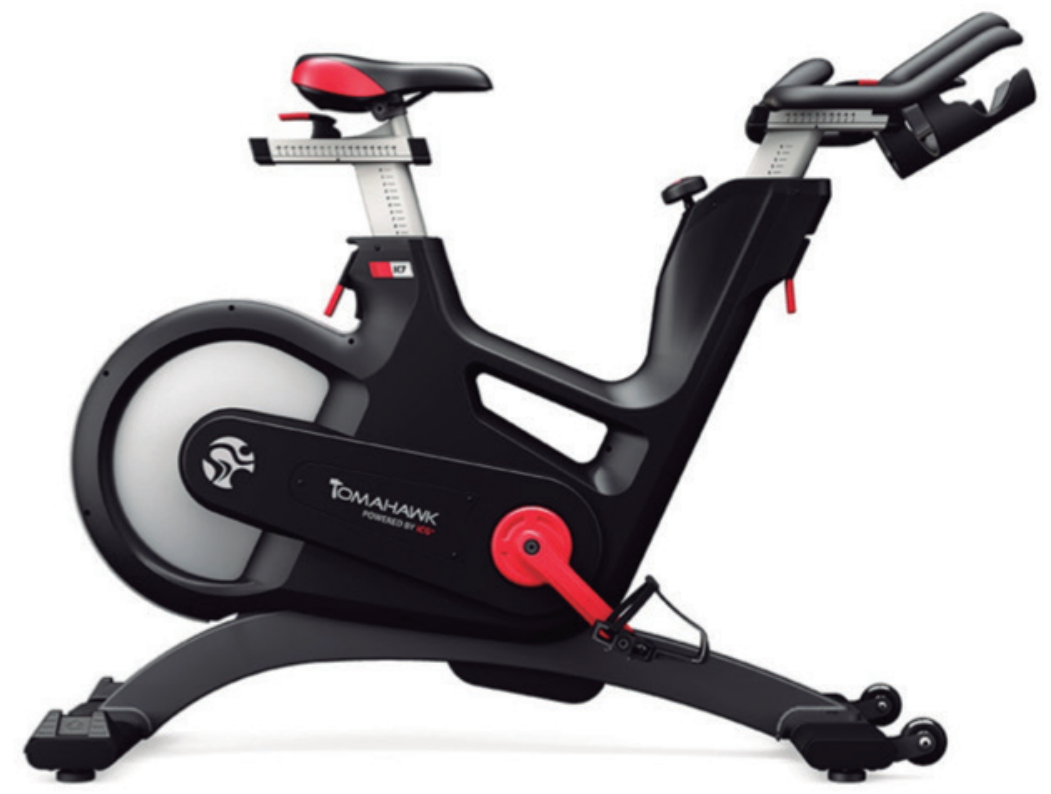

Figura 16. Bicicleta estática IC7 de la marca Tomahawk ${ }^{\circledR}$

La pantalla central nos ofrece los siguientes valores:

- Hora.

- Tiempo de ejercicio.

- Potencia en vatios.

- Cadencia, es decir, número de pedaladas por minuto.

- Velocidad en km/hora.

- Nivel de resistencia, de 0 a 100 niveles.

\subsubsection{Ordenador portátil}

El software específico para el ECG y el espirómetro fueron instalados en un ordenador portátil de la marca Lenovo ${ }^{\circledR}$ modelo ThinkPad Yoga 260 (ver especificaciones técnicas en Anexo 25).

\subsubsection{Pulsómetro}

Se contó con cuatro pulsómetros de marca Polar ${ }^{\circledR}$ modelo A300, todos con sensor de frecuencia cardiaca.

La comunicación entre el sensor de frecuencia cardiaca y el reloj se realizó mediante tecnología inalámbrica Bluetooth ${ }^{\circledR}$ Smart (ver especificaciones técnicas en Anexo 26). 


\subsubsection{Medidor de humedad relativa y temperatura ambiental}

Para el correcto control de las condiciones ambientales de la sala donde se realizó el caso práctico, se contó con un medidor dual de temperatura y humedad modelo DPT 1 de la marca PCE ${ }^{\circledR}$ (ver especificaciones técnicas en Anexo 27).

\subsubsection{Luxómetro}

El luxómetro es un dispositivo destinado a la medición de la cantidad de luz presente en un lugar. Para el estudio se utilizó el modelo 172 de la marca $\mathrm{PCE}^{\circledR}$ (ver especificaciones técnicas en Anexo 28).

\subsubsection{Equipo de protección individual}

En este apartado lleva a cabo una descripción detallada de los elementos del equipo de protección individual que fueron empleados en la realización del caso práctico. Todos los elementos del EPI poseen declaración de conformidad CE y manual de instrucciones.

Los elementos están citados en el orden de colocación del EPI según las recomendaciones del ECDC.

\subsubsection{Cubrebotas}

Se utilizaron dos pares de cubrebotas de la marca ASATEX ${ }^{\circledR}$ modelo CoverChem Plus ${ }^{\circledR}$ con protección química y biológica. Presentan un diseño de caña alta con goma elástica y dos cintas para una óptima sujeción (ver especificaciones técnicas en Anexo 29).

\subsubsection{Buzo de protección}

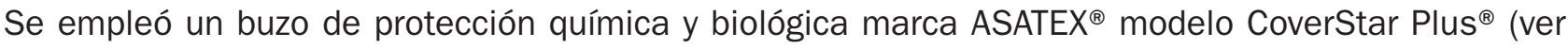
especificaciones técnicas en Anexo 30).

El buzo presenta las siguientes características técnicas:

- Fabricado en material laminado microporoso, suave y ligero.

- Costuras cosidas y termo-selladas.

- Gomas elásticas en puños, tobillos, cintura y capucha.

- Capucha ergonómica fabricada de 3 piezas.

- Goma elástica en capucha para un ajuste óptimo.

- Entrepierna de 3 piezas para mayor movilidad.

- Cremallera con solapa adhesiva para mayor seguridad.

- Presilla elástica para el pulgar.

- Tallas: S-4XL.

\subsubsection{Guantes de nitrilo interiores}

Para el correcto equipamiento con el EPI, el voluntario usó dos pares de guantes, uno interior y otro exterior. El primer par de guantes interiores eran de la marca Ansell ${ }^{\circledR}$, modelo TouchNTuff ${ }^{\circledR}$, de nitrilo, sin polvo, color verde. Los guantes son de muñeca extralarga y con doble ajuste, con tallas entre el n. ${ }^{\circ} 6,5$ y n. ${ }^{\circ} 10$ (ver especificaciones técnicas en Anexo 31). 


\subsubsection{Capuz}

En este punto del equipamiento los voluntarios se colocaron el capuz o verdugo. Se empleó el modelo CoverStar $^{\circledR}$ de la marca ASATEX ${ }^{\circledR}$, con goma elástica en el contorno de la cara y sobre la nuca, para un ajuste adecuado (ver especificaciones técnicas en Anexo 32).

\subsubsection{Mascarilla FFP3}

Los voluntarios se equiparon con una mascarilla autofiltrante FFP3 de la marca ASATEX ${ }^{\circledR}$, modelo NR, con las siguientes características:

- Mascarilla autofiltrante. Aptas para niveles altos de partículas sólidas y líquidas no volátiles (hasta 50 VLA).

- Diseño moldeado.

- Válvula de exhalación.

- Anillo interior de sellado facial para un ajuste hermético.

- Gomas elásticas ajustables a medida para mayor confort y seguridad (ver especificaciones técnicas en Anexo 33).

\subsubsection{Gafas de protección panorámicas}

Para completar la puesta del EPI se utilizaron gafas de protección panorámicas y autoventiladas de la marca $3 \mathrm{M}^{\mathrm{TM}}$ modelo Budget ${ }^{\circledR}$ 4800. Fabricadas en policarbonato, con lentes incoloras tipo 3-1.2 3M 1 B y tratamiento antivaho (ver especificaciones técnicas en Anexo 34).

\subsubsection{Guantes de nitrilo exteriores}

Para el segundo par de guantes exteriores se emplearon guantes de la marca Medical Care ${ }^{\circledR}$, modelo Industry de nitrilo, sin polvo, color azul. Los guantes son de muñeca extralarga y con doble ajuste, con tallas entre el n. ${ }^{\circ} 6,5 \mathrm{y} \mathrm{n}^{\circ} 10$ (ver especificaciones técnicas en Anexo 35).

\subsubsection{Material para la realización del caso práctico}

En el presente apartado se describen los recursos materiales que se emplearon para la realización del caso práctico, desde el maniquí de simulación, electromedicina y todo el material fungible.

\subsubsection{Maniquí de soporte vital avanzado}

Para la realización de las técnicas de soporte vital avanzado necesarias para la simulación del caso práctico se empleó el maniquí de simulación modelo MegaCode Kelly de la marca Laerdal ${ }^{\circledR}$. El maniquí tiene un peso de $70 \mathrm{~kg}$, con extremidades articuladas y conexión vía wifi con una Tablet (Sim$\mathrm{Pad}^{\circledR}$ ) para su manejo.

Con este dispositivo de prácticas se pudieron realizar todas las técnicas necesarias para el caso propuesto:

- Manejo básico y avanzado de la vía aérea. Permite la aspiración de secreciones, inserción de cánula de guedel, ventilación con $\mathrm{AMBU}^{\circledR}{ }^{\circledR}$, intubación orotraqueal, uso de dispositivos alternativos de la vía aérea, cricotirotomía y técnicas de descompresión torácica, entre otros. 
- Acceso vascular en ambos brazos y manos, que permiten la canalización de vías venosas y la administración de fluidos y fármacos.

- Selección de ritmos a medida, mediante el uso del controlador SimPad ${ }^{\circledR}$. Permite la modificación de ritmo, frecuencia cardiaca, QRS (tipo y morfología), elevación o descenso del ST, extrasístoles, bloqueos, marcapasos, entre otras funciones, con un total de más de 1.400 combinaciones posibles.

- Monitorización con 4 derivaciones, simulación de ECG de 12 derivaciones, desfibrilación y cardioversión con cargas reales, marcapasos externos transcutáneos y cambio de ritmo automático tras descarga (si está programado).

- Valoración de constantes vitales. El dispositivo puede o no tener pulso carotideo, tensión arterial, respuesta pupilar, respirar o no respirar; hablar, entre otras funciones.

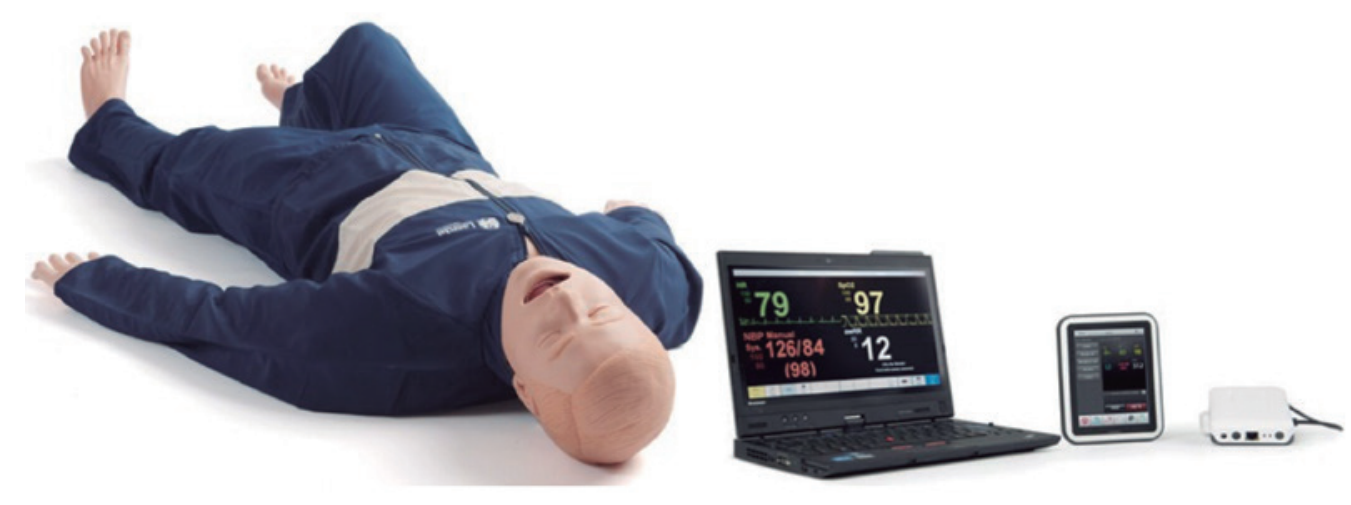

Figura 17. Maniquí de soporte vital avanzado Megacode Kelly ${ }^{\circledR}$

\subsubsection{Electromedicina}

Durante el desarrollo del caso práctico los voluntarios tuvieron la posibilidad de emplear los siguientes elementos:

- Monitor desfibrilador, modelo Argus ProLife 2 de la marca Schiller ${ }^{\circledR}$, con posibilidad de monitorización, toma de tensión arterial, saturación de oxígeno, capnografía, ECG 12 derivaciones, desfibrilación, cardioversión y marcapasos externo transcutáneo.

- Aspirador de secreciones, modelo LCSU 4, de la marca Laerdal ${ }^{\circledR}$.

- Respirador automático, modelo Ambumatic ${ }^{\circledR}$, de la marca AMBU ${ }^{\circledR}$.

- Glucómetro, modelo Accu-Chek Mobile, de la marca Roche ${ }^{\circledR}$.

\subsubsection{Material de soporte vital avanzado}

Para el desarrollo del caso práctico se equiparon tres maletines, con la siguiente checklist cada uno de ellos:

- Maletín de vía aérea, compuesto por los siguientes elementos:

- Botiquín modelo 5111 de la marca Ferno ${ }^{\circledR}$.

- Botella de oxígeno con caudalímetro.

- Ventimask ${ }^{\circledR}$.

- Mascarilla con reservorio. 
- Sondas de Yankauer.

- Sondas de aspiración.

- Cánulas de guedel.

- AMBU $^{\circledR}$.

- Laringoscopio con tres palas.

- Tubos orotraqueales.

- Fiador.

- Lubricante.

- Jeringa de $10 \mathrm{ml}$.

- Tubo de Thomas.

- Fonendoscopio.

- Filtros.

- I-Gel ${ }^{\circledR}$.

- Airtraq ${ }^{\circledR}$.

- Alargadera de oxígeno.

- Maletín de vía venosa, compuesto por los siguientes elementos:

- Botiquín modelo 5108 de la marca Ferno ${ }^{\circledR}$.

- Esfigmomanómetro y fonendoscopio.

- $\mathrm{BOA}^{\circledR}$ y compresores.

- Sueros varios.

- Equipos de infusión.

- Llave de tres pasos.

- Regulador de flujo.

- Esparadrapo.

- Angiocatéter.

- Jeringas de diferentes tamaños.

- Agujas intravenosas e intramusculares.

- Gasas.

- Maletín de medicación:

- Medicación caducada para su carga y administración en el maniquí de simulación.

- Tijeras cortarropa.

- Maletín de trauma, compuesto por los siguientes elementos:

- Botiquín modelo 5107 de la marca Ferno ${ }^{\circledR}$.

- Gasas y compresas.

- Sueros de lavado.

- Venda de Smarch, CAT ${ }^{\circledR}$, IT-clamp ${ }^{\circledR}$ y Celox ${ }^{\circledR}$.

- Venda de crepé y venda cohesiva autoadhesiva.

- Esparadrapo.

- Tijeras cortarropa.

- Collarines.

- Férulas SAM ${ }^{\mathrm{TM}}$.

- Manta térmica. 


\subsubsection{Material vario}

Para poder realizar el caso práctico, además de todo el material anteriormente citado, fue necesario el uso de:

- Calefactor para mantener la sala de prácticas a una temperatura media de $30^{\circ} \mathrm{C}$. Se utilizó el calefactor TDS 50 E de la marca TROTEC ${ }^{\circledR}$, con una potencia calorífica de 9 kW y un flujo de aire: 845 $\mathrm{m}^{3} / \mathrm{h}$.

- Walkie-talkie. Se emplearon dos equipos modelo SL4010 de la marca Motorola ${ }^{\circledR}$.

\subsection{Aspectos éticos}

Durante el desarrollo del estudio se contemplaron los siguientes aspectos:

\subsubsection{Marco ético-jurídico}

- Código de Buenas Prácticas Científicas. Para la realización de esta tesis doctoral se ha asumido el Código de Buenas Prácticas Científicas Human Resources Strategy for Researchers HR STRATEGY (HRS4R). Este código está integrado por un conjunto de principios y normas referentes a la actividad científica, con el objetivo de mejorar la calidad de la investigación y de garantizar unos principios éticos, como complemento a la legislación vigente.

- Marco jurídico. El marco jurídico que resulta de especial interés para la realización de este estudio está compuesto por la siguiente normativa (sin perjuicio de las normas y tratados internacionales):

- Ley orgánica 15/1999, de 13 de diciembre, de protección de datos.

- Ley 14/2007, de 3 de julio, de investigación biomédica.

- Ley 14/2011, de 1 de junio, de la Ciencia, la Tecnología y la Innovación.

- Ley 24/2015, de 24 de julio, de Patentes.

- Declaración de Helsinki. Normas, principios y recomendaciones que deben regir la investigación biomédica en seres humanos, incluida la investigación del material humano y de información identificables ${ }^{(50)}$. Este estudio ha sido evaluado y autorizado previamente por el Comité Ético de Investigación Clínica del Hospital Universitario Río Hortega, con informe favorable de fecha 7 de abril de 2016 (ver Anexo 36).

\subsubsection{Privacidad sobre la identidad de los voluntarios}

Al entrar a formar parte del estudio, a cada voluntario se le asigna un número de identificación, con el fin de que su nombre y apellidos no consten en ningún documento generado en el estudio, excepto en el consentimiento informado, que se guarda en archivo diferente al resto de datos.

En el momento en el que el voluntario se presentaba en el vestíbulo de la Facultad de Ciencias de Salud se le conducía a las aulas del ECOE, y se le asignaba una carpeta codificada con una letra y un número, código que figuraba en cada documento del mismo sujeto, para, de esta forma, garantizar su confidencialidad. Su nombre y apellidos figuran únicamente en el consentimiento informado, que se archiva en una carpeta diferente al resto de la documentación. 
Tabla 12. Codificación de los sujetos de estudio

\begin{tabular}{|l|l|l|}
\hline Género & Código & Número \\
\hline Hombre & M & $101-199$ \\
\hline Mujer & F & $201-299$ \\
\hline
\end{tabular}

El autor es responsable de seguir los protocolos establecidos por su Área Sanitaria para acceder y almacenar los datos clínicos de los voluntarios y los datos clínicos generados del estudio.

\subsubsection{Consentimiento informado}

Antes de comenzar con la fase de experimentación, los voluntarios - todos ellos y de forma clara e inequívoca - fueron informados mediante un documento denominado Consentimiento informado (ver Anexo 4).

En dicho momento, los voluntarios debieron leer el documento de consentimiento informado de forma obligatoria, poner su nombre, apellidos y fecha; y decidir si deseaban continuar con el estudio firmando el documento. De esta forma, el sujeto conoció las técnicas y procedimientos a los que iba a ser sometido, y las infrecuentes pero posibles complicaciones que se podrían generar a raíz de algunas técnicas, así como la confidencialidad de todo el proceso.

Una vez firmado el consentimiento informado pasaron a las siguientes fases del estudio, conociendo la posibilidad de abandonar el mismo en cualquier momento.

\subsection{Revisión bibliográfica}

La labor de revisión bibliográfica ha sido realizada a través de buscadores médicos, que han resultado muy útiles para la elaboración de este estudio: la página de Internet PubMed (http://www.ncbi. nlm.nih.gov/ PubMed), un servicio de acceso libre a la base de datos Medline proporcionado por la National Library of Medicine (NLM), Doyma (http://www.elsevier.es) y Blackwell-Synergy (http:// www.3.interscience. wiley.com). Para la búsqueda inicial se han empleado términos libres y vocabulario controlado ("Servicios de Urgencias", "Emergency services"; "Reanimación cardiopulmonar", "Cardiopulmonary resuscitation"; "exposición a agentes biológicos", "exposure to biological agents"; "estrés fisiológico", "physiological stress"; “límite anaerobio”, “anaerobic threshold”; "protección personal”, "personal protection").

La búsqueda libre ha sido completada con la utilización de vocabulario controlado (MeSH), restringiéndola a un término o ampliándola a varios si ha sido preciso. Los términos de búsqueda han sido relacionados mediante operadores lógicos e implementados mediante truncadores, limitándose a los años 1970-2017, todos los idiomas, investigación en humanos y artículos con abstract. De los artículos recuperados, han sido seleccionados los que aportaban la información más válida y relevante, según criterio personal.

Asimismo, han sido utilizados libros de texto, monografías y manuales actualizados de interés relevante. Del mismo modo, se utilizó el fondo bibliográfico de la biblioteca del Hospital Universitario Río Hortega y de las bibliotecas de Ciencias de la Salud de Valladolid. Una parte de la bibliografía ha sido 
obtenida a través de los estudios o revisiones procedentes de las fuentes anteriores. La revisión bibliográfica se hizo en dos tiempos: en un momento previo al diseño del estudio, para lograr una idea del estado actual de los estudios sobre el tema a nivel internacional, y una nueva revisión posterior al diseño, con el objetivo de priorizar los datos obtenidos y establecer modelos comparativos.

En cuanto a la redacción de las referencias bibliográficas, se utilizó el estilo recomendado por el International Committee of Medical Journal Editors, conocido como Normas de Vancouver, y disponibles en las direcciones electrónicas: www.icmje.org y www.nlm.nih.gov/bsd/uniform_requirements.html

\subsection{Análisis estadístico}

Para realizar el análisis estadístico, las variables cualitativas se resumen con su distribución de frecuencias, y las variables cuantitativas en su media y desviación estándar (DE). En todos los casos se comprobó la distribución de la variable frente a los modelos teóricos; y, en caso de asimetría, se calculó la mediana y su rango intercuartil (RIC).

Se evaluó la asociación entre variables cualitativas con el test de la $x^{2}$ o prueba exacta de Fisher, en el caso de que más de un $25 \%$ de los esperados fueran menores de 5.

Se analizó el comportamiento de la variables cuantitativas por cada una de las variables independientes categorizadas mediante el test de la t de Student (en comparaciones de una variable con dos categorías) y/o el análisis de la variancia (ANOVA). Mediante esta técnica, se evaluaron las diferencias de medias debido al efecto individual o principal de cada factor $\mathrm{y} / \mathrm{o}$ al efecto de sus interacciones. Se estimaron los efectos medios absolutos y sus intervalos de confianza al 95\% (IC95\%).

Para el análisis entre pares de variables cuantitativas se calculó el coeficiente de correlación de Pearson. Se determinó el contraste de la hipótesis nula de que el coeficiente es igual a 0. Cuando la relación fue lineal, se ajustaron modelos de regresión múltiple lineales. La estimación de parámetros se calculó mediante el método de mínimos cuadrados.

Para el estudio de la fiabilidad entre medidas cuantitativas se utilizó el coeficiente de correlación intraclase (CCl) y su IC95\%, así como el método gráfico de Bland-Altmann. Para ello se calcularon las diferencias entre medidas y la media de ambos valores. Para evaluar variables cualitativas se estimó el índice kappa ponderado por pesos cuadráticos.

Se ajustó un modelo de regresión logística, con el objeto de evaluar la asociación de aquellas variables que predecían una mala tolerancia. Este modelo permite identificar la relación entre un conjunto de variables explicativas y la probabilidad de control de las variables estudiadas.

La capacidad de calibración del modelo se evaluó con el test de Hosmer y Lemeshow (p cercanas a 1 denotan alta calibración) y la capacidad de discriminación se estudió con el área bajo la curva de las probabilidades predichas por el modelo ajustado (AUC).

En todos los contrastes de hipótesis se rechazó la hipótesis nula con un error de tipo I o error alfa menor a 0,05.

El paquete informático utilizado para el análisis fue SPSS ver. 20.0. 
Resultados

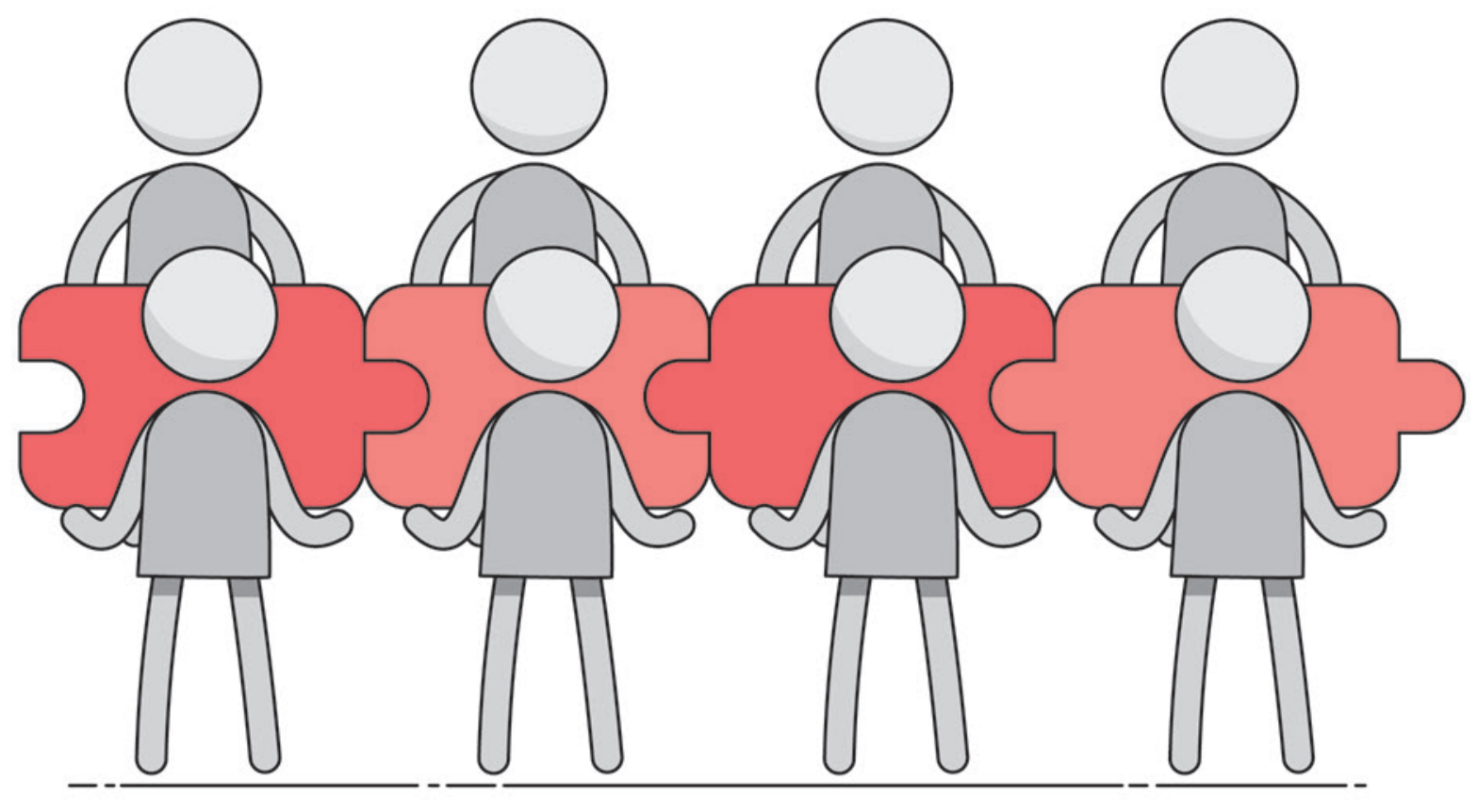

UniversidaddeValladolid 


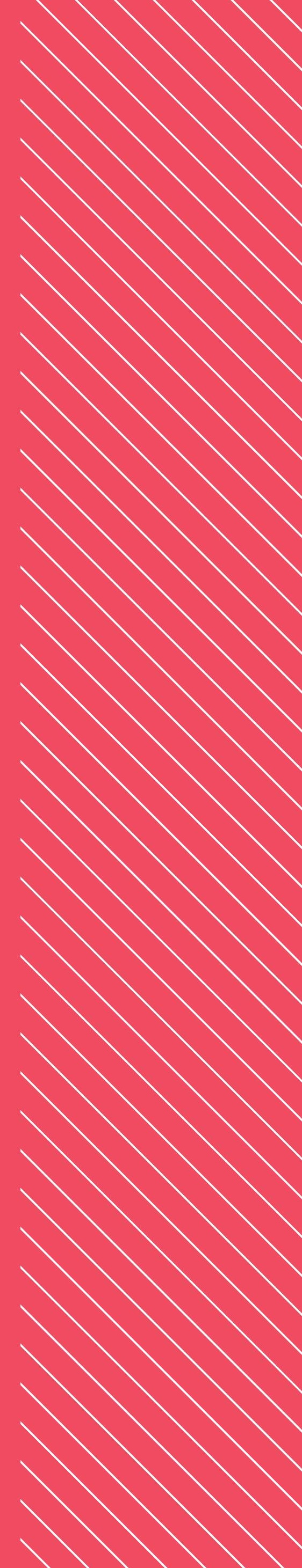




\subsection{Descriptivos generales}

La muestra final analizada estuvo compuesta por 24 sujetos de pregrado de enfermería, 25 de pregrado de medicina, 25 enfermeros y 22 médicos. En la Tabla $n .{ }^{\circ} 13$ se recogen las características de los individuos por grupos, siendo el más numeroso en mujeres el grupo de pregrado de enfermería -ya que supusieron el $70,8 \%$ del total del grupo- . Todos los participantes del estudio fueron de raza blanca, exceptuando el grupo de pregrado de medicina, que tuvo un participante de raza negra y un indígena.

El $81,8 \%$ de los médicos tenían como experiencia un curso avanzado, mientras que en enfermería solo contaba con esta experiencia el $48 \%$ ( $p<0,001)$. En los grupos de pregrado, el $58,3 \%$ de enfermería y el 92,0\% en medicina no poseían ninguna experiencia en NBQ. La frecuencia de consumo de alcohol fue mayor en el grupo de enfermería, suponiendo un 68,0\%, frente a los otros grupos $(p=0,054)$ y respecto al consumo de tabaco en el momento del estudio, también presentaron mayores frecuencias los enfermeros $(16,0 \%)$, pero no diferentes al resto de los grupos $(p=0,768)$.

Tabla 13. Características de los grupos de estudio

\begin{tabular}{|c|c|c|c|c|c|c|c|c|c|c|}
\hline \multicolumn{11}{|c|}{ Grupo } \\
\hline & & \multicolumn{2}{|c|}{$\begin{array}{c}\text { Pregrado } \\
\text { Enfermería } \\
\qquad \mathrm{N}=24\end{array}$} & \multicolumn{2}{|c|}{$\begin{array}{l}\text { Pregrado } \\
\text { Medicina } \\
\text { N=25 }\end{array}$} & \multicolumn{2}{|c|}{$\begin{array}{l}\text { Enfermero } \\
\qquad \mathrm{N}=\mathbf{2 5}\end{array}$} & \multicolumn{2}{|c|}{$\begin{array}{l}\text { Médico } \\
\mathrm{N}=22\end{array}$} & \multirow[b]{2}{*}{$\mathrm{p}$} \\
\hline & & $\begin{array}{c}\mathrm{N} .{ }^{\circ} \\
\text { casos }\end{array}$ & $\%$ & $\begin{array}{l}\mathrm{N} .^{\circ} \\
\text { casos }\end{array}$ & $\%$ & $\begin{array}{l}\mathrm{N} .{ }^{\circ} \\
\text { casos }\end{array}$ & $\%$ & $\begin{array}{l}\mathrm{N} .^{\circ} \\
\text { casos }\end{array}$ & $\%$ & \\
\hline \multirow{2}{*}{ Sexo } & Hombre & 7 & 29,2 & 11 & 44,0 & 10 & 40,0 & 12 & 54,5 & 0,372 \\
\hline & Mujer & 17 & 70,8 & 14 & 56,0 & 15 & 60,0 & 10 & 45,5 & \\
\hline \multirow{3}{*}{ Raza } & Blanca & 24 & 100,0 & 23 & 92,0 & 25 & 100,0 & 22 & 100,0 & 0,446 \\
\hline & Africano & 0 & 0,0 & 1 & 4,0 & 0 & 0,0 & 0 & 0,0 & \\
\hline & Indígena & 0 & 0,0 & 1 & 4,0 & 0 & 0,0 & 0 & 0,0 & \\
\hline \multirow{4}{*}{$\begin{array}{l}\text { Experien- } \\
\text { cia NBQ* }\end{array}$} & Ninguna & 14 & 58,3 & 23 & 92,0 & 5 & 20,0 & 1 & 4,5 & $<0,001$ \\
\hline & $\begin{array}{l}\text { Curso } \\
\text { básico }\end{array}$ & 10 & 41,7 & 2 & 8,0 & 6 & 24,0 & 2 & 9,1 & \\
\hline & $\begin{array}{l}\text { Curso } \\
\text { avanzado }\end{array}$ & 0 & 0,0 & 0 & 0,0 & 12 & 48,0 & 18 & 81,8 & \\
\hline & $\begin{array}{l}\text { Experien- } \\
\text { cia real }\end{array}$ & 0 & 0,0 & 0 & 0,0 & 2 & 8,0 & 1 & 4,5 & \\
\hline \multirow{2}{*}{ Embarazo } & SI & 0 & 0,0 & 0 & 0,0 & 0 & 0,0 & 0 & 0,0 & \\
\hline & NO & 24 & 100,0 & 25 & 100,0 & 25 & 100,0 & 22 & 100,0 & \\
\hline
\end{tabular}


Tabla 13. Características de los grupos de estudio (continuación)

\begin{tabular}{|c|c|c|c|c|c|c|c|c|c|c|}
\hline \multirow{2}{*}{$\begin{array}{l}\text { Consumo } \\
\text { de alcohol }\end{array}$} & SI & 8 & 33,3 & 9 & 36,0 & 17 & 68,0 & 9 & 40,9 & 0,054 \\
\hline & NO & 16 & 66,7 & 16 & 64,0 & 8 & 32,0 & 13 & 59,1 & \\
\hline \multirow{2}{*}{ Fumador } & SI & 2 & 8,3 & 2 & 8,0 & 4 & 16,0 & 3 & 13,6 & 0,768 \\
\hline & NO & 22 & 91,7 & 23 & 92,0 & 21 & 84,0 & 19 & 86,4 & \\
\hline \multirow{2}{*}{ Alergia } & SI & 9 & 37,5 & 11 & 44,0 & 8 & 32,0 & 5 & 22,7 & 0,472 \\
\hline & NO & 15 & 62,5 & 14 & 56,0 & 17 & 68,0 & 17 & 77,3 & \\
\hline \multirow{2}{*}{ Patología } & SI & 18 & 75,0 & 23 & 92,0 & 22 & 88,0 & 19 & 86,4 & 0,375 \\
\hline & NO & 6 & 25,0 & 2 & 8,0 & 3 & 12,0 & 3 & 13,6 & \\
\hline \multirow{2}{*}{$\begin{array}{l}\text { Medica- } \\
\text { mento }\end{array}$} & SI & 16 & 66,7 & 12 & 48,0 & 8 & 32,0 & 9 & 40,9 & 0,097 \\
\hline & NO & 8 & 33,3 & 13 & 52,0 & 17 & 68,0 & 13 & 59,1 & \\
\hline
\end{tabular}

En la Tabla n. 14 se recogen las características de los subgrupos agrupadas en función de su actividad asistencial. Se observa la misma distribución de las variables aunque el sexo se homogeneiza $(p=0,603)$; el consumo de tabaco sale significativamente mayor en el subgrupo de emergencias sanitarias con una frecuencia del $28,6 \%(p=0,018)$.

Tabla 14. Características de los subgrupos de estudio

\begin{tabular}{|l|l|l|c|c|c|c|}
\hline \multicolumn{2}{|c|}{ Subgrupo } \\
\hline
\end{tabular}


Tabla 14. Características de los subgrupos de estudio (continuación)

\begin{tabular}{|c|c|c|c|c|c|c|c|c|}
\hline \multirow{4}{*}{$\begin{array}{l}\text { Experien- } \\
\text { cia NBQ }\end{array}$} & Ninguna & 37 & 75,5 & 5 & 19,2 & 1 & 4,8 & $<0,001$ \\
\hline & $\begin{array}{l}\text { Curso } \\
\text { básico }\end{array}$ & 12 & 24,5 & 8 & 30,8 & 0 & 0,0 & \\
\hline & $\begin{array}{l}\text { Curso } \\
\text { avanzado }\end{array}$ & 0 & 0,0 & 13 & 50,0 & 17 & 81,0 & \\
\hline & $\begin{array}{l}\text { Experien- } \\
\text { cia real }\end{array}$ & 0 & 0,0 & 0 & 0,0 & 3 & 14,3 & \\
\hline \multirow{2}{*}{$\begin{array}{l}\text { Consu- } \\
\text { mo de } \\
\text { alcohol }\end{array}$} & SI & 17 & 34,7 & 16 & 61,5 & 10 & 47,6 & 0,081 \\
\hline & NO & 32 & 65,3 & 10 & 38,5 & 11 & 52,4 & \\
\hline \multirow{2}{*}{ Fumador } & SI & 4 & 8,2 & 1 & 3,8 & 6 & 28,6 & 0,018 \\
\hline & NO & 45 & 91,8 & 25 & 96,2 & 15 & 71,4 & \\
\hline \multirow{2}{*}{ Alergia } & SI & 20 & 40,8 & 9 & 34,6 & 4 & 19,0 & 0,213 \\
\hline & NO & 29 & 59,2 & 17 & 65,4 & 17 & 81,0 & \\
\hline \multirow{2}{*}{ Patología } & SI & 41 & 83,7 & 20 & 76,9 & 21 & 100,0 & 0,074 \\
\hline & NO & 8 & 16,3 & 6 & 23,1 & 0 & 0,0 & \\
\hline \multirow{2}{*}{$\begin{array}{l}\text { Medica- } \\
\text { mentos }\end{array}$} & SI & 28 & 57,1 & 8 & 30,8 & 9 & 42,9 & 0,085 \\
\hline & NO & 21 & 42,9 & 18 & 69,2 & 12 & 57,1 & \\
\hline
\end{tabular}

\subsection{Parámetros basales y antropométricos}

Los parámetros basales recogidos se describen en la Tabla n. ${ }^{\circ} 15$, clasificados por grupo de estudio. La edad media fue significativamente diferente entre los grupos de pregrado y los grupos profesionales, siendo la edad media de enfermería de 35,6 años (DE 7,8 ) y 45,4 años (DE 6,5) en el grupo de médicos $(p<0,001)$. Esta diferencia se hace ostensible en la experiencia laboral, que rondó los 4 años en pregrado y, sin embargo, en el grupo de enfermería fue de 10,7 años (DE 6,2) y en el de médicos de 16,0 años (DE 6,5)(p<0,001).

En cuanto a los parámetros antropométricos, las medias - tanto de contornos como de composición corporal - fueron mayores en el grupo de médicos, con pesos ideales corregidos más altos $(65,7 \mathrm{~kg}$ y DE 8,0). Los parámetros de presión arterial y frecuencia cardiaca fueron similares en los grupos de estudio. No se encontraron diferencias en el índice de perfusión basal ni en la saturación de oxígeno. 
Tabla 15. Descripción de los parámetros basales por grupo de estudio

\begin{tabular}{|c|c|c|c|c|c|c|c|c|c|}
\hline \multicolumn{10}{|c|}{ Grupo } \\
\hline & \multicolumn{2}{|c|}{$\begin{array}{l}\text { Pregrado } \\
\text { Enfermería } \\
\quad \mathrm{N}=24\end{array}$} & \multicolumn{2}{|c|}{$\begin{array}{c}\text { Pregrado } \\
\text { Medicina } \\
\mathrm{N}=25\end{array}$} & \multicolumn{2}{|c|}{$\begin{array}{c}\text { Enfermero } \\
\qquad \mathrm{N}=25\end{array}$} & \multicolumn{2}{|c|}{$\begin{array}{l}\text { Médico } \\
\mathrm{N}=22\end{array}$} & \\
\hline & Media & $\mathrm{DE}$ & Media & $\mathrm{DE}$ & Media & $\mathrm{DE}$ & Media & $\mathrm{DE}$ & $\mathrm{p}$ \\
\hline Edad & 23,3 & 3,3 & 22,3 & 2,2 & 35,6 & 7,8 & 45,4 & 6,5 & $<0,001$ \\
\hline Experiencia laboral & 4,0 & 0,2 & 4,5 & 1,3 & 10,7 & 6,2 & 16,0 & 6,5 & $<0,001$ \\
\hline $\begin{array}{l}\text { Horas desde la } \\
\text { última ingesta }\end{array}$ & 2,8 & 1,6 & 2,1 & 1,2 & 2,5 & 1,1 & 2,7 & 1,0 & 0,243 \\
\hline Horas de sueño & 7,1 & 0,8 & 6,7 & 0,8 & 7,4 & 2,0 & 6,4 & 1,2 & 0,056 \\
\hline $\begin{array}{l}\text { Cantidad de alcohol } \\
\text { consumida }\end{array}$ & 1,3 & 2,2 & 1,8 & 2,9 & 3,5 & 6,4 & 2,4 & 3,4 & 0,272 \\
\hline $\begin{array}{l}\text { Número de } \\
\text { cigarrillos/día }\end{array}$ & 0,6 & 1,7 & 0,6 & 2,2 & 2,0 & 5,2 & 1,5 & 4,9 & 0,487 \\
\hline $\begin{array}{l}\text { Años de } \\
\text { tabaquismo }\end{array}$ & 1,0 & 2,7 & 0,7 & 2,6 & 3,4 & 8,9 & 3,0 & 8,1 & 0,319 \\
\hline $\begin{array}{l}\text { Perímetro del } \\
\text { pecho }\end{array}$ & 86,8 & 6,5 & 91,6 & 7,8 & 93,5 & 8,8 & 98,0 & 10,2 & $<0,001$ \\
\hline $\begin{array}{l}\text { Perímetro de } \\
\text { cintura }\end{array}$ & 75,0 & 7,5 & 80,3 & 9,4 & 81,8 & 11,9 & 89,1 & 12,5 & $<0,001$ \\
\hline $\begin{array}{l}\text { Perímetro de } \\
\text { cadera }\end{array}$ & 87,9 & 8,6 & 92,6 & 10,6 & 94,6 & 8,8 & 99,7 & 11,5 & 0,001 \\
\hline Perímetro de cuello & 32,8 & 3,3 & 33,4 & 3,4 & 34,9 & 4,4 & 36,7 & 4,1 & 0,005 \\
\hline $\begin{array}{l}\text { Contorno de } \\
\text { muñeca }\end{array}$ & 15,7 & 1,2 & 16,0 & 1,2 & 16,1 & 1,5 & 16,9 & 1,3 & 0,019 \\
\hline Contorno del brazo & 27,4 & 3,4 & 28,4 & 4,1 & 28,5 & 3,2 & 31,0 & 4,1 & 0,013 \\
\hline Peso & 61,8 & 10,5 & 70,3 & 13,6 & 69,1 & 14,9 & 78,4 & 17,0 & 0,002 \\
\hline Grasa corporal & 21,2 & 8,1 & 20,9 & 10,1 & 23,1 & 6,1 & 25,0 & 9,8 & 0,335 \\
\hline Masa muscular & 46,1 & 8,2 & 52,9 & 11,4 & 50,5 & 11,4 & 55,3 & 11,4 & 0,029 \\
\hline Masa ósea & 2,5 & 0,4 & 2,8 & 0,5 & 2,7 & 0,6 & 2,9 & 0,6 & 0,026 \\
\hline BMI & 22,2 & 3,3 & 24,2 & 3,9 & 24,4 & 3,5 & 26,9 & 4,6 & 0,001 \\
\hline Peso ideal & 58,2 & 7,2 & 61,7 & 8,3 & 58,7 & 7,7 & 61,5 & 7,2 & 0,256 \\
\hline $\begin{array}{l}\text { Peso ideal } \\
\text { corregido }\end{array}$ & 60,7 & 9,0 & 64,3 & 10,4 & 61,9 & 10,5 & 65,7 & 8,0 & 0,277 \\
\hline
\end{tabular}


Tabla 15. Descripción de los parámetros basales por grupo de estudio (continuación)

\begin{tabular}{|c|c|c|c|c|c|c|c|c|c|}
\hline $\begin{array}{l}\text { Frecuencia cardiaca } \\
\text { en reposo }\end{array}$ & 70,3 & 6,9 & 69,4 & 9,4 & 65,1 & 10,2 & 67,8 & 8,7 & 0,199 \\
\hline $\begin{array}{l}\text { Frecuencia cardiaca } \\
\text { real }\end{array}$ & 82,4 & 14,7 & 79,4 & 13,9 & 77,6 & 11,7 & 81,5 & 13,5 & 0,611 \\
\hline $\begin{array}{l}\text { Presión arterial } \\
\text { sistólica }\end{array}$ & 125,6 & 14,2 & 133,0 & 15,6 & 128,4 & 12,3 & 131,2 & 14,6 & 0,298 \\
\hline $\begin{array}{l}\text { Presión arterial } \\
\text { diastólica }\end{array}$ & 78,3 & 9,8 & 79,2 & 9,9 & 82,5 & 9,5 & 84,6 & 9,4 & 0,100 \\
\hline $\begin{array}{l}\text { Frecuencia } \\
\text { respiratoria }\end{array}$ & 16,7 & 1,2 & 17,2 & 1,6 & 15,8 & 1,5 & 16,6 & 1,9 & 0,023 \\
\hline Temperatura & 36,9 & 0,4 & 36,8 & 0,4 & 36,4 & 0,6 & 36,5 & 0,5 & 0,001 \\
\hline Hemoglobina & 13,6 & 1,6 & 13,7 & 1,6 & 13,5 & 1,5 & 14,0 & 1,3 & 0,775 \\
\hline Índice de perfusión & 3,4 & 3,5 & 2,6 & 2,2 & 3,1 & 2,9 & 4,2 & 2,8 & 0,314 \\
\hline $\begin{array}{l}\text { Saturación de } \\
\text { oxígeno }\end{array}$ & 98,5 & 1,2 & 98,4 & 1,5 & 98,1 & 1,5 & 97,9 & 1,6 & 0,482 \\
\hline
\end{tabular}

En la Tabla $n .^{\circ} 16$ se pueden observar los parámetros basales por subgrupos de estudio. La muestra de emergencias sanitarias fue la de mayor edad (43,2 años y DE 7,5); seguida de la de urgencias hospitalarias $(37,7$ años y DE 8,9$)(p<0,001)$. En el subgrupo de emergencias sanitarias pudimos encontrar más fumadores $(p=0,001)$ y más consumidores de alcohol $(p=0,054)$.

En cuanto a los datos antropométricos, los sujetos de emergencias sanitarias presentaron mayores perímetros de pecho $(p=0,001)$, cintura $(p=0,001)$, cadera $(p=0,003)$, cuello $(p=0,003)$ y contorno de muñeca $(p=0,042)$. El IMC de este grupo fue de $26,6 \mathrm{~kg} / \mathrm{m}^{2}(D E 4,6)$. No se encontraron diferencias basales en la grasa corporal, masa muscular y ósea. La frecuencia cardiaca en reposo fue inferior en el grupo de urgencias hospitalarias frente al resto $(p=0,007)$, y la presión arterial diastólica fue superior en el grupo de emergencias sanitarias $(p=0,042)$. En el grupo de pregrado fueron superiores en media la temperatura $(p<0,001)$ y la frecuencia respiratoria $(p=0,025)$. 
Tabla 16. Descripción de los parámetros por subgrupo

\begin{tabular}{|c|c|c|c|c|c|c|c|}
\hline \multicolumn{8}{|c|}{ Subgrupo } \\
\hline & \multicolumn{2}{|c|}{$\begin{array}{l}\text { Pregrado } \\
n=49\end{array}$} & \multicolumn{2}{|c|}{$\begin{array}{l}\text { Urgencias } \\
\text { Hospitalarias } \\
\text { n=26 }\end{array}$} & \multicolumn{2}{|c|}{$\begin{array}{c}\text { Emergencias } \\
\text { Sanitarias } \\
n=21\end{array}$} & \\
\hline & Media & $\mathrm{DE}$ & Media & DE & Media & DE & $\mathrm{p}$ \\
\hline Edad & 22,8 & 2,8 & 37,7 & 8,9 & 43,2 & 7,5 & $<0,001$ \\
\hline Experiencia laboral & 4,2 & 1,0 & 11,7 & 7,3 & 15,0 & 5,7 & $<0,001$ \\
\hline Horas desde la última ingesta & 2,4 & 1,4 & 2,3 & 1,0 & 3,0 & 1,0 & 0,214 \\
\hline Horas de sueño & 6,9 & 0,8 & 6,9 & 1,6 & 6,9 & 1,9 & 0,986 \\
\hline Cantidad de alcohol consumida & 1,5 & 2,6 & 2,1 & 2,3 & 4,1 & 7,3 & 0,054 \\
\hline Número de cigarrillos/día & 0,6 & 2,0 & 0,1 & 0,6 & 3,9 & 7,0 & 0,001 \\
\hline Años de tabaquismo & 0,8 & 2,6 & 1,0 & 4,9 & 6,0 & 10,9 & $0,004 *$ \\
\hline Perímetro del pecho & 89,3 & 7,5 & 93,8 & 9,4 & 97,8 & 9,8 & 0,001 \\
\hline Perímetro de cintura & 77,7 & 8,8 & 82,8 & 10,5 & 88,3 & 14,5 & 0,001 \\
\hline Perímetro de cadera & 90,3 & 9,9 & 95,2 & 10,2 & 99,3 & 10,4 & 0,003 \\
\hline Perímetro de cuello & 33,1 & 3,3 & 35,1 & 3,6 & 36,5 & 5,1 & 0,003 \\
\hline Contorno de muñeca & 15,9 & 1,1 & 16,3 & 1,4 & 16,7 & 1,5 & 0,042 \\
\hline Contorno del brazo & 27,9 & 3,8 & 29,7 & 3,6 & 29,6 & 4,1 & 0,078 \\
\hline Peso & 66,1 & 12,8 & 71,7 & 15,0 & 75,7 & 18,1 & 0,036 \\
\hline Grasa corporal & 21,0 & 9,1 & 22,8 & 7,3 & 25,5 & 8,7 & 0,138 \\
\hline Masa muscular & 49,5 & 10,4 & 52,3 & 11,0 & 53,3 & 12,4 & 0,348 \\
\hline Masa ósea & 2,6 & 0,5 & 2,8 & 0,6 & 2,8 & 0,6 & 0,318 \\
\hline BMI & 23,2 & 3,7 & 24,7 & 3,7 & 26,6 & 4,6 & 0,005 \\
\hline Peso ideal & 60,0 & 7,9 & 60,7 & 8,0 & 59,1 & 7,0 & 0,780 \\
\hline Peso ideal corregido & 62,5 & 9,8 & 63,7 & 10,1 & 63,6 & 8,9 & 0,843 \\
\hline Frecuencia cardiaca en reposo & 69,8 & 8,2 & 63,5 & 9,0 & 70,0 & 9,1 & 0,007 \\
\hline Frecuencia cardiaca real & 80,9 & 14,2 & 76,4 & 11,5 & 83,2 & 13,0 & 0,191 \\
\hline Presión arterial sistólica & 129,4 & 15,2 & 129,7 & 13,1 & 129,9 & 13,9 & 0,991 \\
\hline Presión arterial diastólica & 78,7 & 9,8 & 82,4 & 8,4 & 84,8 & 10,6 & 0,042 \\
\hline Frecuencia respiratoria & 17,0 & 1,4 & 16,5 & 1,7 & 15,9 & 1,7 & 0,025 \\
\hline
\end{tabular}


Tabla 16. Descripción de los parámetros por subgrupo (continuación)

\begin{tabular}{|l|c|c|c|c|c|c|c|}
\hline Temperatura & 36,8 & 0,4 & 36,5 & 0,5 & 36,4 & 0,6 & $<0,001$ \\
\hline Hemoglobina & 13,6 & 1,6 & 13,6 & 1,5 & 13,9 & 1,4 & 0,647 \\
\hline Índice de perfusión & 3,0 & 2,9 & 4,0 & 3,3 & 3,1 & 2,3 & 0,314 \\
\hline Saturación de oxígeno & 98,4 & 1,3 & 98,2 & 1,5 & 97,8 & 1,6 & 0,253 \\
\hline$* p<0,05$ Emergencias versus resto & & & & &
\end{tabular}

\subsection{Descripción de los parámetros horarios y ambientales de la prueba}

En las Tablas 17 y 18 se recoge la descripción de los parámetros horarios y ambientales de la prueba (caso clínico). No se encontraron diferencias en la distribución horaria de la realización de la prueba ni en sus parámetros ambientales, entre los grupos de estudio ( $p=0,419)$.

Tabla 17. Distribución de la hora de realización de la prueba en los grupos de estudio

\begin{tabular}{|c|c|c|c|c|c|c|c|c|c|}
\hline \multicolumn{10}{|c|}{ Subgrupo } \\
\hline & \multicolumn{2}{|c|}{ Total } & \multicolumn{2}{|c|}{ Pregrado } & \multicolumn{2}{|c|}{$\begin{array}{l}\text { Urgencias } \\
\text { Hospitalarias }\end{array}$} & \multicolumn{2}{|c|}{$\begin{array}{c}\text { Emergencias } \\
\text { Sanitarias }\end{array}$} & \\
\hline & N. ${ }^{\circ}$ & $\%$ & N. ${ }^{\circ}$ & $\%$ & N. ${ }^{\circ}$ & $\%$ & N. ${ }^{\circ}$ & $\%$ & \\
\hline \multirow{4}{*}{$\begin{array}{l}\text { Hora } \\
\text { de la } \\
\text { Prueba }\end{array}$} & $10: 00$ & 13 & $13,5 \%$ & 10 & $20,4 \%$ & 2 & $7,7 \%$ & 1 & $4,8 \%$ \\
\hline & $12: 00$ & 32 & $33,3 \%$ & 15 & $30,6 \%$ & 11 & $42,3 \%$ & 6 & $28,6 \%$ \\
\hline & $16: 00$ & 22 & $22,9 \%$ & 9 & $18,4 \%$ & 6 & $23,1 \%$ & 7 & $33,3 \%$ \\
\hline & $18: 00$ & 29 & $30,2 \%$ & 15 & $30,6 \%$ & 7 & $26,9 \%$ & 7 & $33,3 \%$ \\
\hline
\end{tabular}

Tabla 18. Descripción de los datos de temperatura y humedad en el momento de la prueba

\begin{tabular}{|c|c|c|c|}
\hline & & Temperatura & Humedad \\
\hline \multirow{4}{*}{$\begin{array}{l}\text { Media } \\
\text { DE } \\
\text { Mínimo } \\
\text { Máximo }\end{array}$} & & 33,66 & 51,16 \\
\hline & & 27,18 & 1,54 \\
\hline & & 29,10 & 48,90 \\
\hline & & 32,50 & 54,20 \\
\hline \multirow[t]{3}{*}{ Percentiles } & 25 & 30,30 & 50,23 \\
\hline & Mediana & 30,90 & 51,00 \\
\hline & 75 & 31,50 & 52,58 \\
\hline
\end{tabular}




\subsection{Variaciones de parámetros fisiológicos}

En la Tabla 19 se recogen los parámetros fisiológicos basales y posteriores a la prueba. Se detectan cambios significativos en todos ellos, pero no se han encontrado diferencias significativas por grupos y subgrupos estudiados (Tablas 20 y 21 ).

Tabla 19. Variaciones de parámetros fisiológicos en el global de la muestra

\begin{tabular}{|c|c|c|c|c|c|c|}
\hline \multirow[b]{2}{*}{ Frecuencia cardiaca posterior } & \multirow{2}{*}{$\begin{array}{l}\text { Media } \\
91,59\end{array}$} & \multirow{2}{*}{$\begin{array}{c}\text { DE } \\
13,06\end{array}$} & \multicolumn{3}{|c|}{$\begin{array}{l}\text { Diferencia media } \\
\text { IC95\% }\end{array}$} & \multirow{2}{*}{$\begin{array}{c}p \\
<0,001\end{array}$} \\
\hline & & & 11,43 & 9,18 & 13,68 & \\
\hline Frecuencia cardiaca real & 80,17 & 13,37 & & & & \\
\hline Presión arterial sistólica posterior & 125,19 & 15,06 & $-4,36$ & $-6,95$ & $-1,78$ & 0,001 \\
\hline Presión arterial sistólica & 129,55 & 14,26 & & & & \\
\hline Presión arterial diastólica posterior & 79,46 & 9,31 & $-1,59$ & $-3,22$ & 0,03 & 0,054 \\
\hline Presión arterial diastólica & 81,05 & 9,83 & & & & \\
\hline Frecuencia respiratoria posterior & 17,30 & 2,14 & 0,72 & 0,22 & 1,22 & 0,005 \\
\hline Frecuencia respiratoria & 16,58 & 1,59 & & & & \\
\hline Temperatura posterior & 37,21 & 0,42 & 0,56 & 0,46 & 0,65 & $<0,001$ \\
\hline Temperatura & 36,65 & 0,52 & & & & \\
\hline Hemoglobina posterior & 14,16 & 1,48 & 0,48 & 0,26 & 0,70 & $<0,001$ \\
\hline Hemoglobina & 13,68 & 1,48 & & & & \\
\hline Índice de perfusión posterior & 6,58 & 3,49 & 3,28 & 2,52 & 4,04 & $<0,001$ \\
\hline Índice de perfusión & 3,29 & 2,90 & & & & \\
\hline Saturación de oxígeno posterior & 96,25 & 1,24 & $-1,97$ & $-2,26$ & $-1,68$ & $<0,001$ \\
\hline Saturación de oxígeno & 98,22 & 1,45 & & & & \\
\hline
\end{tabular}


Tabla 20. Variaciones en los parámetros fisiológicos por subgrupos de estudio

\begin{tabular}{|c|c|c|c|c|}
\hline & & Media & $\mathrm{DE}$ & $p$ \\
\hline \multirow{3}{*}{ Variación FC } & Pregrado & 11,78 & 11,61 & 0,860 \\
\hline & Urgencias Hospitalarias & 11,73 & 11,42 & \\
\hline & Emergencias Sanitarias & 10,24 & 9,92 & \\
\hline \multirow{3}{*}{ Variación PAS } & Pregrado & $-4,31$ & 13,20 & 0,997 \\
\hline & Urgencias Hospitalarias & $-4,54$ & 11,50 & \\
\hline & Emergencias Sanitarias & $-4,29$ & 13,77 & \\
\hline \multirow{3}{*}{ Variación PAD } & Pregrado & $-1,41$ & 9,06 & 0,918 \\
\hline & Urgencias Hospitalarias & $-1,42$ & 7,22 & \\
\hline & Emergencias Sanitarias & $-2,24$ & 6,45 & \\
\hline \multirow{3}{*}{ Variación FR } & Pregrado & 0,29 & 2,28 & 0,129 \\
\hline & Urgencias Hospitalarias & 0,85 & 2,33 & \\
\hline & Emergencias Sanitarias & 1,57 & 2,89 & \\
\hline \multirow{3}{*}{ Variación Temp } & Pregrado & 0,51 & 0,39 & 0,555 \\
\hline & Urgencias Hospitalarias & 0,60 & 0,54 & \\
\hline & Emergencias Sanitarias & 0,61 & 0,47 & \\
\hline \multirow{3}{*}{ Variación HB } & Pregrado & 0,32 & 1,16 & 0,188 \\
\hline & Urgencias Hospitalarias & 0,80 & 0,86 & \\
\hline & Emergencias Sanitarias & 0,45 & 1,07 & \\
\hline \multirow{3}{*}{ Variación Índice de Perfusión } & Pregrado & 3,56 & 4,10 & 0,609 \\
\hline & Urgencias Hospitalarias & 2,66 & 4,06 & \\
\hline & Emergencias Sanitarias & 3,41 & 2,30 & \\
\hline \multirow{3}{*}{ Variación SAT } & Pregrado & $-2,08$ & 1,26 & 0,267 \\
\hline & Urgencias Hospitalarias & $-2,12$ & 1,56 & \\
\hline & Emergencias Sanitarias & $-1,52$ & 1,57 & \\
\hline
\end{tabular}


Tabla 21. Variaciones en los parámetros fisiológicos por subgrupos y sexo

\begin{tabular}{|c|c|c|c|c|c|}
\hline Sexo & & & Media & DE & p \\
\hline \multirow{24}{*}{ Hombre } & \multirow{3}{*}{ Variación FC } & Pregrado & 18,00 & 11,51 & 0,252 \\
\hline & & Urgencias Hospitalarias & 13,08 & 10,07 & \\
\hline & & Emergencias Sanitarias & 11,80 & 8,26 & \\
\hline & \multirow{3}{*}{ Variación PAS } & Pregrado & $-3,78$ & 16,34 & 0,946 \\
\hline & & Urgencias Hospitalarias & $-4,25$ & 12,94 & \\
\hline & & Emergencias Sanitarias & $-2,30$ & 10,87 & \\
\hline & \multirow{3}{*}{ Variación PAD } & Pregrado & $-2,33$ & 8,54 & 0,961 \\
\hline & & Urgencias Hospitalarias & $-2,92$ & 6,58 & \\
\hline & & Emergencias Sanitarias & $-2,00$ & 7,54 & \\
\hline & \multirow{3}{*}{ Variación FR } & Pregrado & $-0,17$ & 1,86 & 0,066 \\
\hline & & Urgencias Hospitalarias & 1,17 & 2,66 & \\
\hline & & Emergencias Sanitarias & 2,40 & 3,95 & \\
\hline & \multirow{3}{*}{ Variación Temp } & Pregrado & 0,57 & 0,41 & 0,585 \\
\hline & & Urgencias Hospitalarias & 0,74 & 0,67 & \\
\hline & & Emergencias Sanitarias & 0,71 & 0,35 & \\
\hline & \multirow{3}{*}{ Variación HB } & Pregrado & 0,56 & 1,14 & 0,850 \\
\hline & & Urgencias Hospitalarias & 0,70 & 0,78 & \\
\hline & & Emergencias Sanitarias & 0,77 & 0,88 & \\
\hline & \multirow{3}{*}{$\begin{array}{l}\text { Variación Índice } \\
\text { de Perfusión }\end{array}$} & Pregrado & 3,88 & 5,15 & 0,615 \\
\hline & & Urgencias Hospitalarias & 2,47 & 2,88 & \\
\hline & & Emergencias Sanitarias & 3,78 & 2,49 & \\
\hline & \multirow{3}{*}{ Variación SAT } & Pregrado & $-1,83$ & 1,10 & 0,681 \\
\hline & & Urgencias Hospitalarias & $-1,67$ & 1,07 & \\
\hline & & Emergencias Sanitarias & $-1,40$ & 1,65 & \\
\hline
\end{tabular}


Tabla 21. Variaciones en los parámetros fisiológicos por subgrupos y sexo (continuación)

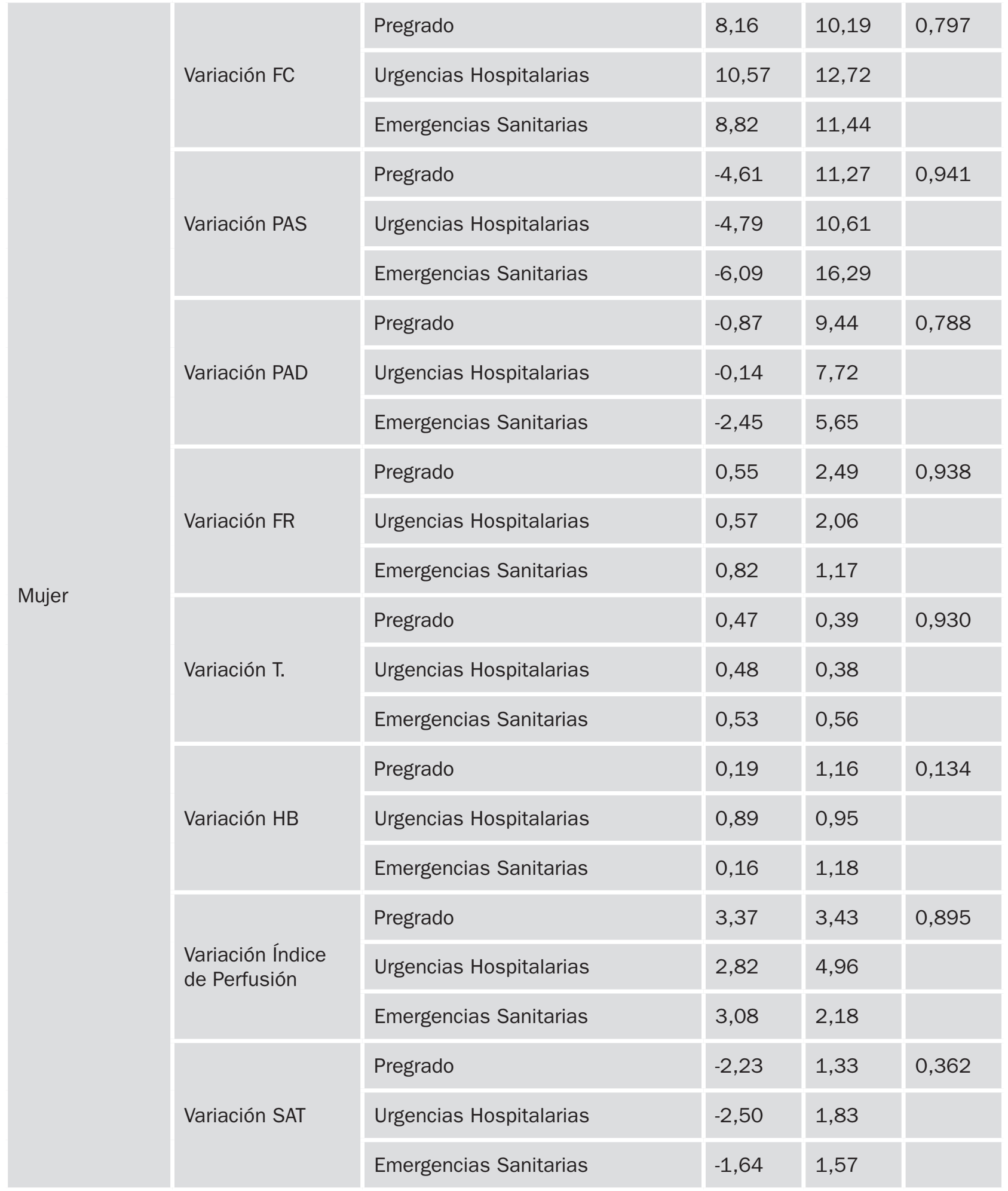

Del total de la muestra, un 10,41\% de sujetos (10 de 96), presentó una temperatura timpánica final menor que la inicial, es decir: un 89,65\% (86 de 96) tuvieron una temperatura final superior a la inicial. Para este parámetro no se han encontrado diferencias significativas por sexo, grupo o subgrupo. 


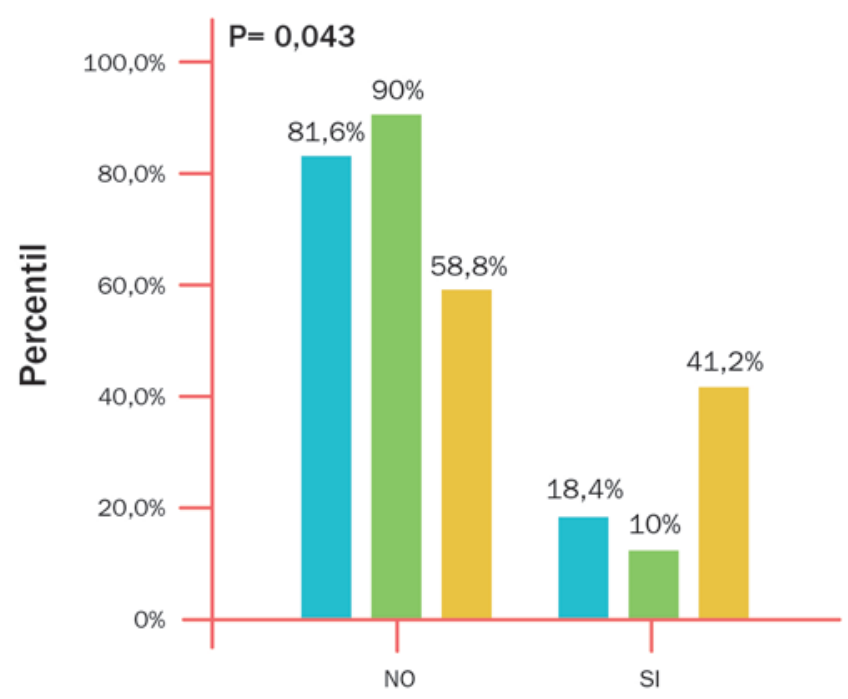

No tolera temperatura final 1 grado
Actividad Física
Actividad Física Baja (sedentario)
Actividad Física Moderada
Actividad Física Alta

Figura 18. Relación entre el aumento de la temperatura corporal y el nivel de actividad física

La variación de las constantes vitales no presentó diferencias significativas por grupos o subgrupos de estudio, pero se pudo observar un patrón uniforme en toda la muestra, que fue el siguiente: más FC posterior que inicial, menos TAS y TAD final que las iniciales, mayor FR, temperatura, hemoglobina total, e IP final que inicial, y menos saturación de oxígeno final que inicial.

Del total de la muestra, un 19,8\% (19 de 96) presentaron una alteración térmica positiva de $1^{\circ} \mathrm{C}$ o más, y del total de sujetos con elevación de la temperatura $(n=86)$, un $20,93 \%$ (18 de 86), presentaron una elevación de la temperatura mayor de $1^{\circ} \mathrm{C}$ o más, no encontrándose diferencias por sexo, grupo o subgrupo; 7 individuos presentaron un nivel de actividad alto, y 8 individuos un nivel de actividad bajo, siendo el grupo más estable en cuanto a la termorregulación, así como el que presenta menos extremos térmicos, el grupo de personas con un nivel de actividad física moderada (ver Figura 18).

Un 28\% de los sujetos de estudio (27 de 96) presentaron más TAS final que inicial, un $42 \%$ más TAD final que inicial (40 de 96), y un 13\% ambas cifras de TA elevadas (12 de 96). De los sujetos que de forma global presentaron elevaciones de TAS y TAD final respecto a la basal, 11 de 12 presentaron un incremento de la FC final respecto a la inicial, y 9 de 11 elevaciones de la FR final respecto a la inicial. 


\subsection{Variaciones antropométricas}

En cuanto a las variaciones antropométricas, estas se recogen en la Tabla 22 para el total de la muestra. Se detectaron pérdidas de peso de 0,15 kg (IC95\% -0,28;-0,01), de grasa corporal -1,38 (IC95\% -1,85;-0,90) y de IMC 0,09 kg/m² (IC95\% -0,16;-0,02). La masa muscular se incrementó en 0,71 (IC95\% 0,37;1,06) y el agua total en 1,23 (IC95\% 0,86;1,60).

Al analizarlo por grupos (ver Tabla 23), se encontraron diferencias entre médico y enfermero con respecto a los grupos de pregrado en cuanto a la pérdida de grasa corporal ( $p=0,041$ ).

Por otro lado, en la Tabla 24 se describen los cambios dentro de cada grupo de las variaciones estudiadas. Estas variaciones por subgrupo estudiado se recogen en la Tabla 25. Se observa que las diferencias de variación de grasa corporal fueron mayores en las emergencias sanitarias (-2,34 IC95\% -3,55; -1,14) que en el resto de los grupos.

Para evaluar las diferencias por sexo se estratificaron las variaciones dentro de los subgrupos (ver Tabla 26), encontrándose que el grupo de mayor variación en las emergencias sanitarias eran las mujeres (-3,08 IC95\% -5,17;-1,00).

Tabla 22. Variaciones antropométricas del global de la muestra

\begin{tabular}{|c|c|c|c|c|}
\hline \multicolumn{5}{|c|}{ IC95\% } \\
\hline & $\begin{array}{l}\text { Diferencia } \\
\text { final-inicial }\end{array}$ & Inferior & Superior & $p$ \\
\hline Peso & $-0,15$ & $-0,28$ & $-0,01$ & 0,034 \\
\hline Grasa corporal & $-1,38$ & $-1,85$ & $-0,90$ & $<0,001$ \\
\hline Masa muscular & 0,71 & 0,37 & 1,06 & $<0,001$ \\
\hline BMI & $-0,09$ & $-0,16$ & $-0,02$ & 0,008 \\
\hline Agua total & 1,23 & 0,86 & 1,60 & $<0,001$ \\
\hline
\end{tabular}


Tabla 23. Variaciones antropométricas comparando los grupos de estudio

\begin{tabular}{|c|c|c|c|c|c|c|c|c|c|}
\hline \multicolumn{10}{|c|}{ Grupo } \\
\hline & \multicolumn{2}{|c|}{$\begin{array}{l}\text { Pregrado } \\
\text { Enfermería }\end{array}$} & \multicolumn{2}{|c|}{$\begin{array}{l}\text { Pregrado } \\
\text { Medicina }\end{array}$} & \multicolumn{2}{|c|}{ Enfermero } & \multicolumn{2}{|c|}{ Médico } & \multirow[t]{2}{*}{$p$} \\
\hline & Media & $\mathrm{DE}$ & Media & $\mathrm{DE}$ & Media & $\mathrm{DE}$ & Media & $\mathrm{DE}$ & \\
\hline Variación peso & $-0,27$ & 0,56 & $-0,04$ & 1,07 & $-0,07$ & 0,41 & $-0,23$ & 0,41 & 0,996 \\
\hline $\begin{array}{l}\text { Variación grasa } \\
\text { corporal }\end{array}$ & $-0,85$ & 2,05 & $-0,83$ & 2,98 & $-1,93$ & 1,81 & $-1,94$ & 2,35 & 0,041 \\
\hline $\begin{array}{l}\text { Variación masa } \\
\text { muscular }\end{array}$ & 0,38 & 1,74 & 0,39 & 2,25 & 1,03 & 0,97 & 1,08 & 1,53 & 0,140 \\
\hline Variación BMI & $-0,11$ & 0,21 & $-0,08$ & 0,15 & $-0,01$ & 0,18 & $-0,18$ & 0,62 & 0,284 \\
\hline Variación agua total & 1,07 & 2,03 & 1,25 & 1,62 & 1,48 & 1,44 & 1,11 & 2,25 & 0,924 \\
\hline
\end{tabular}

Tabla 24. Variaciones antropométricas por grupos de estudio

\begin{tabular}{|c|c|c|c|c|c|}
\hline \multicolumn{6}{|c|}{ IC95\% } \\
\hline & & $\begin{array}{l}\text { Diferencia } \\
\text { final-inicial }\end{array}$ & Inferior & Superior & $\mathrm{p}$ \\
\hline \multirow{5}{*}{$\begin{array}{l}\text { Pregrado } \\
\text { Enfermería }\end{array}$} & Variación peso & $-0,27$ & $-0,51$ & $-0,03$ & 0,027 \\
\hline & Variación grasa corporal & $-0,85$ & $-1,71$ & 0,02 & 0,055 \\
\hline & Variación masa muscular & 0,38 & $-0,35$ & 1,12 & 0,291 \\
\hline & Variación IMC & $-0,11$ & $-0,20$ & $-0,02$ & 0,021 \\
\hline & Variación agua total & 1,07 & 0,21 & 1,93 & 0,017 \\
\hline \multirow{5}{*}{$\begin{array}{l}\text { Pregrado } \\
\text { Medicina }\end{array}$} & Variación peso & $-0,04$ & $-0,48$ & 0,40 & 0,854 \\
\hline & Variación grasa corporal & $-0,83$ & $-2,06$ & 0,40 & 0,178 \\
\hline & Variación masa muscular & 0,39 & $-0,54$ & 1,32 & 0,393 \\
\hline & Variación IMC & $-0,08$ & $-0,14$ & $-0,02$ & 0,008 \\
\hline & Variación agua total & 1,25 & 0,58 & 1,92 & 0,001 \\
\hline \multirow{5}{*}{ Enfermero } & Variación peso & $-0,07$ & $-0,24$ & 0,10 & 0,411 \\
\hline & Variación grasa corporal & $-1,93$ & $-2,68$ & $-1,19$ & $<0,001$ \\
\hline & Variación masa muscular & 1,03 & 0,63 & 1,43 & $<0,001$ \\
\hline & Variación IMC & $-0,01$ & $-0,08$ & 0,06 & 0,822 \\
\hline & Variación agua total & 1,48 & 0,88 & 2,07 & $<0,001$ \\
\hline
\end{tabular}


Tabla 24. Variaciones antropométricas por grupos de estudio (continuación)

\begin{tabular}{|l|l|c|c|c|c|}
\hline & Variación peso & $-0,23$ & $-0,41$ & $-0,04$ & 0,018 \\
\hline & Variación grasa corporal & $-1,94$ & $-2,98$ & $-0,90$ \\
\hline \multirow{2}{*}{ Médico } & Variación masa muscular & 1,08 & 0,40 & 1,75 & 0,003 \\
\hline & Variación IMC & $-0,18$ & $-0,46$ & 0,09 & 0,184 \\
\hline
\end{tabular}

Tabla 25. Variaciones antropométricas por subgrupos de estudio

\begin{tabular}{|c|c|c|c|c|c|}
\hline \multicolumn{6}{|c|}{ IC95\% } \\
\hline & & Media & Inferior & Superior & $p$ \\
\hline \multirow{5}{*}{ Pregrado } & Variación peso & $-0,15$ & $-0,40$ & 0,09 & 0,219 \\
\hline & Variación grasa corporal & $-0,84$ & $-1,57$ & $-0,11$ & 0,025 \\
\hline & Variación masa muscular & 0,39 & $-0,19$ & 0,96 & 0,181 \\
\hline & Variación IMC & $-0,10$ & $-0,15$ & $-0,04$ & 0,001 \\
\hline & Variación agua total & 1,16 & 0,64 & 1,68 & $<0,001$ \\
\hline \multirow{5}{*}{ Urgencias Hospitalarias } & Variación peso & $-0,14$ & $-0,32$ & 0,04 & 0,123 \\
\hline & Variación grasa corporal & $-1,61$ & $-2,17$ & $-1,05$ & $<0,001$ \\
\hline & Variación masa muscular & 0,94 & 0,54 & 1,34 & $<0,001$ \\
\hline & Variación IMC & $-0,02$ & $-0,08$ & 0,04 & 0,526 \\
\hline & Variación agua total & 1,28 & 0,67 & 1,89 & $<0,001$ \\
\hline \multirow{5}{*}{ Emergencias Sanitarias } & Variación peso & $-0,15$ & $-0,32$ & 0,03 & 0,094 \\
\hline & Variación grasa corporal & $-2,34$ & $-3,55$ & $-1,14$ & 0,001 \\
\hline & Variación masa muscular & 1,19 & 0,50 & 1,88 & 0,002 \\
\hline & Variación IMC & $-0,18$ & $-0,47$ & 0,12 & 0,225 \\
\hline & Variación agua total & 1,34 & 0,32 & 2,36 & 0,013 \\
\hline
\end{tabular}


Tabla 26. Variaciones antropométricas por subgrupo y sexo

\begin{tabular}{|c|c|c|c|c|c|c|}
\hline \multicolumn{7}{|c|}{ IC95\% } \\
\hline Sexo & & & Media & Inferior & Superior & p \\
\hline \multirow{15}{*}{ Hombre } & \multirow{3}{*}{ Variación peso } & Pregrado & $-0,42$ & $-0,71$ & $-0,13$ & 0,799 \\
\hline & & Urgencias Hospitalarias & $-0,36$ & $-0,66$ & $-0,06$ & \\
\hline & & Emergencias Sanitarias & $-0,29$ & $-0,54$ & $-0,04$ & \\
\hline & \multirow{3}{*}{$\begin{array}{l}\text { Variación grasa } \\
\text { corporal }\end{array}$} & Pregrado & $-0,41$ & $-1,89$ & 1,07 & 0,422 \\
\hline & & Urgencias Hospitalarias & $-1,31$ & $-2,37$ & $-0,25$ & \\
\hline & & Emergencias Sanitarias & $-1,53$ & $-2,85$ & $-0,21$ & \\
\hline & \multirow{3}{*}{$\begin{array}{l}\text { Variación masa } \\
\text { muscular }\end{array}$} & Pregrado & $-0,13$ & $-1,39$ & 1,13 & 0,200 \\
\hline & & Urgencias Hospitalarias & 0,78 & $-0,02$ & 1,57 & \\
\hline & & Emergencias Sanitarias & 1,36 & $-0,21$ & 2,93 & \\
\hline & \multirow{3}{*}{ Variación IMC } & Pregrado & $-0,14$ & $-0,25$ & $-0,03$ & 0,442 \\
\hline & & Urgencias Hospitalarias & $-0,10$ & $-0,19$ & $-0,01$ & \\
\hline & & Emergencias Sanitarias & $-0,35$ & $-1,00$ & 0,30 & \\
\hline & \multirow{3}{*}{$\begin{array}{l}\text { Variación agua } \\
\text { total }\end{array}$} & Pregrado & 1,38 & 0,57 & 2,20 & 0,904 \\
\hline & & Urgencias Hospitalarias & 1,08 & $-0,18$ & 2,35 & \\
\hline & & Emergencias Sanitarias & 1,06 & $-1,15$ & 3,27 & \\
\hline \multirow{15}{*}{ Mujer } & \multirow{3}{*}{ Variación peso } & Pregrado & 0,00 & $-0,35$ & 0,35 & 0,972 \\
\hline & & Urgencias Hospitalarias & 0,05 & $-0,14$ & 0,24 & \\
\hline & & Emergencias Sanitarias & $-0,02$ & $-0,28$ & 0,24 & \\
\hline & \multirow{3}{*}{$\begin{array}{l}\text { Variación grasa } \\
\text { corporal }\end{array}$} & Pregrado & $-1,08$ & $-1,91$ & $-0,25$ & 0,044 \\
\hline & & Urgencias Hospitalarias & $-1,86$ & $-2,50$ & $-1,23$ & \\
\hline & & Emergencias Sanitarias & $-3,08$ & $-5,17$ & $-1,00$ & \\
\hline & \multirow{3}{*}{$\begin{array}{l}\text { Variación masa } \\
\text { muscular }\end{array}$} & Pregrado & 0,69 & 0,11 & 1,27 & 0,540 \\
\hline & & Urgencias Hospitalarias & 1,09 & 0,67 & 1,50 & \\
\hline & & Emergencias Sanitarias & 1,04 & 0,69 & 1,38 & \\
\hline & \multirow{3}{*}{ Variación IMC } & Pregrado & $-0,07$ & $-0,12$ & $-0,01$ & 0,040 \\
\hline & & Urgencias Hospitalarias & 0,05 & $-0,02$ & 0,12 & \\
\hline & & Emergencias Sanitarias & $-0,02$ & $-0,11$ & 0,08 & \\
\hline & \multirow{3}{*}{$\begin{array}{l}\text { Variación agua } \\
\text { total }\end{array}$} & Pregrado & 1,03 & 0,33 & 1,74 & 0,533 \\
\hline & & Urgencias Hospitalarias & 1,44 & 0,88 & 2,01 & \\
\hline & & Emergencias Sanitarias & 1,59 & 0,82 & 2,36 & \\
\hline
\end{tabular}




\subsection{Estudio de la actividad física}

En las Tablas 27 y 28 se recogen las frecuencias de la actividad física por grupos de estudio y subgrupos. La actividad diaria fue significativamente diferente entre los grupos, destacando que los enfermeros (88,0\%), frente al pregrado de medicina (48,0\%), tenían una actividad diaria activa mayor $(p<0,05)$. Esta misma diferencia se observa por subgrupos, siendo la actividad física diaria activa de un $80,8 \%$ en los miembros de urgencias hospitalarias y de un $81,0 \%$ en los de emergencias sanitarias, comparado con los sujetos de pregrado que solo la tenían en un $51,0 \%(p=0,025)$.

Tabla 27. Distribución de frecuencias de la actividad física por grupos de estudio

\begin{tabular}{|c|c|c|c|c|c|c|c|c|c|c|}
\hline \multicolumn{11}{|c|}{ Grupo } \\
\hline & & \multicolumn{2}{|c|}{$\begin{array}{l}\text { Pregrado } \\
\text { Enfermería } \\
\qquad \mathbf{N}=24\end{array}$} & \multicolumn{2}{|c|}{$\begin{array}{l}\text { Pregrado } \\
\text { Medicina } \\
\qquad N=25\end{array}$} & \multicolumn{2}{|c|}{$\begin{array}{l}\text { Enfermero } \\
\qquad \mathbf{N}=\mathbf{2 5}\end{array}$} & \multicolumn{2}{|c|}{$\begin{array}{l}\text { Médico } \\
\text { N=22 }\end{array}$} & $p$ \\
\hline & & $\mathrm{N}^{0}$ & $\%$ & $\mathrm{~N}^{\circ}$ & $\%$ & $\mathrm{~N}^{\circ}$ & $\%$ & $\mathrm{~N}^{\circ}$ & $\%$ & \\
\hline \multirow{3}{*}{$\begin{array}{l}\text { Actividad } \\
\text { diaria }\end{array}$} & Sedentario & 9 & 37,5 & 9 & 36,0 & 0 & 0,0 & 5 & 22,7 & 0,022 \\
\hline & Activo & 13 & 54,2 & 12 & 48,0 & 22 & $88,0 *$ & 16 & 72,7 & \\
\hline & Intenso & 2 & 8,3 & 4 & 16,0 & 3 & 12,0 & 1 & 4,5 & \\
\hline \multirow{3}{*}{$\begin{array}{l}\text { Actividad } \\
\text { física }\end{array}$} & $\begin{array}{l}\text { Actividad } \\
\text { física baja } \\
\text { (sedentario) }\end{array}$ & 16 & 66,7 & 8 & 32,0 & 11 & 44,0 & 14 & 63,6 & 0,247 \\
\hline & $\begin{array}{l}\text { Actividad física } \\
\text { moderada }\end{array}$ & 5 & 20,8 & 11 & 44,0 & 9 & 36,0 & 5 & 22,7 & \\
\hline & $\begin{array}{l}\text { Actividad física } \\
\text { alta }\end{array}$ & 3 & 12,5 & 6 & 24,0 & 5 & 20,0 & 3 & 13,6 & \\
\hline \multirow{3}{*}{ Motivación } & Baja & 3 & 12,5 & 1 & 4,0 & 0 & 0,0 & 0 & 0,0 & 0,083 \\
\hline & Media & 8 & 33,3 & 8 & 32,0 & 5 & 20,0 & 11 & 50,0 & \\
\hline & Alta & 13 & 54,2 & 16 & 64,0 & 20 & 80,0 & 11 & 50,0 & \\
\hline
\end{tabular}


Tabla 28. Distribución de frecuencias de la actividad física por grupos de estudio

\begin{tabular}{|c|c|c|c|c|c|c|c|c|}
\hline \multicolumn{9}{|c|}{ Subgrupo } \\
\hline & & \multicolumn{2}{|c|}{ Pregrado } & \multicolumn{2}{|c|}{$\begin{array}{c}\text { Urgencias } \\
\text { Hospitalarias }\end{array}$} & \multicolumn{2}{|c|}{$\begin{array}{c}\text { Emergencias } \\
\text { Sanitarias }\end{array}$} & \\
\hline & & N. ${ }^{\circ}$ & $\%$ & N. ${ }^{\circ}$ & $\%$ & N. ${ }^{\circ}$ & $\%$ & $p$ \\
\hline \multirow{3}{*}{ Actividad diaria } & Sedentario & 18 & 36,7 & 2 & 7,7 & 3 & 14,3 & 0,025 \\
\hline & Activo & 25 & 51,0 & 21 & 80,8 & 17 & 81,0 & \\
\hline & Intenso & 6 & 12,2 & 3 & 11,5 & 1 & 4,8 & \\
\hline \multirow{3}{*}{ Actividad física } & Baja (sedentario) & 24 & 49,0 & 16 & 61,5 & 9 & 42,9 & 0,525 \\
\hline & Moderada & 16 & 32,7 & 5 & 19,2 & 9 & 42,9 & \\
\hline & Alta & 9 & 18,4 & 5 & 19,2 & 3 & 14,3 & \\
\hline \multirow{3}{*}{ Motivación } & Baja & 4 & 8,2 & 0 & 0,0 & 0 & 0,0 & 0,337 \\
\hline & Media & 16 & 32,7 & 10 & 38,5 & 6 & 28,6 & \\
\hline & Alta & 29 & 59,2 & 16 & 61,5 & 15 & 71,4 & \\
\hline
\end{tabular}

Tras realizar el cuestionario de actividad física IPAQ a todos los voluntarios, se pudo constatar que la mayoría de los sujetos de la muestra (51\%) presentaban un nivel de actividad bajo (sedentario), y que, precisamente, el $53,1 \%$ de estos sujetos con bajo nivel de actividad presentaron más FC durante la realización del masaje cardiaco externo durante el caso clínico que su umbral anaeróbico calculado mediante la cicloergometría, frente al $23,3 \%$ de los voluntarios con actividad física moderada y el $23,5 \%$ de los voluntarios con actividad física alta $(p=0,012)$.

En las Figuras 19 y 20 se recogen las frecuencias de la actividad física por sexo y por subgrupo de profesionales o estudiantes. La actividad diaria según el cuestionario IPAQ fue ligeramente superior en hombres frente a mujeres, $y$ en estudiantes frente a profesionales $(p=0,816$ y 0,918 respectivamente). 


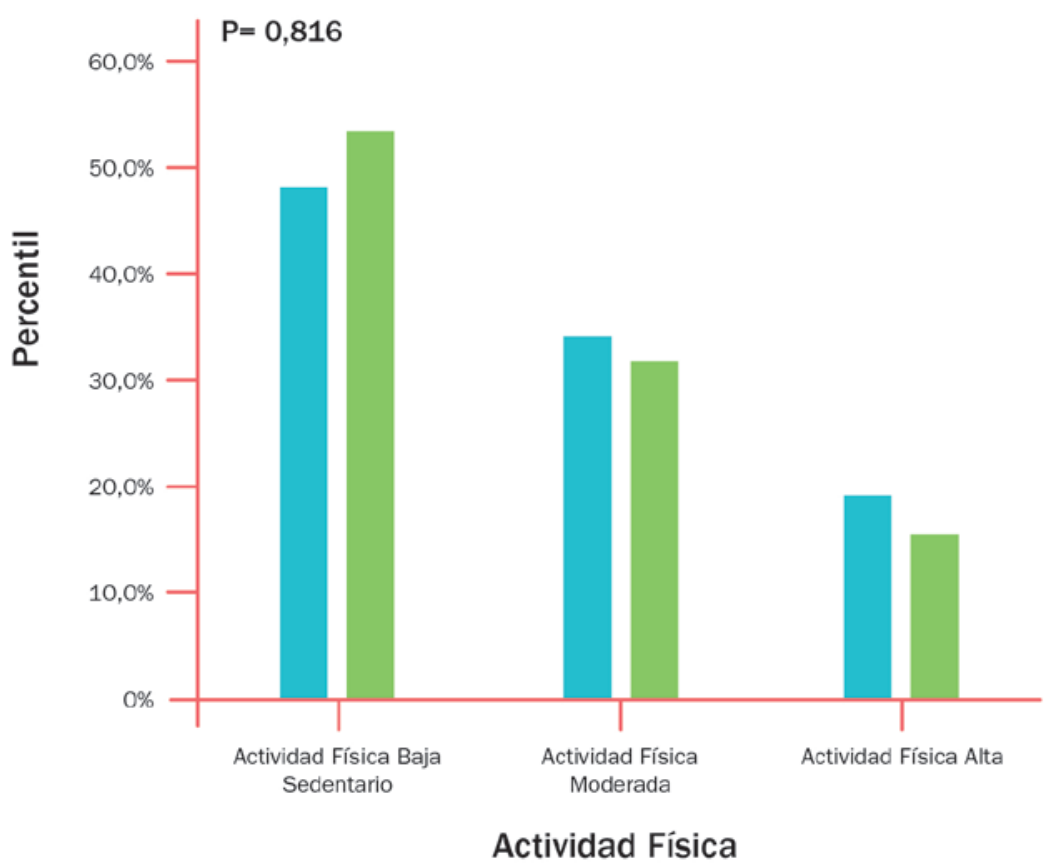

Sexo

Hombre

Mujer

Figura 19. Distribución de frecuencias de actividad física por sexo

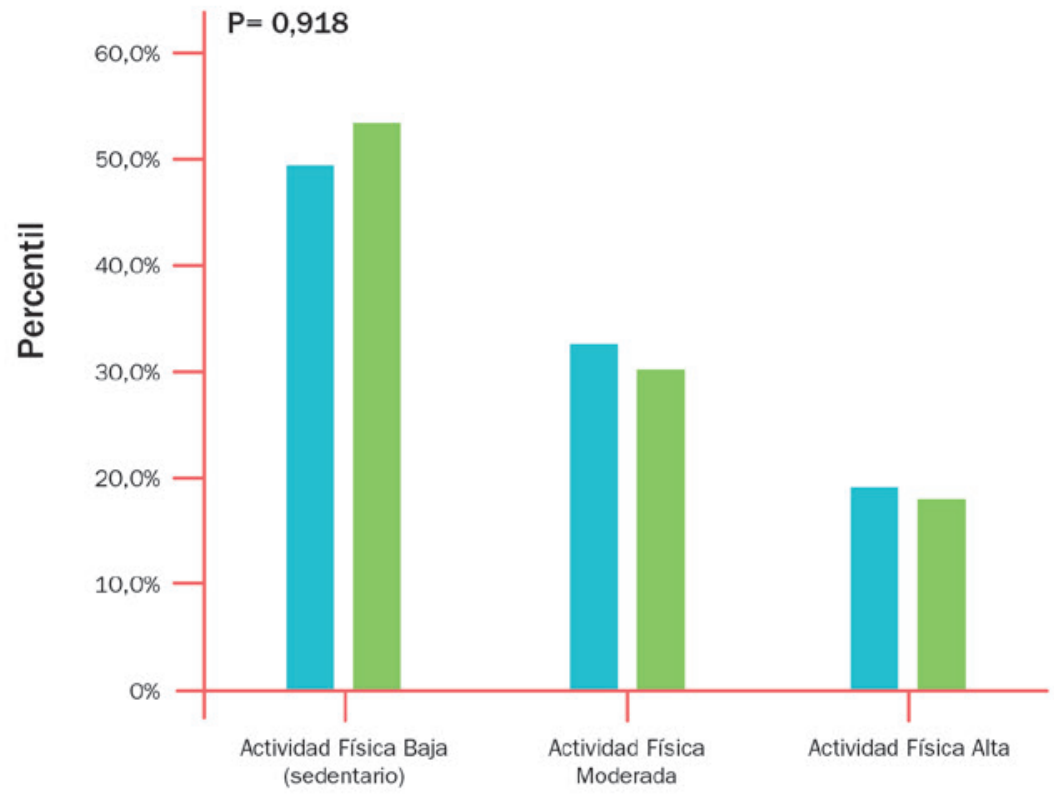

Actividad Física

Grupo profesional

Estudiante

Profesional

Figura 20. Distribución de frecuencias de actividad física por subgrupo de estudio: estudiantes o profesionales 


\subsection{Relación entre frecuencias cardiacas}

En la Tabla 29 se recogen las diferencias entre grupos de estudio. La frecuencia cardiaca máxima de Tanaka $(p<0,001)$, el umbral anaeróbico teórico $(p<0,001)$, la frecuencia cardiaca en el umbral anaeróbico $(p<0,001)$ y la presión arterial sistólica en el esfuerzo $(p=0,032)$ fueron diferentes por grupo, encontrándose diferencias entre los grupos de pregrado y los enfermeros o médicos.

En la Tabla 30 se recogen las diferencias entre subgrupos de estudio. La frecuencia cardiaca máxima de Tanaka $(p<0,001)$, el umbral anaeróbico teórico $(p<0,001)$, la frecuencia cardiaca en el umbral anaeróbico $(p<0,001)$ fueron diferentes por subgrupo, encontrándose las diferencias entre los grupos de pregrado y el resto.

Tabla 29. Diferencias de parámetros entre los grupos de estudio

\begin{tabular}{|c|c|c|c|c|c|c|c|c|c|}
\hline \multicolumn{10}{|c|}{ Grupo } \\
\hline & \multicolumn{2}{|c|}{$\begin{array}{l}\text { Pregrado } \\
\text { Enfermería }\end{array}$} & \multicolumn{2}{|c|}{$\begin{array}{l}\text { Pregrado } \\
\text { Medicina }\end{array}$} & \multicolumn{2}{|c|}{ Enfermero } & \multicolumn{2}{|c|}{ Médico } & \multirow[t]{2}{*}{$p$} \\
\hline & Media & DE & Media & DE & Media & DE & Media & DE & \\
\hline $\begin{array}{l}\text { Frecuencia cardiaca } \\
\text { máxima (Tanaka) }\end{array}$ & 191,7 & 2,4 & 192,5 & 1,6 & 182,7 & 5,7 & 175,6 & 4,7 & $<0,001$ \\
\hline $\begin{array}{l}\text { Umbral anaeróbico teó- } \\
\text { rico }(86 \%)\end{array}$ & 169 & 2 & 169 & 1 & 161 & 5 & 155 & 4 & $<0,001$ \\
\hline Glucemia basal & 103 & 16 & 108 & 18 & 111 & 21 & 119 & 22 & 0,066 \\
\hline Lactato basal & 2,4 & ,8 & 2,8 & 2,2 & 2,2 & 1,1 & 2,4 & 1,8 & 0,572 \\
\hline Tiempo de la ergometría & 9 & 1 & 9 & 2 & 9 & 1 & 9 & 1 & 0,087 \\
\hline $\begin{array}{l}\text { Frecuencia cardiaca } \\
\text { umbral anaeróbico }\end{array}$ & 164 & 6 & 163 & 8 & 156 & 9 & 152 & 9 & $<0,001$ \\
\hline Umbral de lactato & 7,7 & 3,5 & 8,2 & 3,8 & 7,5 & 3,6 & 8,8 & 5,9 & 0,736 \\
\hline Umbral de glucosa & 108 & 14 & 107 & 16 & 100 & 13 & 110 & 23 & 0,180 \\
\hline Umbral de potencia & 199 & 61 & 240 & 87 & 236 & 73 & 217 & 82 & 0,223 \\
\hline $\begin{array}{l}\text { Frecuencia cardiaca } \\
\text { máxima test }\end{array}$ & 186 & 6 & 182 & 7 & 182 & 12 & 179 & 11 & 0,083 \\
\hline $\begin{array}{l}\text { Presión arterial sistólica } \\
\text { esfuerzo }\end{array}$ & 136 & 15 & 145 & 18 & 142 & 15 & 130 & 23 & 0,032 \\
\hline $\begin{array}{l}\text { Presión arterial diastóli- } \\
\text { ca esfuerzo }\end{array}$ & 84 & 11 & 86 & 12 & 90 & 12 & 80 & 18 & 0,105 \\
\hline
\end{tabular}


Tabla 30. Diferencias de parámetros entre los subgrupos de estudio.

\begin{tabular}{|c|c|c|c|c|c|c|c|}
\hline \multicolumn{8}{|c|}{ Subgrupo } \\
\hline & \multicolumn{2}{|c|}{ Pregrado } & \multicolumn{2}{|c|}{$\begin{array}{l}\text { Urgencias } \\
\text { Hospitalarias }\end{array}$} & \multicolumn{2}{|c|}{$\begin{array}{l}\text { Emergencias } \\
\text { Sanitarias }\end{array}$} & \multirow[t]{2}{*}{$p$} \\
\hline & Media & $\mathrm{DE}$ & Media & $\mathrm{DE}$ & Media & $\mathrm{DE}$ & \\
\hline $\begin{array}{l}\text { Frecuencia cardiaca } \\
\text { máxima (Tanaka) }\end{array}$ & 192,1 & 2,1 & 181,2 & 6,5 & 177,2 & 5,5 & $<0,001$ \\
\hline $\begin{array}{l}\text { Umbral anaeróbico teóri- } \\
\text { co }(86 \%)\end{array}$ & 169 & 2 & 159 & 6 & 156 & 5 & $<0,001$ \\
\hline Glucemia basal & 106 & 17 & 117 & 25 & 111 & 17 & 0,058 \\
\hline Lactato basal & 2,6 & 1,7 & 2,4 & 1,7 & 2,1 & 1,1 & 0,539 \\
\hline Tiempo de la ergometría & 9 & 1 & 9 & 1 & 9 & 1 & 0,933 \\
\hline $\begin{array}{l}\text { Frecuencia cardiaca um- } \\
\text { bral anaeróbico }\end{array}$ & 163 & 7 & 155 & 10 & 153 & 8 & $<0,001$ \\
\hline Umbral de lactato & 8,0 & 3,6 & 8,3 & 4,7 & 7,8 & 5,0 & 0,916 \\
\hline Umbral de glucosa & 108 & 15 & 104 & 20 & 105 & 18 & 0,671 \\
\hline Umbral de potencia & 220 & 77 & 232 & 80 & 221 & 75 & 0,823 \\
\hline $\begin{array}{l}\text { Frecuencia cardiaca } \\
\text { máxima test }\end{array}$ & 184 & 7 & 181 & 13 & 179 & 10 & 0,172 \\
\hline $\begin{array}{l}\text { Presión arterial sistólica } \\
\text { esfuerzo }\end{array}$ & 141 & 17 & 134 & 19 & 139 & 21 & 0,338 \\
\hline $\begin{array}{l}\text { Presión arterial diastólica } \\
\text { esfuerzo }\end{array}$ & 85 & 12 & 83 & 16 & 88 & 15 & 0,404 \\
\hline
\end{tabular}

En la Tabla 31 se recogen las comparaciones intraindividuo de las frecuencias cardíacas y los umbrales de parámetros. En cuanto a la frecuencia cardiaca máxima de Tanaka, esta fue 26,91 Ipm (IC95\% $25,47 ; 28,35)$ mayor que la frecuencia cardiaca del umbral anaeróbico. En cuanto a la frecuencia cardiaca máxima del test, fue 23,03 Ipm (IC95\% 21,43; 24,63) mayor que la frecuencia cardiaca del umbral anaeróbico. Al comparar la frecuencia cardiaca máxima del test con la frecuencia cardiaca máxima de Tanaka, se encontró un descenso medio de 3,88 Ipm (IC95\% -5,91; -1,85). El umbral de lactato se incrementó en 5,59 (IC95\% 4,77; 6,40). 
Tabla 31. Comparaciones emparejadas entre las distintas medidas de las frecuencias cardíacas.

\begin{tabular}{|l|l|l|l|l|l|}
\hline & Media & DE & $\begin{array}{c}\text { Dife- } \\
\text { rencia } \\
\text { media }\end{array}$ & IC95\% \\
\hline Frecuencia cardiaca máxima (Tanaka) & 185,90 & 7,89 & 26,91 & 25,47 & 28,35 \\
\hline Frecuencia cardiaca umbral anaeróbico & 158,99 & 9,44 & $<, 001$ \\
\hline Frecuencia cardiaca máxima test & 182,02 & 9,75 & 23,03 & 21,43 & 24,63 \\
\hline Frecuencia cardiaca umbral anaeróbico & 158,99 & 9,44 & & $<, 001$ \\
\hline Frecuencia cardiaca máxima test & 182,02 & 9,75 & $-3,88$ & $-5,91$ & $-1,85$ \\
\hline Frecuencia cardiaca máxima (Tanaka) & 185,90 & 7,89 & $<0,001$ \\
\hline Umbral de lactato & 8,01 & 4,22 & 5,59 & 4,77 & 6,40 \\
\hline Lactato basal & 2,43 & 1,57 & & $<0,001$ \\
\hline Umbral de glucosa & 106,03 & 16,91 & $-3,96$ & $-8,06$ \\
\hline Glucemia basal & 109,99 & 19,74 & & 0,14 \\
\hline
\end{tabular}

En el estudio realizado se puede percibir que un 46,9\% de los voluntarios realizan un sobreesfuerzo físico muy elevado para llevar a cabo las maniobras de reanimación, presentando más FC durante las maniobras de masaje cardiaco externo que durante una cicloergometría, es decir, un porcentaje considerable de voluntarios (45 de 96) sobrepasan su umbral anaeróbico obtenido mediante una cicloergometría reglada. En las Figuras 21 y 22 se puede observar la distribución del umbral anaeróbico por sexos y por subgrupos de estudio (estudiantes o profesionales).

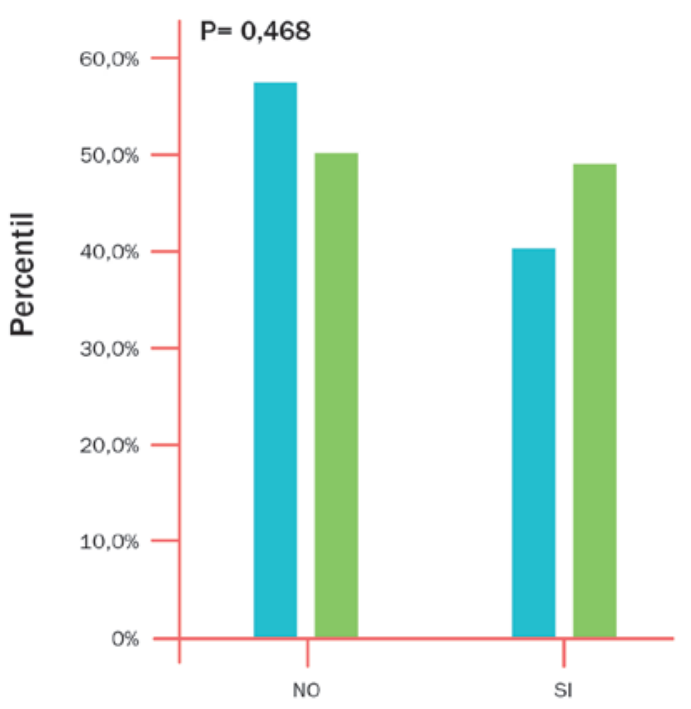

Actividad Física

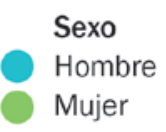

Figura 21. Distribución del umbral anaeróbico por sexo 


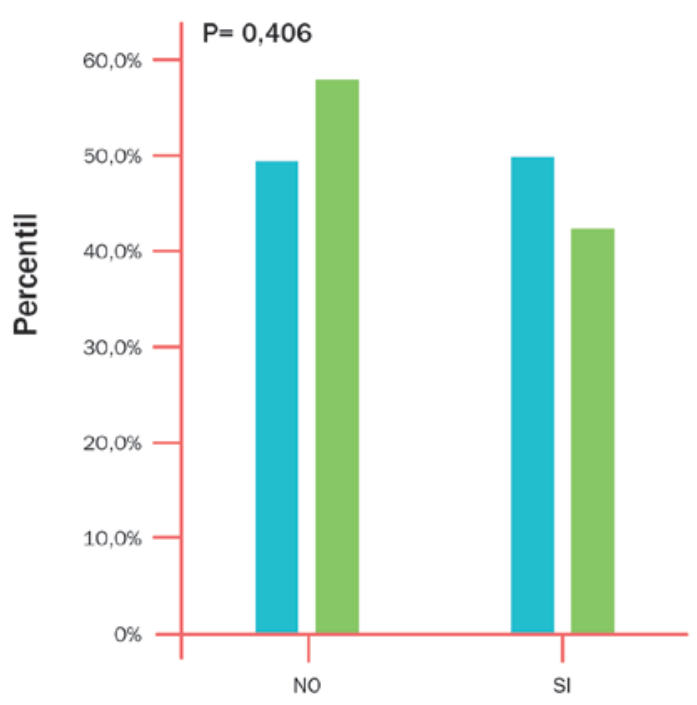

Estudio UA

Grupo profesional

Estudiante

Profesional

Figura 22. Distribución del umbral anaeróbico por subgrupo de estudio: estudiantes o profesionales

En la Figura 23 se puede apreciar la distribución de la FC del umbral anaeróbico en relación con el nivel de actividad física, y observar que existe una relación directa entre el nivel de entrenamiento y la tolerancia de la FC.

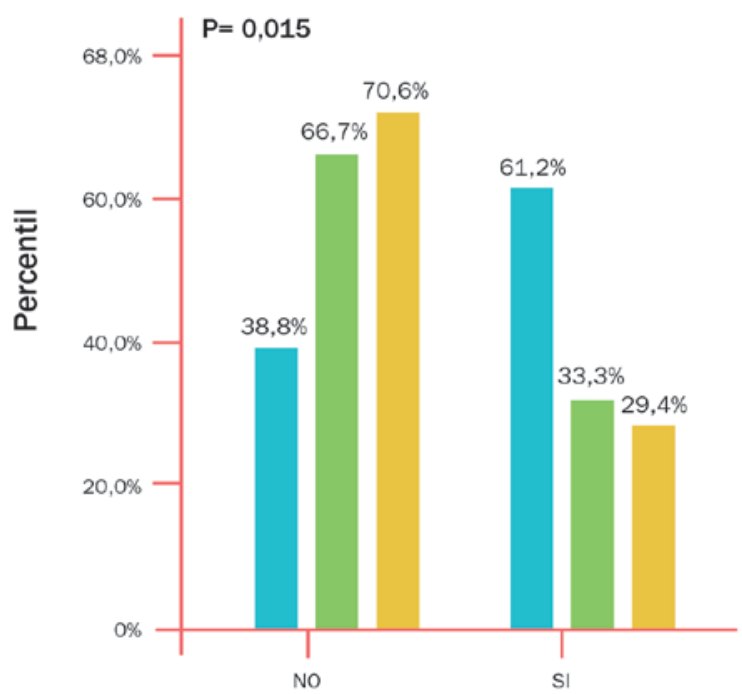

Estudio UA

\section{Actividad Física}

Actividad Física Baja (sedentario)

Actividad Física Moderada

Actividad Física Alta

Figura 23. Distribución del umbral anaeróbico en función del nivel de actividad física 
Si relacionamos el nivel de actividad física con el valor del umbral anaeróbico, encontramos una relación directa entre el nivel de entrenamiento alto y una mejor respuesta de la frecuencia cardiaca. Se ha podido observar que existe una relación lineal entre el nivel de entrenamiento y la disminución de la FC; de hecho, de todos los voluntarios sedentarios (49 de 96), 30 de ellos (un 61,2\%) toleraron mal en términos de umbral anaeróbico la realización del masaje cardiaco externo. De los sujetos con nivel de entrenamiento activo (30 de 96), 10 de ellos toleraron mal la prueba (un 31,3 \%), y de los sujetos con un alto nivel de entrenamiento (17 de 96), 5 individuos (29,41\%) toleraron mal la prueba (Figura 24).

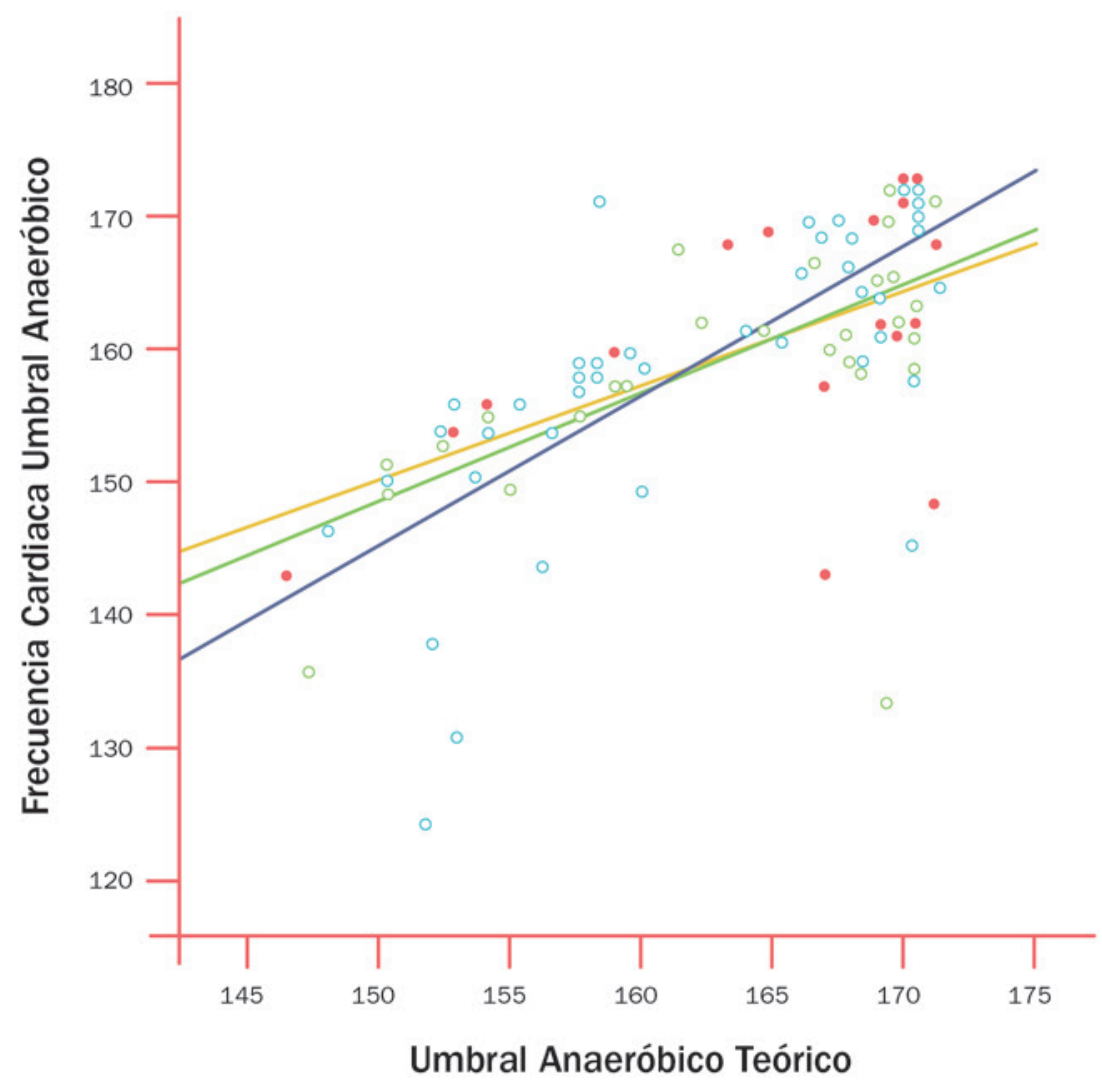

\begin{tabular}{|ll|}
\hline Actividad Física & \\
Actividad Física Baja (Sedentario) & Actividad Física Baja (Sedentario): \\
Actividad Física Moderada & $\mathrm{R}^{2}$ Linear $=0,551$ \\
Actividad Física Alta & Actividad Física Moderada: \\
Actividad Física Baja (Sedentario) & $\mathrm{R}^{2}$ Linear $=0,401$ \\
Actividad Física Moderada & Actividad Física Alta: \\
Actividad Física Alta & $\mathrm{R}^{2}$ Linear $=0,309$ \\
\hline
\end{tabular}

Figura 24. Relación entre el UAT y la FCUA con el nivel de actividad física 
Para realizar la Tabla 32 se estimó un modelo de regresión lineal con el fin de evaluar las diferencias en los grupos de la frecuencia cardiaca máxima del test, ajustada según la frecuencia cardiaca máxima de Tanaka y el sexo. Fueron los pregrado de medicina — con un descenso de 4,88 Ipm—y los médicos — con un incremento de 8,34 Ipm - los que presentaron una tendencia a la significación frente al grupo de pregrado de enfermería.

Tabla 32. Modelo multivariable de regresión lineal para explicar el cambio en la frecuencia cardiaca máxima del test

\begin{tabular}{|c|c|c|c|c|c|}
\hline & & & & \multicolumn{2}{|c|}{ IC95\% } \\
\hline & & Pendiente & $p$ & Inferior & Superior \\
\hline Constante & & 0,43 & 0,992 & $-88,41$ & 89,27 \\
\hline $\begin{array}{l}\text { Frecuencia cardiaca máxi- } \\
\text { ma (Tanaka) }\end{array}$ & & 0,96 & $<0,001$ & 0,49 & 1,43 \\
\hline \multirow[t]{4}{*}{ Grupo } & Pregrado Enfermería & Referencia & & & \\
\hline & Pregrado Medicina & $-4,88$ & 0,058 & $-9,94$ & 0,17 \\
\hline & Enfermero & 4,47 & 0,175 & $-2,02$ & 10,97 \\
\hline & Médico & 8,34 & 0,070 & $-0,70$ & 17,38 \\
\hline Sexo (Mujer/Hombre) & & 1,00 & 0,598 & $-2,74$ & 4,74 \\
\hline
\end{tabular}

Como conclusión de la presente sección de resultados de estudio de la FC, se realizó un cálculo del coeficiente de correlación interclase para comprobar la fiabilidad de la obtención teórica del umbral anaeróbico. Para el cálculo de este valor se ha aplicado la ecuación de Tanaka, y al valor resultante se le ha aplicado el 88\%, obteniendo la cifra del umbral anaeróbico teórico. Por otro lado, mediante la cicloergometría (Protocolo Conconi) se obtiene de forma empírica el valor umbral de FC (punto de deflexión de la FC en la curva durante la cicloergometría). EL coeficiente de correlación interclase arrojó una fiabilidad buena, con un CCI de 0,694 (IC95\% 0,54-0,80), y p<0,001. 


\subsection{Estudio de la frecuencia cardiaca durante el caso clínico}

En las Figuras 25, 26 y 27 se recoge la evolución de las frecuencias cardíacas en el caso clínico, para el global, por subgrupos y por sexo.

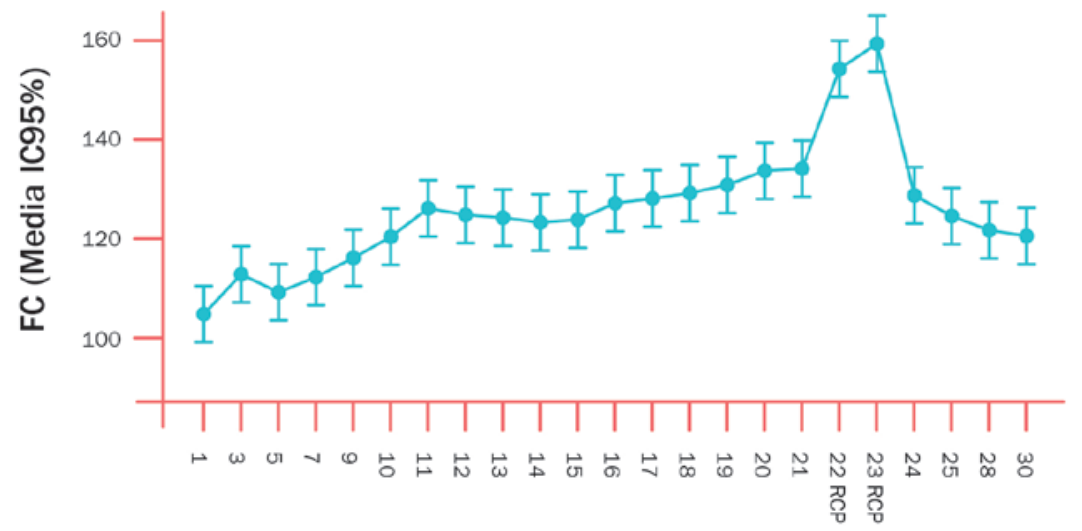

Figura 25. Frecuencia cardiaca en el caso clínico con el EPI colocado en el total de la muestra estudiada

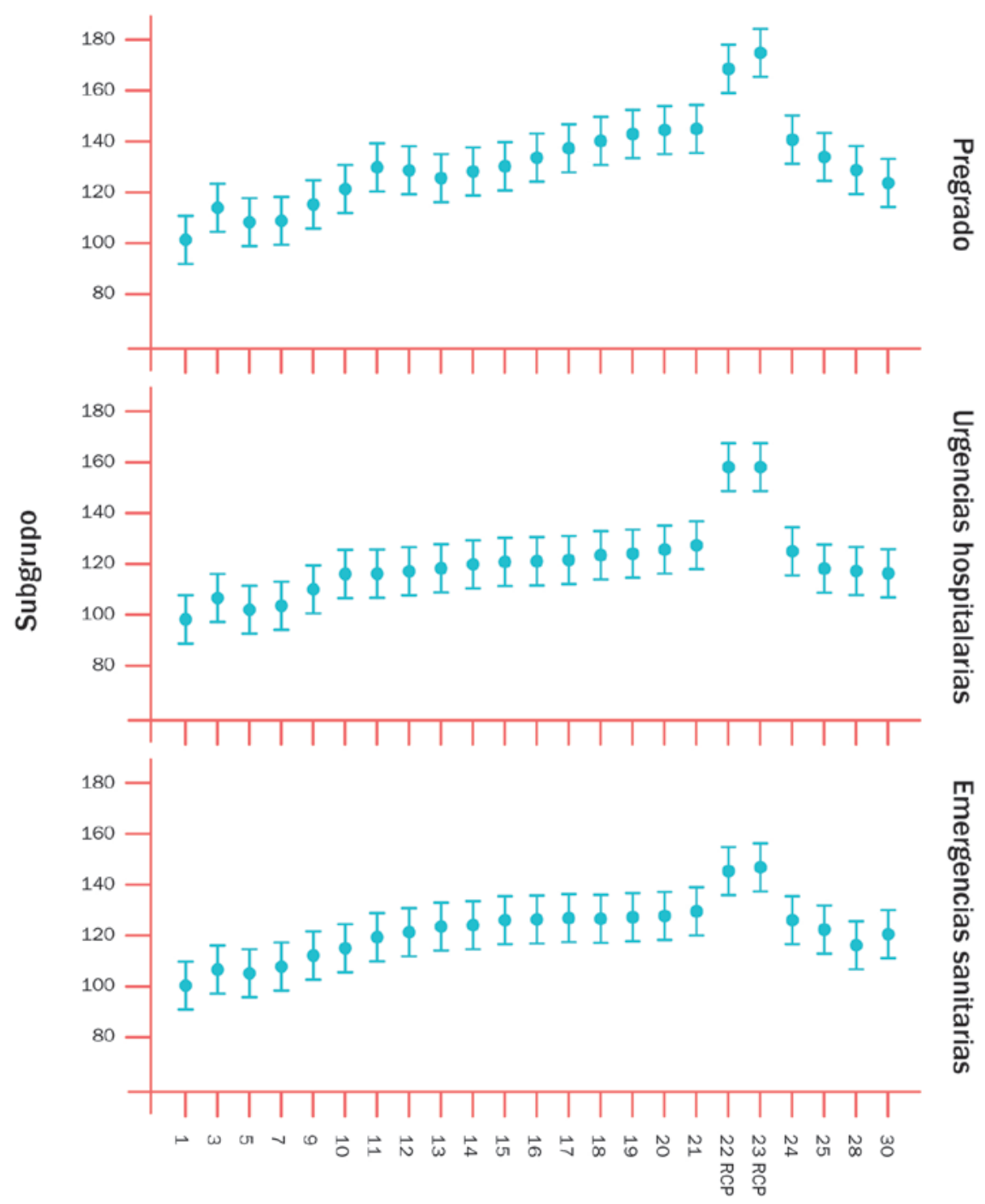

Figura 26. Frecuencia cardiaca en el caso clínico en los subgrupos estudiados 


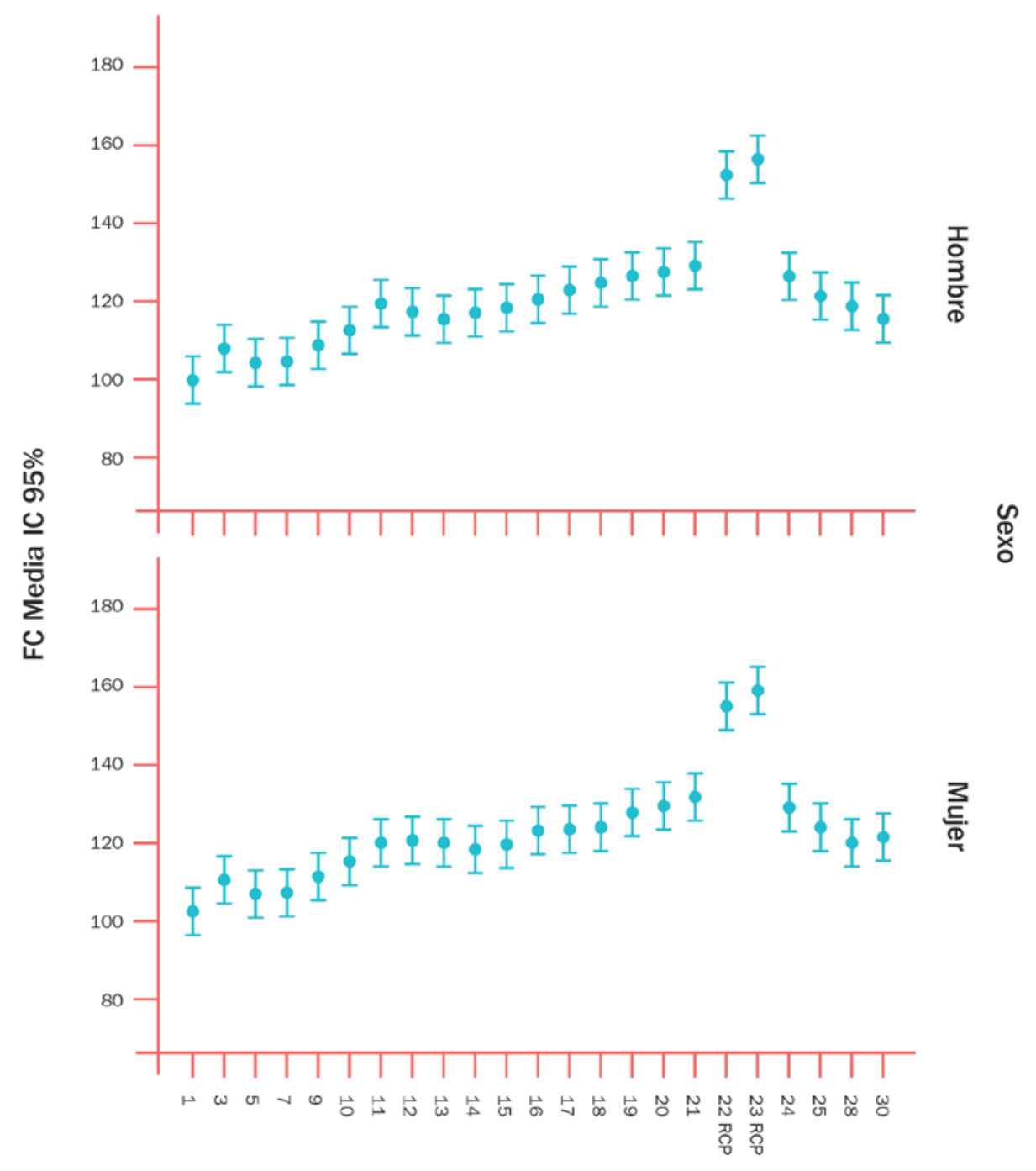

Figura 27. Frecuencia cardiaca en el caso clínico según sexo del sujeto

Para elaborar la Figura 28, se realizó un gráfico de Bland-Altmann con el fin de evaluar las diferencias entre la frecuencia cardiaca del umbral anaeróbico real (ergometría) y la frecuencia cardiaca en el caso clínico (media de momentos 22 y 23). El eje de ordenadas es la diferencia entre ambas medidas (ergometría media de 22 y 23) y el eje de abscisas es la media de ambas medidas. El valor 0 supondría que no hay error entre ambas. Los valores negativos representan sujetos que alcanzan más valor en la RCP que la prevista por la ergometría. La mediana de error es de -2,25 lpm (RIC $-11,9 ; 9,0)$, es decir, el 50\% de la muestra toma valores en la RCP mayores de 2,25 Ipm con respecto a la ergometría. 


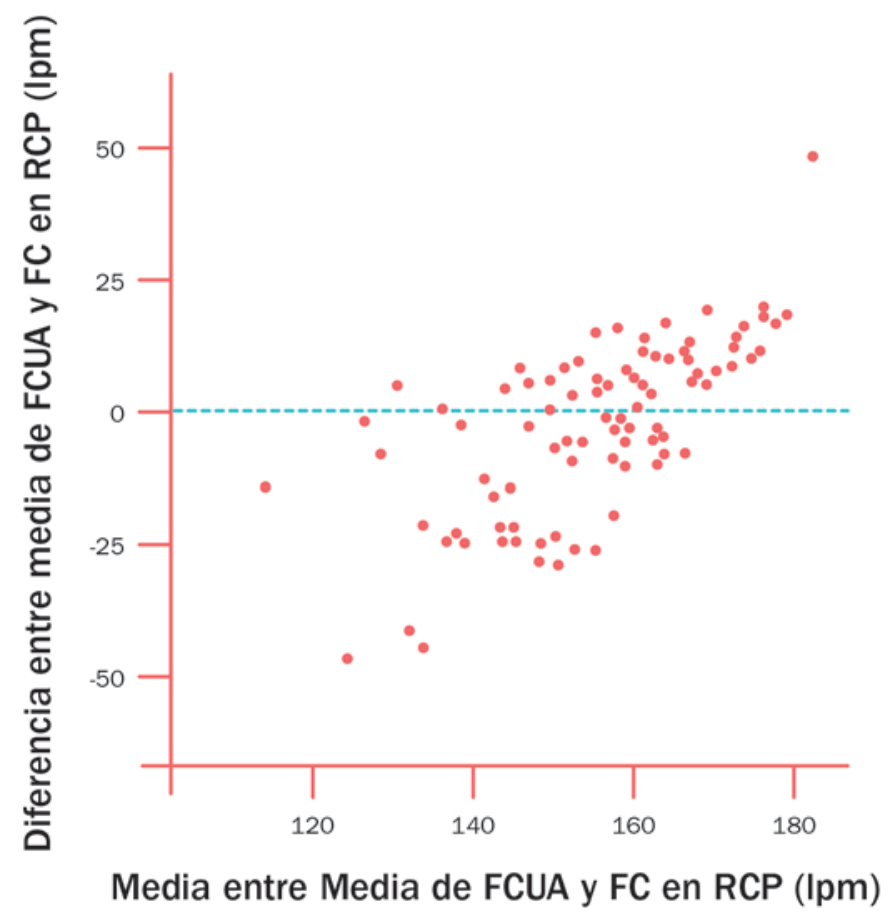

Figura 28. Gráfico de Bland-Altmann para evaluar las diferencias entre la frecuencia cardiaca en el umbral anaeróbico y la frecuencia cardiaca en el caso clínico (media de momentos 22 y 23). El eje de ordenadas es la diferencia entre ambas medidas (FCUA- media de 22 y 23) y el eje de abscisas es la media de ambas medidas. El valor 0 supondría que no hay error entre ambas. Los valores negativos representan sujetos que alcanzan más valor en la RCP que la prevista por la ergometría

Se definió, así pues, si toleraba la prueba tomando los valores que eran superiores a la ergometría. El $46,9 \%$ (45/96) de la muestra toleró mal la prueba. Se construyó un modelo de regresión logística en el que se incluyeron el sexo, la edad, la experiencia NBQ, los subgrupos de estudio, el ser fumador, la grasa corporal basal, la masa muscular y ósea y el índice de masa corporal.

No se detectó ninguna variable que explicara la no tolerancia.

Cuando se evaluó la tolerancia a la prueba según los criterios de las frecuencias cardiacas (cantidad de sujetos que presenta más FC en el caso clínico que en la cicloergometría), el 70,8\% (68/96) toleró mal la prueba.

Se construyó un modelo de regresión logística para evaluar la probabilidad de tolerar mal la prueba por la frecuencia cardiaca (ver Tabla 33), en el que se incluyeron el sexo, la edad, la experiencia laboral, los subgrupos de estudio, el ser fumador, la grasa corporal basal, la masa muscular y ósea y el índice de masa corporal. Las variables que se asociaron independientemente con la probabilidad de tolerar mal la prueba fueron la edad - con un incremento de mala respuesta de un $10 \%$ por cada año de edad (OR 1,10 IC95\% 1,02;1,20 p=0,020) - y los subgrupos, mostrando peor tolerancia el grupo de pregrado frente al de emergencias sanitarias (OR 25,43 IC95\% 3,16;204,55 p=0,002). 
Tabla 33. Modelo multivariable de regresión logística para evaluar la probabilidad de tolerar mal la prueba

\begin{tabular}{|c|c|c|c|c|}
\hline & $p$ & Odds ratio & \multicolumn{2}{|c|}{ IC95\% } \\
\hline Edad & 0,020 & 1,10 & 1,02 & 1,20 \\
\hline Subgrupo & 0,005 & & & \\
\hline Pregrado & 0,002 & 25,43 & 3,16 & 204,55 \\
\hline Urgencias & 0,255 & 2,23 & 0,56 & 8,92 \\
\hline Emergencias & & Referencia & & \\
\hline Constante & 0,035 & 0,02 & & \\
\hline
\end{tabular}

\subsection{Estudio del lactato}

Para llevar a cabo el estudio del lactato, se recogen en la Tabla 34 los datos descriptivos de las medias de lactato obtenidas durante el estudio. Se analizó en grupos y subgrupos con modelos de regresión lineal ajustados por edad y sexo. Los grupos de pregrado de medicina $(p=0,003)$, los enfermeros $(p=0,006)$ y los médicos $(p=0,041)$ obtuvieron medias significativamente menores que el grupo de pregrado de enfermería. El subgrupo de urgencias hospitalarias obtuvo variaciones menores que el de emergencias hospitalarias $(p=0,050)$ (ver Tabla 35).

Cuando se evaluó la tolerancia a la prueba según los criterios del lactato (RCP-ergometría) o de los lactatos final y basal, no hubo concordancia entre las clasificaciones (índice kappa 0,17 p=0,090). En el caso de tolerar mal por cifras de lactato respecto al lactato de la RCP vs el lactato de la cicloergometría, el 54,3\% (54/96) toleró mal la prueba.

Tabla 34. Descripción de las medias de lactato por grupo de estudio

\begin{tabular}{|l|c|c|c|c|c|c|c|c|}
\hline \multicolumn{9}{|c|}{ Subgrupo } \\
\hline & \multicolumn{3}{|c|}{ Total } & Pregrado & $\begin{array}{c}\text { Urgencias } \\
\text { Hospitalarias }\end{array}$ & $\begin{array}{c}\text { Emergencias } \\
\text { Sanitarias }\end{array}$ \\
\hline & Media & DE & Media & DE & Media & DE & Media & DE \\
\hline Lactato basal & 2,4 & 1,6 & 2,6 & 1,7 & 2,4 & 1,7 & 2,1 & 1,1 \\
\hline Umbral de lactato & 8,0 & 4,2 & 8,0 & 3,6 & 8,3 & 4,7 & 7,8 & 5,0 \\
\hline Umbral de lactato RCP & 8,7 & 4,6 & 8,1 & 3,9 & 9,8 & 5,1 & 8,8 \\
\hline Lactato final & 3,7 & 2,3 & 4,2 & 2,6 & 3,4 & 2,1 & 2,9 \\
\hline
\end{tabular}


Tabla 35. Modelo multivariable de regresión lineal para estudiar el lactato final en grupos y subgrupos

\begin{tabular}{|c|c|c|c|c|c|}
\hline & & & & \multicolumn{2}{|c|}{ IC95\% } \\
\hline & & Pendiente & $p$ & Inferior & Superior \\
\hline Constante & & 2,69 & 0,091 & $-0,44$ & 5,82 \\
\hline \multicolumn{6}{|l|}{ Grupo } \\
\hline & Pregrado Enfermería & Referencia & & & \\
\hline & Pregrado Medicina & $-2,06$ & 0,003 & $-3,43$ & $-0,70$ \\
\hline & Enfermero & $-2,50$ & 0,006 & $-4,25$ & $-0,74$ \\
\hline & Médico & $-2,54$ & 0,041 & $-4,98$ & $-0,11$ \\
\hline Sexo (Mujer/Hombre) & & $-0,61$ & 0,231 & $-1,62$ & 0,40 \\
\hline Edad (año) & & 0,04 & 0,374 & $-0,05$ & 0,13 \\
\hline Constante & & 0,86 & 0,560 & $-2,05$ & 3,76 \\
\hline Sexo (Mujer/Hombre) & & $-0,40$ & 0,444 & $-1,45$ & 0,64 \\
\hline Edad (años) & & 0,06 & 0,158 & $-0,02$ & 0,15 \\
\hline \multicolumn{6}{|l|}{ Subgrupo } \\
\hline & Pregrado & $-1,50$ & 0,089 & $-3,22$ & 0,23 \\
\hline & Urgencias hospitalarias & $-2,14$ & 0,0 & $-4,28$ & $<0,001$ \\
\hline & Emergencias sanitarias & Referencia & & & \\
\hline
\end{tabular}

Se construyó un modelo de regresión logística para evaluar la probabilidad de tolerar según el criterio de lactato (RCP-ergometría - ver Tabla 36-), en el que se incluyeron el sexo, la edad, la experiencia laboral, los subgrupos de estudio, el ser fumador, la grasa corporal basal, la masa muscular y ósea y el índice de masa corporal. Las variables que se asociaron independientemente con la probabilidad de tolerar la prueba fueron el sexo, con un incremento de respuesta en hombres frente a mujeres (OR 18,09 IC95\% 2,27;144,27 p=0,006), la grasa corporal (OR 1,23 IC95\% 1,08;1,41 p=0,003) y el IMC (OR 0,72 IC95\% 0,56;0,92 p=0,009), interpretándose que, a medida que aumenta el IMC, la probabilidad de tolerar la prueba es menor. 
Tabla 36. Modelo multivariable de regresión logística para evaluar la probabilidad de tolerar RCP

\begin{tabular}{|l|c|c|c|c|}
\hline & $\mathbf{p}$ & Odds ratio & \multicolumn{2}{|c|}{ IC95\% } \\
\hline Sexo (Hombre/Mujer) & 0,006 & 18,09 & 2,27 & 144,27 \\
\hline Grasa corporal & 0,003 & 1,23 & 1,08 & 1,41 \\
\hline IMC (kg/m2) & 0,009 & 0,72 & 0,56 & 0,92 \\
\hline Constante & 0,116 & 12,11 & \\
\hline
\end{tabular}

A continuación, se estudió qué cantidad de sujetos presentaban alteraciones en el metabolismo del ácido láctico, es decir, cuál era la cantidad de voluntarios que presentaban valores alterados en una, dos o tres de las mediciones de ácido láctico. Un valor de referencia a partir del cual se considera que un sujeto presenta fatiga metabólica es $4 \mathrm{mmol} / \mathrm{L}^{(51)}$, presentando valores por encima de esta cifra un 33,33\% de los sujetos (32 de 96). Un 70,80\% (68 de 96) tuvieron cifras de ácido láctico final mayor que las cifras iniciales, y un 56,3\% (54 de 96) obtuvieron cifras de lactato durante la realización de la RCP mayores que durante la realización de la cicloergometría.

Un 15,60\% (15 de 96) no presentó ninguna alteración en las cifras de lactato, un 31,30\% (30 de 96) presentó una de las tres mediciones posibles alteradas, un 30,20\% (29 de 96) dos mediciones de lactato alteradas, y un $22,90 \%$ (22 de 96 ) los tres datos que indican mala tolerancia del lactato alterados.

Se observó que existe una correlación entre las alteraciones de los niveles de ácido láctico y el nivel de entrenamiento, pudiendo comprobar que en el grupo de individuos sedentarios todos presentaron alteraciones; no así en el grupo de personas activas (entrenadas), del que ningún voluntario presentó tres alteraciones de los niveles (ver Figura 29).

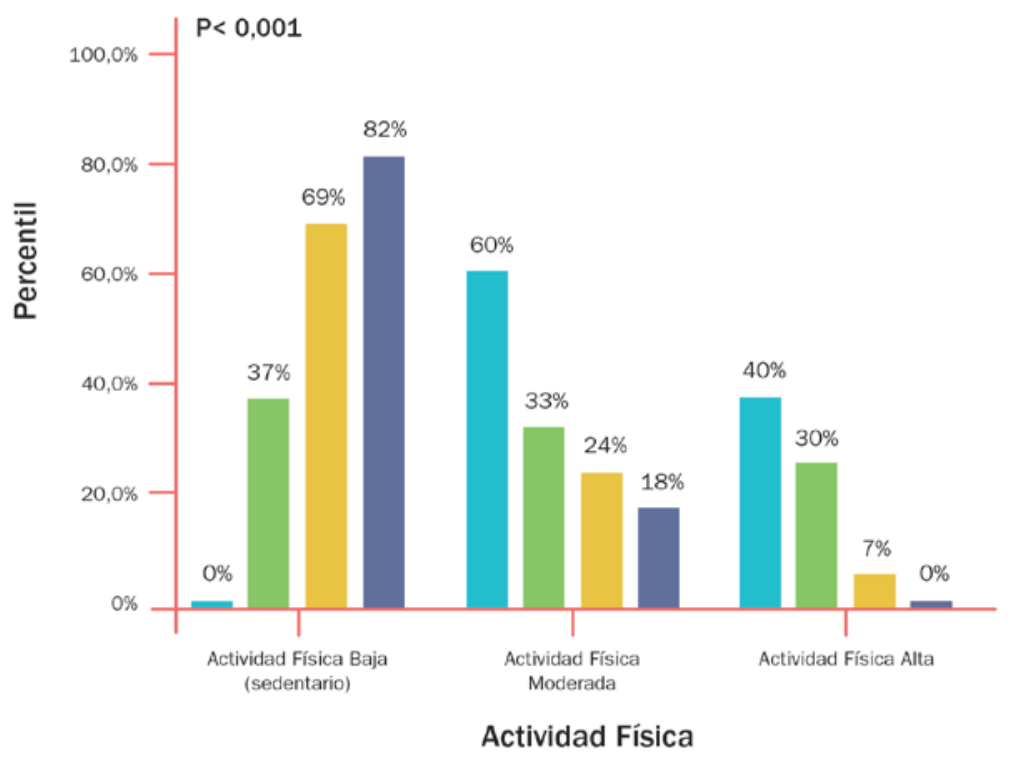

\begin{tabular}{|cc}
$\mathbf{N}^{0}$ de mediciones de lactato alterada \\
Ninguna & 2 \\
1 & 3
\end{tabular}

Figura 29. Gráfico de distribución de las alteraciones de ácido láctico en relación con el nivel de entrenamiento 
Asimismo, se estudió la correlación entre el umbral de potencia y el umbral de lactato, encontrándose una modificación del comportamiento entre los subgrupos de estudio. En la Figura 30 se puede apreciar cómo el coeficiente de determinación es prácticamente nulo en pregrado, mientras que se dio una relación inversa en urgencias hospitalarias, con un r2 de 0,05, y en el caso del subgrupo de emergencias sanitarias alcanzó un 0,22, por lo que es en este grupo en el que se encuentra una mayor correlación entre el umbral de potencia y el umbral de lactato.

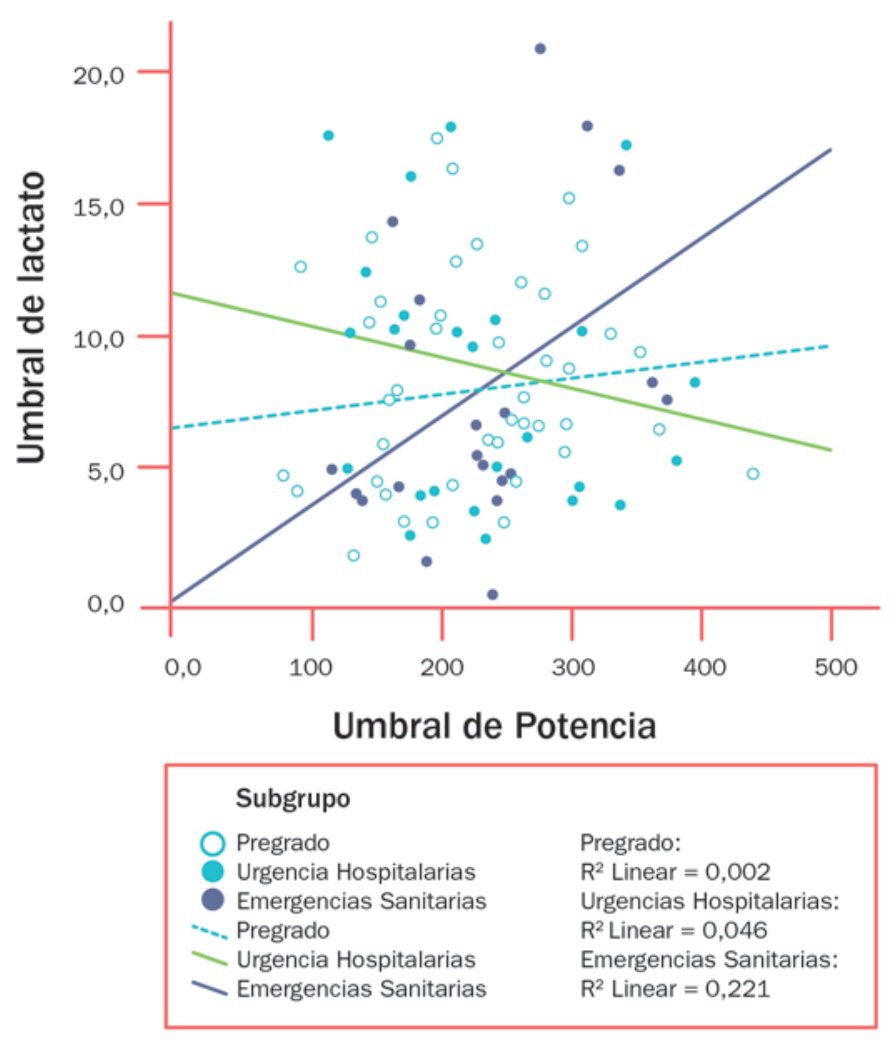

Figura 30. Relación del umbral de potencia con el umbral de lactato por subgrupos estudiados ( $p$ de interacción <0,05)

Se ajustó también un modelo de regresión logística multivariable en la que se incluyeron las variables de grupo profesional, edad, sexo, fumador, masa muscular, masa ósea, IMC, PAS y PAD y el índice de perfusión inicial (ver Tabla 37). 
Tabla 37. Modelo logístico multivariable para predecir mala tolerancia (lactato final $>4 \mathrm{mmol} / \mathrm{L}$ )

\begin{tabular}{|c|c|c|c|c|c|}
\hline & & & & IC9 & OR \\
\hline & & $p$ & $\begin{array}{l}\text { Odds ratio } \\
\text { ajustada }\end{array}$ & Inferior & Superior \\
\hline \multirow{10}{*}{$\begin{array}{l}\text { Modelo } \\
\text { completo }\end{array}$} & $\begin{array}{l}\text { Grupo profesional (estudiante/ } \\
\text { profesional) }\end{array}$ & 0,138 & 3,65 & 0,66 & 20,20 \\
\hline & Sexo (Hombre/Mujer) & 0,807 & 0,75 & 0,07 & 7,83 \\
\hline & Edad (incremento un año) & 0,745 & 1,01 & 0,93 & 1,10 \\
\hline & Tabaco (sí/no) & 0,817 & 1,19 & 0,28 & 5,05 \\
\hline & Mmusc (unidad) & 0,100 & 1,77 & 0,90 & 3,51 \\
\hline & Mosea (unidad) & 0,096 & 0,00 & 0,00 & 7,56 \\
\hline & BMI (unidad) & 0,222 & 1,11 & 0,94 & 1,31 \\
\hline & PAS (unidad) & 0,620 & 1,01 & 0,96 & 1,06 \\
\hline & PAD (unidad) & 0,747 & 1,01 & 0,95 & 1,08 \\
\hline & Iperf (unidad) & 0,959 & 1,00 & 0,84 & 1,20 \\
\hline \multirow{4}{*}{ Modelo final } & $\begin{array}{l}\text { Grupo profesional (estudiante/ } \\
\text { profesional) }\end{array}$ & 0,035 & 2,89 & 1,08 & 7,75 \\
\hline & Mmusc (unidad) & 0,040 & 1,77 & 1,01 & 3,37 \\
\hline & Mosea (unidad) & 0,032 & 0,01 & 0,00 & 0,96 \\
\hline & BMI (unidad) & 0,046 & 1,15 & 1,03 & 1,32 \\
\hline
\end{tabular}

Las variables que predicen la mala tolerancia — definida como un lactato final $>4 \mathrm{mmol} / \mathrm{L}$ - son el grupo profesional, la masa muscular, la masa ósea y el IMC. Los estudiantes presentaron una mala tolerancia 2,89 veces mayor que los profesionales. La masa muscular y el IMC, al aumentar, incrementan la mala tolerancia; y la masa ósea fue inversa (a mayor masa ósea, mejor tolerancia.

La capacidad de predicción del modelo fue muy buena, con una ABC de 0,75 (IC95\% 0,64-0,85); $p<0,001$ y un test de ajuste global del modelo de $p=0,922$ (ver Figura 31). 


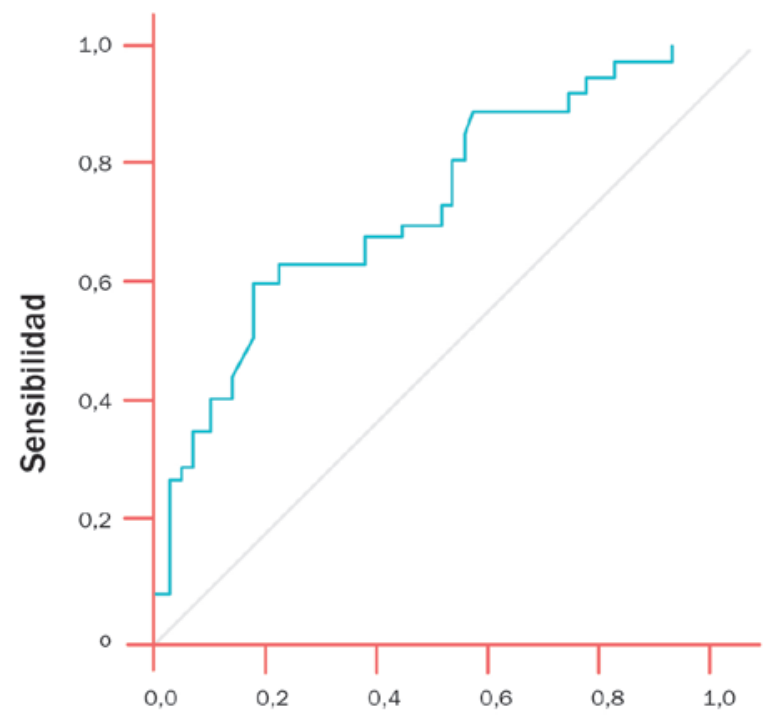

1- Especifidad

Figura 31 . Curva de rendimiento diagnóstico $(R O C)$ del modelo multivariable final para predecir la mala tolerancia (lactato final $>4 \mathrm{mmol} / \mathrm{L}$ )

\subsection{Variación del índice de perfusión}

En la Figura 32 se pueden observar las medias de los índices de perfusión basal e índices de perfusión basal posteriores a la prueba en los grupos de estudio. Se encontraron significativos los incrementos absolutos de la media de IP, en todos los grupos de estudio (Tabla 38), siendo en pregrado de Enfermería de 3,3 (IC95\% 1,1;5,5), en el pregrado de Medicina de 3,8 (IC95\% 2,7;4,9), en enfermeros de 3,8 (IC95\% 2,2;5,4) y en médicos de 2,1 (IC95\% 1,0;3,1).

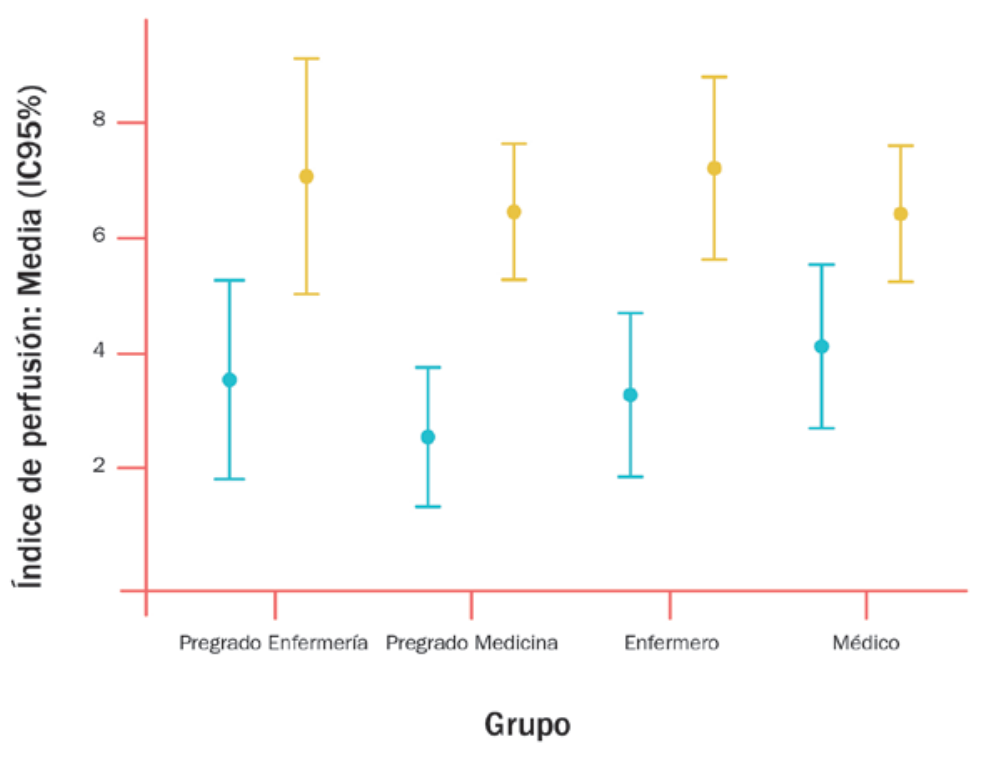

Índice de Perfusión

Índice de Perfusión Posterior

Figura 32. Valores medios del índice de perfusión por grupos de estudio, antes y después de la prueba 
Tabla 38. Variación media del índice de perfusión por grupos de estudio, antes y después de la prueba

\begin{tabular}{|c|c|c|c|c|c|c|c|}
\hline Grupo & $\begin{array}{l}\text { Índice de } \\
\text { perfusión }\end{array}$ & Media & $\mathrm{DE}$ & Efecto absoluto medio & \multicolumn{2}{|c|}{ IC95\% } & $p$ \\
\hline \multirow{2}{*}{$\begin{array}{l}\text { Pregrado } \\
\text { Enfermería }\end{array}$} & Posterior & 6,7 & 4,5 & 3,3 & 1,1 & 5,5 & 0,006 \\
\hline & Basal & 3,4 & 3,5 & & & & \\
\hline \multirow{2}{*}{$\begin{array}{l}\text { Pregrado } \\
\text { Medicina }\end{array}$} & Posterior & 6,4 & 3,3 & 3,8 & 2,7 & 4,9 & $<0,001$ \\
\hline & Basal & 2,6 & 2,2 & & & & \\
\hline \multirow[t]{2}{*}{ Enfermero } & Posterior & 7,0 & 3,6 & 3,8 & 2,2 & 5,4 & $<0,001$ \\
\hline & Basal & 3,1 & 2,9 & & & & \\
\hline \multirow[t]{2}{*}{ Médico } & Posterior & 6,2 & 2,3 & 2,1 & 1,0 & 3,1 & $<0,001$ \\
\hline & Basal & 4,2 & 2,8 & & & & \\
\hline
\end{tabular}

Con el fin de evaluar las variables asociadas a los IP tanto basal, como posterior y su variación se correlacionaron con las variables estudiadas (Tablas 39, 40 y 41). Los IP basal $(r=0,23 ; p=0,03)$ y posterior $(r=0,23 ; p=0,03)$ correlacionaron de forma directa con la cantidad de alcohol consumida, pero no la variación del IP $(r=0,04 ; p=0,72)$.

El IP posterior se correlacionó con la talla $(r=0,21 ; p=0,04)$, con el perímetro de cuello ( $r=0,24$; $p=0,02)$, con la masa muscular $(r=0,24 ; p=0,02)$, con la masa ósea $(r=0,24 ; p=0,02)$ y con el peso ideal $(r=0,21 ; p=0,04)$.

La frecuencia cardiaca en reposo correlacionó de forma inversa con el IP posterior $(r=-0,26 ; p=0,01)$ y su variación ( $r=-0,23 ; p=0,01)$, al igual que la frecuencia cardiaca real $(r=-0,26 ; p=0,01)$ y la saturación de oxígeno $(r=-0,27 ; p=0,01)$. El tiempo de ergometría $(r=0,23 ; p=0,02)$ correlacionó de forma directa con el IP posterior y la variación del mismo $(r=0,25 ; p=0,02)$. Cabe destacar que la glucemia basal correlacionó de forma inversa con la variación de IP $(r=-0,21 ; p=0,04)$.

Tabla 39. Correlaciones de los parámetros cuantitativos con los índices de perfusión, antes y después de la prueba, así como su variación absoluta

\begin{tabular}{|c|c|c|c|c|}
\hline & & Índice de perfusión & Índice de perfusión posterior & Variación índice de perfusión \\
\hline \multirow{2}{*}{ Edad } & r & 0,19 & 0,01 & $-0,14$ \\
\hline & $\mathrm{p}$ & 0,07 & 0,92 & 0,19 \\
\hline \multirow{2}{*}{$\begin{array}{l}\text { Experiencia } \\
\text { laboral }\end{array}$} & r & 0,20 & 0,03 & $-0,12$ \\
\hline & $\mathrm{p}$ & 0,06 & 0,78 & 0,23 \\
\hline \multirow{2}{*}{$\begin{array}{l}\text { Horas desde la } \\
\text { última ingesta }\end{array}$} & r & $-0,13$ & $-0,19$ & $-0,08$ \\
\hline & $p$ & 0,22 & 0,06 & 0,43 \\
\hline
\end{tabular}


Tabla 39. Correlaciones de los parámetros cuantitativos con los índices de perfusión, antes y después de la prueba, así como su variación absoluta (continuación)

\begin{tabular}{|l|c|c|c|c|}
\hline \multirow{2}{*}{ Horas de sueño } & $r$ & 0,10 & 0,14 & 0,05 \\
\hline & $p$ & 0,32 & 0,17 & 0,61 \\
\hline $\begin{array}{l}\text { Cantidad de al- } \\
\text { cohol consumida }\end{array}$ & $r$ & $0,23 *$ & $0,23 *$ & 0,04 \\
\hline $\begin{array}{l}\text { Número de } \\
\text { cigarrillos/día }\end{array}$ & $\mathrm{p}$ & 0,03 & 0,03 & 0,72 \\
\hline Años de & $\mathrm{p}$ & 0,47 & $-0,05$ & 0,01 \\
\hline tabaquismo & $\mathrm{r}$ & 0,11 & 0,66 & 0,89 \\
\hline
\end{tabular}

Tabla 40. Correlaciones de los parámetros antropométricos cuantitativos con los índices de perfusión, antes y después de la prueba, así como su variación absoluta

\begin{tabular}{|c|c|c|c|c|}
\hline & & Îndice de perfusión & Îndice de perfusión posterior & Variación índice de perfusión \\
\hline \multirow{2}{*}{ Talla } & $r$ & 0,20 & $0,21 *$ & 0,04 \\
\hline & $\mathrm{p}$ & 0,05 & 0,04 & 0,68 \\
\hline \multirow{2}{*}{$\begin{array}{l}\text { Perímetro del } \\
\text { pecho }\end{array}$} & $r$ & 0,16 & 0,10 & $-0,03$ \\
\hline & $\mathrm{p}$ & 0,11 & 0,33 & 0,75 \\
\hline \multirow{2}{*}{$\begin{array}{l}\text { Perímetro de } \\
\text { cintura }\end{array}$} & $r$ & $0,27 * *$ & 0,13 & $-0,09$ \\
\hline & $\mathrm{p}$ & 0,01 & 0,21 & 0,39 \\
\hline \multirow{2}{*}{$\begin{array}{l}\text { Perímetro de } \\
\text { cadera }\end{array}$} & $r$ & 0,18 & 0,08 & $-0,07$ \\
\hline & $p$ & 0,08 & 0,46 & 0,52 \\
\hline \multirow{2}{*}{$\begin{array}{l}\text { Perímetro de } \\
\text { cuello }\end{array}$} & $r$ & $0,25 *$ & $0,24 *$ & 0,03 \\
\hline & $\mathrm{p}$ & 0,01 & 0,02 & 0,77 \\
\hline \multirow{2}{*}{$\begin{array}{l}\text { Contorno de } \\
\text { muñeca }\end{array}$} & $r$ & $0,32 * *$ & 0,14 & $-0,11$ \\
\hline & $p$ & $<0,001$ & 0,18 & 0,27 \\
\hline \multirow{2}{*}{$\begin{array}{l}\text { Contorno del } \\
\text { brazo }\end{array}$} & $r$ & $0,32 * *$ & 0,17 & $-0,09$ \\
\hline & $\mathrm{p}$ & $<0,001$ & 0,10 & 0,40 \\
\hline \multirow{2}{*}{ Peso } & r & 0,17 & 0,16 & 0,02 \\
\hline & $p$ & 0,09 & 0,12 & 0,87 \\
\hline
\end{tabular}


Tabla 40. Correlaciones de los parámetros antropométricos cuantitativos con los índices de perfusión, antes y después de la prueba, así como su variación absoluta (continuación)

\begin{tabular}{|l|c|c|c|c|}
\hline & $r$ & $-0,15$ & $-0,14$ & $-0,01$ \\
\hline Grasa corporal & $p$ & 0,15 & 0,18 & 0,91 \\
\hline Masa muscular & $r$ & $0,24 *$ & $0,24 *$ & 0,040 \\
\hline & $p$ & 0,02 & 0,02 & 0,03 \\
\hline Masa ósea & $r$ & $0,25 *$ & $0,24 *$ & 0,74 \\
\hline IMC & $p$ & 0,02 & 0,02 & $-0,01$ \\
\hline Peso ideal & $r$ & 0,12 & 0,09 & 0,93 \\
\hline Peso ideal & $p$ & 0,25 & 0,39 & 0,04 \\
\hline corregido & $p$ & 0,20 & $0,21 *$ & 0,68 \\
\hline
\end{tabular}

Tabla 41. Correlaciones de los parámetros fisiológicos cuantitativos con los índices de perfusión, antes y después de la prueba, así como su variación absoluta

\begin{tabular}{|c|c|c|c|c|}
\hline & & Îndice de perfusión & Îndice de perfusión posterior & Variación índice de perfusión \\
\hline \multirow{2}{*}{$\begin{array}{l}\text { Frecuencia car- } \\
\text { diaca en reposo }\end{array}$} & $r$ & $-0,01$ & $-0,26 *$ & $-0,23 *$ \\
\hline & $\mathrm{p}$ & 0,89 & 0,01 & 0,02 \\
\hline \multirow{2}{*}{$\begin{array}{l}\text { Frecuencia car- } \\
\text { diaca real }\end{array}$} & $r$ & 0,01 & $-0,26 *$ & $-0,25 *$ \\
\hline & $p$ & 0,91 & 0,01 & 0,02 \\
\hline \multirow{2}{*}{$\begin{array}{l}\text { Presión arterial } \\
\text { sistólica }\end{array}$} & $r$ & 0,04 & 0,17 & 0,12 \\
\hline & $\mathrm{p}$ & 0,68 & 0,10 & 0,23 \\
\hline \multirow{2}{*}{$\begin{array}{l}\text { Presión arterial } \\
\text { diastólica }\end{array}$} & $r$ & $-0,11$ & $-0,13$ & $-0,04$ \\
\hline & $\mathrm{p}$ & 0,30 & 0,21 & 0,71 \\
\hline \multirow{2}{*}{$\begin{array}{l}\text { Frecuencia } \\
\text { respiratoria }\end{array}$} & $r$ & 0,11 & $-0,05$ & $-0,13$ \\
\hline & $p$ & 0,30 & 0,60 & 0,19 \\
\hline
\end{tabular}


Tabla 41. Correlaciones de los parámetros fisiológicos cuantitativos con los índices de perfusión, antes y después de la prueba, así como su variación absoluta (continuación)

\begin{tabular}{|c|c|c|c|c|}
\hline \multirow{2}{*}{ Temperatura } & $r$ & $-0,16$ & 0,00 & 0,12 \\
\hline & $p$ & 0,11 & 0,99 & 0,23 \\
\hline \multirow{2}{*}{ Hemoglobina } & $r$ & $0,37 * *$ & ,215* & $-0,08$ \\
\hline & $p$ & 0,01 & 0,04 & 0,41 \\
\hline \multirow{2}{*}{$\begin{array}{l}\text { Saturación de } \\
\text { oxígeno }\end{array}$} & $r$ & $-0,53 * *$ & $-0,27 * *$ & 0,16 \\
\hline & $p$ & $<0,001$ & 0,01 & 0,12 \\
\hline \multirow{2}{*}{$\begin{array}{l}\text { Frecuencia } \\
\text { cardiaca máxima } \\
\text { (Tanaka) }\end{array}$} & $r$ & $-0,19$ & $-0,01$ & 0,14 \\
\hline & $p$ & 0,07 & 0,92 & 0,19 \\
\hline \multirow{2}{*}{$\begin{array}{l}\text { Umbral anaeróbi- } \\
\text { co teórico }(86 \%)\end{array}$} & $r$ & $-0,19$ & $-0,01$ & 0,14 \\
\hline & $p$ & 0,07 & 0,92 & 0,19 \\
\hline \multirow{2}{*}{ Glucemia basal } & $r$ & $0,44 * *$ & 0,14 & $-0,21 *$ \\
\hline & $p$ & $<0,001$ & 0,18 & 0,04 \\
\hline \multirow{2}{*}{ Lactato basal } & $r$ & 0,07 & 0,09 & 0,03 \\
\hline & $p$ & 0,52 & 0,39 & 0,77 \\
\hline \multirow{2}{*}{$\begin{array}{l}\text { Tiempo de la } \\
\text { ergometría }\end{array}$} & $r$ & $-0,04$ & ,233* & ,248* \\
\hline & $p$ & 0,70 & 0,02 & 0,02 \\
\hline
\end{tabular}

Se ajustó un modelo de regresión lineal para explicar las variables asociadas al IP posterior ajustado por los datos basales de IP. Se incluyeron en el modelo las variables correlacionadas con la IP posterior, así como aquellas que confundían por la distinta distribución en los grupos de estudio.

No se encontraron diferencias entre grupos o en subgrupos.

Las variables independientemente asociadas al IP posterior se presentan en la Tabla 42. El modelo resultante tuvo un $\mathrm{r} 2$ de 0,33. La actividad física moderada vs baja incrementa el IP posterior en 2,55 (IC95\% 1,03;4,06) y mujer vs hombre disminuye 2,68 (IC95\% -5,47; 0,10). 
Tabla 42 . Modelo multivariable de regresión lineal para explicar el índice de perfusión final en la población estudiada

\begin{tabular}{|c|c|c|c|c|c|c|}
\hline & & \multicolumn{2}{|c|}{ Coeficientes } & \multirow[b]{2}{*}{$p$} & \multicolumn{2}{|c|}{ IC95\% pendiente } \\
\hline & & Pendiente & EE & & $\begin{array}{l}\text { Límite } \\
\text { inferior }\end{array}$ & $\begin{array}{l}\text { Límite } \\
\text { superior }\end{array}$ \\
\hline Constante & & $-18,25$ & 25,15 & 0,470 & $-68,24$ & 31,74 \\
\hline \multicolumn{7}{|l|}{ Actividad física } \\
\hline & Moderada vs Baja & 2,55 & 0,76 & 0,001 & 1,03 & 4,06 \\
\hline & Alta vs Baja & 0,59 & 0,92 & 0,527 & $-1,25$ & 2,43 \\
\hline Índice de perfusión & & 0,40 & 0,12 & 0,001 & 0,17 & 0,63 \\
\hline Perímetro de cuello & & 0,26 & 0,16 & 0,111 & $-0,06$ & 0,58 \\
\hline Contorno de muñeca & & $-0,63$ & 0,49 & 0,197 & $-1,60$ & 0,33 \\
\hline Masa ósea & & $-1,77$ & 1,77 & 0,320 & $-5,29$ & 1,75 \\
\hline $\begin{array}{l}\text { Frecuencia cardiaca } \\
\text { en reposo }\end{array}$ & & $-0,06$ & 0,04 & 0,147 & $-0,14$ & 0,02 \\
\hline $\begin{array}{l}\text { Sexo (Mujer vs } \\
\text { Hombre) }\end{array}$ & & $-2,68$ & 1,40 & 0,058 & $-5,47$ & 0,10 \\
\hline Temperatura $\left({ }^{\circ} \mathrm{C}\right)$ & & 1,01 & 0,64 & 0,121 & $-0,27$ & 2,29 \\
\hline
\end{tabular}

De un total de 96 sujetos de estudio, 14 voluntarios (un 15,60 \%) presentaron un IP posterior inferior al previo. De estos 14 sujetos, 13 tenían un cuestionario de actividad física nivel sedentario, uno con actividad moderada, y ningún voluntario con nivel de actividad alto presentó menos IP final que inicial. Los sujetos con un nivel de actividad alto o moderado presentaron una buena capacidad de adaptación al ejercicio físico, por el contrario, los sujetos con bajo nivel de actividad presentaron una peor tolerancia al estrés fisiológico, de hecho, de 49 voluntarios en total con nivel de actividad sedentario, 13 disminuyeron su nivel de IP —un 27\%- (ver Figura 33). 


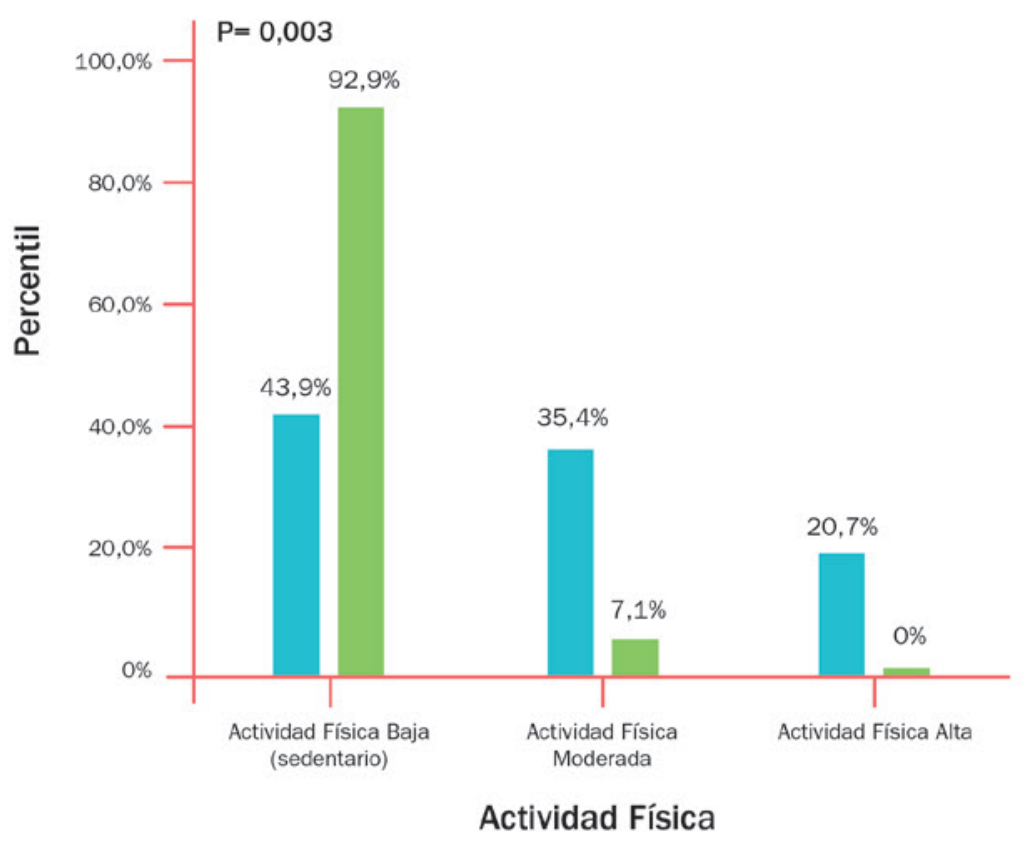
No tolera IP
NO
SI

Figura 33. Distribución de la variación del índice de perfusión en función del nivel de actividad física

\subsection{Selección de talla de trajes de protección}

En cuanto a la selección de talla de los trajes de protección cabe destacar que un $72 \%$ de los voluntarios realizaron una selección inadecuada, y un $66 \%$ solicitaron tallas menores de las necesarias.

La fiabilidad global de talla de traje fue de 0,49 (IC95\% 0,38-0,60), lo que se considera una concordancia moderada. No se encontraron diferencias en la fiabilidad según el grupo profesional estudiado $(p=0,920)$ (ver Tabla 43).

Se ajustó un modelo de regresión logística para explicar los factores asociados a una talla de traje errónea. Las variables incluidas en el modelo fueron sexo, edad, años de experiencia laboral, grupo profesional, fumador, grasa corporal, masa muscular, IMC. Los factores asociados a no escoger la talla del traje adecuada fueron la edad —los más jóvenes erraron más-y si eran estudiantes o no -los estudiantes erraron más- (Tabla 44). 
Tabla 43. Fiabilidad de la talla de traje real con la solicitada por el voluntario

\begin{tabular}{|l|c|c|c|c|c|}
\hline & Kappa & EE & \multicolumn{3}{|c|}{ IC 95\% } \\
\hline Estudiantes & 0,47 & 0,09 & 0,30 & 0,63 & $<0,001$ \\
\hline Profesionales & 0,45 & 0,07 & 0,31 & 0,60 & $<0,001$ \\
\hline Global & 0,49 & 0,06 & 0,38 & 0,60 & $<0,001$ \\
\hline
\end{tabular}

Tabla 44. Modelo de regresión logística para explicar los factores asociados a una talla de traje errónea

\begin{tabular}{|l|c|c|c|c|}
\hline & $p$ & Odds ratio & \multicolumn{2}{|c|}{ IC95\% } \\
\hline Edad & 0,007 & 0,85 & 0,76 & 0,96 \\
\hline $\begin{array}{l}\text { Grupo profesional (profesional/ } \\
\text { estudiante) }\end{array}$ & 0,007 & 0,02 & 0,00 & 0,32 \\
\hline
\end{tabular}

Test de Hosmer-Lemeshow p=0,961; ABC 0,71 (IC95\% 0,60-0,82)

Variables incluidas en el modelo sexo, edad, años de experiencia laboral, grupo profesional, fumador, grasa corporal, masa muscular, IMC. 


\section{6. Discusión}

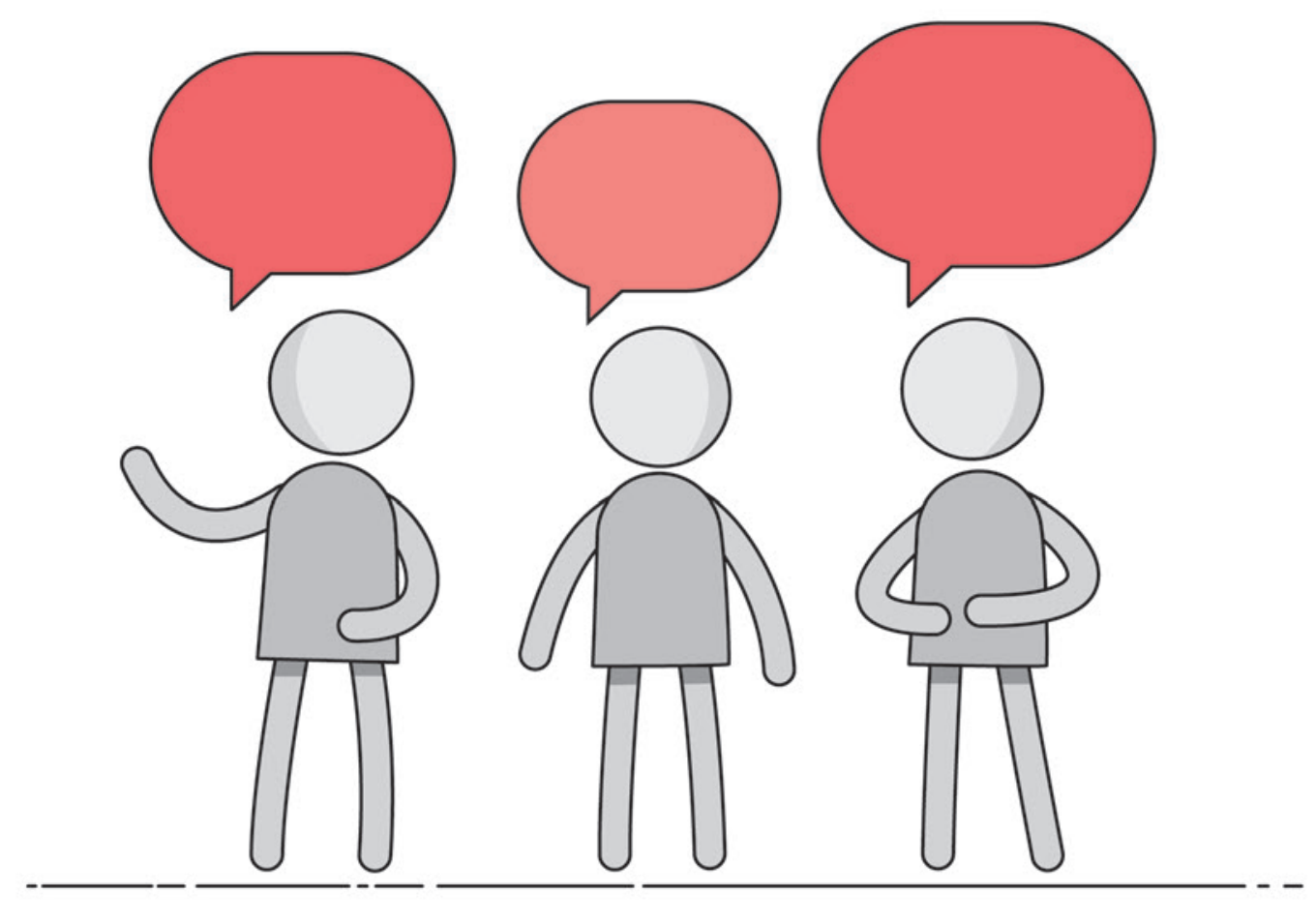




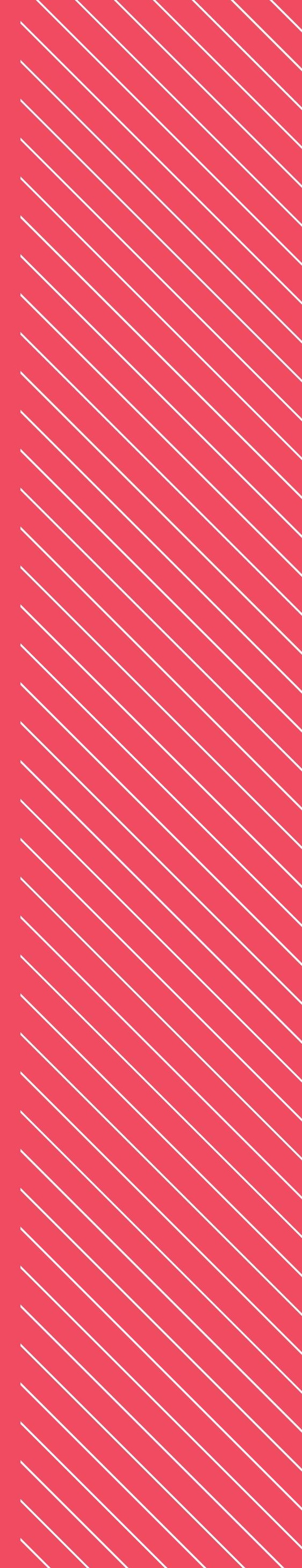




\subsection{Hallazgos más importantes}

Para la elaboración de la presente tesis se ha realizado un estudio quasiexperimental, con el objetivo principal de describir los cambios fisiológicos que experimentan los profesionales que se equipan con trajes de protección individual nivel $D$ frente a riesgos biológicos.

Los servicios de Urgencias y Emergencias deben contemplar dentro de su diseño curricular de competencias el manejo de incidentes con riesgo NBQ, bien porque sean actos fortuitos o porque sean actos terroristas intencionados ${ }^{(52)(53)(54)}$. En líneas generales, podemos afirmar que el uso de equipos de protección frente a riesgos biológicos resulta especialmente duro y arduo para los trabajadores, imponiendo una carga de estrés fisiológico extra para la intervención (55) (56).

Resulta sencillo de demostrar que el hecho de tener que trabajar con equipos de protección frente a riesgos biológicos complica a nivel técnico los procedimientos; sin embargo, no se encuentran estudios extensos sobre el hecho de que el empleo de estos equipos exige una alta intensidad de esfuerzo físico, trabajo de alta intensidad que no permite trabajar en intervalos de tiempo muy grandes ${ }^{(57)}$.

\subsubsection{Variación de las constantes vitales}

La variación de las constantes vitales no presentó diferencias significativas por sexos, grupos o subgrupos de estudio que nos puedan marcar un parámetro que varíe significativamente; sin embargo, se pudo observar un patrón uniforme en toda la muestra. Este patrón nos indica que la mayoría de los voluntarios de la muestra presenta mayor FC posterior que inicial, menos TAS y TAD final que inicial, más FR, temperatura, hemoglobina total e IP final que inicial y menos saturación de oxígeno final que inicial (ver Tablas 19 y 20).

El modelo fisiológico explica determinadas alteraciones, como el aumento de la hemoglobina e IP y descenso de la saturación final. Como respuesta fisiológica al ejercicio intenso y la liberación de catecolaminas, se origina una vasoconstricción periférica ${ }^{(58)}$, que conlleva una redistribución sanguínea, aportando mayor cantidad de glóbulos rojos, y, por tanto, de hemoglobina saturada a órganos centrales; pero, al tiempo, al haber más hemoglobina biodisponible, baja en términos porcentuales la saturación total ${ }^{(59)}$.

A pesar de que, una vez terminado el caso clínico, los voluntarios se desvistieron según protocolo, y dispusieron de 10 minutos de reposo, la FC posterior presentó una diferencia media de 11,43 latidos por minuto mayor al acabar que al comienzo de la prueba, hecho que se justifica por el incremento de actividad y la liberación de catecolaminas. Un 13,54\% (13/96) presentó menos FC posterior que inicial, cinco sujetos presentaban un nivel de forma física alto, dos actividad física moderada, y seis pertenecían al grupo de sedentarios. Los sujetos pertenecientes al grupo de actividad física moderada son los que más estables permanecieron, reafirmando este dato estudios que aconsejan un nivel de actividad física moderado, y que abogan por un estilo de vida saludable, aduciendo que tan malo resulta el sedentarismo como el exceso de ejercicio ${ }^{(60)(61)}$.

Durante la realización de cualquier ejercicio físico de intensidad moderada o alta, se incrementa la tensión arterial para compensar la mayor demanda de energía solicitada. Al concluir el ejercicio, se origina una vasodilatación generalizada, y, como consecuencia, una redistribución sanguínea, disminuyendo la tensión arterial. Después de 5-6 minutos de concluir el ejercicio, la tensión arterial disminuye a los niveles previos de reposo, y, a continuación, disminuye más la tensión arterial, hasta 
cifras inferiores a las basales, manteniéndose este descenso hasta las siguientes 5-6 horas (62)(63). Un 28\% de los sujetos de estudio (27 de 96) presentaron más TAS final que inicial, un $42 \%$ más TAD final que inicial (40 de 96), y un 13\% ambas cifras de TA elevadas (12 de 96). De los sujetos que de forma global presentaron elevaciones de TAS y TAD final respecto a la basal, 11 de 12 presentaron un incremento de la FC final respecto a la inicial, y 9 de 11 elevaciones de la FR final respecto a la inicial. Estos hechos corroboran la presencia de un modelo fisiológico de mala tolerancia a la prueba, tomando como patrón oro el aumento de la TAS y TAD de forma global postejercicio ${ }^{(64)(65)}$.

Actualmente, determinadas profesiones tienen reconocido el estrés térmico por calor como riesgo laboral. Nos referimos a lugares de trabajo como fundiciones, lavanderías, panaderías, invernaderos o trabajos de obra pública, entre otros. En el caso de los profesionales sanitarios, este riesgo no está reconocido, pero el hecho de tener que trabajar con EPI específicos, tales como los equipos de protección frente a riesgos biológicos, y bajo condiciones ambientales adversas, generan un estrés térmico añadido.

Si unimos el estrés térmico con la sobrecarga fisiológica que se origina por calor — debido al propio esfuerzo que suponen las tareas de reanimación-, trabajar con equipos de protección de riesgo biológico altera de forma significativa los mecanismos de termorregulación fisiológica (66) (56). El profesional comenzará a sudar, y se producirá una evaporación en el interior del traje, provocando que la piel se enfríe; al mismo tiempo, aumenta el flujo de sangre hacia la piel (vasodilatación periférica), para aumentar la liberación de calor hacia el exterior (imposible en este caso debido a las propias características de impermeabilidad del traje de protección). Si esta situación se origina bajo un esfuerzo físico muy intenso o duradero en el tiempo, los profesionales que portan estos equipos comienzan a presentar incomodidad y disminución del nivel de atención y capacidad de respuesta ${ }^{(67)}$. Este hecho aumenta la probabilidad de sufrir accidentes laborales y el riesgo de reagudización de enfermedades preexistentes, disminuyendo el tiempo efectivo de trabajo o generando situaciones de trabajo en las que es imposible realizar las tareas asignadas con seguridad, tanto para el paciente, como para el propio trabajador o el resto de los trabajadores ${ }^{(68)(69)}$.

Se puede presuponer que trabajar con un equipo de protección biológica que dificulta enormemente la transpiración y termorregulación puede elevar la temperatura corporal de los trabajadores, este factor añadido al propio esfuerzo físico que se debe realizar genera una carga térmica agregada que acorta los tiempos de trabajo por agotamiento precoz de los trabajadores. Este hecho debe ser tenido en cuenta a la hora de pautar los turnos, cargas y horarios de trabajo con los equipos de protección colocados, pues queda demostrado que se produce un incremento significativo de la temperatura corporal en un 91\% de la muestra.

\subsubsection{Relación entre la frecuencia cardiaca máxima durante la reanimación y el nivel de actividad física (IPAQ)}

A diferencia de otras técnicas y procedimientos que es preciso realizar en la práctica clínica, la reanimación cardiopulmonar requiere unas mínimas condiciones físicas por parte del que la lleva a cabo, debido a que ciertas técnicas, como la realización correcta de un masaje cardiaco externo, requieren un esfuerzo físico intenso, que además debe ser prolongado en el tiempo en muchas ocasiones ${ }^{(70)}$. Tras realizar a todos los voluntarios el cuestionario de actividad física IPAQ, se pudo constatar que la mayoría de la muestra (51\%) presentaban un nivel de actividad bajo (sedentario), y que precisamente 
el 53,1\% de estos sujetos con bajo nivel de actividad presentaron más FC durante la realización del masaje cardiaco externo durante el caso clínico que su umbral anaeróbico calculado mediante la cicloergometría.

Estos datos corroboran la hipótesis de que un nivel de actividad física moderado-alto repercute de forma directa en la mejor tolerancia al esfuerzo físico, igual que en cualquier ámbito de la vida diaria, en tareas tan específicas como una reanimación con un equipo de protección biológica.

Las maniobras de reanimación son duras técnicamente y exigentes a nivel físico ${ }^{(71)}$. Los entrenamientos en esta materia deben estar planificados en cualquier servicio de urgencias y emergencias, y se deben realizar actualizaciones con frecuencia ${ }^{(72)}$. El uso de equipos de protección individual, desde los más simples hasta los más complejos, dificultan las tareas de reanimación $\left({ }^{73)}(74)\right.$ y exigen un esfuerzo físico mayor por parte de los intervinientes en la emergencia ${ }^{(75)}$.

\subsubsection{Relación entre la frecuencia cardiaca máxima durante la reanimación y el umbral anaeróbico (protocolo Conconi)}

Según los tiempos van evolucionando, cada vez es más frecuente y no un hecho excepcional que los servicios de emergencias deban realizar maniobras de soporte vital avanzado o reanimación en pacientes infectados con riesgo biológico ${ }^{(76)(77)}$ o en escenarios con agentes biológicos intencionalmente diseminados, en los que los servicios de emergencias deben realizar su trabajo bajo unos estándares de protección muy exigentes, pero, al mismo tiempo, muy restrictivos en cuanto a movilidad, confort, ergonomía, esfuerzo, transpirabilidad, disminución de la visión y de la audición, entre

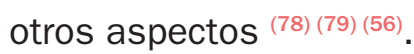

La realización de la RCP en situaciones convencionales está bien evaluada y estudiada, y las organizaciones internacionales realizan recomendaciones completas de cómo proceder en estos casos. Sin embargo, existen otro tipo de situaciones infrecuentes que requieren un estudio especial; nos referimos a la realización de la RCP en espacios singulares como espacios alejados y agrestes, espacios confinados, rescate acuático, incidentes con mercancías peligrosas, eventos con riesgo NBQ, la reciente epidemia por virus Ébola ${ }^{(80)(81)(82)}$, etc. siendo en este estudio la situación particular en la que nos centramos la incidencia que presenta el uso de un EPI categoría D en la FC de los volun-

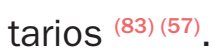

En el estudio realizado se puede apreciar que un $46,9 \%$ de los voluntarios presentan un sobreesfuerzo físico para realizar las maniobras de reanimación muy elevado, mostrando una FC más alta durante las maniobras de masaje cardiaco externo que durante una cicloergometría (ver Figura 28). Este sobreesfuerzo, salvo en personas muy entrenadas, no es bien tolerado a nivel fisiológico ${ }^{(32)}$ ${ }^{(84)}$, incidiendo de forma directa tanto en la calidad de las maniobras de reanimación (actual caso de estudio), como en el agotamiento precoz de los profesionales, hecho que debería ser tenido en cuenta por los servicios de urgencias y emergencias durante la selección de personal y en el posterior entrenamiento y reciclaje periódico de los profesionales ${ }^{(85)(86)(87)}$ (ver Figura 34). 


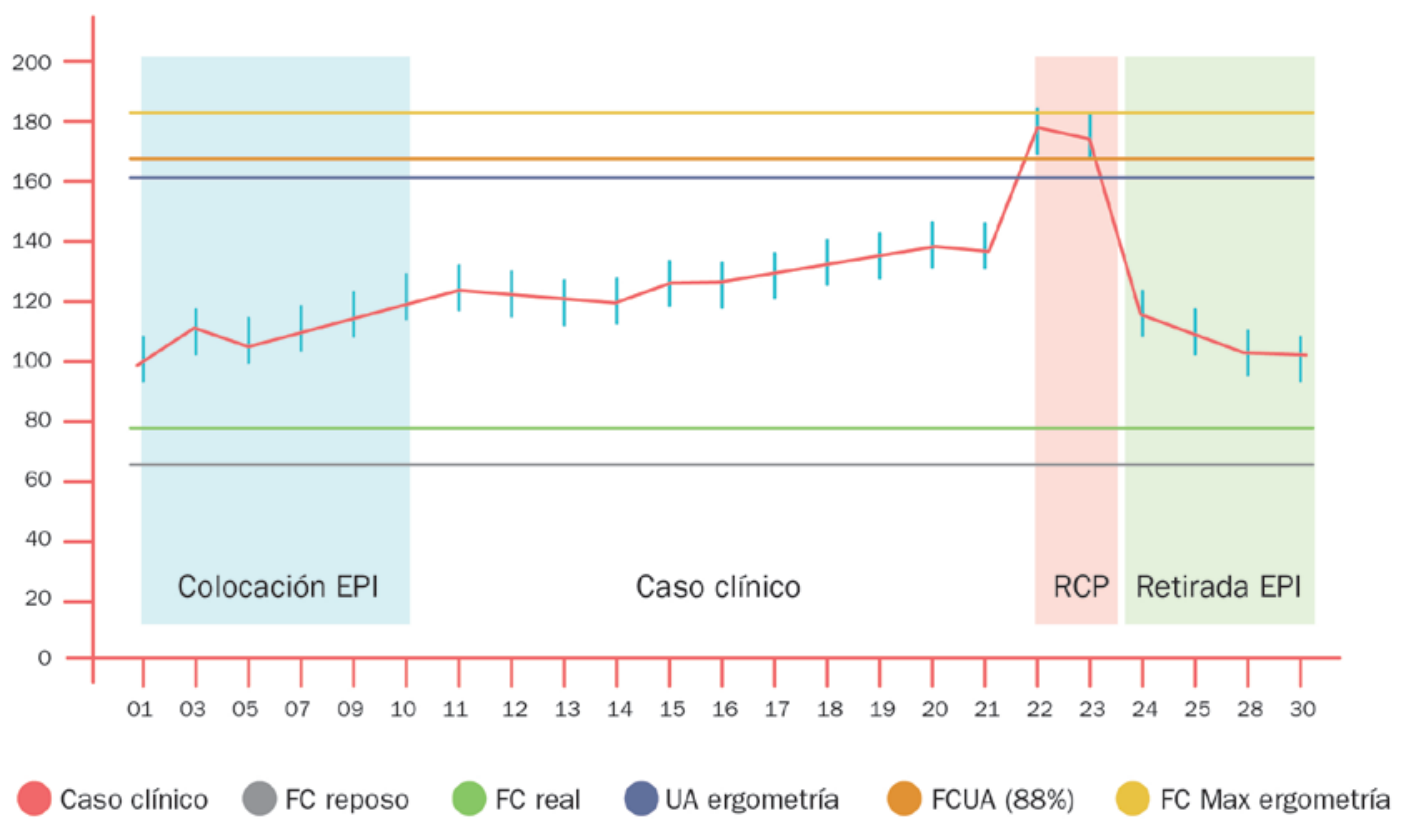

Figura 34. Evolución de las frecuencias cardiacas durante la realización del caso clínico para el global de la muestra

\subsubsection{Relación entre la fórmula de Tanaka y la FC máxima, y entre el UAT y el umbral anaeróbico (cicloergometría)}

Resulta necesario en determinadas situaciones conocer la FCM de los trabajadores para poder evaluar si el tipo de trabajo que realizan se adecua a sus umbrales fisiológicos, ya que es sabido que hay determinadas actividades laborales que generan un incremento de la FC muy notable.

Tradicionalmente se han venido empleando fórmulas para el cálculo de la FCM tales como 220 edad, o similares, pero se ha podido demostrar que la variabilidad y desviación de esta clásica fórmula hace que su uso para fines científicos no sea adecuado ${ }^{(88)(89)}$. La fórmula de Tanaka ha sido ampliamente empleada y validada en distintos estudios, representando una herramienta muy útil para el cálculo de la FCM ${ }^{(90)(91)}$.

La cuestión que se plantea en este caso es si realmente la fórmula de Tanaka predice con exactitud la FCM, por lo que se ha comparado con la FCM obtenida mediante cicloergometría (protocolo Conconi). Para ello se han comparado las dos mediciones, observando la fórmula de Tanaka (valor teórico) con respecto a la obtención de la FCM de una forma reglada mediante cicloergometría (valor práctico y objetivo).

Una vez conocida la FCM, entendida como el número de latidos máximos que puede soportar un corazón durante un minuto sometido a máximo esfuerzo ${ }^{\left({ }^{92}\right)}$, es necesario calcular el umbral anaeróbico, es decir, calcular la cifra de FC que es tolerable para trabajar a alta intensidad y no sobrepasar los umbrales peligrosos, en los que se trabaja ya en metabolismo anaeróbico. Este umbral anaeróbico teórico a nivel de FC se calcula en un $88 \%$ de la FCM. Cuando se trabaja por encima de este rango, es necesario comenzar a metabolizar el ácido láctico, y solo podrán soportar este nivel de actividad trabajadores con muy buena condición física ${ }^{(93)}$. 
Al igual que con el cálculo de la FCM mediante la fórmula de Tanaka y la FCM obtenida mediante cicloergometría, se puede obtener de una forma empírica el umbral de FC a partir del cual el sujeto comienza a trabajar bajo metabolismo anaeróbico. Durante la prueba de esfuerzo, con el voluntario monitorizado, podemos observar un punto de deflexión de la frecuencia cardiaca. Es el momento del ciclo cardiaco en el que el sujeto experimenta un leve estancamiento o deflexión de su frecuencia cardiaca durante la realización de la prueba (fase de meseta), que se acerca mucho al momento en el que se pasa del metabolismo aeróbico al anaeróbico. A continuación, el voluntario pasa de trabajar con un metabolismo aeróbico a uno anaeróbico, identificándose en la ergometría por medio de la observación de la fase de meseta. A continuación, el índice de fatiga es mayor que el índice de rendimiento (con excepciones en deportistas de élite cuyo cuerpo está acostumbrado a trabajar en metabolismo anaeróbico).

Comparados los datos entre el umbral anaeróbico teórico (88\% de la FCM obtenida mediante la fórmula de Tanaka) y el umbral anaeróbico real obtenido de forma empírica mediante la ergometría, podemos observar que presenta un coeficiente de correlación interclase con una buena fiabilidad [CCl de 0,694 (IC95\% 0,54-0,80), y p<0,001], dato que corrobora la utilidad y exactitud predictiva de esta fórmula ${ }^{(94)(95)}$ (ver Figura 35).

A la vista de los datos anteriores, se puede concluir que el cálculo teórico, tanto de la FCM como del UAT, presenta una buena fiabilidad comparada con los datos obtenidos de forma clínica mediante la ergometría, por lo que esta forma de obtener dichos parámetros está validada para la muestra y puede ser utilizada con seguridad.

Del mismo modo, se puede observar que la fórmula es más precisa para los sujetos con un alto nivel de entrenamiento que para los sujetos sedentarios; es decir, en voluntarios con bajo nivel de actividad la desviación del cálculo del UAT a través de la fórmula de Tanaka presenta una desviación mayor que para sujetos con un nivel de actividad alto.

Estos datos nos indican que el cálculo del UAT es más sensible cuanto más entrenado esté el sujeto, dato que se debe considerar a la hora de realizar los cálculos.

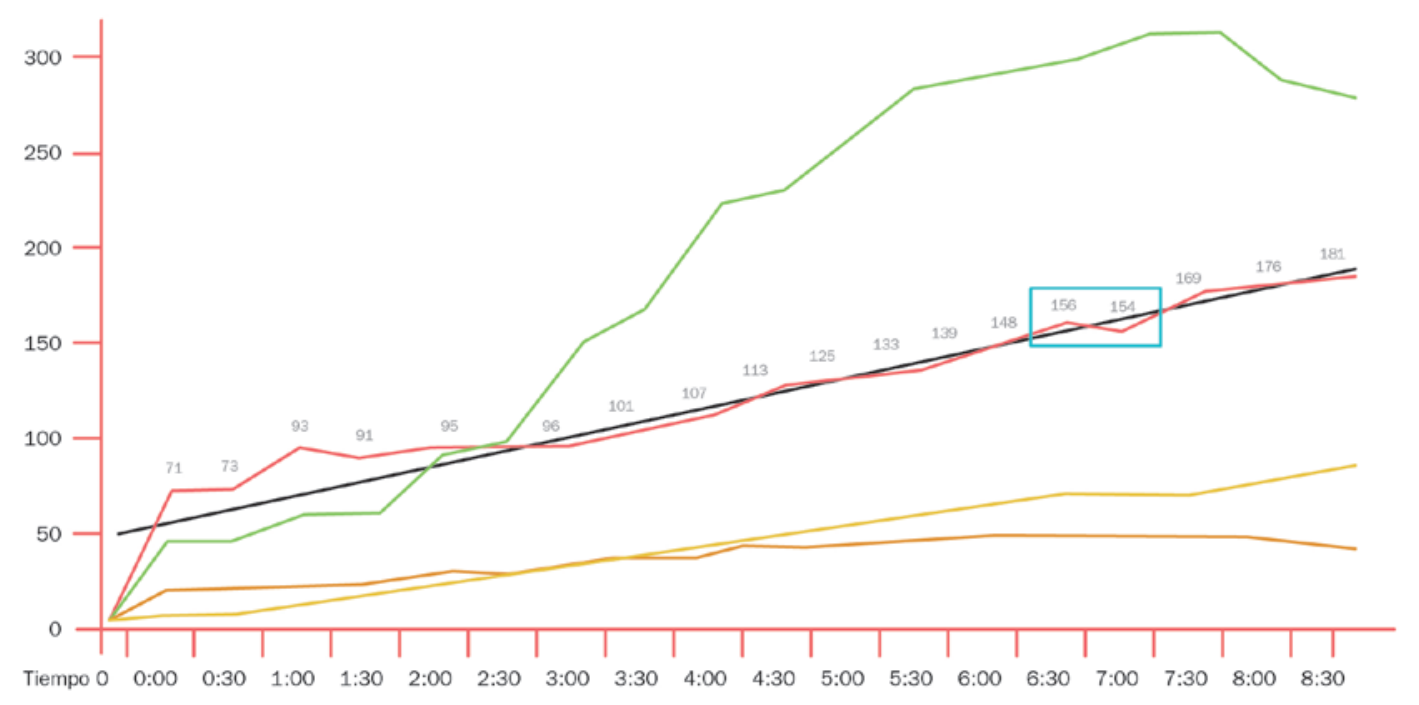

Carga Velocidad P.C. Potencia Deflexión

Figura 35. Ejemplo de cicloergometría, varón de 43 años, nivel de actividad física tipo 3 (alto). FCM fórmula Tanaka 175,9 Ipm, UAT $155 \mathrm{lpm}$. FCM test $181 \mathrm{lpm}$, UA test $154 \mathrm{lpm}$ 


\subsubsection{Variación del ácido láctico}

Respecto a la variación del ácido láctico, debe mencionarse, en primer lugar, que en ejercicios de mucha intensidad y corta duración (aún más cuanto menos entrenada esté la persona), el organismo no tiene suficiente cantidad inmediatamente disponible de oxígeno, y debe conseguir energía por vías menos eficientes y que generan más desechos metabólicos (metabolismo glucolítico). El ácido láctico se genera como subproducto metabólico, reciclando el organismo este metabolito a medida que se va originando, hasta un punto en el que el cuerpo es incapaz de reciclar el ácido láctico y este se empieza a acumular por encima de $4 \mathrm{mmol} / \mathrm{L}^{(96)(97)}$, superando el denominado umbral anaeróbico. En personas entrenadas, este umbral puede ser superior, y —aún más importante- la capacidad de lavado de ácido láctico es mucho más rápida, por lo que no se acumulan grandes cantidades. En personas poco entrenadas, esta acumulación de ácido láctico origina una inhibición selectiva de las enzimas responsables de degradar la glucosa para obtener energía, disminuyendo la producción de energía, al tiempo que se dificultan los procesos normales de absorción del calcio, hecho que, además, dificulta la contracción de las fibras musculares. En consecuencia, en niveles elevados de ácido láctico, la capacidad de generar energía disminuye y la capacidad muscular decrece, apareciendo de forma precoz la fatiga ${ }^{(98)(99)(100)}$.

Cuanto más entrenado esté el sujeto, mejor y más rápida será la respuesta normal al ejercicio de intensidad media o alta, y más eficiente será la vuelta a la normalidad. De hecho, un parámetro bien consensuado y que nos indica de una forma indirecta la aparición de fatiga son los niveles de ácido láctico por encima de $4 \mathrm{mmol} / \mathrm{L}$ al final de la intervención ${ }^{(51)}$. Cuando es necesario producir energía en ausencia de oxígeno, el producto final de la contracción muscular es el ácido láctico, que desaparece con rapidez cuando cesa el esfuerzo, es decir, cuando cesa la necesidad exagerada de energía, el organismo recicla 4/5 partes del ácido láctico resintetizándolo en glucógeno. Cuando el organismo no está acostumbrado o el esfuerzo es muy intenso o muy prolongado en el tiempo, comienza a acumularse el ácido láctico en sangre (lactacidemia) (ver Figura 36).

En el presente estudio se ha podido observar que hay voluntarios con cifras de lactato finales mayores que las iniciales, cifras de lactato en la RCP mayores que en la cicloergometría, o cifras finales mayores de $4 \mathrm{mmol} / \mathrm{L}$. De los sujetos entrenados, ningún voluntario presentó los tres valores alterados, y, sin embargo, en sujetos sedentarios no existe ningún sujeto sin alteraciones del patrón del ácido láctico (ver Figura 29).

Podemos afirmar, por tanto, que las personas con un bajo nivel de actividad física presentan un bajo nivel de tolerancia respecto al ejercicio físico intenso. Este dato no resulta llamativo, ni mucho menos novedoso, pero, junto con parámetros asociados como las modificaciones de la TAS o TAD, el IP o las FC, reafirma la presencia de un patrón de voluntarios de la muestra que toleran muy mal el ejercicio propuesto. Este hecho es fundamental, porque nos puede orientar durante la selección hacia el tipo de profesional que sea el más adecuado para este tipo de funciones. 


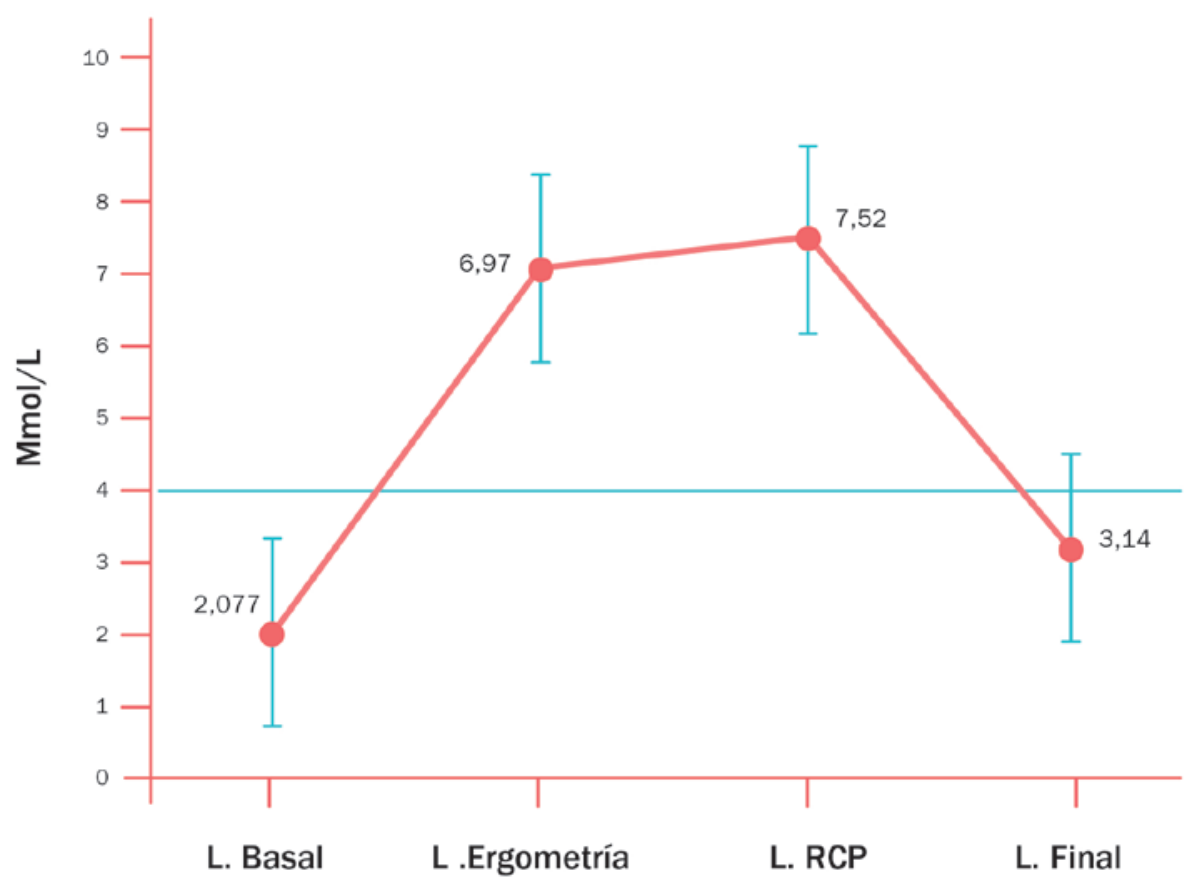

Figura 36. Comportamiento del ácido láctico en 4 determinaciones durante el estudio. La línea azul marca el umbral de $4 \mathrm{mmol} / \mathrm{L}$ a partir del cual comienza la lactacidemia

Para concluir el estudio del ácido láctico, se ha realizado un modelo de regresión logística multivariable para poder predecir qué sujetos van a presentar al final de la prueba más de $4 \mathrm{mmol} / \mathrm{L}$ de ácido láctico, valor umbral que marca la mala tolerancia metabólica a la prueba ${ }^{(51)}$. Conociendo de antemano la masa muscular, el IMC, la masa ósea y el nivel de experiencia (estudiante o profesional), podemos predecir con una capacidad muy buena (75\%) el mal comportamiento metabólico de los sujetos (ver Figura 31).

Este valor predictivo es especialmente relevante, pues permite hacer un cribaje previo con una alta sensibilidad para saber quién podría tolerar mal la realización de un trabajo con este equipo de protección individual frente a riesgos biológicos.

Conociendo el posible comportamiento de los trabajadores a nivel fisiológico, se puede realizar una selección más eficiente, y evitar en la medida de lo posible situaciones de riesgo innecesario en las intervenciones.

\subsubsection{Comportamiento del índice de perfusión}

El índice de perfusión se trata de una medida indirecta, no invasiva y continua, que proporciona información muy útil en distintos contextos clínicos. Este parámetro se refiere a la relación entre el flujo sanguíneo pulsátil y no pulsátil en los tejidos periféricos, de modo que un IP alto significa vasodilatación, y un IP bajo, vasoconstricción. La medición del IP es independiente de otras variables fisiológicas tales como $\mathrm{FC}, \mathrm{SpO}_{2}$, consumo de oxígeno o temperatura, dato que hace todavía más relevante el estudio de este parámetro.

El abanico de situaciones clínicas en las que el IP ha demostrado su utilidad incluye la monitorización de la efectividad de la anestesia epidural, ya que un aumento del IP tras la administración de anestesia indica un incremento en la vasodilatación periférica, que normalmente se produce antes 
de la aparición del efecto anestésico ${ }^{(101)}$. En neonatos en estado crítico está contrastado que un bajo IP es una medida objetiva y precisa de enfermedad aguda ${ }^{(102)}$. De igual modo, este parámetro está siendo empleado para la estimación de la administración de volumen en pacientes con trauma grave, en estados de sepsis ${ }^{(103)(104)(105)}$, o en cirugías de reimplante y después de bypass cardiopulmonar, para la evaluación de la perfusión periférica.

No existen estudios suficientes que avalen el uso del IP en personas sanas, pero toda la bibliografía consultada (106)(107) (108) concluye que un alto IP origina vasodilatación y buena perfusión, y un bajo IP provoca vasoconstricción y mala perfusión. Extrapolando estos datos, podemos concluir que, en la muestra de estudio que nos ocupa, los voluntarios que presentan menos IP al finalizar que al comenzar no toleran bien el esfuerzo que supone el caso clínico; además, se ha encontrado un patrón común en el comportamiento de la hemoglobina total y de la saturación de oxígeno.

Un 15\% de los voluntarios presentaron un IP posterior inferior al previo, lo que se traduce en una situación de vasoconstricción periférica después de la realización del ejercicio físico que supuso el caso clínico, cuando lo esperable era una vasodilatación para aumentar la perfusión. De estos 14 sujetos, 13 tenían un cuestionario de actividad física nivel sedentario, uno con actividad moderada, y ningún voluntario con nivel de actividad alto presentó menos IP final que inicial. Los sujetos con un nivel de actividad alto o moderado presentaron una buena capacidad de adaptación al ejercicio físico; por el contrario, los sujetos con bajo nivel de actividad dieron muestras de una peor tolerancia al estrés fisiológico.

\subsubsection{Patrón fisiológico de mala tolerancia al uso de equipos de protección biológico nivel D}

En el momento en el que los voluntarios realizan la cicloergometría o el caso clínico, teniendo que hacer masaje cardiaco externo, el organismo, al verse sometido a un ejercicio de una intensidad media o alta, experimenta cambios súbitos para poder adaptarse a la nueva situación de demanda de energía necesaria. Una vez finalizada la actividad y, por tanto, la demanda excesiva de energía, el organismo recupera los niveles basales de actividad; incluso algunos parámetros fisiológicos se sitúan a niveles inferiores a los iniciales, como, por ejemplo, la tensión arterial, la cantidad de glucosa en sangre o la temperatura.

Teniendo en cuenta todos los datos hasta ahora evaluados, y una vez revisada la bibliografía referente al tema ${ }^{(109)(110)}$, se ha elaborado un patrón fisiológico de mala tolerancia al uso de equipos de protección biológico nivel D (ver Tabla 44). 
Tabla 45. Parámetros estudiados para la obtención del patrón fisiológico de mala tolerancia

\begin{tabular}{|c|c|c|}
\hline Parámetro & Buena tolerancia & Mala tolerancia \\
\hline FC media minutos $22-23$ caso clínico $(R C P)>$ FCUA & - & + \\
\hline FC final > FC inicial & - & + \\
\hline IP posterior $<$ IP inicial & + & - \\
\hline $\mathrm{SpO}_{2}$ final $>\mathrm{SpO}_{2}$ inicial & - & + \\
\hline $\mathrm{Hb}$ final $<\mathrm{Hb}$ inicial & + & - \\
\hline Temperatura final $>1^{\circ} \mathrm{C}$ con respecto a la $\mathrm{t}$. inicial & - & + \\
\hline Glucemia inicial > final y glucemia esfuerzo > inicial & + & - \\
\hline TAS final > TAS inicial & - & + \\
\hline TAD final > TAD inicial & - & + \\
\hline TAS y TAD finales > TAS y TAD iniciales & - & + \\
\hline TAS esfuerzo > TAS inicial & + & - \\
\hline TAD esfuerzo > TAD inicial & + & - \\
\hline TAS y TAD esfuerzo > TAS y TAD iniciales & + & - \\
\hline Lactato final > lactato inicial & - & + \\
\hline Lactato RCP > lactato ergometría & - & + \\
\hline Lactato final y RCP > lactato inicial y ergometría & - & + \\
\hline Lactato final $>4 \mathrm{mmol} / \mathrm{L}$ & - & + \\
\hline
\end{tabular}

Una de las consecuencias esperadas y cardiosaludables del ejercicio físico es el descenso de la FC. Así pues, podríamos esperar cifras de FC inferiores o iguales después de acabar la prueba y tras un periodo de reposo de 10 minutos ${ }^{(62)(63)}$. A pesar de eso, un $86,45 \%$ de los sujetos presentó más FC posterior que basal; solo 13 sujetos presentaron menos FC final (ver Figura 37). Este dato lleva a pensar que el nivel de actividad física y de entrenamiento previo de los voluntarios es muy bajo, y a la mayoría no les permite tolerar de forma adecuada el esfuerzo al que han sido sometidos. 


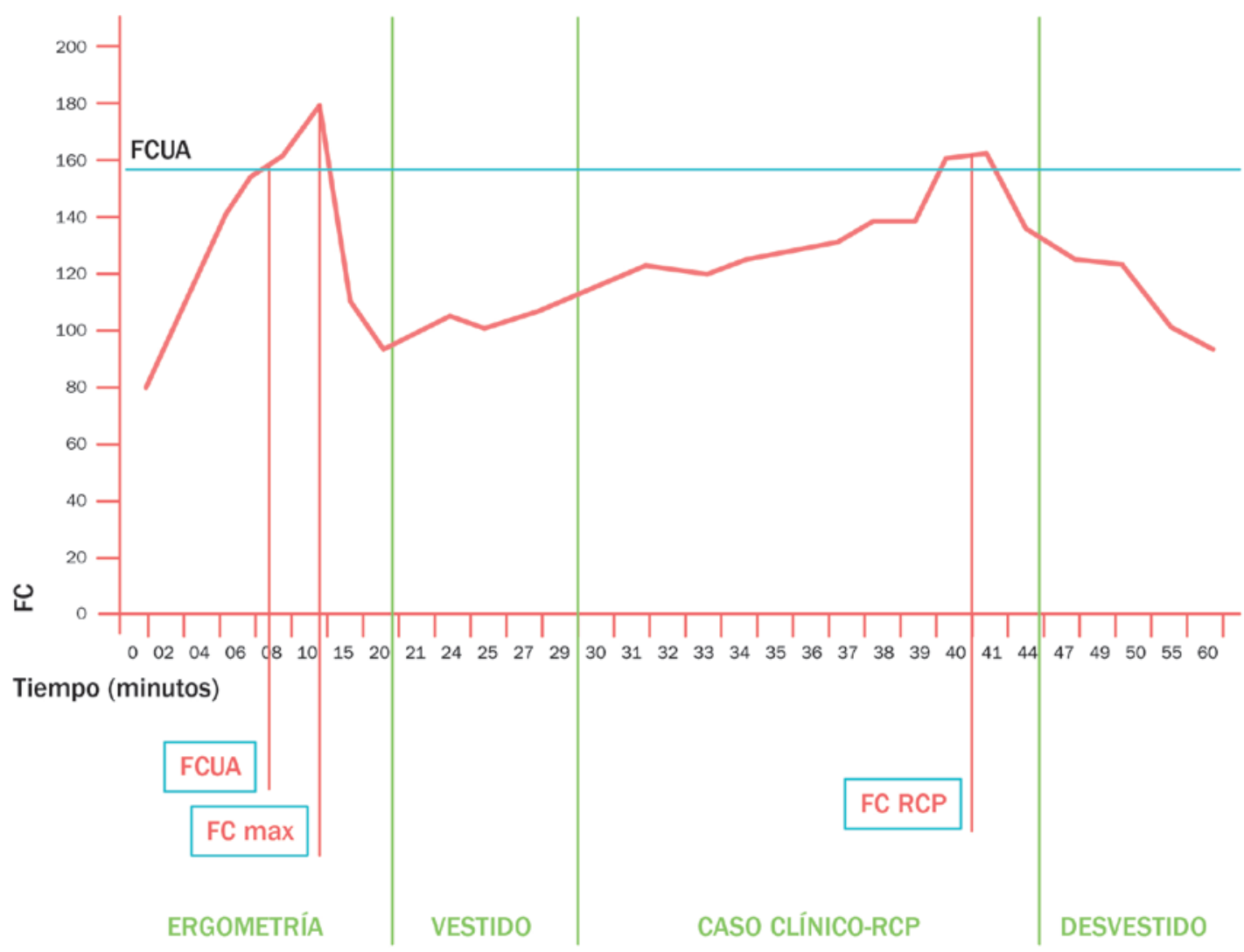

Figura 37. Comportamiento de la FC durante toda la prueba

Lo esperable es que al concluir la prueba los sujetos presentaran un mayor IP que al principio, debido a la vasodilatación periférica originada por el ejercicio. Un IP final menor que inicial indica que la redistribución sanguínea que debe acompañar de forma fisiológica durante el ejercicio físico no se ha producido.

A pesar de ser un parámetro independiente del IP, al aumentar la perfusión periférica disminuye la saturación, es decir, se da una redistribución celular, y se pone a disposición toda la hemoglobina circulante, por lo que hay más hemoglobina total pero la misma cantidad de oxígeno disponible. Los sujetos con más saturación final que inicial tienen un patrón de redistribución sanguínea poco apto para el ejercicio, en total un $11,45 \%$ de la muestra (11 de 96$)$.

Continuando con el razonamiento anterior, un efecto esperado del aumento de las demandas de energía necesarias como consecuencia del ejercicio físico es la puesta a disposición de toda la hemoglobina disponible. El patrón normal indica que, al acabar el caso clínico, los voluntarios deben presentar más hemoglobina total que al inicio, dato que cuadra con el incremento de IP y el leve descenso de la saturación de oxígeno. Por lo tanto, concluir la prueba con menos hemoglobina total al final que basal puede indicar mala tolerancia al ejercicio. Un 31,25\% de los sujetos (30 de 96) presentaron una mala tolerancia fisiológica con respecto a este parámetro (Figura 38). 


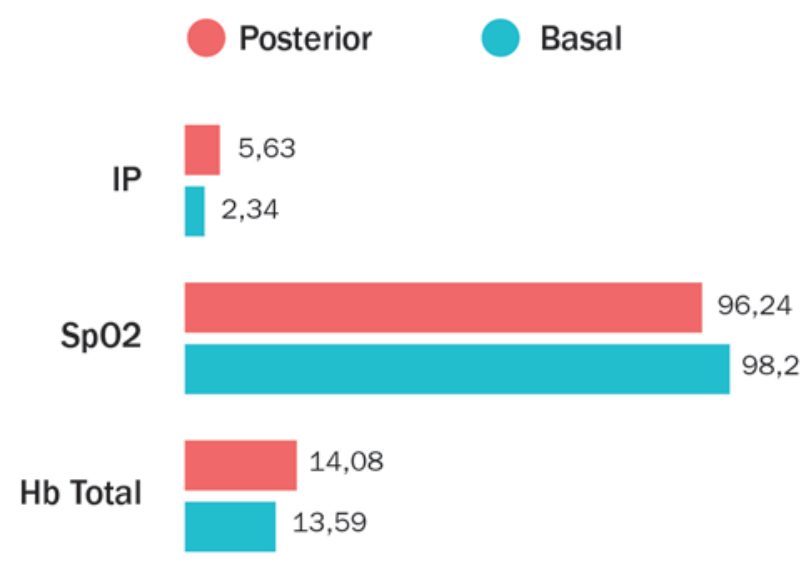

Figura 38. Patrón de comportamiento de IP, $\mathrm{SpO}_{2}$ y Hb total, determinaciones basal y final

Además de los anteriores parámetros, cabe destacar, asimismo, la modificación de la temperatura corporal. Tal y como se ha citado anteriormente, trabajar con equipos de protección individual frente a riesgos biológicos supone un estrés térmico para el trabajador, tanto por las propias características de los equipos (ausencia de transpiración, impermeabilidad, etc.), como por el esfuerzo físico inherente a la propia actividad. Al concluir el caso clínico, y tras 10 minutos de reposo, los voluntarios deberían tener la misma o incluso un leve descenso de la temperatura, debido a los mecanismos normales de termorregulación, sin embargo, un 91\% de la muestra presentó mayor temperatura final que inicial, y, de hecho, un $21 \%$ de los sujetos con más temperatura final que inicial presentó más de $1^{\circ} \mathrm{C}$ de incremento.

Uno de los efectos esperados del ejercicio físico es el control de la glucemia, de hecho, después del ejercicio, es normal apreciar un pequeño descenso de las cifras de glucemia sanguínea; por lo tanto, cabría esperar cifras de glucemia final ligeramente inferiores a las iniciales. De igual modo, en la determinación que se realiza durante la fase de máximo esfuerzo en la ergometría, cabe esperar un ligero aumento de la glucemia, para que el cuerpo pueda utilizar toda la glucosa disponible. Como resultado final, un 26,04\% (25 de 96) presentó un patrón de uso de glucosa totalmente inadecuado, con menos tasa de glucemia en esfuerzo que en reposo, y con más glucemia final que inicial.

El comportamiento esperable durante la realización de un ejercicio físico en las cifras de TA es un descenso de las cifras finales (después de un tiempo de reposo), con respecto a las basales. De igual modo, las cifras de TA en esfuerzo (durante la realización de la ergometría en el ciclo de metabolismo o anaeróbico) deben ser sustancialmente mayores que las cifras basales, debido al esfuerzo y al mayor bombeo de sangre fruto del incremento de las demandas de oxígeno. Un $28 \%$ (27 de 96) de sujetos presentan cifras de TAS mayor al final que las basales, un $42 \%$ (40 de 96) cifras de TAD final mayor que las basales, y un 13\% (12 de 96) ambas cifras finales superiores. Un porcentaje del 29,16\% (28 de 96) tuvieron menos TAS de esfuerzo que inicial, y un 28,12\% (28 de 96), menos cifras de TAD en esfuerzo que basal. Estos datos, junto con el estudio del modelo metabólico (comportamiento del ácido láctico), pueden indicarnos mala tolerancia al ejercicio físico, y, unido al resto de parámetros, orientan hacia la existencia de un patrón de mala tolerancia al uso de este tipo de equipos. No resulta posible comparar estos datos con estudios similares, ya que el resto de estudios que tangencialmente se acercan al tema de conocimiento no comparten ni metodología, ni evaluación similar ni intervención del equipo. 


\subsubsection{Selección de las tallas de los trajes de protección}

Los incidentes en los que se ven involucrados los agentes NBQ representan un verdadero problema de gestión, de asistencia, y — hecho relevante y novedoso para los SEM- de protección y autoprotección ${ }^{(9)}$, elementos fundamentales para el control del escenario inestable. Así pues, se marca de una forma nítida la línea general de la estrategia: evitar nuevas contaminaciones, bien sea de los profesionales o bien del entorno ${ }^{(10)}$.

Trabajar con equipos de protección individual adaptados al riesgo supone el manejo materiales nuevos o poco conocidos, en el mejor de los casos, aunque en muchas ocasiones resulta probable que los profesionales deban emplear equipos desconocidos o para los que no han obtenido la formación pertinente. No solo se debe manejar la patología médica o quirúrgica de los afectados, sino que se debe tener en mente la contención del incidente, la descontaminación y el manejo masivo de heridos y/o contaminados; todo ello bajo un estricto nivel de protección (111)(112) (113).

Estos operativos son especialmente sensibles, pues requieren una gran formación previa, conocimientos extrasanitarios, capacitación en el uso de equipos de protección individual específicos para riesgos concretos y, además, un manejo diferencial de los pacientes afectados por este tipo de situaciones: triaje inverso, descontaminación, uso de antídotos, etc., hechos que llevan a que las actuaciones en este tipo de incidente sean esencialmente complejas y requieran un mayor grado de adiestramiento, como nos ha demostrado la crisis por la enfermedad del virus Ébola ${ }^{(12)(114) .}$

Gracias al uso de equipos de protección individual se ha mejorado la asistencia a las víctimas, así como se han incrementado los casos de supervivencia de los intervinientes en incidentes tanto químicos como biológicos; pero el uso de este tipo de protección puede traducirse en la reducción de la capacidad operativa de una persona ${ }^{(115)(116)}$. En la selección de equipos de protección para la preparación biológica y química, se debe llegar a un equilibrio entre el grado de protección necesario para el peligro potencial en cuestión y la dificultad resultante para llevar a cabo las funciones por parte de los usuarios ${ }^{(117)}$.

El trabajo en situaciones de riesgo NBQ con el nivel necesario de protección afecta de forma directa - a nivel fisiológico- sobre a los trabajadores de la salud, generando un estrés físico muy importante, y llegando a un punto en el que es aconsejable dejar el operativo en curso y proceder a la retirada del equipo de protección, a causa de los riesgos no tolerables o el estrés fisiológico tan elevado que está sufriendo el trabajador (118)(119)(120). 
Tabla 46. Relación entre la talla de traje pedida y la real

\begin{tabular}{|c|c|c|c|c|c|c|c|c|}
\hline & \multicolumn{8}{|c|}{ Talla de Traje Real } \\
\hline \multirow{7}{*}{ 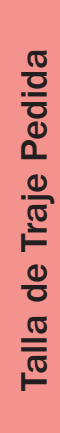 } & & XS & $S$ & M & L & XL & $2 X L$ & Tota \\
\hline & XS & 3 & 6 & 3 & 1 & 0 & 0 & 13 \\
\hline & $\mathrm{S}$ & 3 & 7 & 16 & 6 & 2 & 0 & 24 \\
\hline & M & 0 & 1 & 9 & 15 & 10 & 1 & 36 \\
\hline & L & 0 & 0 & 1 & 4 & 3 & 4 & 12 \\
\hline & $3 X L$ & 0 & 0 & 0 & 0 & 0 & 1 & 1 \\
\hline & Total & 6 & 14 & 29 & 26 & 15 & 6 & 96 \\
\hline
\end{tabular}

$66 \%$ talla menor

La mayor parte de los voluntarios no eligieron la talla del traje que precisarían utilizar en un incidente con riesgo biológico, ya que solicitaron tallas menores de las que deberían utilizar (ver Tabla 46). No se ha encontrado relación estadísticamente significativa con la edad, sexo, experiencia laboral o formación previa en NBQ, al ser el primer estudio realizado a tal efecto y con los datos conocidos hasta la actualidad.

El uso inadecuado de este tipo de protección puede traducirse en la reducción de la capacidad operativa, por lo que es necesario insistir sobre el riesgo que representa trabajar con una talla inadecuada del traje. Se precisaría el esfuerzo de incluir en los cursos de instrucción NBQ unas directrices adecuadas para aleccionar a los alumnos sobre el cálculo adecuado de la talla del traje que precisan.

\subsection{Comparación con otros estudios}

A través de una revisión amplia y exhaustiva de la bibliografía disponible, se han podido encontrar gran cantidad de estudios que tratan de manera tangencial aspectos relacionados con el tema principal de la presente tesis, pero ningún trabajo que de forma concreta estudie la respuesta fisiológica de los trabajadores de la salud al uso de equipos de protección individual frente a riesgos biológicos.

Muchos autores valoran la realización de técnicas con los EPI colocados - cabe destacar, por ejemplo, los múltiples estudios de Szarpak-. En una reciente publicación ${ }^{(121)}$ estudiaron el manejo avanzado de la vía aérea por personal paramédico con trajes de protección puestos; el mismo autor realizó un estudio similar comparando la utilización del equipo de punción intraósea con traje y sin traje ${ }^{(122)}$, o la realización de técnicas convencionales de acceso vascular con y sin traje ${ }^{(123)}$. Otro estudio de Szarpak ${ }^{(124)}$ valoró la correcta realización de las técnicas de masaje cardiaco externo sobre un maniquí por profesionales con trajes de protección, evaluó la correcta posición, profundidad o calidad, entre otros aspectos, pero no cómo afectaba este sobreesfuerzo físico a los reanimadores.

En estudios que, en cierto modo, se asemejan al objeto de estudio de esta tesis -como podría ser el de Guillaume Grillet et al. de $2015^{(125)}$ - , se ha valorado el comportamiento y la realización de técnicas con 13 voluntarios. El trabajo de Enrique Casalino et al. de $2015^{(126)}$ presenta un tamaño muestral mayor (120 sujetos), pero el objeto de estudio y la metodología varía de forma sustancial, ya que se pretende observar después de tres clases de entrenamiento cómo los voluntarios realizan 
las técnicas y procedimientos con los equipos de protección puestos, pero no cómo responden fisiológicamente a su uso, y sólo fue llevado a cabo con estudiantes, no con profesionales.

Otros autores han valorado la calidad en la puesta, descontaminación y retirada de los equipos de protección. Clay et al., en un estudio con profesionales de las fuerzas armadas, evaluó mediante el uso de luz ultravioleta la correcta retirada de los equipos y la tasa de contaminaciones ${ }^{(127)}$. Otro tipo de trabajos inciden en la importancia del entrenamiento previo en este tipo de emergencias complejas y en cómo mejorar la asistencia y la protección de los trabajadores. Gibson et al. realizaron una investigación para conocer el nivel previo de capacitación al despliegue en situaciones con riesgo biológico tipo Ébola del Ejército de Gran Bretaña ${ }^{(128)}$. Otro estudio que cabe destacar es el de Todd Bell et al., de $2015^{(129)}$, en el que se evalúan mediante marcadores la puesta y retirada del equipo de protección, con 8 voluntarios, 6 enfermeras cualificadas y dos médicos senior. Un proyecto de amplia repercusión y gran impacto fue el desarrollado por Mortelmans et al. ${ }^{(130)}$, que evaluó mediante encuesta el nivel de preparación frente a incidentes NBQ de 93 servicios de emergencias hospitalarios de los Países Bajos, concluyendo que hay una grave falta de preparación, sin embargo, en este caso la evaluación se realiza sobre aspectos técnicos y de procedimiento, no sobre cómo afecta el uso de estos equipos a los trabajadores de la salud.

Otros tipo de tesis analizan de forma muy segmentada cómo responden determinados parámetros fisiológicos a la puesta de trajes de protección NBQ. Un ejemplo muy significativo es el artículo de Richmond et al. ${ }^{(131)}$, que intenta predecir la temperatura corporal que puede tener un trabajador con distintos tipos de trajes de protección y con distintas condiciones ambientales; también es el caso de Adams et al. ${ }^{(132)}$, cuyo estudio trata de investigar la relación del uso de trajes de protección balística en personal con un peso normal o en obesos, y observar si hay diferencias en la temperatura corporal entre un grupo y otro (el tamaño de la muestra fue de 20 personas).

Por otro lado, en otros tipos de tesis se analiza la cantidad de agua que se moviliza con el uso de diferentes equipos de protección NBQ. Brown et al. ${ }^{(100)}$ concluyeron, después de realizar un estudio en el Servicio de Emergencias de Gran Bretaña, que no hay pruebas concretas que nos indiquen qué cantidad de líquido se debe ingerir para prevenir las complicaciones de la deshidratación por el uso de estos equipos específicos de protección, recomendando la realización de pruebas con equipos específicos y condiciones ambientales concretas para poder extraer resultados fiables.

Sin pretender extendernos demasiado en este apartado, cabe aún destacar que existen múltiples artículos que observan aspectos puntuales derivados del uso de equipos de protección NBQ en los

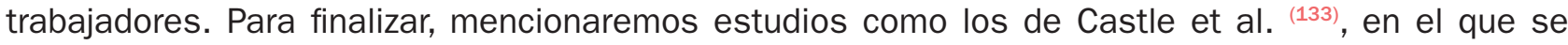
evalúa si afecta negativamente llevar trajes de protección NBQ a la capacidad clínica de preparar de forma segura, con precisión y rapidez, drogas y preparaciones clínicas, concluyendo que la principal complicación era la manipulación física de los propios medicamentos. Por otro lado, el artículo de Blacker et al. ${ }^{(134)}$ contempla las respuestas fisiológicas de policías durante simulaciones de trabajo portando armas y con equipos de protección NBQ, evaluando las modificaciones de peso, agua corporal y temperatura, concluyendo que el aumento de la temperatura corporal constituye la principal limitación fisiológica para el rendimiento con este tipo de equipos.

Para concluir, se han de destacar dos artículos, el de Stein et al. ${ }^{(67)}$, que analiza el tiempo de reacción de los trabajadores portando equipos de protección personal y su respuesta fisiológica. Los autores tratan de describir y comparar los cambios en la frecuencia cardiaca, el pH venoso, en el $\mathrm{pCO}_{2}$, bicarbonato, nivel de lactato, saturación de oxígeno y temperatura. Analizan las variaciones de 
estos parámetros en 19 sujetos sanos, en dos supuestos de 20 minutos de ejercicio sin equipos de protección, y después la variación durante 20 minutos de ejercicio portando trajes de protección. Los investigadores observaron cómo se elevaba más sustancialmente la FC en los voluntarios con los equipos de protección colocados que en el caso control, al igual que la temperatura; sin embargo, debido al tamaño de la muestra, los resultados no fueron estadísticamente significativos.

El último estudio relacionado con la presente investigación, y que resulta de especial relevancia, fue desarrollado por Northington et al. ${ }^{(135)}$, en 2007. En este estudio se evalúa la respuesta fisiológica durante el ejercicio realizado en cinta, equipado el voluntario con un equipo de protección frente a riesgos químicos. La muestra fue muy pequeña $(n=9)$, y el tiempo de ejercicio fue reducido (10 minutos), encontrándose como hallazgo más significativo la elevación de la temperatura de todos los voluntarios.

\subsection{Aplicación práctica}

El objetivo de toda tesis doctoral es, en mayor o menor grado, poder aplicar los hallazgos encontrados a la práctica clínica. Tras el análisis de los resultados obtenidos, la aplicación práctica de los principales hallazgos encontrados son:

\subsubsection{Protocolo de evaluación}

En función de los datos obtenidos a partir del estudio de los datos antropométricos y de bioimpedancia, así como del estudio de los parámetros fisiológicos, se puede realizar un protocolo de evaluación previa con el fin de conocer el estado de salud de los trabajadores que deban equiparse con este tipo de equipos de protección (ver Tabla 47).

Así pues, para este protocolo de evaluación se propone la determinación de los siguientes parámetros:

Tabla 47. Parámetros propuestos para el protocolo de evaluación

\begin{tabular}{|l|l|}
\hline Edad & Historia médica \\
\hline Alergias & Medicamentos \\
\hline Talla & Contorno de pecho \\
\hline Masa muscular & Masa ósea \\
\hline IMC & Porcentaje de agua \\
\hline ECG de reposo & IPAQ \\
\hline FC & TA \\
\hline FR & SpO \\
\hline Temperatura & IP \\
\hline Hemoglobina total & Glucemia \\
\hline Lactato basal & Complexión \\
\hline
\end{tabular}


A través del análisis de estos parámetros, podemos conocer el estado previo de salud del trabajador, así como, si existiera algún parámetro fuera de los límites considerados normales, poder tomar las medidas oportunas.

\subsubsection{Protocolo de entrenamiento}

Una vez realizado el examen de salud de los posibles trabajadores que deban equiparse con estos equipos de protección, el servicio puede desarrollar un protocolo de entrenamiento adaptado al riesgo en particular al que se enfrentan y con los materiales de los que dispongan, de forma que, cuando llegue la situación real de intervención, las incógnitas sobre el comportamiento y las sensaciones de trabajar con estos equipos sean las mínimas posibles (ver Tabla 48).

Tabla 48. Parámetros propuestos para el protocolo de entrenamiento

Toma de constantes vitales básicas: $\mathrm{FC}, \mathrm{FR}, \mathrm{TA}, \mathrm{SpO}_{2}$, glucemia y ácido láctico.

En función de su perímetro torácico y su altura, selección adecuada de la talla de traje.

En caso de duda, elegir una talla más de la necesaria.

Colocar medidor del pulsómetro en el tórax del trabajador.

Seguir las recomendaciones previas a la puesta del equipo.

Realizar colocación del equipo de forma reglada.

Colocar reloj pulsómetro adherido con esparadrapo en la espalda del trabajador.

Hacer dos sentadillas y dos aperturas forzadas de brazos para comprobar la confortabilidad del equipo.

Realizar un caso práctico de la forma más realista posible, con materiales reales y con paciente simulado.

Desvestido según procedimiento.

Vigilancia durante todo el proceso de la FC, por el protocolo de evaluación se conoce el UAT del sujeto, por lo que no debe pasar durante la realización del caso práctico de este umbral de FC máxima recomendada.

\subsubsection{Selección adecuada de la talla de traje}

A la hora de llevar a cabo el tipo de trabajos mencionados en la presente tesis, el traje no es el elemento más importante ni el único del equipo de protección, pero sí, junto con los guantes, el único elemento que dispone de diferentes tallas.

Resulta difícil que un profesional falle en la elección de la talla de guantes, al ser este un elemento de protección cotidiano en su trabajo; sin embargo, y según los datos analizados en el estudio, muy pocos trabajadores conocen su talla de traje real. 
Conociendo de antemano el perímetro torácico y la altura del sujeto, podemos comparar estos datos con el cuadro que aporta el fabricante; así podemos saber con exactitud la talla de traje más adecuada para el trabajador, eliminado posibles problemas serios por elegir una talla inadecuada, sobre todo si se selecciona una talla menor de la necesaria, ya que el riesgo de rotura, retracción de las mangas o incomodidad aumenta innecesariamente. Al mismo tiempo, si el servicio conoce las tallas de sus trabajadores, puede hacer un aprovisionamiento eficaz en función de las tallas necesarias.

\subsubsection{Tanaka y cálculo del UA}

La realización de una cicloergometría de forma reglada requiere una infraestructura importante, recursos humanos especializados y un tiempo considerable, por lo que poder calcular y validar la FCM y el UAT de los voluntarios mediante una sencilla fórmula agiliza mucho todos los procesos. Con el estudio se ha comprobado la fiabilidad y sensibilidad de la fórmula de Tanaka con respecto a una prueba reglada y altamente sensible, como es una cicloergometría (protocolo Conconi).

\subsubsection{Uso de los valores de ácido láctico}

El conocimiento sobre el uso del ácido láctico es una herramienta ampliamente utilizada para optimizar el rendimiento deportivo, tanto en aficionados como en profesionales. De igual modo, este parámetro se emplea de forma ordinaria para conocer el estado o gravedad en ciertas patologías, como podrían ser PCR o sepsis, entre otras.

A lo largo de la investigación, se ha podido apreciar que este valor, fácil de determinar de forma rápida (con un simple pinchazo en un dedo es suficiente), aporta gran información sobre el estado de salud del voluntario, y, sobre todo, nos permite conocer cuál es su nivel de fatiga muscular, por lo que el uso de los valores de ácido láctico es también especialmente importante en personas sanas (independientemente de su estado previo de forma física).

La determinación del valor de ácido láctico es un parámetro muy accesible que aporta una gran cantidad de información, y que debería emplearse rutinariamente para conocer la tolerancia a determinados trabajos que requieren cierto grado de esfuerzo físico.

\subsection{Futuras líneas de investigación}

En función de los datos obtenidos y del planteamiento inicial de la tesis, nos parecería pertinente poder seguir investigando los siguientes aspectos:

- Usar el índice de perfusión y de la hemoglobina total en personas sanas.

- Ampliar la muestra para poder obtener un modelo predictivo que nos pueda indicar qué trabajadores podrían tolerar mal el equipo.

- Realizar de nuevo el estudio, comparando las constantes vitales en trabajadores con y sin traje que realizaran el mismo caso clínico.

- Determinar el tiempo de trabajo aconsejable con estos equipos.

- Evaluar la calidad de las maniobras de soporte vital avanzadas con el equipo de protección frente a riesgos biológicos colocado.

- Relacionar el nivel de actividad física del trabajador con el tiempo que tolera el uso de estos equipos. 
- Hacer un estudio conjunto entre factores fisiológicos y psicológicos, así como investigar sobre cómo interaccionan entre ambos a la hora de modificar la respuesta frente al uso de este tipo de equipos.

\subsection{Limitaciones de la investigación}

Como todo estudio de investigación, esta tesis doctoral presenta unos objetivos científicos concretos y está realizada en un contexto específico, limitado, por lo que cabría destacar la presencia de las siguientes limitaciones:

1. Delimitación del área de investigación. El equipamiento para trabajar o abordar situaciones con riesgo NBQ es extremadamente amplio. En esta tesis se ha elegido un equipo de protección individual nivel $D$ frente a riesgos biológicos por ser el más usual en este tipo de situaciones, pero se tiene la consciencia de que no es el único tipo de equipamiento que existe, y también de que las diferencias entre un tipo de protección y otra son totalmente distintas. Por ejemplo, el uso de equipos de categoría A encapsulados y con uso de equipos de respiración autónoma no puede ser comparable al uso de equipos nivel D antisalpicaduras. Por ello, los resultados obtenidos son aplicables a las situaciones en las que se empleen los equipos utilizados en este estudio.

2. El acceso a la información relacionada con el tema de estudio no ha sido fácil. No se ha encontrado ningún estudio previo que analice de forma global el tema que aborda la presente tesis. Existen estudios previos sobre aspectos puntuales del uso de equipos de protección y la repercusión sobre aspectos específicos de la salud, pero no de forma global.

3. La presente investigación solo alcanza a estudiantes y profesionales de la ciudad de Valladolid, en un periodo corto de tiempo, y siguiendo las recomendaciones y equipamientos vigentes en el momento del desarrollo del estudio clínico.

4. La investigación se limita al estudio de los parámetros fisiológicos y antropométricos citados en la metodología, pero no se discute la utilidad de otros parámetros como los niveles de cortisol, pH o insulina, entre otros; sin embargo, se desecharon del estudio por la complejidad que requería realizar las determinaciones.

5. El presente estudio analiza multitud de parámetros con el objetivo de encontrar un dato fisiológico que nos sirva de patrón oro para poder determinar a priori qué sujetos que se van a equipar con este tipo de equipos van a tolerar fisiológicamente mal este trabajo. Con los datos obtenidos no podemos concluir que hayamos encontrado ese patrón oro. Se deben seguir realizando estudios con muestras más amplias para determinar estos umbrales específicos.

6. Ciertos parámetros estudiados, como el índice de perfusión o el nivel de hemoglobina total y su comportamiento, requieren estudios más profundos. Estos parámetros son ampliamente usados en pacientes, pero no hay bibliografía que respalde su uso en personas sanas.

7. La investigación analiza de forma pormenorizada el comportamiento fisiológico de los voluntarios ante una cicloergometría y ante un caso clínico de RCP con el equipo de protección frente a riesgos biológicos colocado, pero se debe profundizar el estudio para evaluar también la importancia del componente psicológico en la modulación de esta respuesta fisiológica. 


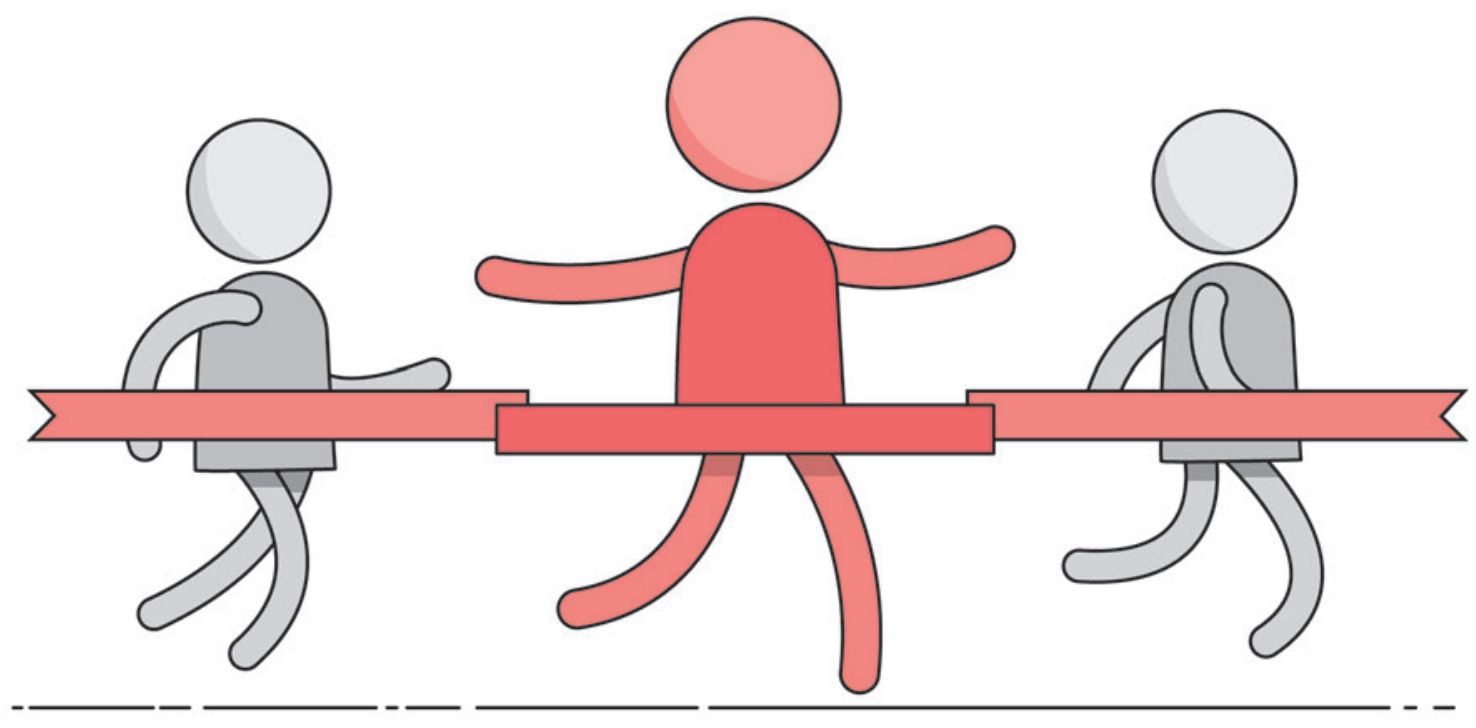




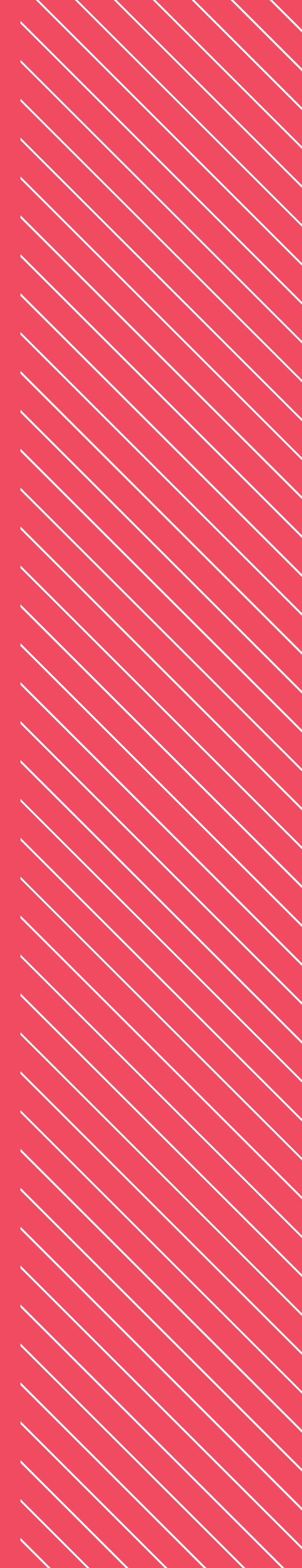


Con este estudio hemos llegado a las siguientes conclusiones en relación a las repercusiones fisiológicas del uso de equipos de protección individual frente a riesgos biológicos sobre los trabajadores de la Salud.

1. Se objetiva una distribución homogénea de los parámetros fisiológicos y antropométricos, no encontrándose diferencias significativas por sexo, grupos o subgrupos.

2. Los profesionales que presentan un nivel de actividad física media o alta toleran mejor las labores de reanimación con un traje de protección biológica individual nivel $\mathrm{D}$, en el caso de reanimación simulada.

3. Para un porcentaje muy elevado de sujetos $(46,9 \%)$, realizar una reanimación con el equipo de protección individual supone un sobreesfuerzo significativo, de modo que sobrepasan su umbral anaeróbico recomendado.

4. La ecuación de Tanaka (cálculo teórico) presenta una gran fiabilidad en relación con el mismo valor obtenido mediante pruebas empíricas (cicloergometría) para la obtención de la frecuencia cardiaca máxima.

5. Los voluntarios que presentan un peor perfil metabólico (datos de lactato alterados) se corresponden con individuos en su mayoría con un nivel de actividad física bajo, y cuya frecuencia cardiaca presenta mala tolerancia al esfuerzo físico.

6. Los sujetos con un incremento de su frecuencia cardiaca del umbral anaeróbico durante el caso clínico presentan de forma general un peor perfil metabólico. Con el modelo planteado se puede, asimismo, predecir qué voluntarios podrían tolerar peor la prueba en relación con el metabolismo.

7. Un $15,60 \%$ de los sujetos del estudio no aumentan su índice de perfusión posterior con respecto al inicial, estos sujetos además presentan un peor perfil metabólico y muscular. Podemos afirmar, por lo tanto, que, para la muestra estudiada, un descenso del IP, después del ejercicio, es un parámetro de mala tolerancia fisiológica.

8. Se ha podido objetivar un patrón fisiológico de mala tolerancia al esfuerzo tras el uso del equipo de protección individual. Estos sujetos presentan alteraciones mantenidas después de un periodo de diez minutos de descanso, con incrementos en la toma posterior de constantes vitales (respecto a los parámetros previos) de la frecuencia cardiaca, tensión arterial, aumento de más de $1^{\circ} \mathrm{C}$ de temperatura, descenso del índice de perfusión y hemoglobina total y aumento de la saturación de oxígeno.

9. Los individuos de la muestra que presentan un patrón común de mala tolerancia fisiológica tras el uso del equipo de protección, en su mayoría, presentan un mal patrón de utilización del ácido láctico, y unas características de antropometría (en toma posterior) y de bio impedancia comunes: menos masa muscular, ósea y agua corporal final que inicial, y más peso, grasa e índice de masa corporal final que inicial, orientando de nuevo hacia la existencia de un patrón uniforme de mala tolerancia.

10. Un $72 \%$ de los voluntarios no solicitan la talla adecuada del traje de protección individual (un $66 \%$ solicitaron tallas menores de las necesarias), por lo que se precisaría un esfuerzo por incluir en los cursos de instrucción nuclear-biológio-químico unas directrices adecuadas para aleccionar a los alumnos sobre el cálculo adecuado de la talla de traje que precisan.

Podemos concluir, que según los datos obtenidos en este estudio, existen unos parámetros fisiológicos, así como un patrón de mala tolerancia fisiológica tras el uso de equipos de protección individual nivel D para la muestra observada, que pueden llevarnos, en futuros estudios, a derivar una regla predictiva que permita valorar qué profesionales pueden tener mejor adaptabilidad y tolerancia en su trabajo en situación de incidente nuclear, biológico o químico. 


\section{Trabajos citados}

1. Lane JE, Dimick J, Syrax M, Bhandary M, Rudy BS. Bioterrorism and disaster preparedness among medical specialties. American Journal of Disaster Medicine. 2012; 7(1): 48-60.

2. Veenema TG, Losinski SLA, Hilmi LM. Increasing Emergency Preparedness. AJN, American Journal of Nursing. 2016 Jan; 116(1): 49-53.

3. Martín Rodríguez F, Delgado Benito JF. Intervención inicial sanitaria en accidentes con víctimas en masa. 1. ${ }^{a}$ ed. Valladolid: Publisher P, editor; 2013.

4. Bayntun C, Houlihan C, Edmunds J. Ebola crisis: beliefs and behaviours warrant urgent attention. The Lancet. 2014 Oct; 384(9952): 1423-1424.

5. Debbie M. The impact of a nurse led rapid response system on adverse, major adverse events and activation of the medical emergency team. Intensive \& Critical Care Nursing. 2015 Apr; 31(2): 83-90.

6. Alenljung B, Maurin Söderholm H. Designing Simulation-Based Training for Prehospital Emergency Care: Participation from a Participants Perspective. Human-Computer Interaction: Designing and Evaluation: 17th International Conference. Los Angeles; 2015: 297-306.

7. Service-Médical-du-RAID. Tactical emergency medicine: lessons from Paris marauding terrorist attack. Critical care. 2015 Dec; 20(37).

8. Torjesen I. Trauma staff change routines in wake of terrorist attack. BMJ. 2017; 357: j2736.

9. Fischer WA, Hynes NA, Perl TM. Protecting Health Care Workers From Ebola: Personal Protective Equipment Is Critical but Is Not Enough. Ann Intern Med. 2014 Oct; 161(10): 753-754.

10. Edmond MB, Diekema DJ, Perencevich EN. Ebola Virus Disease and the Need for New Personal Protective Equipment. JAMA. 2014 Oct; 312(23): 2495-2496.

11. Holland MG, Cawthon D. Personal Protective Equipment and Decontamination of Adults and Children. Emergency Medicine Clinics of North America. 2015 Feb; 33(1): 15-68.

12. Anderson-Fletcher E. The Texas Health Presbyterian Hospital Ebola Crisis: A Perfect Storm of Human Errors, Systems Failures, and Lack of Mindfulness. HCPP White Paper Series. Texas; 2008: 2-28.

13. Nacional CSdEdID. La seguridad frente a artefactos explosivos. $1 .^{a}$ ed. Defensa DdSy, editor. Madrid: Ministerio de Defensa; 2009.

14. Reinares F, García-Calvo C, Vicente A. Dos factores que explican la radicalización yihadista en España (Internet). Disponible en: http://www.realinstitutoelcano.org/wps/portal/rielcano_es/contenido?WCM_GLOBAL_CONTEXT=/elcano/elcano_es/zonas_es/ ari62-2017-reinares-garciacalvo-vicente-dos-factores-explican-radicalizacion-yihadista-espana

15. Ferrándiz II. Bioterrorismo: La amenaza latente. Documentos de trabajo. Madrid: CEU, Instituto Universitario de Estudios Europeos; 2006. Report No.: 84-86117-35-6.

16. Martín Rodríguez F. Gestión de crisis colectivas, una realidad emergente en nuestro entorno. Rev. enferm. CyL. 2009 Sep; 1(1):38-44.

17. Dueñas Laita A. Manual de procedimientos y recomendaciones para la atención sanitaria urgente en incidentes químicos accidentales o terroristas. Manual. Madrid: Ministerio de Sanidad y Política Social, Informes, Estudios e Investigación; 2009. Report No.: NIPO: 351-08-116-5.

18. Khan AS. Public health preparedness and response in the USA since 9/11: a national health security imperative. The Lancet. 2011 Sep; 378(9794): 953-956. 
19. Jamrog DC, Shatz MP, Smith C. Modeling Responses to Anthrax and Smallpox Attacks. Lincoln laboratory Journal. 2007 Jan; 17(1): 115-129.

20. Schladera ZJ, Templea JL, Hostlera D. Exercise in personal protective equipment in a hot, humid environment does not affect risk propensity [Document]; 2016 [DOI:10.1080/23328940.2016 .1148526].

21. Haverkort JJM. Hospital Preparations for Viral Hemorrhagic Fever Patients and Experience Gained from Admission of an Ebola Patient. Emerg Infect Dis. 2016 Feb; 22(2): 184-191.

22. Martín Rodríguez F, Delgado Benito JF. Concepto de crisis en incidentes NBQ. En: Martín Rodríguez, F., editor. Intervención sanitaria en entornos con riesgo NBQ. 2. ${ }^{a}$ ed. Valladolid: PHET Publisher; 2014: 23-33.

23. Clouser JM. Keeping workers safe: Does provision of personal protective equipment match supervisor risk perceptions? American Journal of Industrial Medicine. 2015 Apr; 58(8): 886-896.

24. Ministerio de Fomento. [Internet].; 2015 [citado 26 marzo 2016]; Disponible en: http://www.fomento.gob.es/MFOM/LANG_CASTELLANO/DIRECCIONES_GENERALES/ TRANSPORTE_TERRESTRE/MMPP/Estadisticas/.

25. Hernández BC, Rugarcía YT. Actitudes hacia la prevención de riesgos laborales en profesionales sanitarios en situaciones de alerta epidemiológica. Medicina, Seguridad y Trabajo [Internet]. 2015; 61(239):233-253. Disponible en: http://scielo.isciii.es/scielo. php?script=sci_arttext\&pid=S0465-546X2015000200009

26. Pallister-Wilkins P. Personal Protective Equipment in the humanitarian governance of Ebola: between individual patient care and global biosecurity. Third World Quarterly (Internet). 2016 Mar; 37:507-523. Disponible en: http://dx.doi.org/10.1080/01436597.2015.1116935

27. Cairns CB. Strategic Perspectives on the Bioterrorism Threat. Dossier. Arizona: U.S. House of Representatives Committee on Homeland Security, Subcommittee on Emergency Preparedness, Response, and Communications. Washington: American Enterprise Institute; 2015: 1-6.

28. Real Decreto $773 / 1997$, de 30 de mayo, sobre disposiciones mínimas de seguridad y salud relativas a la utilización por los trabajadores de equipos de protección individual. BOE n 140.12 de junio de 1997: 18000- 18017.

29. Real Decreto $1407 / 1992$, de 20 de noviembre, por el que se regulan las condiciones para la comercialización y libre circulación intracomunitaria de los equipos de protección individual. BOE n 311. 28 de diciembre de 1992: 44120- 44131.

30. Response E. United States Environmental Protection Agency. [Internet].; 2016 [citado 26 mar 2016]. Disponible en: https://www3.epa.gov.

31. Delgado Benito JF. Equipos de protección Individual: tipos y formas de uso. En Martín Rodríguez F., editor. Intervención sanitaria en entornos con riesgo NBQ. Valladolid: PHET Pubisher; 2014: 35-66.

32. Costello JT. The Effects of Metabolic Work Rate and Ambient Environment on Physiological Tolerance Times While Wearing Explosive and Chemical Personal Protective Equipment. BioMed Research International (Internet). 2015. Disponible en: http://dx.doi.org/10.1155/2015/857536

33. Contreras E, Buchanan S. Piloting a personal protection equipment distribution program among Chicago day laborers. American Journal of Industrial Medicine. 2012 Feb; 55(2): 159-166.

34. Mohammed HM. Ebola virus disease: Effects of respiratory protection on healthcare workers. Egyptian Journal of Chest Diseases and Tuberculosis. 2015 Jul; 64(3): 639-644. 
35. Fløe Pedersen RN, Jepsen JR, Ádám B. Regulation and practice of workers' protection from chemical exposures during container handling. Journal of Occupational Medicine and Toxicology. 2014 Sep; 9(33): 9-33.

36. Rim KT, Lim CH. Biologically Hazardous Agents at Work and Efforts to Protect Workers' Health: A Review of Recent Reports. Safety and Health at Work. 2014 Jun; 5(2): 43-52.

37. Silla Stoel M. Clinical assessment of alcohol use and diagnosis of drinking pattern. Trastornos Adictivos. 2009 Jul; 11(3): 191-199.

38. Ministerio de Sanidad, Servicios Sociales e Igualdad. Clasificación Internacional de Enfermedades C1. [Internet]; 2016 [citado 29 Agosto 2016]. Disponible en: https://eciemaps.mspsi.es/ ecieMaps/browser/index_10_mc.html.

39. Baracos V, Caserotti P, Earthman CP, Fields D, Gallagher D, Hall KD et al. Advances in the science and application of body composition measurement. Parenter Enteral Nutr. 2012 Jan; 36(1): 96-107.

40. Antonsen LP, Kirkebøen KA. Evaluation of Fluid Responsiveness: Is Photoplethysmography a Noninvasive Alternative? Anesthesiol Res Pract. 2012 Feb; 39(2): 244-299.

41. Fitzsimons $C$, Kirk A, Murphy M, Mutrie N. Agreement between the IPAQ-long weekday sitting item and the activPAL ${ }^{\mathrm{TM}}$ activity monitor in Scottish adults. Journal of Science and Medicine in Sport. 2012 Dec; 15: S295-S296.

42. Tanaka H. Age-predicted maximal heart rate revisited. Journal of the American College of Cardiology. 2001 Jan; 37(1): 153-156.

43. Velasco Muñoz C, Boer J, Kranendonk L, Varela Santos C, Bartels C. Safe use of personal protective equipment in the treatment of infectious diseases of high consequence. Thecnical document. Stockholm: European Centre for Disease Prevention and Control (ECDC), ECDC; 2014. Report No.: Version 2.

44. Delvecchio L, Reaburn P, Trapp G, Korhonen MT. Effect of concurrent resistance and sprint training on body composition and cardiometabolic health indicators in masters cyclists. J Exerc Rehabil. 2016 Oct; 12(5): 442-450.

45. Silva AC, Dias MRC, Franco VHP, Lima JRP, Novaes JS. Estimativa de umbral de Conconi por medio de la Escala de Borg en cicloergómetro. Fitness \& Performance Journal. 2005 Apr; 4(4): $215-219$.

46. Erdogan A, Cetin C, Karatosun H, Baydar M. Non-invasive Indices for the Estimation of the Anaerobic Threshold of Oarsmen. Journal of International Medical Research. 2010; 38(3): 901-915.

47. Messias LHD, Gobatto CA, Beck WR, Manchado-Gobatto FB. The Lactate Minimum Test: Concept, Methodological Aspects and Insights for Future Investigations in Human and Animal Models. Front Physiol. 2017 Jun; 8(839).

48. Baker JS, Davies B, Thomas N. Metabolic Implications Of High Intensity Cycle Ergometry Exercise For Blood Lactate Accumulation And Clearance. JEPonline. 2005; 8(3): 18-25.

49. Cerda-Kohler H, Pullin Y, Cancino-López J. Effects of continuous and intermittent endurance exercise in autonomic balance, rating perceived exertion and blood lactate levels in healthy subjects. Apunts. Medicina de l'Esport. 2015 Jan-Mar; 50(185): 29-34.

50. Loue S, Molina DP. Las consideraciones éticas sobre la vulnerabilidad en la investigación cualitativa. Revista Facultad Nacional de Salud Pública. 2015 Sep-Dic; 33(3).

51. Stanula A, Gabrys T, Szmatlan-Gabrys U, Roczniok R, Maszczyk A, Pietraszewski P. Calculating lactate anaerobic thresholds in sports involving different endurance preparation. Journal of Exercise Science \& Fitness. 2013 Jun; 11(1): 12-18. 
52. Carter H, Amlôt R. Mass Casualty Decontamination Guidance and Psychosocial Aspects of CBRN Incident Management: A Review and Synthesis. PLOS Currents Disasters. 2016 Sep 27. Edition 1. doi: 10.1371/currents.dis.c2d3d652d9d07a2a620ed5429e017ef5.

53. Calfee MW, Tufts J, Meyer K, McConkey K, Mickelsen L, Rose L et al. Evaluation of standardized sample collection, packaging, and decontamination procedures to assess cross-contamination potential during Bacillus anthracis incident response operations. J Occup Environ Hyg. 2016 Dec; 13(12): 980-992.

54. Jama TJ, Kuisma MJ. Preparedness of Finnish Emergency Medical Services for Chemical Emergencies. Prehosp Disaster Med. 2016 Aug; 31(4): 392-396.

55. Fogel I, David O, Balik CH, EisenKraft A, Poles L, Shental O et al. The association between self-perceived proficiency of personal protective equipment and objective performance: An observational study during a bioterrorism simulation drill. Am J Infect Control. 2017 Jun; 30. doi: 10.1016/j.ajic.2017.05.018.

56. Verbeek JH, ljaz S, Mischke C, Ruotsalainen JH, Mäkelä E, Neuvonen K et al. Personal protective equipment for preventing highly infectious diseases due to exposure to contaminated body fluids in healthcare staff. Cochrane Database Syst Rev. 2016 Apr; 19(4). doi: 10.1002/14651858. CD011621.pub2.

57. Coca A, Quinn T, Kim JH, Wu T, Powell J, Roberge R et al. Physiological Evaluation of Personal Protective Ensembles Recommended for Use in West Africa. Disaster Med Public Health Prep. 2017 Mar; 1(7). doi: 10.1017/dmp.2017.13

58. Wang JS, Chang YL, Chen YC, Tsai HH, Fu TC. Effects of normoxic and hypoxic exercise regimens on monocyte-mediated thrombin generation in sedentary men. Clin Sci (Lond). 2015 Aug; 129(4): 363-374.

59. Jayasinghe S, Lambert G, Torres S, Fraser S, Eikelis N, Turner A. Hypothalamo-pituitary adrenal axis and sympatho-adrenal medullary system responses to psychological stress were not attenuated in women with elevated physical fitness levels. Endocrine. 2016; 51(2): 369-379.

60. Gooding HC, Ning H, Gillman MW, Shay C, Allen N, Goff DC et al. Application of a Lifestyle-Based Tool to Estimate Premature Cardiovascular Disease Events in Young Adults: The Coronary Artery Risk Development in Young Adults (CARDIA) Study. JAMA Intern Med. 2017 Jul. doi: 10.1001/ jamainternmed.2017.2922.

61. Pavey TG, Kolbe-Alexander TL, Uijtdewilligen L, Brown WJ. Which Women are Highly Active Over a 12-Year Period? A Prospective Analysis of Data from the Australian Longitudinal Study on Women's Health. Sports Med. 2017 May. doi: 10.1007/s40279-017-0732-0.

62. Spartano LN, Lyass GA, Larson DM, Lewis SG, Vasan SR. Abstract 19256: Predicting Exercise Systolic Blood Pressure and Heart Rate at 20 Years of Follow-up: Correlates in the Framingham Heart Study. Circulation. 2015; 132(3): A19256-A19256.

63. Garg R, Malhotra V, Kumar A, Dhar U, Tripathi Y. Effect of isometric handgrip exercise training on resting blood pressure in normal healthy adults. Journal of clinical and diagnostic research. 2014 Sep; 8(9): BC08-10.

64. Halliwill JR, Sieck DC, Romero SA, Buck TM, Ely MR. Blood pressure regulation X: what happens when the muscle pump is lost? Post-exercise hypotension and syncope. 2014 Mar; 114(3): 561-578.

65. Moreira OC, Oliveira CEP, Matos DG, Silva SF, Hickner RC, Aidar FJ. Cardiovascular response to strength training is more affected by intensity than volume in healthy subjects. Revista Andaluza de Medicina del Deporte. doi: 10.1016/j.ramd.2017.01.002. 
66. Reidy P, Fletcher T, Shieber C, Shallcross J, Towler H, Ping M et al. Personal protective equipment solution for UK military medical personnel working in an Ebola virus disease treatment unit in Sierra Leone. J Hosp Infect. 2017 May; 96(1): 42-48.

67. Stein C, Makkink A, Vincent-Lambert C. The effect of physical exertion in chemical and biological personal protective equipment on physiological function and reaction time. Prehosp Emerg Care. 2010 Jan-Mar; 14(1): 36-44.

68. Ji T, Qian X, Yuan M, Jiang J. Experimental study of thermal comfort on stab resistant body armor. Springerplus. 2016 Jul; 5(1). doi: 10.1186/s40064-016-2432-x.

69. Xu X, Karis AJ, Buller MJ, Santee WR. Relationship between core temperature, skin temperature, and heat flux during exercise in heat. Eur J Appl Physiol. 2013 Sep; 113(9): 2381-2389.

70. Causer J, Barach P, Williams AM. Expertise in medicine: using the expert performance approach to improve simulation training. Medical Education. 2014 Feb; 48(2): 115-123.

71. Hsieh MJ, Yang CW, Chiang WC, Wang HC, Lin HY, Hsu SH et al. The effects of different retraining frequency of simulation-based short advanced life support training on health professionals. Resuscitation. 2015 Nov; 96: 90.

72. Cook NF, Mcaloon T, O'Neill P, Beggs R. Impact of a web based interactive simulation game (PULSE) on nursing students' experience and performance in life support training: A pilot study. Nurse Education Today. 2012 Aug; 32(6): 714-720.

73. Szarpak L, Madziała M, Smereka J. Comparison of endotracheal intubation performed with 3 devices by paramedics wearing chemical, biological, radiological, and nuclear personal protective equipment. American Journal of Emergency Medicine. 2016 Sep; 34(9): 1902-1903.

74. Chen J, Lu KZ, Yi B, Chen Y. Chest Compression With Personal Protective Equipment During Cardiopulmonary Resuscitation: A Randomized Crossover Simulation Study. Medicine. 2016 Apr; 95(14): e3262.

75. Franklin SM. A Comparison of Personal Protective Standards: Caring for Patients With Ebola Virus. Clin Nurse Spec. 2016 Mar-Apr; 30(2): 1-8.

76. Houlihan CF, McGowan CR, Dicks S, Baguelin M, Moore DAJ, Mabey D et al. Ebola exposure, illness experience, and Ebola antibody prevalence in international responders to the West African Ebola epidemic 2014-2016: A cross-sectional study. PLoS Med. 2017; 14 (5): e1002300.

77. Hunt L, Gupta-Wright A, Simms V, Tamba F, Knott V, Tamba K. Clinical presentation, biochemical, and haematological parameters and their association with outcome in patients with Ebola virus disease: an observational cohort study. Lancet Infect Dis. 2015 Nov; 15(11): 1292-1299.

78. Mello MM, Merritt MW, Halpern SD. Supporting Those Who Go to Fight Ebola. PLoS Med. 2015 Jan; 12(1). doi.org/10.1371/journal.pmed.1001781.

79. Casalino E, Astocondor E, Sanchez JC, Díaz-Santana DE, Águila C, Carrillo JP. Personal protective equipment for the Ebola virus disease: A comparison of 2 training programs. AJIC: American Journal of Infection Control. 2015 Dec; 43(12): 1281-1287.

80. Potter AW, González JA, Xu X. Ebola Response: Modeling the Risk of Heat Stress from Personal Protective Clothing. PLoS ONE. 2015 Nov; 10(11). doi.org/10.1371/journal.pone.0143461.

81. Bah El, Lamah MC, Fletcher T, Jacob ST, Brett-Major DM, Sall AA et al. Clinical Presentation of Patients with Ebola Virus Disease in Conakry, Guinea. N Engl J Med. 2015 Jan; 372: 40-47.

82. Stephens DS, Ribner BC, Gartland BD, Feistritzer NR, Farley MM, Larsen CP. Ebola Virus Disease: Experience and Decision Making for the First Patients outside of Africa. PLoS Med. 2015 Jul; 12(7): e1001857. 
83. Cohen D, Sevdalis N, Taylor D, Kerr K, Heys M, Willett K et al. Emergency preparedness in the 21st century: Training and preparation modules in virtual environments. Resuscitation. 2013 Jan; 84(I): 78-84.

84. Kales SN, Smith DL. Sudden cardiac death in the fire service. Occupational Medicine. 2014; 64(4): 228-230.

85. Wayne DB, Didwania AK, McGaghie WC. Improving the Efficiency of Advanced Life Support Training. Ann Intern Med. 2012 Nov; 157(10): 753.

86. Phillips T, Martin R, Ellis G. Survey of life support training in teachers and provision of automated external defibrillators in secondary schools in South Wales. Lancet. 2014 Nov; 384(Sup. 2): 61.

87. Stewart N, Tanksley A, Edelson D, Arora V. Understanding how basic life support training utiliced by our medical students on clinical rotati. Critical Care Medicine. 2014 Dec; 42(12). doi: 10.1097/01.ccm.0000457737.93494.3e.

88. Verschuren O, Maltais DB, Takken T. The 220-age equation does not predict maximum heart rate in children and adolescents. Developmental Medicine \& Child Neurology. 2011 Sep; 53(9): 861-864.

89. Machado FA, Denadai BS. Validity of maximum heart rate prediction equations for children and adolescents. Arquivos brasileiros de cardiologia. 2011 Aug; 97(2): 136-140.

90. Roy S, McCrory J. Validation of Maximal Heart Rate Prediction Equations Based on Sex and Physical Activity Status. Int J Exerc Sci. 2015 Oct; 8(4): 318-330.

91. Nes BM, Janszky I, Wisløff U, Støylen A, Karlsen T. Age-predicted maximal heart rate in healthy subjects: The HUNT fitness study. Scand J Med Sci Sports. 2013 Dec; 23(6): 697-704.

92. She J, Nakamura H, Makino K, Ohyama Y, Hashimoto H. Selection of suitable maximum-heart-rate formulas for use with Karvonen formula to calculate exercise intensity. International Journal of Automation and Computing. 2015; 12(1): 62-69.

93. Tan SJJ, Allen JC, Tan SY. Determination of ideal target exercise heart rate for cardiac patients suitable for rehabilitation. Clin Cardiol. 2017 Jul; 0: 1-5.

94. Evans HJ, Ferrar KE, Smith AE, Parfitt G, Eston RG. A systematic review of methods to predict maximal oxygen uptake from submaximal, open circuit spirometry in healthy adults. J Sci Med Sport. 2015 Mar; 18(2): 183-188.

95. Bennett H, Parfitt G, Davison K, Eston R. Validity of Submaximal Step Tests to Estimate Maximal Oxygen Uptake in Healthy Adults. Sports Med. 2016 May; 46(5): 737-750.

96. Morales Álamo D, Losa-Reyna J, Torres Peralta R, Martín Rincón M, Pérez Valera M, Curtelin D. What limits performance during whole-body incremental exercise to exhaustion in humans? J Physiol. 2015 Oct; 593(20): 4631-4648.

97. Ražanskas P, Verikas A, Olsson C, Viberq PA. Predicting Blood Lactate Concentration and Oxygen Uptake from sEMG Data during Fatiguing Cycling Exercise. Sensors (Basel). 2015 Aug; 15(8): 20480-20500.

98. Vikmoen O, Raastad T, Seynnes O, Bergstrøm K, Ellefsen S, Rønnestad BR. Effects of Heavy Strength Training on Running Performance and Determinants of Running Performance in Female Endurance Athletes. PLoS One. 2016 Mar; 11(3). doi: 10.1371/journal.pone.0150799.

99. Hall MM, Rajasekaran S, Thomsen TW, Peterson AR. Lactate: Friend or Foe. PM\&R. 2016 Mar; 8(3): S8-S15.

100. Brown PI, McLellan TM, Linnane DM, Wilkinson DM, Richmond VL, Blacker SD et al. Influence of hydration volume and ambient temperature on physiological responses while wearing CBRN protective clothing. Ergonomics. 2010 Dec; 53(12): 1484-1499. 
101. Zheng J, Du L, Liu B. Influence of Body Mass Index and Epidural Anesthesia on Lung Function. Anesthesiology. 2014; 120(2): 509-510.

102. Hakan N, Dilli D, Zenciroglu A, Aydin M, Okumus N. Reference values of perfusion indices in hemodynamically stable newborns during the early neonatal period. European Journal of Pediatrics. 2014; 173(5): 597-602.

103. Van Genderen M, Klijn E, Lima A, Jonge J, Visser S, Voorbeijtel J et al. Microvascular Perfusion as a Target for Fluid Resuscitation in Experimental Circulatory Shock. Crit Care Med. 2014 Feb; 42(2): E96-E105.

104. Rasmy I, Nabil N, Mohamed H, Abdel Raouf S, Hasanin A, Eladawy A et al. The evaluation of perfusion index as a predictor of vasopressor requirement in patient with sever sepsis and septic shock. Intensive Care Medicine Experimental. 2015; 3. doi: 10.1186/2197-425X-3-S1-A230.

105. Greenwood JC, Orloski CJ. End Points of Sepsis Resuscitation. Emerg Med Clin North Am. 2017 Feb; 35(1): 93-107.

106. Csapo R, Alegre LM, Baron R. Time kinetics of acute changes in muscle architecture in response to resistance exercise. Journal Of Science And Medicine In Sport. 2011 May; 14: 270-274.

107. Fryer S, Stone KJ, Sveen J, Dickson T, España-Romero V, Giles D et al. Differences in forearm strength, endurance, and hemodynamic kinetics between male boulderers and lead rock climbers. Eur J Sport Sci. 107 May; 1. doi: 10.1080/17461391.2017.1353135.

108. Gayda M, Lapierre G, Dupuy O, Fraser S, Bherer L, Juneau M et al. Cardiovascular and cerebral hemodynamics during exercise and recovery in obese individuals as a function of their fitness status. Physiol Rep. 2017 Jun; 5(12): e13321.

109. Schiller AM, Howard JT, Convertino VA. The physiology of blood loss and shock: New insights from a human laboratory model of hemorrhage. Exp Biol Med. 2017 Apr; 242(8): 874-883.

110. Parak J, Uuskoski M, Machek J, Korhonen I. Estimating Heart Rate, Energy Expenditure, and Physical Performance With a Wrist Photoplethysmographic Device During Running. JMIR Mhealth Uhealth. 2017 Jul; 5(7): e97.

111. Holland MG, Cawthon D. Personal Protective Equipment and Decontamination of Adults and Children. Emergency Medicine Clinics of North America. 2015 Feb; 33(1): 51-68.

112. Cique Moya A. Evacuación de pacientes con sospecha o confirmación de enfermedad por el virus del Ébola. Emergencias. 2015; 27: 121-128.

113. Cique Moya A. Evacuación sanitaria en condiciones de bioseguridad. Emergencias. 2007; 19: 144-150.

114. Cique Moya A. Zonificación sanitaria en incidentes NBQ. Emergencias. 2007; 19: 211-221.

115. Fujiki S, Ishizaki T, Nakayama T. Variations in status of preparation of personal protective equipment for preventing norovirus gastroenteritis in long-term care facilities for the elderly. Journal of Evaluation in Clinical Practice. 2017 May. doi: 10.1111/jep.12761.

116. Penta S, Marlowe V, Gill K, Kendra J. Of Earthquakes and Epidemics: Examining the Applicability of the All-Hazards Approach in Public Health Emergencies. Risk, Hazards \& Crisis in Publy Policy. 2017 Mar; 8(1): 48-67.

117. Stephens DS, Ribner BS, Gartland BD, Freistritzer NR, Farley MM, Larsen CP et al. Ebola Virus Disease: Experience and Decision Making for the First Patients outside of Africa. PLoS Med. $2015 \mathrm{Jul} ; 12(7)$ : e1001857.

118. Holland MG, Cawthon D. Personal Protective Equipment and Decontamination of Adults and Children. Emergency Medicine Clinics of North America. 2015 Feb; 33(1): 51-68. 
119. Kang J, O'Donnell JM, Colaianne B, Bircher N, Ren D, Smith KJ. Use of personal protective equipment among health care personnel: Results of clinical observations and simulations. AJIC. 2017 Jan; 45(1): 17-23.

120. Sprecher AG, Caluwaerts A, Draper M, Feldmann H, Frey CP, Funk RH et al. Personal Protective Equipment for Filovirus Epidemics: A Call for Better Evidence. The Journal of Infectious Diseases. 2015; 212(2): S98-S100.

121. Szarpak L, Madziala M, Smereka J. Comparison of endotracheal intubation performed with 3 devices by paramedics wearing chemical, biological, radiological, and nuclear personal protective equipment. Am J Emerg Med. 2016 Sep; 34(9): 1902-1903.

122. Szarpak L, Ramírez JG, Buljan D, Drozd A, Madziala M, Czyzewski L. Comparison of Bone Injection Gun and Jamshidi intraosseous access devices by paramedics with and without chemical-biological-radiological-nuclear personal protective equipment: a randomized, crossover, manikin trial. Am J Emerg Med. 2016 Jul; 34(7): 1307-1308.

123. Szarpak L, Truszewski Z, Smereka J, Madziala M, Czyzewski L. Comparison of two intravascular access techniques when using CBRN-PPE: A randomized crossover manikin trial. Am J Emerg Med. 2016 Jun; 34(6): 1170-1172.

124. Szarpak L, Truszewski Z, Ga忟zkowski R, Czyzewski L. Comparison of two chest compression techniques when using CBRN-PPE: a randomized crossover manikin trial. American Journal of Emergency Medicine. 2016 May; 34(5): 913-915.

125. Grillet G, Marjanovic N, Diverrez JM, Tattevin P, Tadié JM, L'Her E. Intensive care medical procedures are more complicated, more stressful, and less comfortable with Ebola personal protective equipment: A simulation study. Journal of Infection. 2015 Dec; 71(6): 703-706.

126. Casalino E, Astocondor E, Sánchez JC, Díaz-Santana DE, Águila C, Carillo JP. Personal protective equipment for the Ebola virus disease: A comparison of 2 training programs. American Journal of Infection Control. 2015 Dec; 43(43): 1281-1287.

127. Clay KA, O'Shea MK, Fletcher T, Moore AJ, Burns DS, Craig D, Adam M et al. Use of an ultraviolet tracer in simulation training for the clinical management of Ebola virus disease. Journal of Hospital Infection. 2015 Nov; 91(3): 275-277.

128. Gibson C, Fletcher T, Clay K, Griffiths A. Foreign Medical Teams in support of the Ebola outbreak: a UK military model of pre-deployment training and assurance. J R Army Med Corps. 2016 Jun; 162(3): 163-168.

129. Bell T, Smoot J, Patterson J, Smalligan R, Jordan R. Ebola virus disease: The use of fluorescents as markers of contamination for personal protective equipment. IDCases. 2015 Dec; 2: 27-30.

130. Mortelmans LJM, Gaakeer MI, Dieltiens G, Anseeuw K, Sabbe MB. Are Dutch Hospitals Prepared for Chemical, Biological, or Radionuclear Incidents? A Survey Study. Prehosp Disaster Med. 2017 May; 8: 1-9.

131. Richmond VL, Davey S, Griggs K, Havenith G. Prediction of Core Body Temperature from Multiple Variables. Ann Occup Hyg. 2015 Nov; 59(9): 1168-1178.

132. Adams JD, Mcdermott BP, Ridings CB, Mainer LL, Ganio MS, Kavouras SA. Effect of Air-Filled Vest on Exercise-Heat Strain When Wearing Ballistic Protection. Annals Of Occupational Hygiene. 2014; 58(8): 1057-1064.

133. Castle N, Bowen J, Spencer N. Does wearing CBRN-PPE adversely affect the ability for clinicians to accurately, safely, and speedily draw up drugs? Clin Toxicol (Phila). 2010 Jul; 48(6): 522-527. 
134. Blacker SD, Carter JM, Wilkinson DM, Richmond VL, Rayson MP, Peattie M. Physiological responses of Police Officers during job simulations wearing chemical, biological, radiological and nuclear personal protective equipment. Ergonomics. 2013; 56(1): 137-147.

135. Northington WE, Suyama J, Goss FL, Randall C, Gallagher M, Hostler D. Physiological responses during graded treadmill exercise in chemical-resistant personal protective equipment. Prehosp Emerg Care. 2007 Oct-Dec; 11(4): 394-398. 


\section{Nivel A (tipo 1)}

- Traje totalmente encapsulado y sellado, con equipo autónomo de respiración, guantes de protección química con doble capa y calzado con idénticas características.

- Máxima protección frente a agresivos químicos; habitualmente solo lo utilizan bomberos o fuerzas de seguridad que trabajan en la zona de mayor contaminación (zona caliente).

- Muy caro, pesado y caliente.

- Casi imposible realizar maniobras de reanimación.

\section{Nivel B (tipo 2)}

- Protección excelente de piel y pulmones.

- Se utiliza cuando se precisa protección respiratoria, pero el riesgo de agresión a la superficie cutánea es inferior.

- Lleva también equipo de respiración autónomo, aunque la resistencia del traje, guantes y cubre calzado es algo inferior.

- Menos caro.

- Más ligero que nivel A, pero puede ser pesado y caliente.

- Limita maniobras de reanimación.

\section{Nivel C (tipo 3-4)}

- Protección excelente de la piel y suficiente para los pulmones.

- Máscara de pantalla que cubre toda la cara con filtro químico (presión negativa), se debe seleccionar bien el filtro y asegurar que la máscara esté bien adaptada al rostro de la persona.

- Traje de menor protección con guantes y calzas.

- Se utiliza cuando las concentraciones del tóxico son bajas y existe poco riesgo de exposición cutánea de los intervinientes.

- Menos caro, más ligero y menos caliente.

- Se pueden realizar maniobras de reanimación aunque con dificultad.

\section{Nivel D (tipo 5-6)}

- Protección cutánea mínima frente agresiones químicas.

- Protección respiratoria frente partículas.

- Guantes y calzas antideslizantes.

- Traje más ligero y transpirable.

- Permite realizar maniobras de reanimación. 
Anexo 2. Hoja de inscripción de voluntarios

\begin{tabular}{|l|l|l|l|}
\hline ESTUDIO CLÍNICO & $\begin{array}{l}\text { Repercusiones fisiológicas del uso de equi- } \\
\text { pos de protección individual frente a riesgos } \\
\text { biológicos sobre los trabajadores de la Salud }\end{array}$ & Ref. & ANEXO N. ${ }^{\circ} \mathbf{2}$ \\
\hline Investigador & Francisco Martín Rodríguez & $41 / 16$ \\
\hline Doc. & HOJA DE INSCRIPCIÓN DE VOLUNTARIOS & Fer. & 2.0 \\
\hline & & Pág. & 1 de 2 \\
\hline
\end{tabular}

- Le estamos pidiendo que participe en un estudio.

- Usted NO tiene que participar en el estudio.

- Si dice que Sí, puede dejar de participar en el estudio en cualquier momento.

\section{1. ¿Por qué se está haciendo este estudio de investigación?}

1.1. Queremos saber más sobre cómo afectan los equipos de protección individual nivel $D$ tipo 4-5-6 a los trabajadores de la salud. Este estudio nos ayudará a comprender mejor las respuestas fisiológicas que experimentan los trabajadores ante estas situaciones.

1.2. Le estamos pidiendo a personas como usted: estudiantes de medicina y enfermería y médicos y enfermeros, que nos ayuden.

\section{2. ¿Dónde se realizará el estudio?}

2.1. Usted deberá acudir a la Facultad de Medicina de la Universidad de Valladolid, Edificio de Ciencias de Salud, Calle Ramón y Cajal, 7, 47005, Valladolid.

2.2. El estudio se desarrollará en las aulas ECOE, en la planta baja. Si no sabe llegar usted deberá esperar en el hall de entrada, cerca de la conserjería, y alguien de la organización saldrá a buscarle.

2.3. En caso de no encontrar en aula o de que nadie acuda a recogerle puede llamar a los siguientes teléfonos: 686452313 o 670016011.

\section{3. ¿Qué indumentaria debo llevar para realizar el estudio?}

3.1. Durante el desarrollo del estudio usted va a realizar esfuerzo físico de diferente intensidad y se va a equipar con un traje de protección, por ello, es recomendable que acuda con ropa de deporte y si es posible camiseta de algodón oscura.

3.2. La prueba de esfuerzo se va a realizar en una bicicleta, puede pedalear con zapatillas de deporte normales o de ciclismo con calas incorporadas si dispone de ellas.

3.3. Es recomendable traer al menos una camiseta de recambio para usar al final de la prueba. 


\begin{tabular}{|l|l|l|l|}
\hline ESTUDIO CLÍNICO & $\begin{array}{l}\text { Repercusiones fisiológicas del uso de equi- } \\
\text { pos de protección individual frente a riesgos } \\
\text { biológicos sobre los trabajadores de la Salud }\end{array}$ & Ref. & ANEXO N. ${ }^{\circ} \mathbf{2}$ \\
\hline Investigador & Francisco Martín Rodríguez & $41 / 16$ \\
\hline Doc. & HOJA DE INSCRIPCIÓN DE VOLUNTARIOS & Fer. & 2.0 \\
\hline & & Pág. & 2 de 2 \\
\hline
\end{tabular}

\section{4. ¿Cuánto tiempo dura el estudio?}

4.1. El estudio precisa de unas dos horas y media de su tiempo.

\begin{tabular}{|l|l|l|l|l|l|}
\hline NOMBRE & APELLIDO 1 & APELLIDO 2 & CATEGORÍA & TELÉFONO & E-MAIL \\
\hline & & & & \\
\hline & & & & \\
\hline
\end{tabular}


Anexo 3. Cuestionario internacional de actividad física IPAQ

\begin{tabular}{|l|l|l|l|}
\hline ESTUDIO CLÍNICO & $\begin{array}{l}\text { Repercusiones fisiológicas del uso de equi- } \\
\text { pos de protección individual frente a riesgos } \\
\text { biológicos sobre los trabajadores de la Salud }\end{array}$ & Ref. & ANEXO N. ${ }^{\circ}$ 3 \\
\hline Investigador & Francisco Martín Rodríguez & $41 / 16$ \\
\hline Doc. & $\begin{array}{l}\text { CUESTIONARIO INTERNACIONAL DE } \\
\text { ACTIVIDAD FISICA IPAQ }\end{array}$ & Fecha & 2.0 \\
\hline
\end{tabular}

- Las preguntas se referirán al tiempo que usted destinó a estar físicamente activo en los últimos 7 días. Por favor responda a cada pregunta aun si no se considera una persona activa. Por favor, piense acerca de las actividades que realiza en su trabajo, como parte de sus tareas en el hogar o en el jardín, moviéndose de un lugar a otro, o en su tiempo libre para la recreación, el ejercicio o el deporte.

Piense en todas las actividades intensas que usted realizó en los últimos 7 días. Las actividades físicas intensas se refieren a aquellas que implican un esfuerzo físico intenso y que le hacen respirar mucho más intensamente que lo normal. Piense solo en aquellas actividades físicas que realizó durante por lo menos 10 minutos seguidos.

1. Durante los últimos 7 días, ¿en cuántos realizó actividades físicas intensas tales como levantar pesos pesados, cavar, hacer ejercicios aeróbicos o andar rápido en bicicleta?

Días por semana

Ninguna actividad física intensa $\longrightarrow$ Vaya a la pregunta $n .^{\circ} 3$

2. Habitualmente, ¿cuánto tiempo en total dedicó a una actividad física intensa en uno de esos días?

horas por día

minutos por día

No sabe/No está seguro

Piense en todas las actividades moderadas que usted realizó en los últimos 7 días. Las actividades moderadas son aquellas que requieren un esfuerzo físico moderado que lo hace respirar algo más intensamente que lo normal. Piense solo en aquellas actividades físicas que realizó durante por lo menos 10 minutos seguidos. 


\begin{tabular}{|l|l|l|l|}
\hline ESTUDIO CLÍNICO & $\begin{array}{l}\text { Repercusiones fisiológicas del uso de equi- } \\
\text { pos de protección individual frente a riesgos } \\
\text { biológicos sobre los trabajadores de la Salud }\end{array}$ & Ref. & ANEXO N. ${ }^{\circ 3}$ \\
\hline Investigador & Francisco Martín Rodríguez & $41 / 16$ \\
\hline Doc. & $\begin{array}{l}\text { CUESTIONARIO INTERNACIONAL DE } \\
\text { ACTIVIDAD FISICA IPAQ }\end{array}$ & Fer. & 2.0 \\
\hline
\end{tabular}

3. Durante los últimos 7 días, ¿en cuántos días hizo actividades físicas moderadas como transportar pesos livianos, andar en bicicleta a velocidad regular o jugar dobles de tenis? No incluya caminar

Días por semana

Ninguna actividad física moderada $\longrightarrow$ Vaya a la pregunta $n^{\circ} 5$

4. Habitualmente, ¿cuánto tiempo en total dedicó a una actividad física moderada en uno de esos días?

horas por día

minutos por día

No sabe/No está seguro

Piense en el tiempo que usted dedicó a caminar en los últimos 7 días. Esto incluye caminar en el trabajo o en la casa, para trasladarse de un lugar a otro, o cualquier otra caminata que usted podría hacer solamente para la recreación, el deporte, el ejercicio o el ocio.

5. Durante los últimos 7 días, ¿en cuántos caminó por lo menos 10 minutos seguidos?

Días por semana

Ninguna caminata $\longrightarrow$ Vaya a la pregunta $n^{\circ} 7$

6. Habitualmente, ¿cuánto tiempo en total dedicó a caminar en uno de esos días?

horas por día

minutos por día

No sabe/No está seguro

La última pregunta es acerca del tiempo que pasó usted sentado durante los días hábiles de los últimos 7 días. Esto incluye el tiempo dedicado al trabajo, en la casa, en una clase, y durante el tiempo libre. Puede incluir el tiempo que pasó sentado ante un escritorio, visitando amigos, leyendo, viajando en ómnibus, o sentado o recostado mirando la televisión. 


\begin{tabular}{|l|l|l|l|}
\hline ESTUDIO CLÍNICO & $\begin{array}{l}\text { Repercusiones fisiológicas del uso de equi- } \\
\text { pos de protección individual frente a riesgos } \\
\text { biológicos sobre los trabajadores de la Salud }\end{array}$ & Ref. & ANEXO N. ${ }^{\circ} 3$ \\
\hline Investigador & Francisco Martín Rodríguez & $41 / 16$ \\
\hline Doc. & $\begin{array}{l}\text { CUESTIONARIO INTERNACIONAL DE } \\
\text { ACTIVIDAD FISICA IPAQ }\end{array}$ & Fecha & 2.0 \\
\hline
\end{tabular}

\section{Durante los últimos 7 días, ¿cuánto tiempo pasó sentado en un día hábil?}

horas por día

minutos por día

No sabe/No está seguro

\section{VALOR DEL TEST}

1. Caminatas: 3'3 MET*x minutos de caminata $x$ días por semana (Ej. 3'3 x 30 minutos $x 5$ días $=495 \mathrm{MET}$ )

2. Actividad Física Moderada: $4 \mathrm{MET} * \mathrm{X}$ minutos $\mathrm{x}$ días por semana

3. Actividad Física Vigorosa: 8 MET* X minutos $x$ días por semana

A continuación, sume los tres valores obtenidos:

Total = caminata + actividad física moderada + actividad física vigorosa

\section{CRITERIOS DE CLASIFICACIÓN}

\section{Actividad Física Moderada:}

- 3 o más días de actividad física vigorosa por lo menos 20 minutos por día.

- 5 o más días de actividad física moderada y/o caminata al menos 30 minutos por día.

- 5 o más días de cualquiera de las combinaciones de caminata, actividad física moderada o vigorosa logrando como mínimo un total de 600 MET*

\section{Actividad Física Vigorosa:}

- Actividad Física Vigorosa por lo menos 3 días por semana logrando un total de al menos 1500 MET* $^{*}$

- 7 días de cualquier combinación de caminata, con actividad física moderada y/o actividad física vigorosa, logrando un total de al menos 3000 MET*

\section{* Unidad de medida del test}




\begin{tabular}{|l|l|l|l|}
\hline ESTUDIO CLÍNICO & $\begin{array}{l}\text { Repercusiones fisiológicas del uso de equi- } \\
\text { pos de protección individual frente a riesgos } \\
\text { biológicos sobre los trabajadores de la Salud }\end{array}$ & Ref. & ANEXO N. ${ }^{\circ} \mathbf{4}$ \\
\hline Investigador & Francisco Martín Rodríguez & $41 / 16$ \\
\hline Doc. & $\begin{array}{l}\text { FORMULARIO DE CONSENTIMIENTO } \\
\text { INFORMADO }\end{array}$ & Fer. & 2.0 \\
\hline
\end{tabular}

- Le estamos pidiendo que participe en un estudio.

- Si dice que Sí, puede dejar de participar en el estudio en cualquier momento.

- Usted NO tiene que participar en el estudio.

- Por favor, tome todo el tiempo que necesite para decidir.

\section{NOMBRE}

APELLIDOS

FECHA

\section{1. ¿Para qué se firma este documento?}

1.1. Lo firma para poder participar en este estudio de investigación.

\section{2. ¿Por qué se está haciendo este estudio de investigación?}

2.1. Queremos saber más sobre cómo afectan los equipos de protección individual categoría I tipo 4-5-6 a los trabajadores de la salud. Este estudio nos ayudará a comprender mejor las respuestas fisiológicas y psicológicas que experimentan los trabajadores ante estas situaciones.

2.2. Le estamos pidiendo a personas como usted: estudiantes de medicina y enfermería y médicos y enfermeros, que nos ayuden.

\section{3. ¿Qué pasa si digo que sí quiero participar en el estudio?}

3.1. Se le realizará una completa historia médica, incluyendo datos como edad, actividad física, toma de alcohol, tabaquismo, antecedentes médicos y quirúrgicos, toma de medicación, alergias, etc., estudio de personalidad y ansiedad, etc.

3.2. A continuación se hará un estudio antropométrico, con medición de perímetros, análisis por bioimpedancia, peso, etc.

3.3. Amplia evaluación y valoración fisiológica, comprendiendo toma de constantes vitales (frecuencia cardiaca, tensión arterial, frecuencia respiratoria, saturación, temperatura, reIleno capilar, prueba del pliegue cutáneo, pupilas, escala de Glasgow, índice de perfusión), electrocardiograma de reposo, espirometría, etc. 


\begin{tabular}{|l|l|l|l|}
\hline ESTUDIO CLÍNICO & $\begin{array}{l}\text { Repercusiones fisiológicas del uso de equi- } \\
\text { pos de protección individual frente a riesgos } \\
\text { biológicos sobre los trabajadores de la Salud }\end{array}$ & Ref. & ANEXO N. ${ }^{\circ} \mathbf{4}$ \\
\hline Investigador & Francisco Martín Rodríguez & Ver. & 2.0 \\
\hline Doc. & $\begin{array}{l}\text { FORMULARIO DE CONSENTIMIENTO } \\
\text { INFORMADO }\end{array}$ & Fecha & $20 / 4 / 16$ \\
\hline & Pág. & 2 de 4 \\
\hline
\end{tabular}

3.4. Deberá realizar una prueba de esfuerzo sencilla sobre una bicicleta. La ergometría dura un máximo de 10 minutos y es apta incluso para personas con problemas cardiovasculares. Se adaptará la resistencia de la bicicleta sus características físicas y a su nivel previo de entrenamiento. Estará monitorizado en todo momento y puede abandonar la prueba en cualquier momento.

3.5. Durante todo el estudio se realizan tres determinaciones de ácido láctico y glucosa. Para ello, se realizarán tres punciones en las yemas de los dedos o en el lóbulo de la oreja, de esta forma podremos determinar de una forma objetiva su umbral anaeróbico real.

3.6. Se equipará bajo supervisión con un equipo de protección individual categoría I tipo 4-5-6, y realizará pruebas de destreza y de esfuerzo físico en una habitación con temperatura y humedad controlada $\left(28^{\circ} \mathrm{C}\right.$ y aproximadamente $80 \%$ de humedad). A continuación se procederá a la retirada controlada del equipo de protección guiada por un supervisor.

3.7. A lo largo de todo el estudio se monitorizará de forma continua multitud de parámetros, repitiendo algunas valoraciones para comprobar si existen diferencias.

4. ¿Qué pasa si digo que NO quiero participar en el estudio?

4.1. Nadie le tratará de una forma diferente.

4.2. Usted puede recoger su pertenencias e irse.

4.3. No perderá ningún beneficio.

5. ¿Qué pasa si digo que Sí pero cambio de opinión más tarde?

5.1. Usted puede dejar de participar en el estudio en cualquier momento.

5.2. A usted no se le penalizará.

5.3. Usted puede recoger su pertenencias e irse.

5.4. No perderá ningún beneficio.

6. ¿Cuánto tiempo dura el estudio?

6.1. El estudio precisa de unas dos horas de su tiempo. 


\begin{tabular}{|l|l|l|l|}
\hline ESTUDIO CLÍNICO & $\begin{array}{l}\text { Repercusiones fisiológicas del uso de equi- } \\
\text { pos de protección individual frente a riesgos } \\
\text { biológicos sobre los trabajadores de la Salud }\end{array}$ & Ref. & ANEXO N. ${ }^{\circ} \mathbf{4}$ \\
\hline Investigador & Francisco Martín Rodríguez & $41 / 16$ \\
\hline Doc. & $\begin{array}{l}\text { FORMULARIO DE CONSENTIMIENTO } \\
\text { INFORMADO }\end{array}$ & Ver. & 2.0 \\
\hline
\end{tabular}

\section{Efectos adversos}

7.1. Durante el desarrollo del estudio pueden aparecer efectos adversos debidos al esfuerzo físico o durante la colocación, uso y retirada del equipo de protección. Aunque es infrecuente pueden aparecer:

- Lipotimias.

- Pérdidas de conocimiento.

- Hipotensión/hipertensión.

- Taquicardia.

- Crisis de ansiedad.

- Hipoglucemia.

- Lesiones en la puesta y retirada del traje.

7.2. El equipo de investigadores está preparado para solucionar las complicaciones y efectos adversos que puedan surgir, deteniendo el estudio ante la más mínima duda.

8. ¿Quién verá mis respuestas y resultados?

8.1. Las únicas personas autorizadas para ver sus respuestas y resultados son las que trabajan en el estudio y las que se aseguran de que este se realice de manera correcta.

8.2. Al comenzar el estudio, el nombre y apellidos de los voluntarios son codificados mediante un código de tres números y una letra, y este código es lo único que se verá en los informes de resultados. En ningún documento se hará constar el nombre real del voluntario.

8.3. Sus respuestas a la encuesta, su información médica, y una copia firmada de este documento se mantendrán bajo llave en nuestros archivos.

8.4. Cuando compartamos los resultados del estudio, no incluiremos su nombre. Haremos todo lo posible para que nadie fuera del estudio sepa que usted participó en él.

8.5. No se incluirá este estudio ni sus resultados en ningún expediente médico.

9. ¿Me costará algo participar en el estudio?

9.1. No, todo es gratuito.

9.2. De igual modo es un estudio sin ánimo de lucro, no recibirá nada a cambio, no le pagaremos por su tiempo. 


\begin{tabular}{|l|l|l|l|}
\hline ESTUDIO CLÍNICO & $\begin{array}{l}\text { Repercusiones fisiológicas del uso de equi- } \\
\text { pos de protección individual frente a riesgos } \\
\text { biológicos sobre los trabajadores de la Salud }\end{array}$ & Ref. & ANEXO N. ${ }^{\circ} \mathbf{4}$ \\
\hline Investigador & Francisco Martín Rodríguez & $41 / 16$ \\
\hline Doc. & $\begin{array}{l}\text { FORMULARIO DE CONSENTIMIENTO } \\
\text { INFORMADO }\end{array}$ & Fer. & 2.0 \\
\hline
\end{tabular}

10. ¿Qué debo hacer si tengo preguntas?

10.1. Por favor llame a Francisco Martín si:

- Tiene alguna pregunta sobre el estudio.

- Tiene preguntas sobre sus derechos.

- Cree que se ha lesionado de alguna manera por participar en este estudio.

11. ¿Tengo que firmar este documento?

\subsection{NO, FÍRMELO SOLO SI DESEA PARTICIPAR EN EL ESTUDIO.}

\section{2. ¿Qué debo hacer si quiero participar en el estudio?}

12.1. Tiene que firmar este documento. Existe una copia a su disposición.

12.2. Al firmar este documento está diciendo que:

- Está de acuerdo con participar en el estudio.

- Le hemos explicado la información que contiene este documento y hemos contestado todas sus preguntas.

12.3. Usted sabe que:

- No tiene que contestar preguntas que no quiera contestar.

- En cualquier momento, puede dejar el estudio y no le pasará nada a usted.

- Puede llamar a la oficina encargada de investigaciones de la Facultad de Ciencias de la Salud si tiene alguna pregunta sobre el estudio o sobre sus derechos.

\begin{tabular}{|l|l|}
\hline Nombre del voluntario & Nombre de la persona que explica el procedimiento \\
\hline Firma voluntario & Firma \\
\hline
\end{tabular}


Anexo 5. Hoja de reconocimiento 1. Filiación y examen médico

\begin{tabular}{|l|l|l|l|}
\hline ESTUDIO CLÍNICO & $\begin{array}{l}\text { Repercusiones fisiológicas del uso de equi- } \\
\text { pos de protección individual frente a riesgos } \\
\text { biológicos sobre los trabajadores de la Salud }\end{array}$ & Ref. & ANEXO N. ${ }^{\circ} \mathbf{5}$ \\
\hline Investigador & Francisco Martín Rodríguez & $41 / 16$ \\
\hline Doc. & $\begin{array}{l}\text { HOJA DE RECONOCIMIENTO 1. FILIACIÓN Y } \\
\text { EXAMEN MÉDICO }\end{array}$ & Fecha & $20 / 4 / 16$ \\
\hline
\end{tabular}

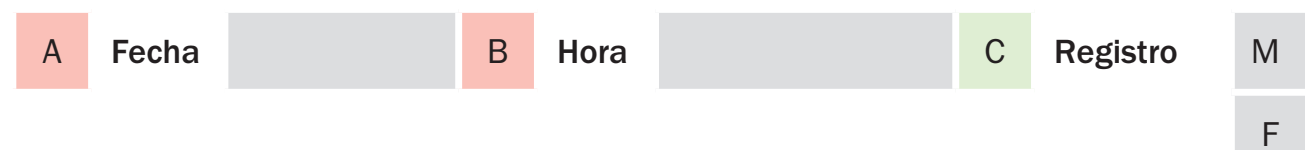

\begin{tabular}{|c|c|c|}
\hline \multirow[t]{4}{*}{1} & Grupo & G. Enfermería \\
\hline & & G. Medicina \\
\hline & & Enfermero \\
\hline & & Médico \\
\hline \multirow[t]{5}{*}{2} & Raza & Blanca \\
\hline & & Africano \\
\hline & & Asiático \\
\hline & & Aborigen \\
\hline & & Indígena \\
\hline 3 & Edad & \\
\hline \multirow[t]{4}{*}{4} & E. Civil & Soltero \\
\hline & & Casado \\
\hline & & Divorciado \\
\hline & & Viudo \\
\hline 5 & Experiencia & \\
\hline \multicolumn{3}{|c|}{ *Si estudiante anotar qué curso estudia } \\
\hline \multirow[t]{4}{*}{6} & Experiencia & Nnguna \\
\hline & EPI NBQ & Curso básico \\
\hline & & Curso avanzado \\
\hline & & Experiencia real \\
\hline 7 & Ingesta & \\
\hline \multicolumn{3}{|c|}{ *Anotar hora última ingesta } \\
\hline 8 & Sueño & \\
\hline *Ar & $r n^{\circ}$ horas $d$ & 24 horas \\
\hline
\end{tabular}

\begin{tabular}{|c|c|c|c|c|c|c|c|c|c|}
\hline \multirow[t]{4}{*}{9} & \multicolumn{9}{|c|}{ Alergias } \\
\hline & 1 & 2 & 3 & 4 & 5 & 6 & 7 & 8 & 9 \\
\hline & 10 & 11 & 12 & 13 & 14 & 15 & 16 & 17 & 18 \\
\hline & 19 & 20 & 21 & 22 & 23 & 24 & 25 & & \\
\hline \multirow[t]{2}{*}{10} & \multicolumn{5}{|c|}{ Embarazo } & \multicolumn{4}{|l|}{ No } \\
\hline & & & & & & Si & & & \\
\hline 11 & \multicolumn{9}{|l|}{ FUR } \\
\hline 12 & \multicolumn{5}{|c|}{ Alcohol } & \multicolumn{4}{|l|}{ No } \\
\hline & & & & & & Si & & & \\
\hline 13 & \multicolumn{9}{|c|}{ Cantidad } \\
\hline \multicolumn{10}{|c|}{ *Anotar $n^{\circ}$ UBE } \\
\hline 14 & \multicolumn{5}{|c|}{ Tabaco } & \multicolumn{4}{|l|}{ No } \\
\hline & & & & & & Si & & & \\
\hline 15 & \multicolumn{9}{|c|}{ Cigarros/día } \\
\hline 16 & \multicolumn{9}{|c|}{$N^{\circ}$ años } \\
\hline 17 & \multicolumn{9}{|c|}{ A. médico-quirúrgicos } \\
\hline & 1 & 2 & 3 & 4 & 5 & 6 & 7 & 8 & 9 \\
\hline & 10 & 11 & 12 & 13 & 14 & 15 & 16 & 17 & 18 \\
\hline & 19 & 20 & 21 & 22 & & & & & \\
\hline 18 & \multicolumn{9}{|c|}{ Medicación (ATC) } \\
\hline & 1 & 2 & 3 & 4 & 5 & 6 & 7 & 8 & 9 \\
\hline & 10 & 11 & 12 & 13 & 14 & & & & \\
\hline
\end{tabular}


Anexo 6. Hoja de reconocimiento 2. Antropometría y bioimpedancia

\begin{tabular}{|l|l|l|l|}
\hline ESTUDIO CLÍNICO & $\begin{array}{l}\text { Repercusiones fisiológicas del uso de equi- } \\
\text { pos de protección individual frente a riesgos } \\
\text { biológicos sobre los trabajadores de la Salud }\end{array}$ & Ref. & ANEXO N. ${ }^{\circ} \mathbf{6}$ \\
\hline Investigador & Francisco Martín Rodríguez & Ver. & 2.0 \\
\hline Doc. & $\begin{array}{l}\text { HOJA DE RECONOCIMIENTO 2. ANTROPOME- } \\
\text { TRÍA Y BIO-IMPEDANCIA }\end{array}$ & Fecha & $20 / 4 / 16$ \\
\hline & Pág. & 1 de 1 \\
\hline
\end{tabular}

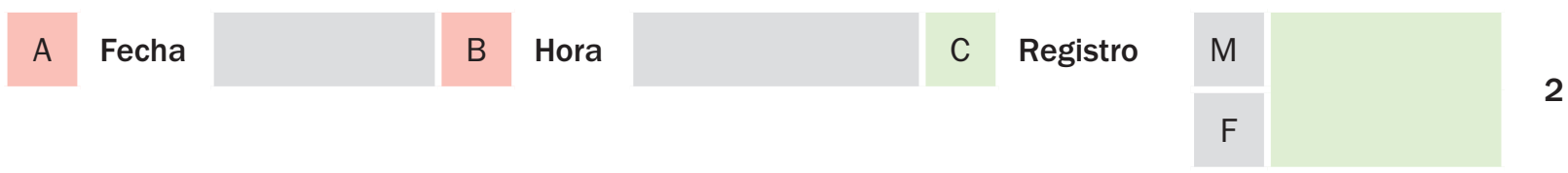

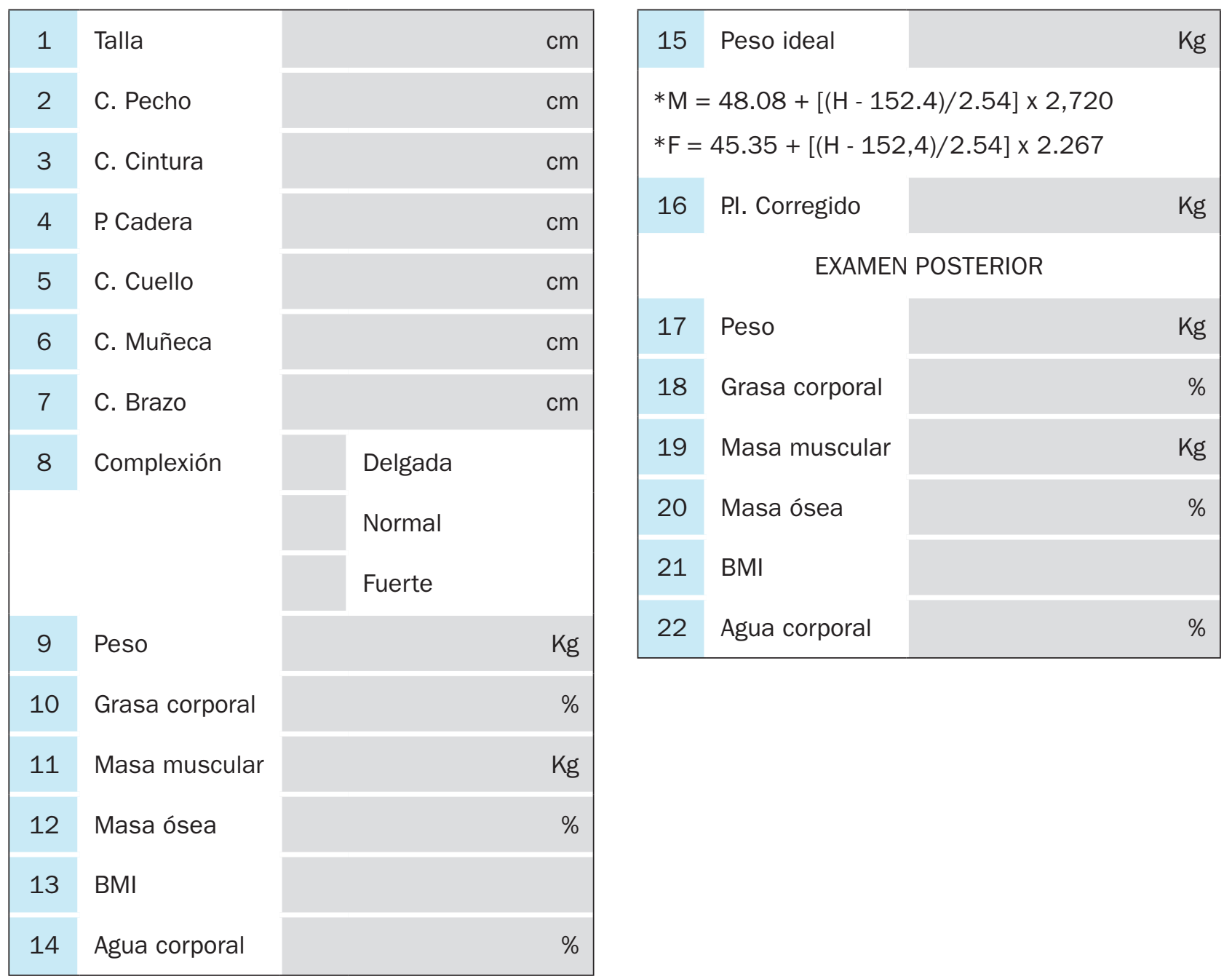


Anexo 7. Hoja de reconocimiento 3. Toma de constantes vitales

\begin{tabular}{|l|l|l|l|}
\hline ESTUDIO CLÍNICO & $\begin{array}{l}\text { Repercusiones fisiológicas del uso de equi- } \\
\text { pos de protección individual frente a riesgos } \\
\text { biológicos sobre los trabajadores de la Salud }\end{array}$ & Ref. & ANEXO N. ${ }^{\circ} \mathbf{7}$ \\
\hline Investigador & Francisco Martín Rodríguez & $41 / 16$ \\
\hline Doc. & $\begin{array}{l}\text { HOJA DE RECONOCIMIENTO 3. TOMA DE } \\
\text { CONSTANTES VITALES }\end{array}$ & Fecha & $20 / 4 / 16$ \\
\hline
\end{tabular}

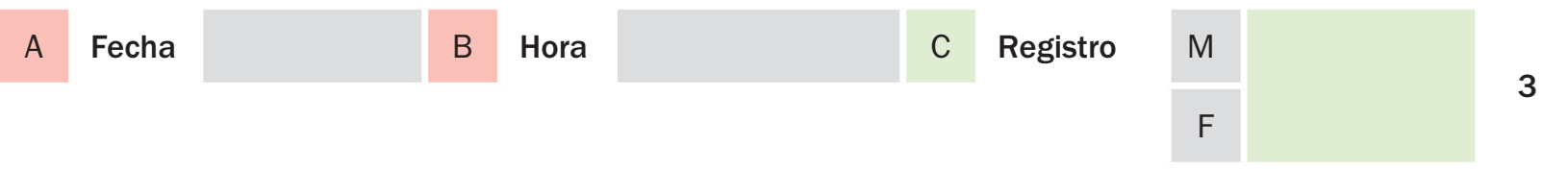

\begin{tabular}{|c|c|c|c|c|c|}
\hline 1 & FC reposo & Ipm & \multicolumn{3}{|c|}{ EXAMEN POSTERIOR } \\
\hline 2 & FC real & Ipm & 10 & Glucemia final & $\mathrm{mg} / \mathrm{dl}$ \\
\hline 3 & TA sistólica & $\mathrm{mmHg}$ & 11 & Lactato final & $\mathrm{mmol} / \mathrm{L}$ \\
\hline 4 & TA diastólica & $\mathrm{mmHg}$ & 12 & FC & Ipm \\
\hline 5 & F. Respiratoria & rxm & 13 & TA sistólica & $\mathrm{mmHg}$ \\
\hline 6 & Temperatura & ${ }^{\circ} \mathrm{C}$ & 14 & TA diastólica & $\mathrm{mmHg}$ \\
\hline 7 & Hemoglobina & $\mathrm{mg} / \mathrm{dl}$ & 15 & F. Respiratoria & $\mathrm{rxm}$ \\
\hline 8 & I. Perfusión & $\%$ & 16 & Temperatura & ${ }^{\circ} \mathrm{C}$ \\
\hline 9 & Saturación & $\%$ & 17 & Hemoglobina & $\mathrm{mg} / \mathrm{dl}$ \\
\hline & & & 18 & I. Perfusión & $\%$ \\
\hline & & & 19 & Saturación & $\%$ \\
\hline
\end{tabular}


Anexo 8. Hoja de reconocimiento 4-a. Cicloergometría

\begin{tabular}{|l|l|l|l|}
\hline ESTUDIO CLÍNICO & $\begin{array}{l}\text { Repercusiones fisiológicas del uso de equi- } \\
\text { pos de protección individual frente a riesgos } \\
\text { biológicos sobre los trabajadores de la Salud }\end{array}$ & Ref. & ANEXO N. ${ }^{\circ} \mathbf{8}$ \\
\hline Investigador & Francisco Martín Rodríguez & Ver. & $21 / 16$ \\
\hline Doc. & $\begin{array}{l}\text { HOJA DE RECONOCIMIENTO 4-A. } \\
\text { CICLO-ERGOMETRÍA }\end{array}$ & Fecha & $20 / 4 / 16$ \\
\hline & Pág. & 1 de 1 \\
\hline
\end{tabular}

A Fecha

B

Hora

C Registro

M

F

\begin{tabular}{|c|c|c|}
\hline 1 & Edad & \\
\hline \multirow[t]{3}{*}{2} & $\begin{array}{l}\text { Act. Física } \\
\text { (IPAQ) }\end{array}$ & Alto \\
\hline & & Moderado \\
\hline & & Sedentario \\
\hline \multirow[t]{3}{*}{3} & Motivación & Alta \\
\hline & & Media \\
\hline & & Baja \\
\hline 4 & FC reposo & Ipm \\
\hline 5 & FCM (Tanaka) & Ipm \\
\hline \multicolumn{3}{|c|}{$* 208,75$ - [0,73*edad] } \\
\hline 6 & U.A.T. & $\mathrm{mmHg}$ \\
\hline \multicolumn{3}{|c|}{ *88\% de la FCM } \\
\hline 7 & Glucemia basal & $\mathrm{mg} / \mathrm{dl}$ \\
\hline 8 & Lactato basal & $\mathrm{mmol} / \mathrm{L}$ \\
\hline
\end{tabular}

\begin{tabular}{|c|c|c|c|}
\hline \multicolumn{4}{|c|}{ Test conconi } \\
\hline \multirow[t]{2}{*}{9} & \multicolumn{3}{|l|}{ Inicio } \\
\hline & \multicolumn{3}{|l|}{ Fin } \\
\hline 10 & \multicolumn{3}{|l|}{ Tiempo total } \\
\hline \multirow[t]{2}{*}{11} & ECG & $\mathrm{Si}$ & No \\
\hline & Espirometría & SI & No \\
\hline 12 & PDFC & & Ipm \\
\hline 13 & U.A. Lactato & & $\mathrm{mmol} / \mathrm{L}$ \\
\hline 14 & U.A. Potencia & & W \\
\hline 15 & FCM test & & Ipm \\
\hline 16 & TA sistólica & & $\mathrm{mmHg}$ \\
\hline 17 & TA diastólica & & $\mathrm{mmHg}$ \\
\hline 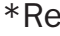 & 50 de 51 y $F$ & & \\
\hline
\end{tabular}


Anexo 9. Hoja de reconocimiento 4-b. Cicloergometría

\begin{tabular}{|l|l|l|l|}
\hline ESTUDIO CLÍNICO & $\begin{array}{l}\text { Repercusiones fisiológicas del uso de equi- } \\
\text { pos de protección individual frente a riesgos } \\
\text { biológicos sobre los trabajadores de la Salud }\end{array}$ & CEIC & ANEXO N. \\
\hline Investigador & Francisco Martín Rodríguez & Ver. & 2.0 \\
\hline Doc. & $\begin{array}{l}\text { HOJA DE RECONOCIMIENTO 4-B. } \\
\text { CICLO-ERGOMETRÍA }\end{array}$ & Fecha & $20 / 4 / 16$ \\
\hline
\end{tabular}

A Fecha

B Hora

C Registro

M
F

4

B

\begin{tabular}{|c|c|c|c|}
\hline Tiempo & Potencia & Velocidad & F.C. \\
\hline 0,5 & 0 & & \\
\hline 1 & 0 & & \\
\hline 1,5 & 0 & & \\
\hline 2 & 0 & & \\
\hline 2,5 & 0 & & \\
\hline 3 & 0 & & \\
\hline 3,5 & 0 & & \\
\hline 4 & 0 & & \\
\hline 4,5 & 0 & & \\
\hline 5 & 4 & & \\
\hline 5,5 & 8 & & \\
\hline 6 & 12 & & \\
\hline 6,5 & 16 & & \\
\hline 7 & 20 & & \\
\hline 7,5 & 24 & & \\
\hline 8 & 28 & & \\
\hline 8,5 & 32 & & \\
\hline 9 & 36 & & \\
\hline 9,5 & 40 & & \\
\hline 10 & 44 & & \\
\hline
\end{tabular}

\begin{tabular}{|c|c|c|c|}
\hline Tiempo & Potencia & Velocidad & F.C. \\
\hline 10,5 & 48 & & \\
\hline 11 & 52 & & \\
\hline 11,5 & 56 & & \\
\hline 12 & 60 & & \\
\hline 12,5 & 64 & & \\
\hline 13 & 68 & & \\
\hline 13,5 & 72 & & \\
\hline 14 & 76 & & \\
\hline 14,5 & 80 & & \\
\hline 15 & 84 & & \\
\hline 15,5 & 0 & & \\
\hline 16 & 0 & & \\
\hline 16,5 & 0 & & \\
\hline 17 & 0 & & \\
\hline 17,5 & 0 & & \\
\hline 18 & 0 & & \\
\hline 18,5 & 0 & & \\
\hline 19 & 0 & & \\
\hline 19,5 & 0 & & \\
\hline 20 & 0 & & \\
\hline
\end{tabular}


Anexo 10. Hoja de reconocimiento 5. Checking y criterios de exclusión

\begin{tabular}{|l|l|l|l|}
\hline ESTUDIO CLÍNICO & $\begin{array}{l}\text { Repercusiones fisiológicas del uso de equi- } \\
\text { pos de protección individual frente a riesgos } \\
\text { biológicos sobre los trabajadores de la Salud }\end{array}$ & Ref. & ANEXO N. ${ }^{\circ} 10$ \\
\hline Investigador & Francisco Martín Rodríguez & Ver. & $21 / 16$ \\
\hline Doc. & $\begin{array}{l}\text { HOJA DE RECONOCIMIENTO 5. CHECKING Y } \\
\text { CRITERIOS DE EXCLUSIÓN }\end{array}$ & Fecha & $20 / 4 / 16$ \\
\hline & Pág. & 1 de 1 \\
\hline
\end{tabular}

\begin{tabular}{|l|l|l|l|l|l|l|l} 
A Fecha & B Hora & C Registro & M
\end{tabular}

$\mathrm{F}$

\begin{tabular}{|rll|}
\hline & & \multicolumn{1}{|c|}{ LISTADO EXCLUSIÓN } \\
\hline 1 & ARRITMIAS \\
\hline 2 & SCA \\
\hline 3 & ASMA EN CURSO \\
\hline 4 & ESPIROMETRÍA ANORMAL \\
\hline 5 & FC BASAL $>150$ \\
\hline 6 & FC BASAL $<35$ \\
\hline 7 & TAS $>160 \mathrm{mmHg}$ \\
\hline 8 & TAD $>95 \mathrm{mmHg}$ \\
\hline 9 & TAS $<80 \mathrm{mmHg}$ \\
\hline 10 & IMC $>30$ \\
\hline 11 & IMPOTENCIA FUNCIONAL \\
\hline 12 & GCS $<15$ \\
\hline 13 & SpO2 $<92 \%$ \\
\hline 14 & GC $<65$ mg/dl \\
\hline 15 & Hb $<8$ \\
\hline 16 & FIEBRE \\
\hline 17 & CIRUGÍA MAYOR $<30$ DÍAS \\
\hline 18 & DAI/HOLTER \\
\hline
\end{tabular}
19 ANSIEDAD GRAVE
20 EPILEPSIA
21 ANTICOAGULACIÓN
22 DEFICIENCIA AUDITIVA SEVERA
23 DEFICIENCIA VISUAL SEVERA
24 ENF. CUTÁNEAS EN FASE AGUDA
25 INFECCIONES EN CURSO
26 E. INMUNOLÓGICAS SISTÉMICAS
27 HISTORIA MÉDICA
28 ANTROPOMETRÍA
29 ESTUDIO FISIOLÓGICO
30 ERGOMETRÍA
31 ESTUDIO PSICOLÓGICO
32 EXPLICACIÓN DESTREZAS
33 CONSENTIMIENTO INFORMADO
APTO
NO APTO 
Anexo 11. Hoja de reconocimiento 6. Caso clínico

\begin{tabular}{|l|l|l|l|}
\hline ESTUDIO CLÍNICO & $\begin{array}{l}\text { Repercusiones fisiológicas del uso de equi- } \\
\text { pos de protección individual frente a riesgos } \\
\text { biológicos sobre los trabajadores de la Salud }\end{array}$ & Ref. & ANEXO N. ${ }^{\circ} \mathbf{1 1}$ \\
\hline Investigador & Francisco Martín Rodríguez & Ver. & $21 / 16$ \\
\hline Doc. & HOJA DE RECONOCIMIENTO 6. CASO CLÍNICO & Fecha & $20 / 4 / 16$ \\
\hline
\end{tabular}

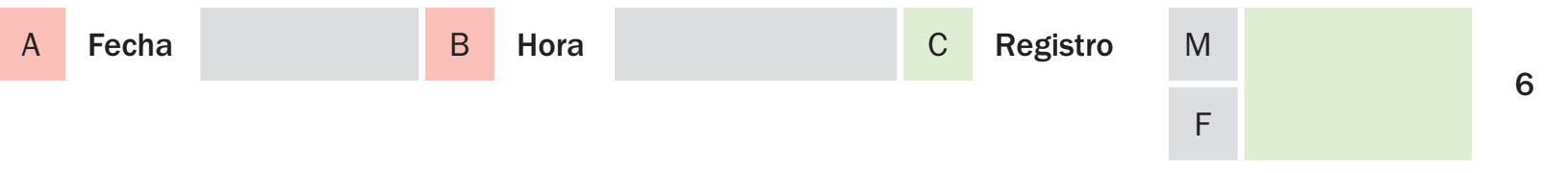

\begin{tabular}{|l|l|l|}
\hline Tiempo & \multicolumn{1}{|c|}{ Potencia } & F.C. \\
\hline 1 & Puesta de EPI & \\
\hline 2 & Puesta de EPI & \\
\hline 3 & Puesta de EPI & \\
\hline 4 & Puesta de EPI & \\
\hline 5 & Puesta de EPI & \\
\hline 6 & Puesta de EPI & \\
\hline 7 & Puesta de EPI & \\
\hline 8 & Puesta de EPI & \\
\hline 9 & Puesta de EPI & \\
\hline 10 & Entrada sala simulación & \\
\hline 11 & Comienza el caso & \\
\hline 12 & Técnicas & \\
\hline 13 & Técnicas & \\
\hline 14 & Técnicas & \\
\hline 15 & Técnicas & \\
\hline 16 & Técnicas & \\
\hline 17 & Técnicas & \\
\hline 18 & Técnicas & \\
\hline 19 & RCP & \\
\hline 20 & RCP & \\
\hline 21 & RCP & \\
\hline 22 & RCP & \\
\hline 23 & Técnicas & \\
\hline 24 & Técnicas & \\
\hline
\end{tabular}

\begin{tabular}{|l|l|l|}
\hline 25 & Retirada EPI & \\
\hline 26 & Retirada EPI & \\
\hline 27 & Retirada EPI & \\
\hline 28 & Retirada EPI & \\
\hline 29 & Retirada EPI & \\
\hline 30 & Retirada EPI & \\
\hline
\end{tabular}

\begin{tabular}{|c|c|c|c|c|c|c|c|}
\hline 1 & Humedad & & & & & & $\%$ \\
\hline 2 & Temperatura & & & & & & ${ }^{\circ} \mathrm{C}$ \\
\hline 3 & Luminosidad & & & & & & \\
\hline 4 & Traje pedido & S & M & $\mathrm{L}$ & $X \mathrm{~L}$ & $2 X \mathrm{~L}$ & $3 X \mathrm{XL}$ \\
\hline 5 & Traje real & S & M & L & $X L$ & $2 \mathrm{XL}$ & $3 X \mathrm{XL}$ \\
\hline 6 & U.A. Lactato & & & & & \multicolumn{2}{|c|}{$\mathrm{mmol} / \mathrm{L}$} \\
\hline
\end{tabular}


Anexo 12. Especificaciones técnicas de la cinta métrica mecánica marca SECA modelo 206

\begin{tabular}{|l|}
\hline Rango de medición en $\mathrm{cm}$ \\
\hline División \\
\hline Dimensiones ( AxAxP) \\
\hline CE
\end{tabular}

\section{$0-220 \mathrm{~cm}$}

$1 \mathrm{~mm}$

$125 \times 125 \times 173 \mathrm{~mm}$

CE0123

Anexo 13. Especificaciones técnicas de la cinta ergonómica para medir perímetros marca SECA modelo 201

\begin{tabular}{l} 
Rango de medición en $\mathrm{cm}$ \\
División \\
Dimensiones ( AxAxP) \\
\hline CE
\end{tabular}

$0-201 \mathrm{~cm}$

$1 \mathrm{~mm}$

$70 \times 22 \times 65 \mathrm{~mm}$

CE0123

Anexo 14. Especificaciones técnicas de la báscula diagnóstica TANITA modelo BC-601

\begin{tabular}{l|}
\hline Capacidad de peso \\
\hline Incrementos de peso \\
\hline Incrementos de grasa corporal \\
\hline CE \\
\hline
\end{tabular}

$150 \mathrm{~kg}$

$0.1 \mathrm{~kg}(0.2 \mathrm{lb})(0.2 \mathrm{lb})$

$0,1 \%$

CE0108

Anexo 15. Especificaciones técnicas del monitor de presión arterial no invasiva marca SCHILLER modelo BP-200 plus

\begin{tabular}{l} 
Intervalo de medición TAS \\
\hline Intervalo de medición TAD \\
Intervalo de medición frecuencia cardiaca \\
\hline Interfaz \\
Medición en intervalos \\
Diámetro del brazo \\
\hline CE \\
\hline
\end{tabular}

\begin{tabular}{|l|}
\hline $50-270 \mathrm{mmHg}$ \\
\hline $20-150 \mathrm{mmHg}$ \\
\hline $40-250$ latidos por minuto \\
\hline RS232 \\
\hline $2-20$ minutos programable \\
\hline $12-50 \mathrm{~cm}$ \\
\hline CE0123 \\
\hline
\end{tabular}


Anexo 16. Especificaciones técnicas del cronómetro marca CASIO modelo HS-3V-1

\begin{tabular}{|l|l|}
\hline Precisión a temperatura normal & $+/-99,997685 \%$ \\
\hline Unidad de medición & $1 / 100$ de segundo \\
\hline Temperatura de operación & $0^{\circ} \mathrm{C}$ a $40^{\circ} \mathrm{C}$ \\
\hline CE & CE0108 \\
\hline
\end{tabular}

Anexo 17. Especificaciones técnicas de termómetro timpánico marca BRAUN modelo ThermoScan PRO 6000

\begin{tabular}{l} 
Rango de temperatura \\
\hline Rango de temperatura de funcionamiento \\
\hline Precisión \\
\hline Normas \\
\hline CE
\end{tabular}

Entre $20,0^{\circ} \mathrm{C}$ y $42,2{ }^{\circ} \mathrm{C}$

Entre $10,0^{\circ} \mathrm{C}$ y $40,0^{\circ} \mathrm{C}$

$\pm 0,2^{\circ} \mathrm{C}$ para el intervalo comprendido entre $35,0^{\circ} \mathrm{C}$ y $42,0{ }^{\circ} \mathrm{C}$

ASTM 1965-98; EN 12470-5:2003; MDD (93/42/CEE), anexo II

\section{CE0123}

Anexo 18. Especificaciones técnicas del medidor no invasivo de hemoglobina marca MASIMO modelo Pronto 7

\begin{tabular}{l} 
Temperatura de funcionamiento \\
Humedad de funcionamiento \\
Altitud de funcionamiento \\
Modo de sensibilidad normal de hemoglobina \\
total (SpHb) \\
Saturación de oxígeno arterial (SpO2) \\
Frecuencia cardiaca (FC) \\
Índice de perfusión (IP) \\
\hline CE
\end{tabular}

Entre $5^{\circ} \mathrm{C}$ a $+40^{\circ} \mathrm{C}$

De $5 \%$ a 95 \% sin condensación

De 500 mbar a 1060 mbar

$0-25 \mathrm{gr} / \mathrm{dl}$

0-100\%

30-250 latidos por minuto

$0,02-20 \%$

CE0123 
Anexo 19. Especificaciones técnicas del medidor no invasivo saturación de oxígeno marca MASIMO modelo Rad-5vTM

\begin{tabular}{|l|l|}
\hline Temperatura de funcionamiento & Entre $0{ }^{\circ} \mathrm{C} \mathrm{a}+50{ }^{\circ} \mathrm{C}$ \\
\hline Humedad de funcionamiento & De $5 \%$ a $95 \%$ sin condensación \\
\hline Altitud de funcionamiento & De 500 mbar a 1060 mbar \\
\hline Rango de medición de saturación de oxígeno & $1-100 \%$ \\
\hline Rango de medición de frecuencia cardiaca (FC) & $25-240$ latidos por minuto \\
\hline CE & CE0123 \\
\hline
\end{tabular}

Anexo 20. Especificaciones técnicas del medidor de ácido láctico marca Roche modelo Accutrend ${ }^{\circledR}$ Plus

\begin{tabular}{|l|l|}
\hline Intervalo de temperatura para las mediciones & Lactato: $15-35^{\circ} \mathrm{C}$ \\
\hline Humedad relativa & $10-85 \%$ \\
\hline Intervalo de medición & $\begin{array}{l}\text { Lactato: } 0,8-21,7 \mathrm{mmol} / \mathrm{L} \text { (valor en sangre), } \\
0,7-26 \mathrm{mmol} / \mathrm{L} \text { (valor en plasma) }\end{array}$ \\
\hline Interfaz & Interfaz de infrarrojos, LED/IRED clase 1 \\
\hline Tipo de muestra & Sangre capilar fresca \\
\hline Volumen de la muestra & Una gota de sangre que cuelgue libremente \\
\hline CE & CE0123 \\
\hline
\end{tabular}

Anexo 21. Especificaciones técnicas del glucómetro Accu-Chek Mobilede la marca Roche ${ }^{\circledR}$.

\begin{tabular}{l} 
Cantidad mínima de sangre necesaria \\
\hline Rango de medición \\
\hline Método de medición \\
\hline Tipo de muestra \\
\hline CE \\
\hline
\end{tabular}

$0,3 \mu \mathrm{l}$

$10-600 \mathrm{mg} / \mathrm{dl}$ o $0,6-33,3 \mathrm{mmol} / \mathrm{l}$

Fotometría de reflexión determinación fotométrica de la glucosa en la sangre capilar fresca

Sangre capilar fresca

CE0123 
Anexo 22. Especificaciones técnicas del espirómetro modelo MiniSpir de la marca MIR

\begin{tabular}{|l|l|}
\hline Sensor de temperatura & Semiconductor $\left(0-45^{\circ} \mathrm{C}\right)$ \\
\hline Sensor de flujo & Turbina digital bidireccional \\
\hline Rango de flujo & $\pm 16 \mathrm{l} / \mathrm{s}$ \\
\hline Precisión de volumen & $\pm 3 \%$ o $50 \mathrm{ml}$ \\
\hline Precisión de flujo & $\pm 5 \%$ o $200 \mathrm{ml} / \mathrm{s}$ \\
\hline Resistencia dinámica a $12 \mathrm{l} / \mathrm{s}$ & $<0,5 \mathrm{cmH} 20 / \mathrm{l} / \mathrm{s}$ \\
\hline Puerto de comunicación & USB \\
\hline CE & CEO 23 \\
\hline
\end{tabular}

Anexo 23. Especificaciones técnicas del ECG modelo Cardio Perfect de la marca Welch Allyn ${ }^{\circledR}$

Velocidad de presentación por defecto
Sensibilidad por defecto
Unidad de amplitud
Puerto de comunicación
CE

$5,10,12,5,25,50,100 \mathrm{~mm} / \mathrm{seg}$

5,10 o $20 \mathrm{~mm} / \mathrm{mV}$

Puede ser en microvoltios o milímetros

USB de Prolink

MDD 93/42/CE

Anexo 24. Especificaciones técnicas la bicicleta estática IC7 de la marca Tomahawk ${ }^{\circledR}$

\begin{tabular}{|l|l|}
\hline Medidor de potencia & WattRate ${ }^{\circledR},+1 \%$ de tolerancia, directa al eje \\
\hline Fuente de alimentación & Generador autolimentado \\
\hline Sistema de resistencia & Magnético con 100 niveles \\
\hline Volante de inercia & Trasero, aluminio, distribuido equilibradamente \\
\hline Transmisión & 2 etapas hibrido Poly-V y cinta dentada \\
\hline Relación de la transmisión & $1: 11$ \\
\hline Factor Q & $155 \mathrm{~mm} \mathrm{/} .1$ “ \\
\hline Tipo de biela & CrMo $172,5 \mathrm{~mm} / 6.79 “$ \\
\hline Máximo peso del usuario & $150 \mathrm{~kg}$ \\
\hline CE & $2006 / 42 / \mathrm{CE}$ y 2004/108/CE \\
\hline
\end{tabular}


Anexo 25. Especificaciones técnicas del ordenador portátil ThinkPad Yoga 260 marca Lenovo

\begin{tabular}{|l|l|}
\hline Procesador & Intel ${ }^{\circledR}$ Core $^{\mathrm{TM}}$ i3-6100U \\
\hline Sistema operativo & Windows 10 Pro \\
\hline Memoria & DDR4 DIMM de 16 GB \\
\hline Tarjeta gráfica & Chipset Intel ${ }^{\circledR}$ integrado \\
\hline Almacenamiento & SSD de 512 GB \\
\hline Pantalla & FHD de 12,5 pulgadas (1920 x 1080), 300 nits \\
\hline Comunicación & $\begin{array}{l}\text { WiGig, tarjeta combinada de Wi-Fi y Bluetooth } \\
\text { (4.1, SCR, LTE-A }\end{array}$ \\
\hline Puertos & $\begin{array}{l}2 \text { USB 3.0, puerto mini DisplayPort } \\
\text { OneLink+ } \text {, HDM microSD }\end{array}$ \\
\hline CE & $\begin{array}{l}\text { Compliance to the Electromagnetic Compatibili- } \\
\text { ty Directive }\end{array}$ \\
\hline
\end{tabular}

Anexo 26. Especificaciones técnicas del pulsómetro marca Polar modelo A300

\begin{tabular}{|c|c|}
\hline Tipo de batería & $\begin{array}{l}\text { Batería recargable de polímero de litio de } 68 \\
\text { mAh }\end{array}$ \\
\hline Temperatura de funcionamiento & $-10^{\circ} \mathrm{C} \mathrm{a}+50^{\circ} \mathrm{C}$ \\
\hline Precisión del reloj & $\begin{array}{l}\text { Superior a } \pm 0,5 \text { segundos/día a una tempera- } \\
\text { tura de } 25^{\circ} \mathrm{C} /\end{array}$ \\
\hline Precisión del monitor de frecuencia cardiaca & $\begin{array}{l} \pm 1 \% \text { o } 1 \text { ppm (el valor que sea mayor). } \\
\text { La definición corresponde a unas condiciones } \\
\text { estables. }\end{array}$ \\
\hline Rango de medición de frecuencia cardiaca & 15-240 latidos por minuto \\
\hline CE & 1999/5/CE y $2011 / 65 / U E$ \\
\hline
\end{tabular}


Anexo 27. Especificaciones técnicas del medidor dual DTP 1 marca PCE ${ }^{\circledR}$

\begin{tabular}{|l|l|}
\hline Rango de medición de temperatura & $-50+380{ }^{\circ} \mathrm{C}$ \\
\hline Rango de medición de humedad & 0 a $100 \%$ H.R. (sin condensación) \\
\hline Precisión medición temperatura & $\pm 3,5^{\circ} \mathrm{C}$ de $-50+20^{\circ} \mathrm{C}$ \\
\hline Precisión medición humedad & $\pm 1 \%+1,5^{\circ} \mathrm{C}$ de 20 a $350^{\circ} \mathrm{C}$ \\
\hline Alimentación & $1 \times$ batería de $9 \mathrm{~V}$ \\
\hline CE & 001932 \\
\hline
\end{tabular}

Anexo 28. Especificaciones técnicas del luxómetro 172 marca PCE ${ }^{\circledR}$

\begin{tabular}{|c|c|}
\hline Rango & $\begin{array}{l}400,0 \text { / } 4000 \text { / lux } \\
40,00 \text { / 400,0 klux (1klux = } 1000 \text { Lux }) \\
40,00 \text { / 400,0 / } 4000 / \text { fc } \\
40,00 \text { kfc (1 kfc = } 1000 \text { fc) }\end{array}$ \\
\hline Resolución & $\begin{array}{l}0,1 / 1 / 10 / 100 \text { lux } \\
0,01 / 0,1 / 1 / 10 \text { FootCandle }\end{array}$ \\
\hline Precisión & $\begin{array}{l} \pm 5 \% \text { del valor de medición } \pm 10 \text { dígitos } \\
(<10.000 \text { lux }) \\
\pm 10 \% \text { del valor de medición } \pm 10 \text { dígitos } \\
(>10.000 \text { lux })\end{array}$ \\
\hline Condiciones ambientales & O a $40{ }^{\circ} \mathrm{C}$ y $80 \%$ H.R. \\
\hline Alimentación & 1 x batería de $9 \mathrm{~V}$ \\
\hline CE & 001932 \\
\hline
\end{tabular}


Anexo 29. Especificaciones técnicas del cubrebotas modelo CoverChem Plus ${ }^{\circledR}$ marca ASATEX ${ }^{\circledR}$

\begin{tabular}{ll} 
Categoría EPI & III \\
\hline Tipo & PB 3 (-B) \\
& $\begin{array}{l}\text { Químicos. } \\
\text { Normativa }\end{array}$ \\
\hline & EN 14126:2003; protección biológica (sangre y virus).
\end{tabular}

Anexo 30. Especificaciones técnicas del buzo modelo CoverStar Plus ${ }^{\circledR}$ marca ASTAEX ${ }^{\circledR}$

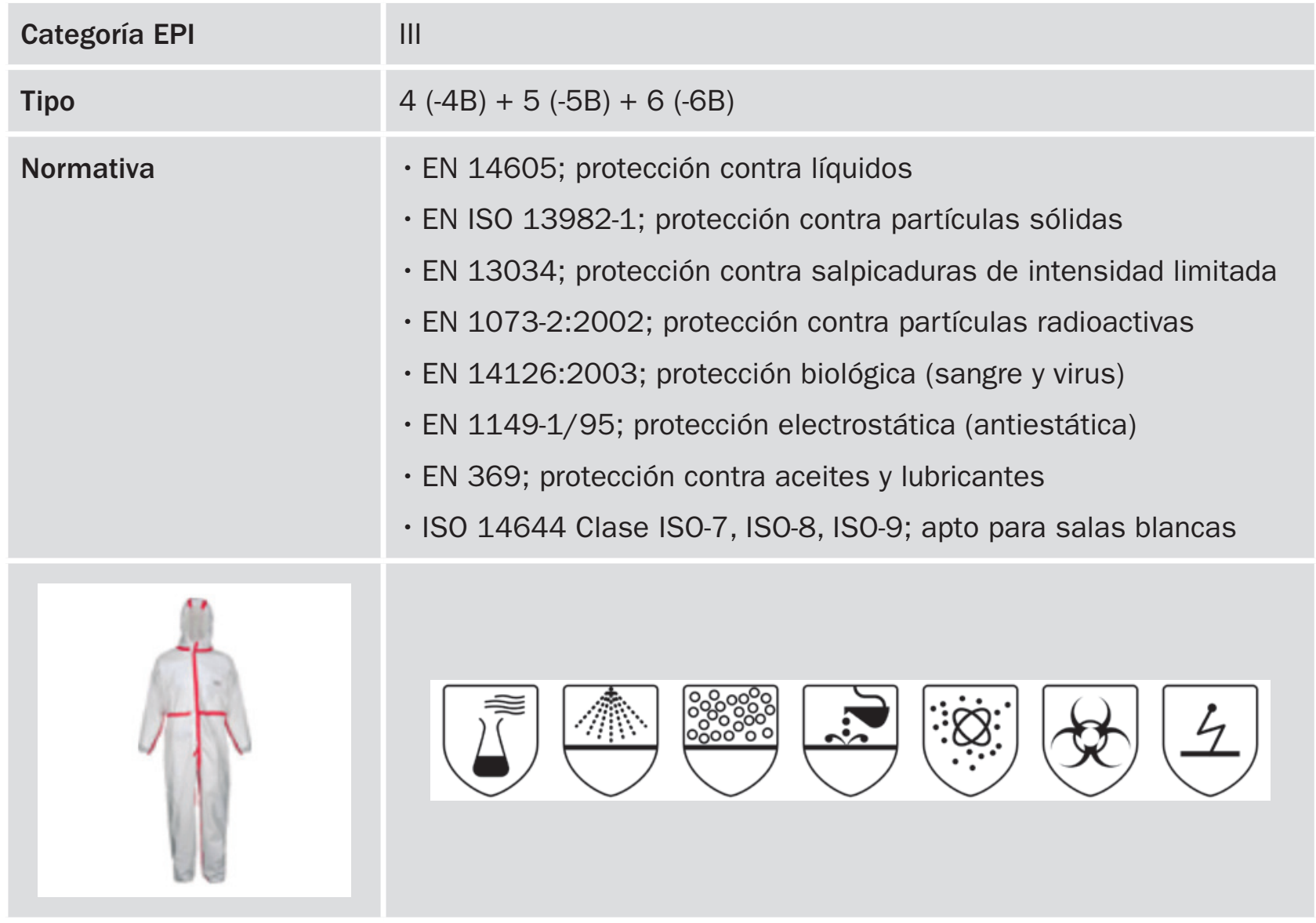


Anexo 31. Especificaciones técnicas de los guantes TouchNTuff ${ }^{\circledR}$ marca Ansell ${ }^{\circledR}$

\begin{tabular}{|c|c|}
\hline Categoría EPI & III \\
\hline Normativa & $\begin{array}{l}\cdot \text { EN 455-1/2 } \\
\cdot \text { EN 1149-1 y 1149-3 } \\
\cdot \text { EN 1149-5 } \\
\cdot \text { EN374 }\end{array}$ \\
\hline
\end{tabular}

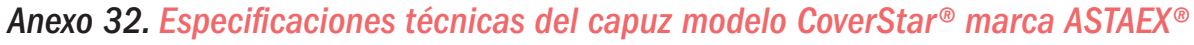

\begin{tabular}{ll}
\hline Categoría EPI & I \\
\hline Normativa & EN ISO 13982-1; protección contra partículas sólidas \\
& • EN 13034; protección contra salpicaduras de intensidad limitada \\
$\cdot$ EN 14126:2003; protección biológica (sangre y virus) & EN 1149-1/95; protección electrostática (antiestática)
\end{tabular}


Anexo 33. Especificaciones técnicas del buzo modelo CoverStar Plus ${ }^{\circledR}$ marca ASATEX ${ }^{\circledR}$

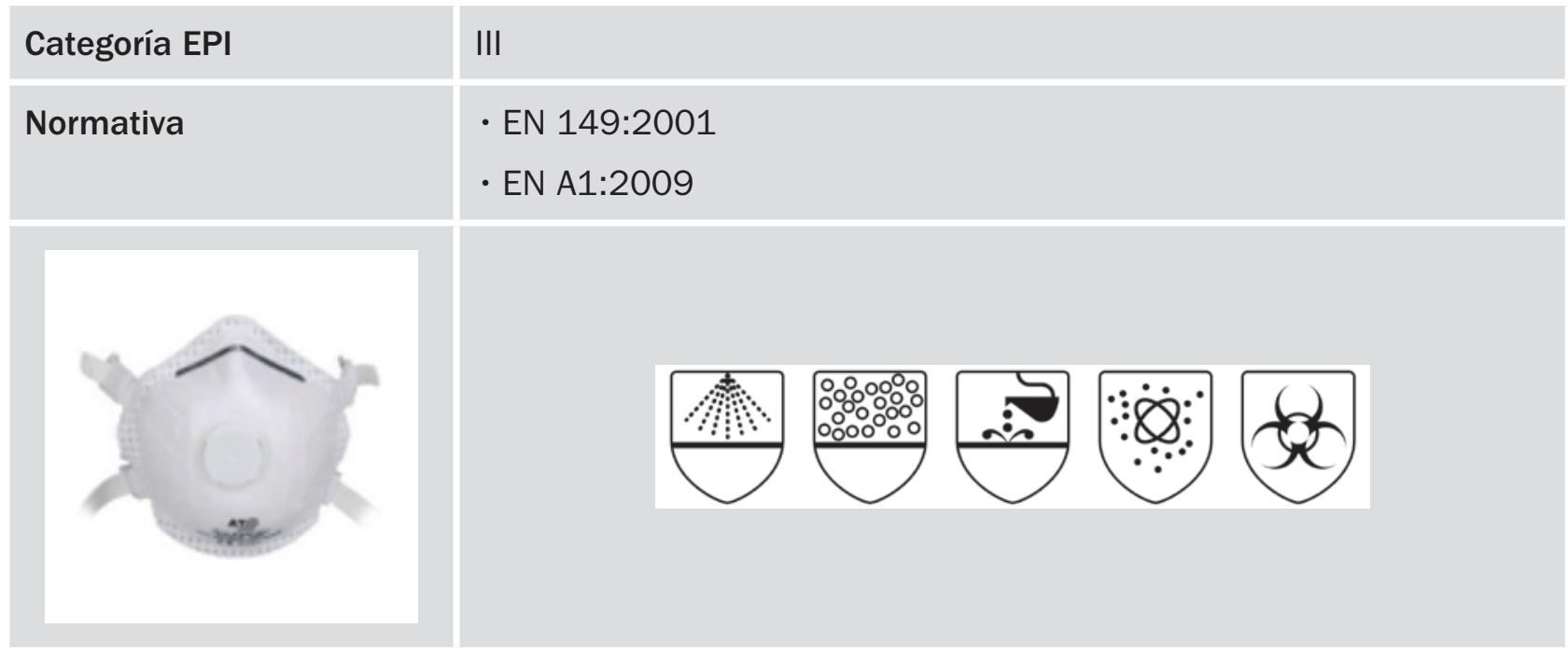

Anexo 34. Especificaciones técnicas de las gafas panorámicas modelo Budget ${ }^{\circledR} 4800$ de la marca $3 M$

\begin{tabular}{|l|l|}
\hline Categoría EPI & III \\
\hline Normativa & $\begin{array}{l}\text { EN 166:2001 } \\
\text { - EN166 B 3 CE } \\
\text { - DE 89/686/CEE }\end{array}$ \\
\hline
\end{tabular}


Anexo 35. Especificaciones técnicas de los guantes industry de la marca Medical Care ${ }^{\circledR}$

\begin{tabular}{|c|c|}
\hline Categoría EPI & III \\
\hline Normativa & $\begin{array}{l}\cdot \text { EN } 455-1 / 2 \\
\cdot \text { EN 1149-1 y 1149-3 } \\
\cdot \text { EN 1149-5 } \\
\cdot \text { EN374 }\end{array}$ \\
\hline
\end{tabular}




\section{INFORME DEL COMITÉ ÉTICO DE INVESTIGACIÓN CLÍNICA}

Dña. ROSA $\mathrm{M}^{\mathrm{a}}$ CONDE VICENTE, Secretario del Comité Ético de Investigación Clínica del Hospital Universitario Río Hortega, Área de Salud Valladolid Oeste

\section{CERTIFICA:}

Que este Comité, en su reunión del dia 6 de Abril de 2016, ha tenido conocimiento del Proyecto de Investigación (Código Interno CEIC: 41/16) titulado: "Repercusiones fisiológicas y psicológicas del uso de equipos de protección individual CAT I Tipo 4-5-6 sobre los trabajadores de la salud", y considera que:

Una vez evaluados los aspectos éticos del mismo, acuerda que no hay inconveniente alguno para su realización, por lo que emite INFORME FAVORABLE.

Este Proyecto de Investigación será realizado por el Dr. Pedro Arnillas Gómez y D". Francisco Martín Rodríguez, pertenecientes a la Gerencia de Emergencias Sanitarias (Emergencias I), como Investigadores Principales.

Lo que firmo en Valladolid, a 7 de Abril de 2016.

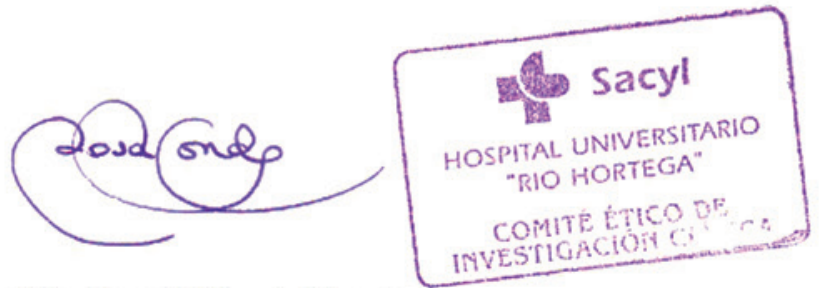

Fdo. Dña. Rosa $\mathrm{M}^{\mathrm{a}}$ Conde Vicente SECRETARIO CEIC 